\title{
Nucleophilic Difluoromethylenation of Ketones Using Diethyl Difluoro(trimethylsilyl)methylphosphonate Mediated by 18-Crown-6 Ether/KOAc
}

\author{
Yu-Hui Wang, $†$ Zhong-Yan Cao $\dagger$ and Jian Zhou*†,, \\ $\dagger$ Shanghai Key Laboratory of Green Chemistry and Chemical Process, School of Chemistry and Molecular \\ Engineering, East China Normal University, 3663N Zhongshan Road, Shanghai 200062, P. R. China \\ $\$$ State Key Laboratory of Organometallic Chemistry, Shanghai Institute of Organic Chemistry, Chinese \\ Academy of Sciences, Shanghai 200032, P R China. \\ E-mail:.jzhou@chem.ecnu.edu.cn
}

Supporting information 
${ }^{1} \mathrm{H},{ }^{13} \mathrm{C},{ }^{19} \mathrm{~F}$ and ${ }^{31} \mathrm{P}$ NMR spectra for all compounds
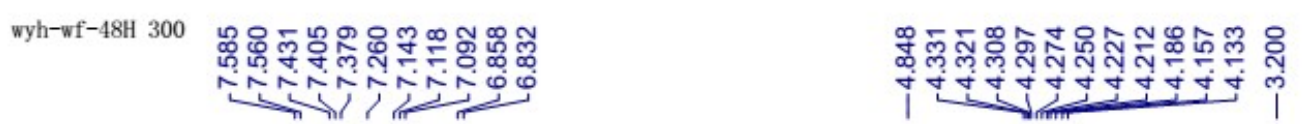

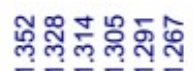

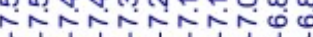

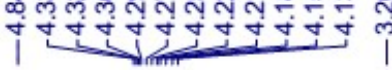

는

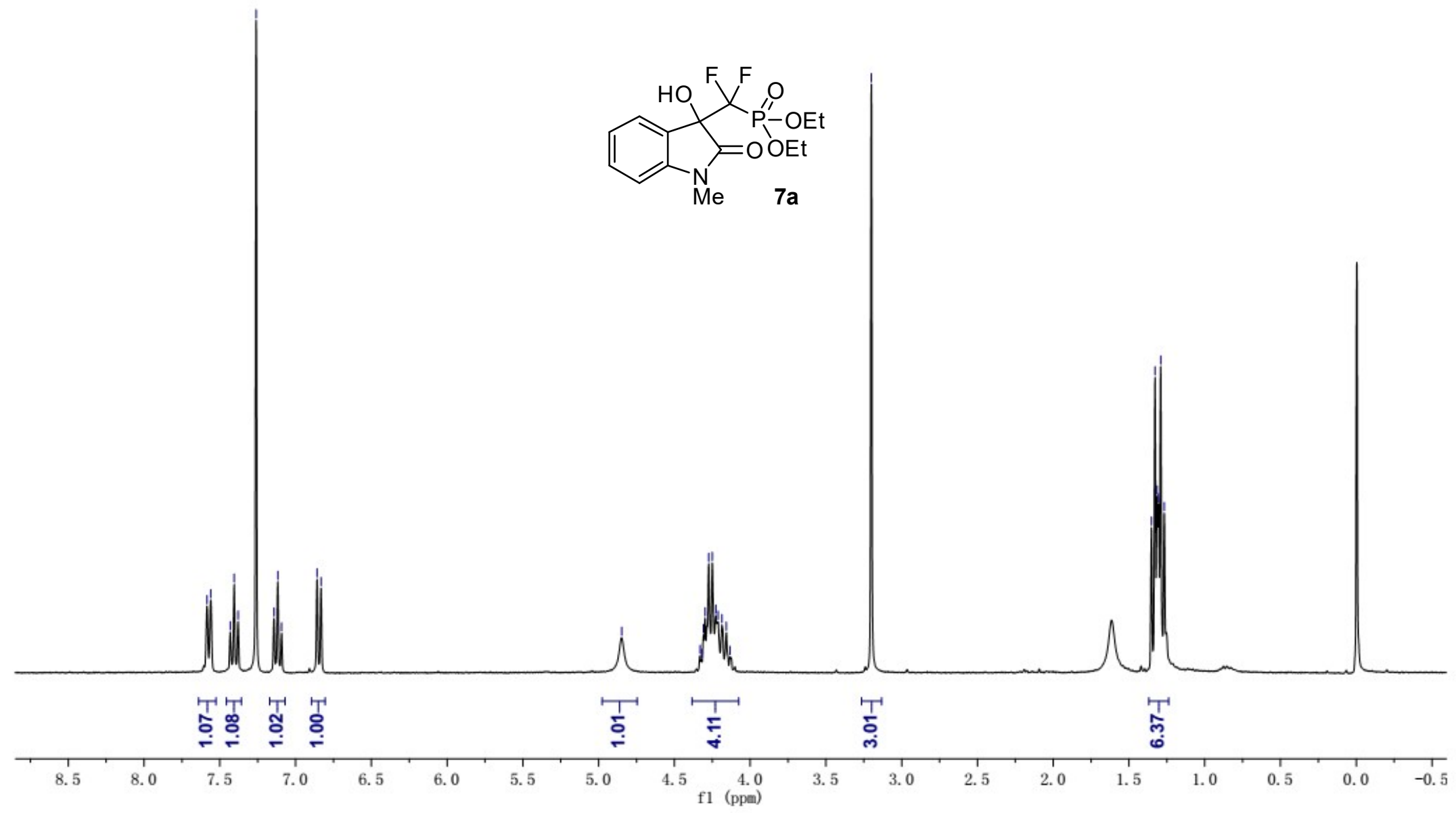


wyh-wf-48C 5000 กิ่งก่

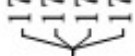

$7 a$

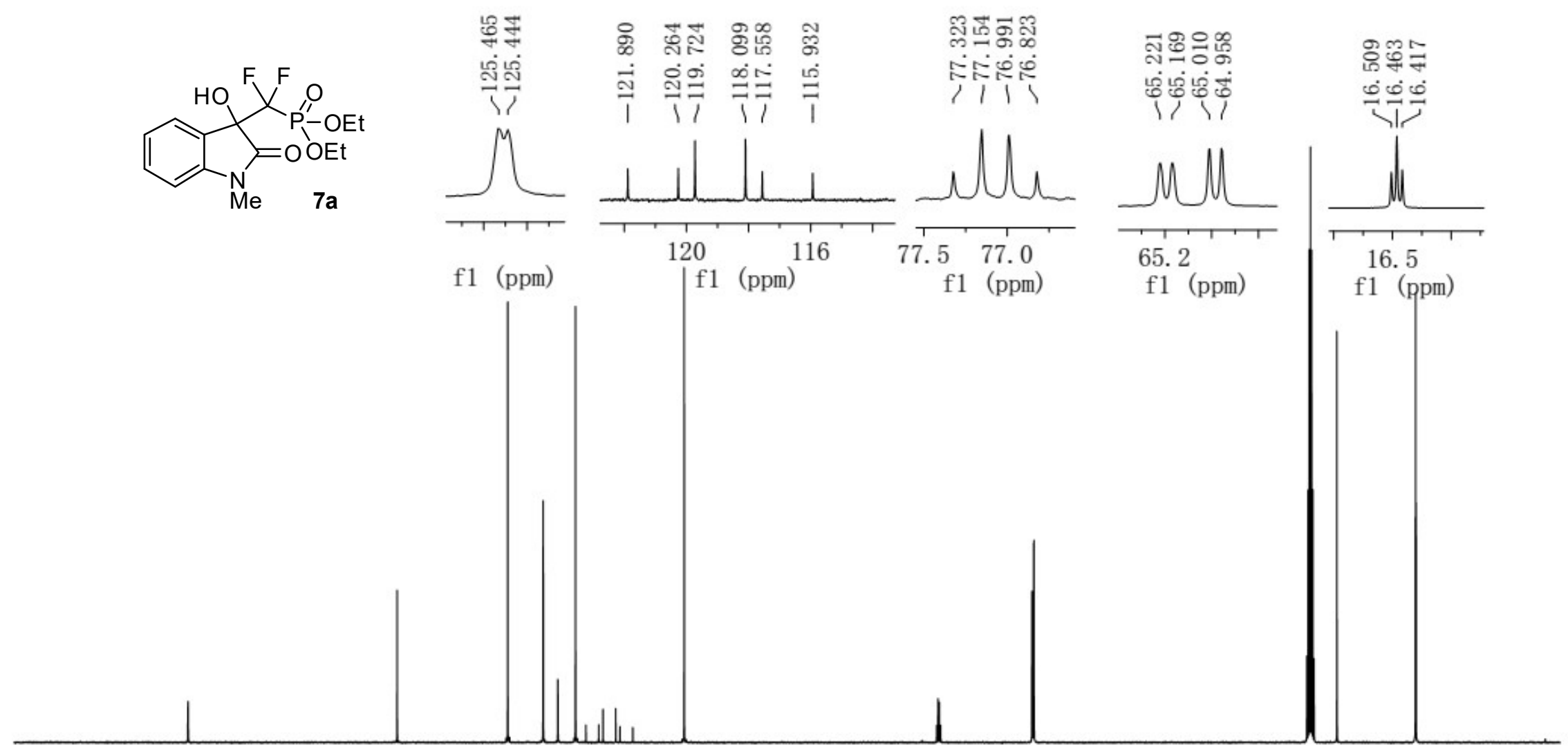

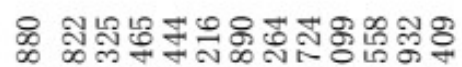

ம்

1

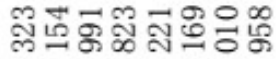

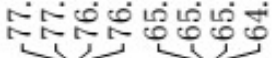

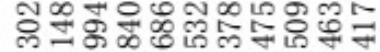

-

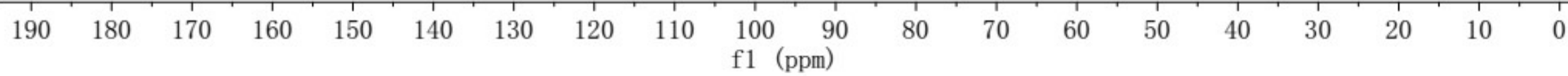




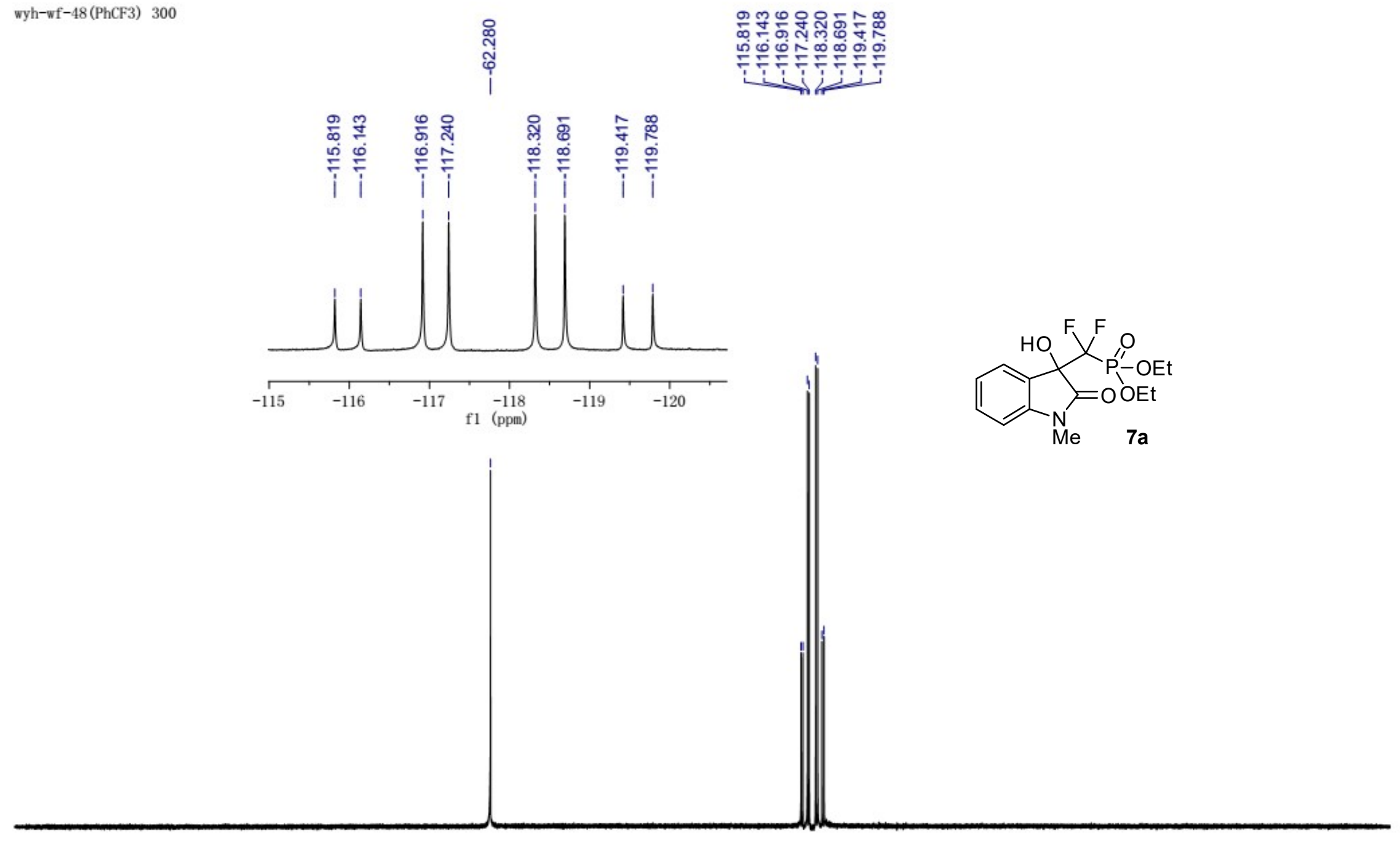

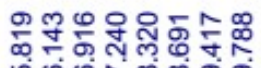

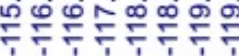
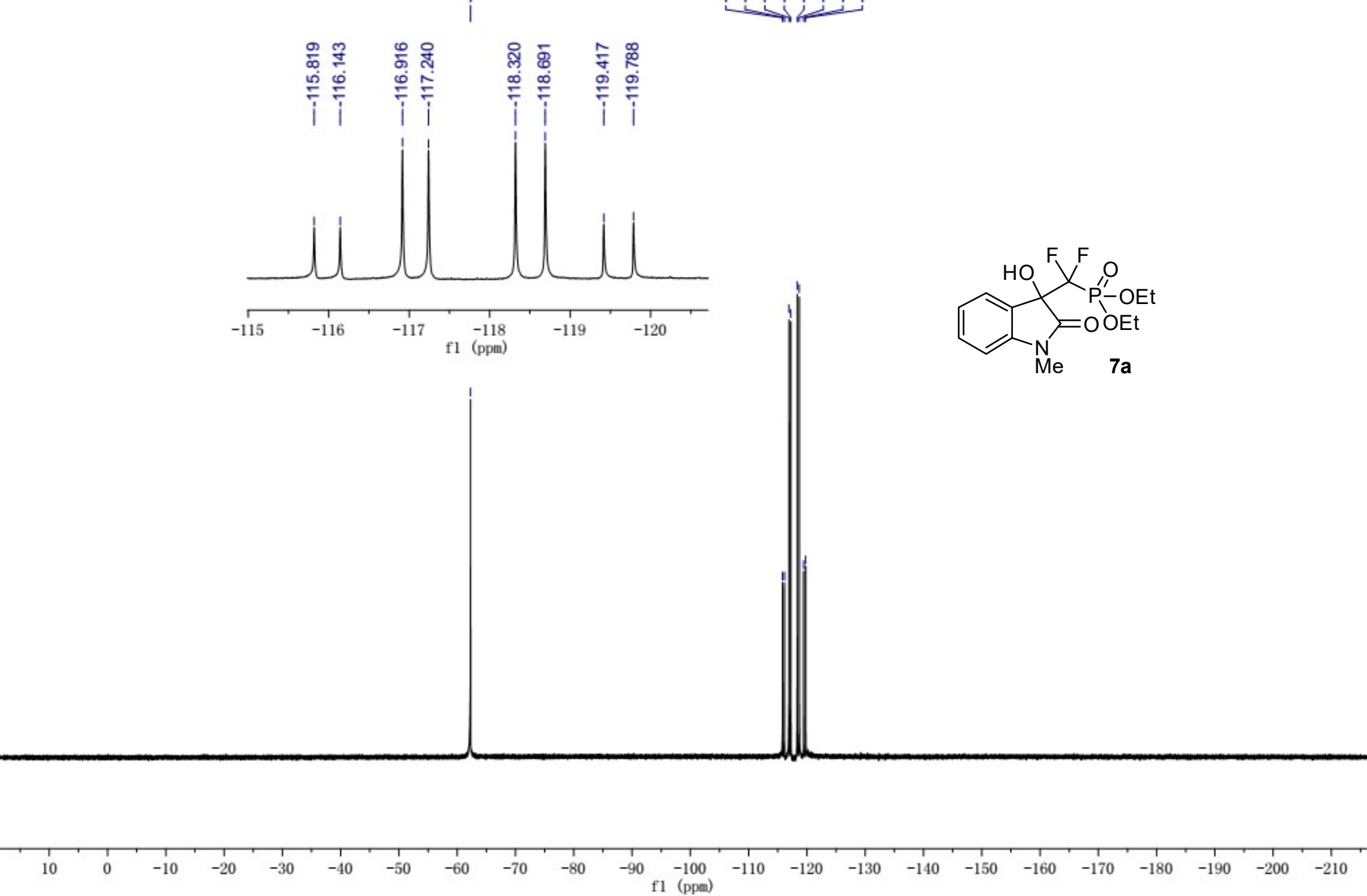


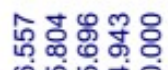

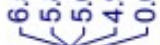
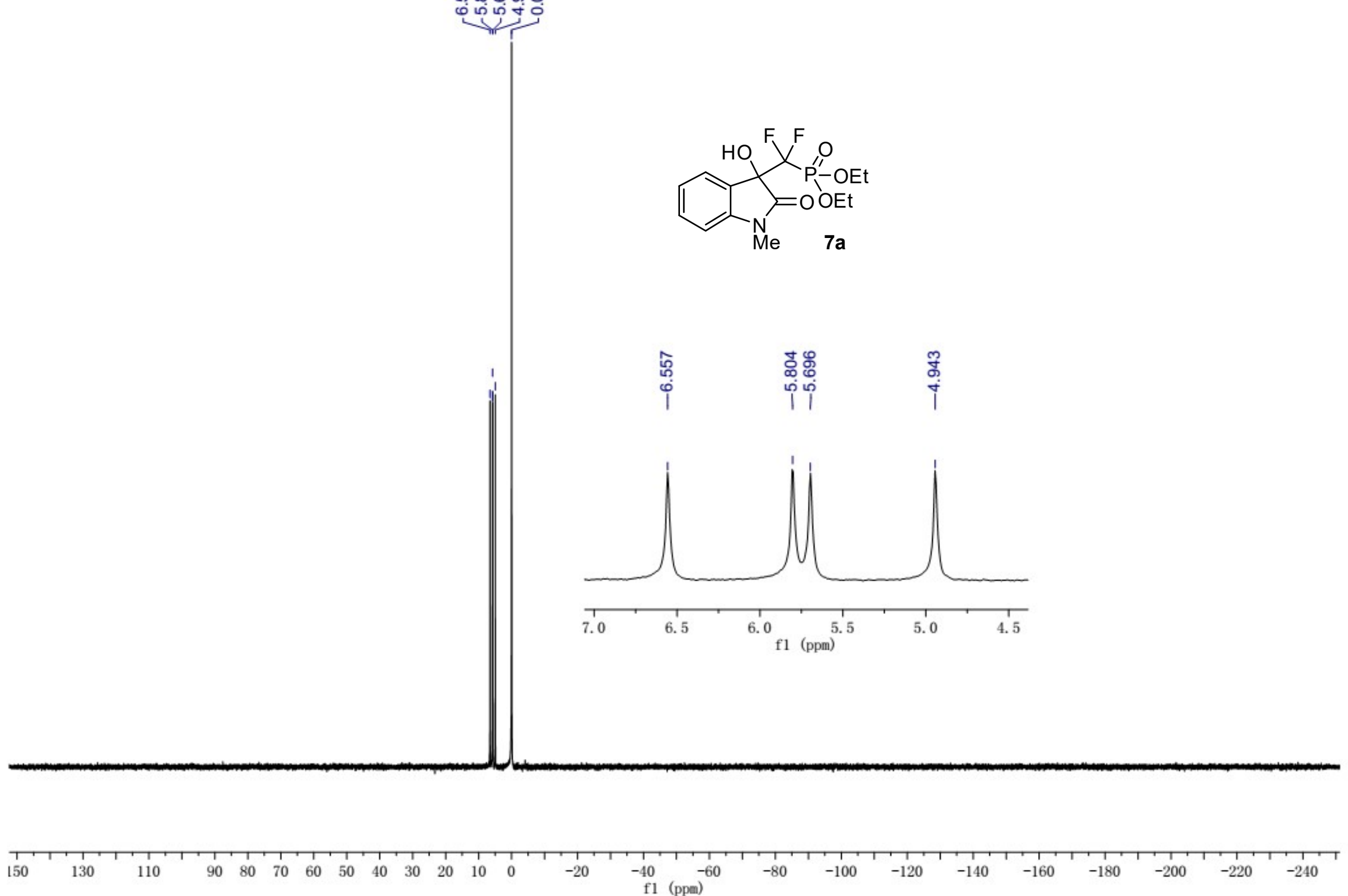


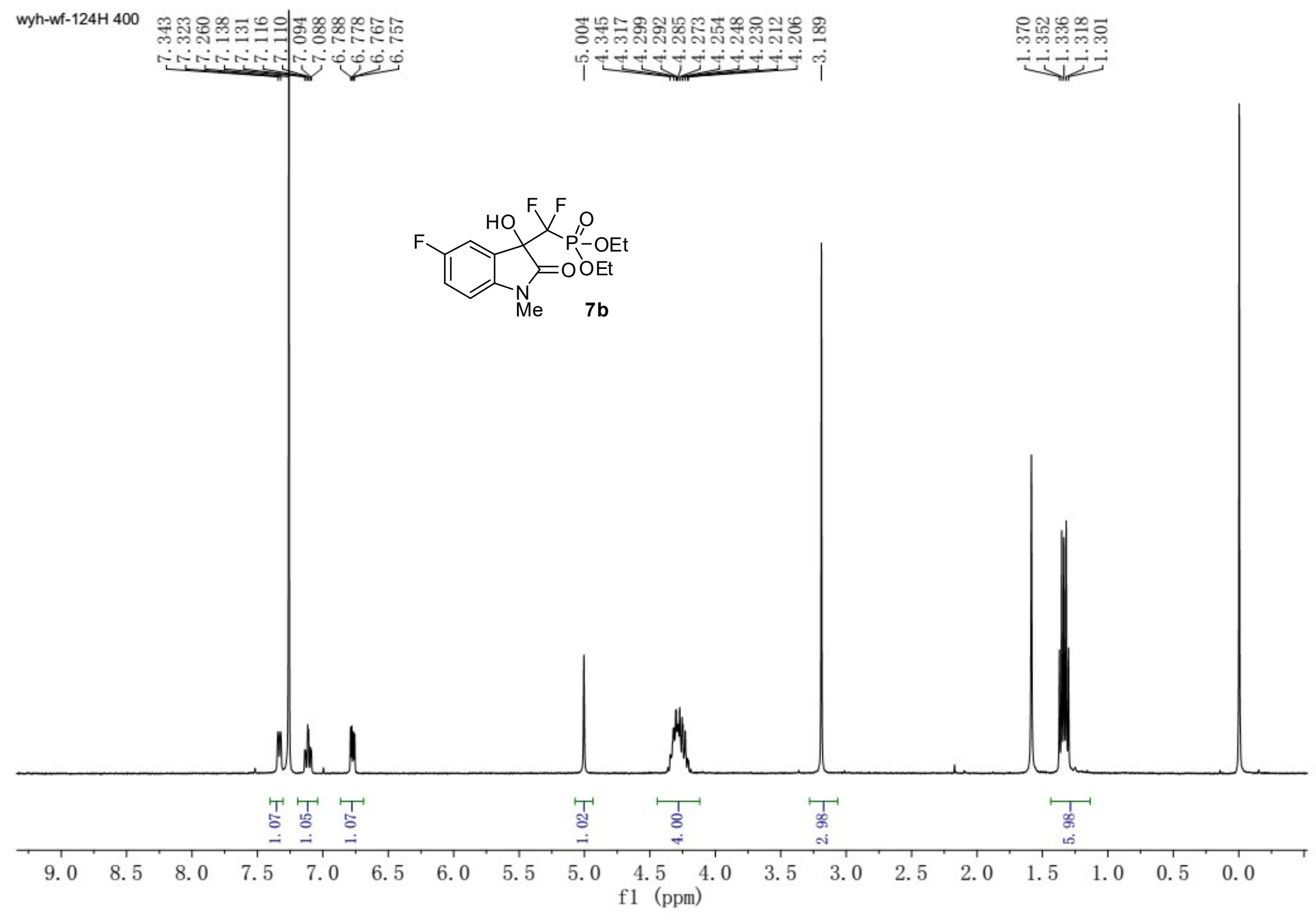




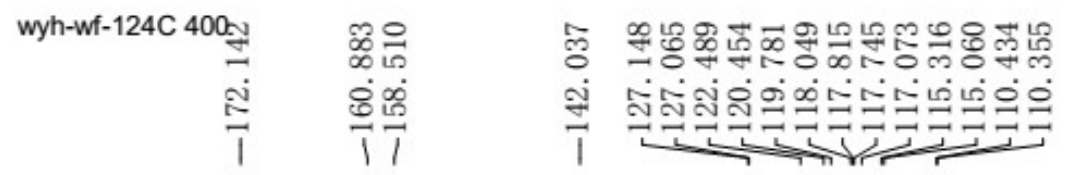

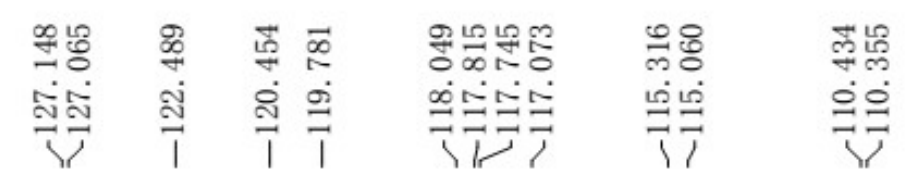

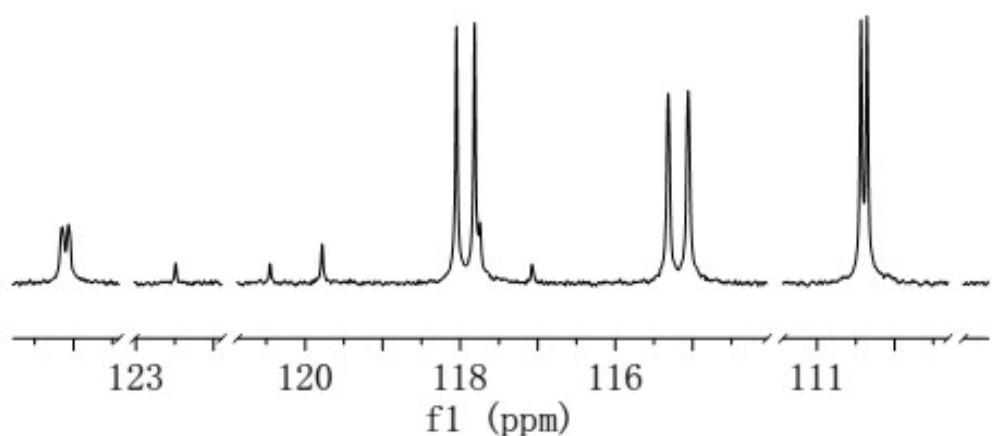

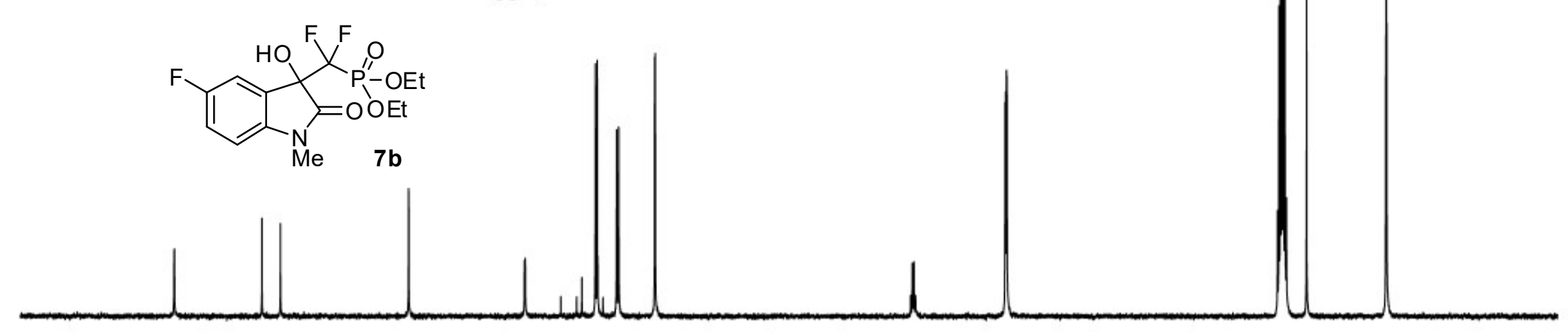

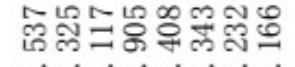

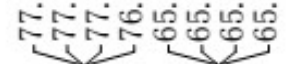

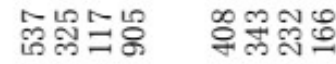

소요

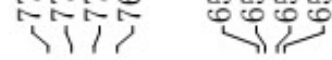

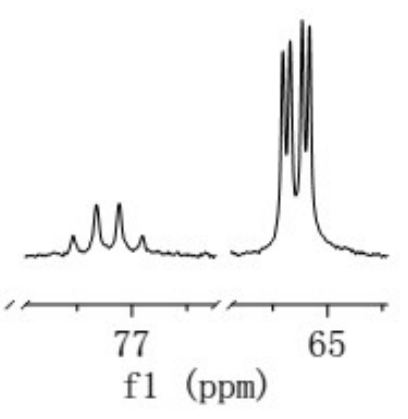

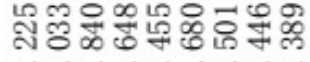

केंगु

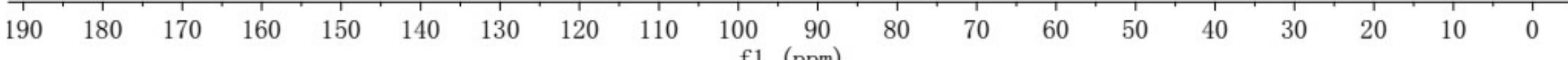


wyh-wf-124F (PhCF3) 300M

ֻัฐ

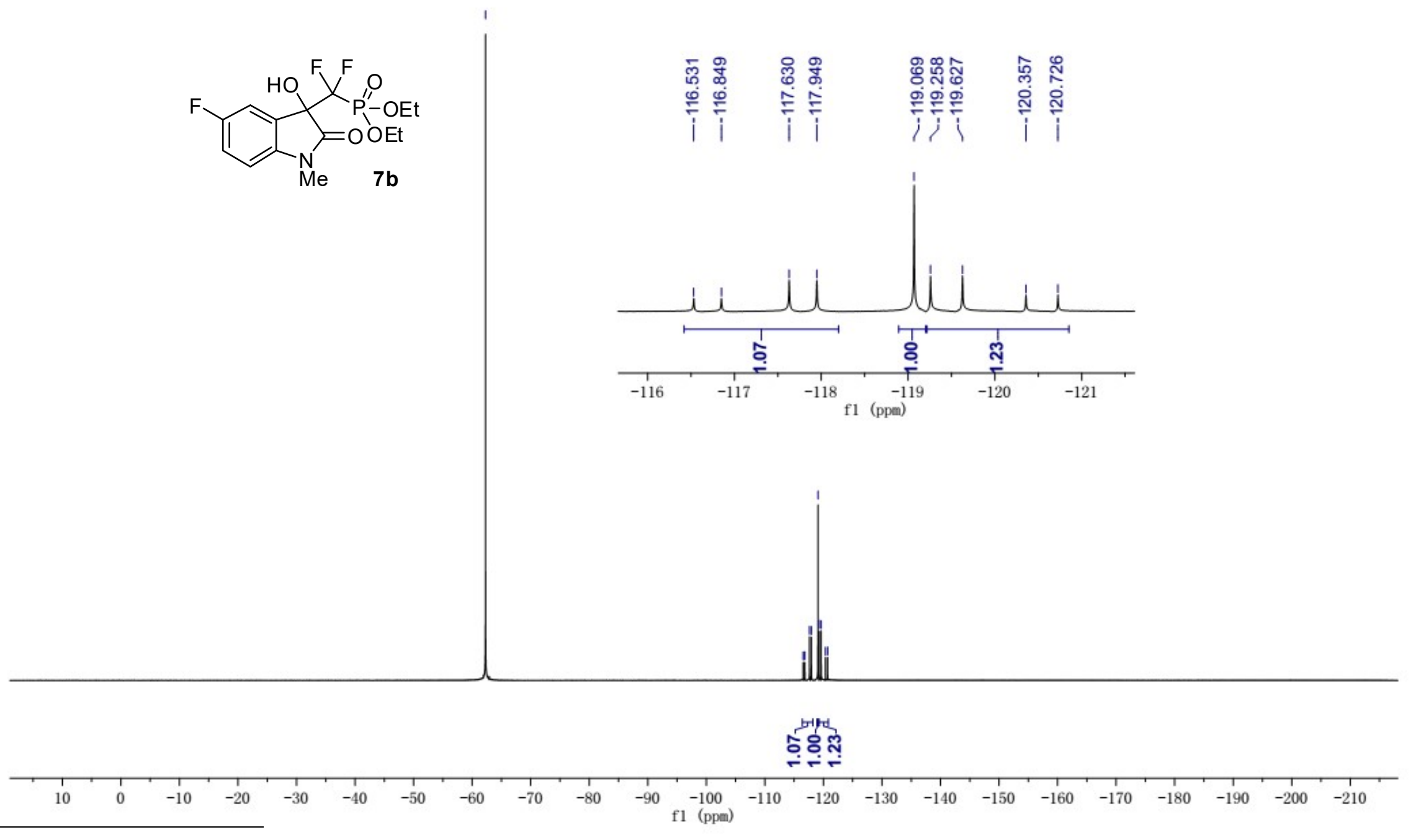

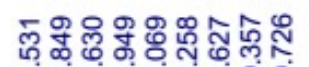

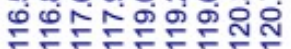



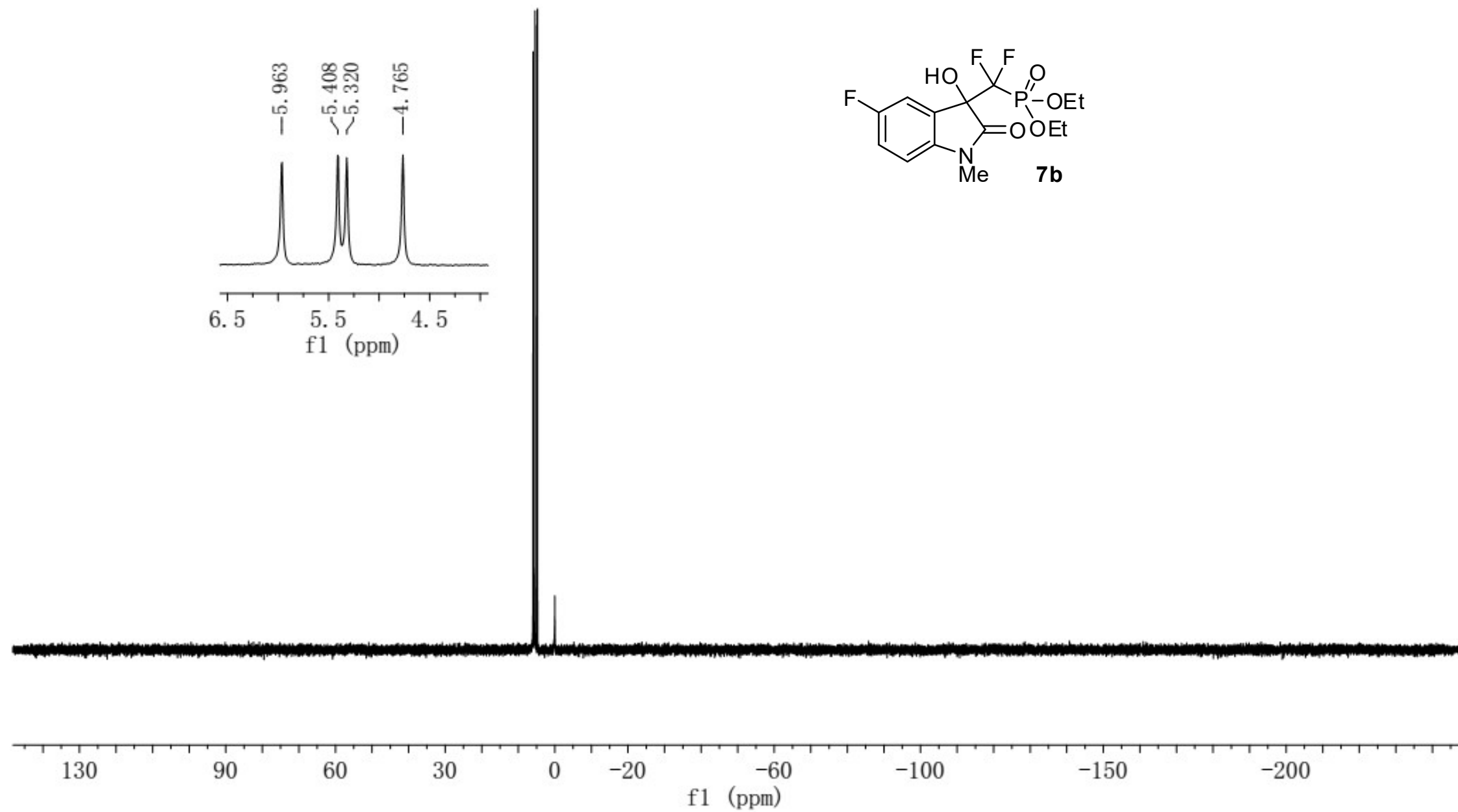


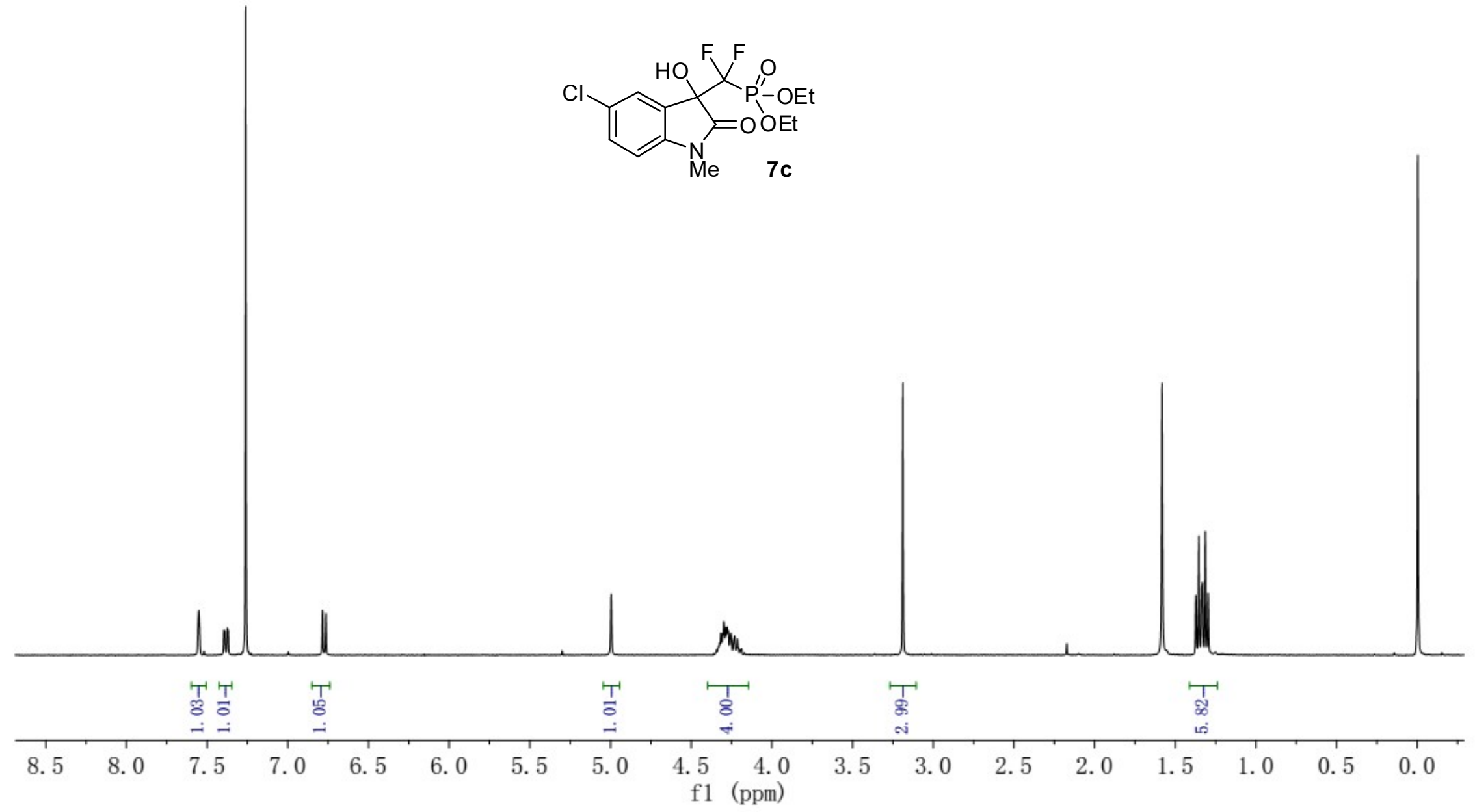



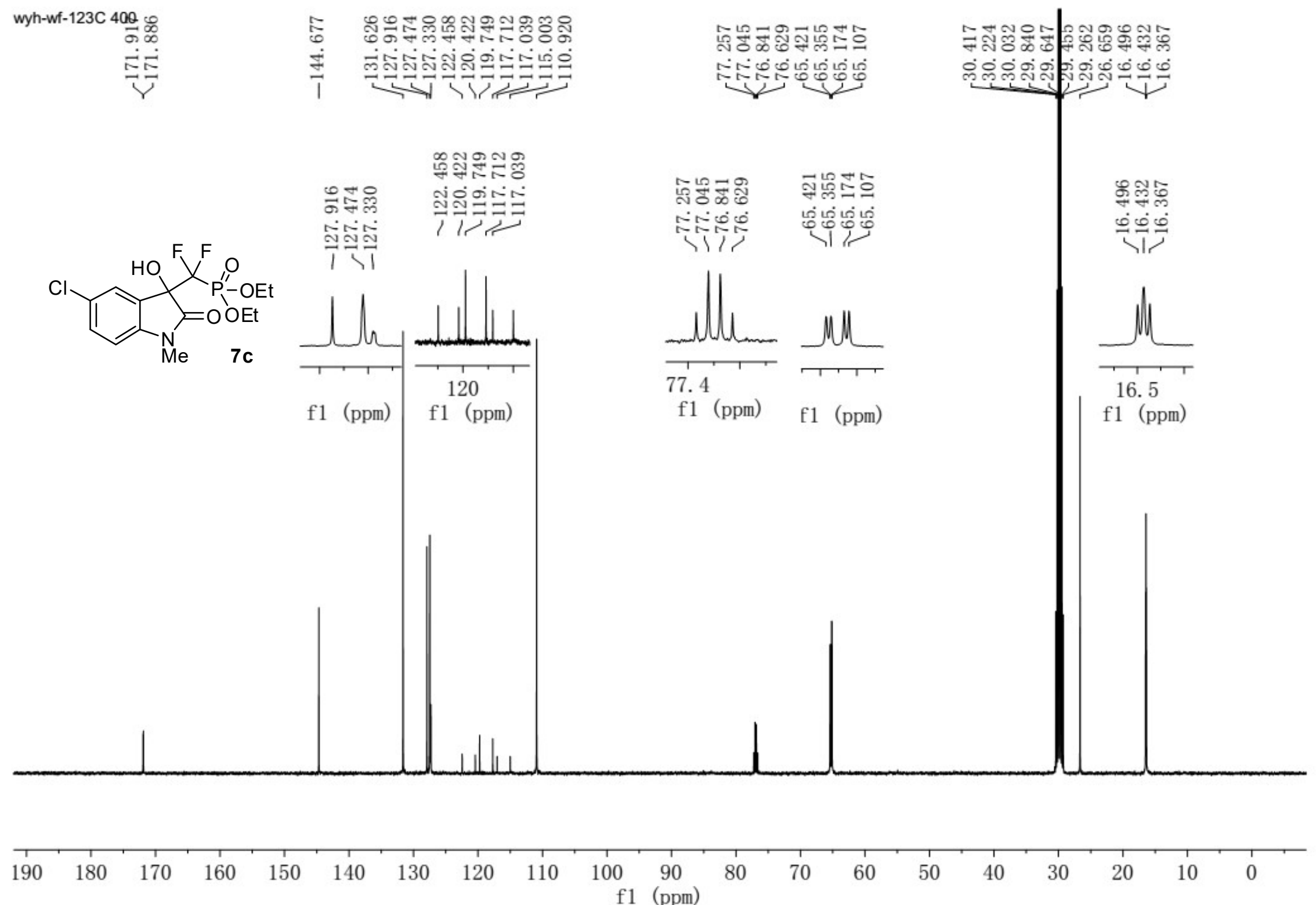
wyh-wf-123F (PhCF3) 300
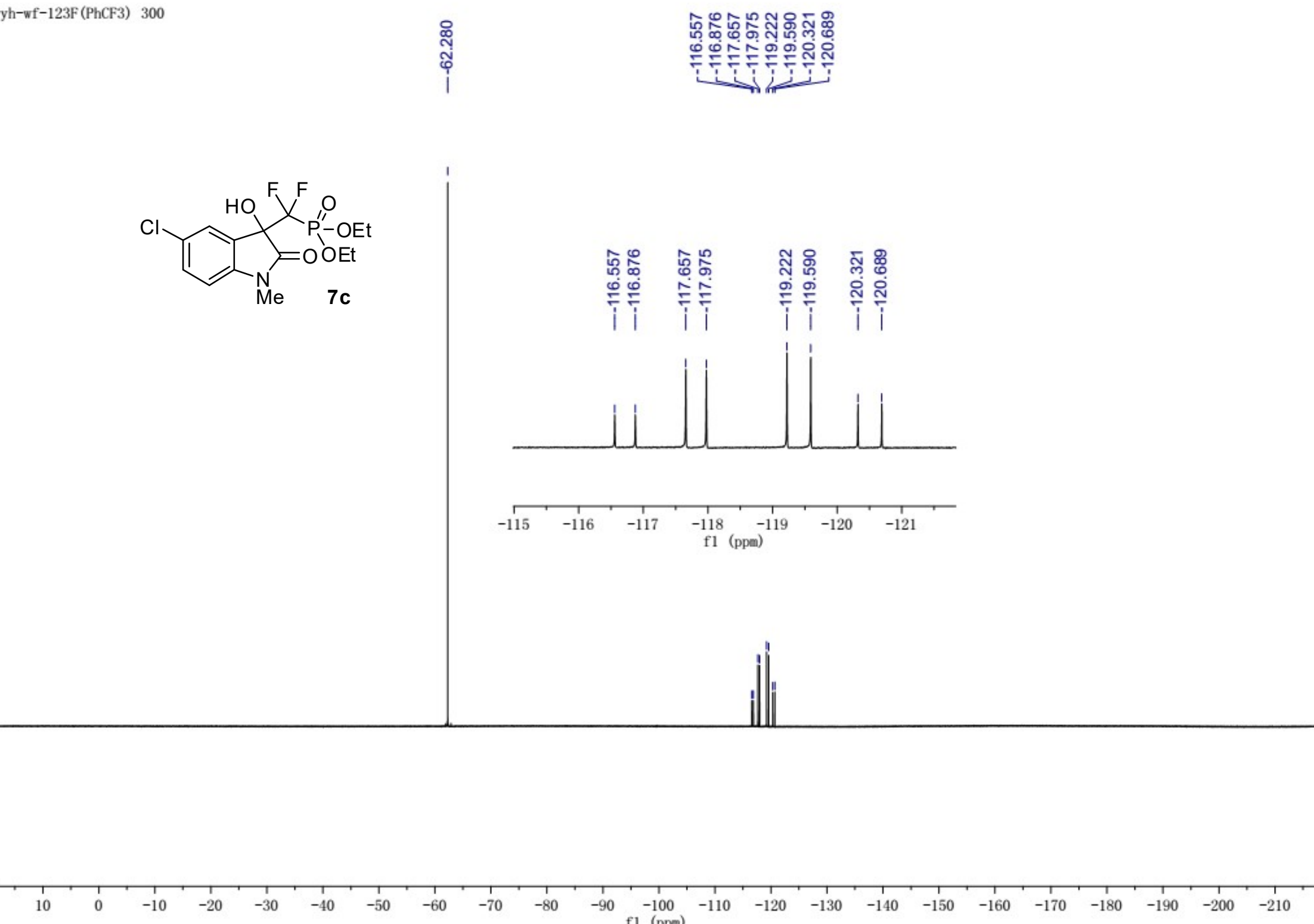
해애워
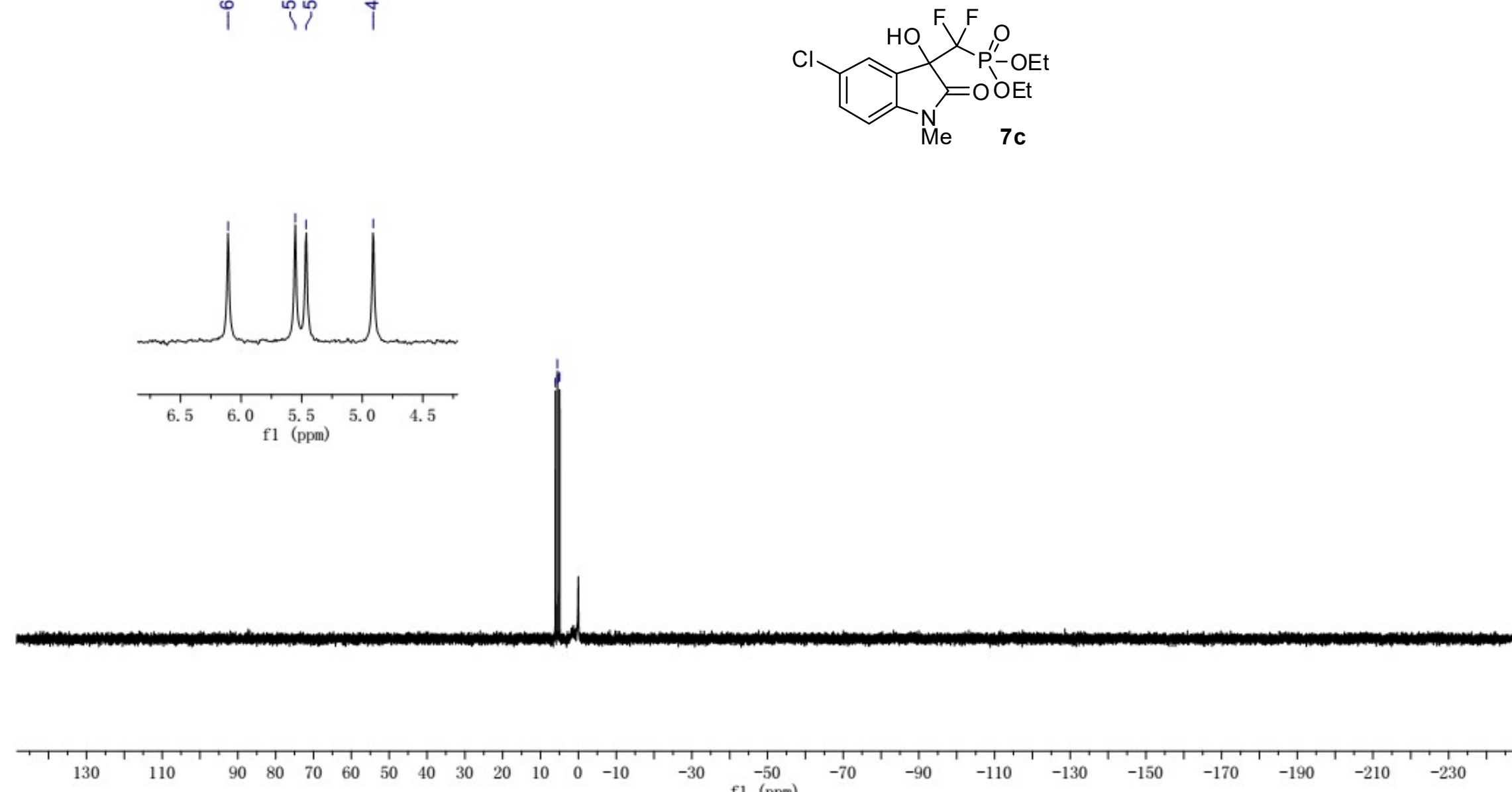


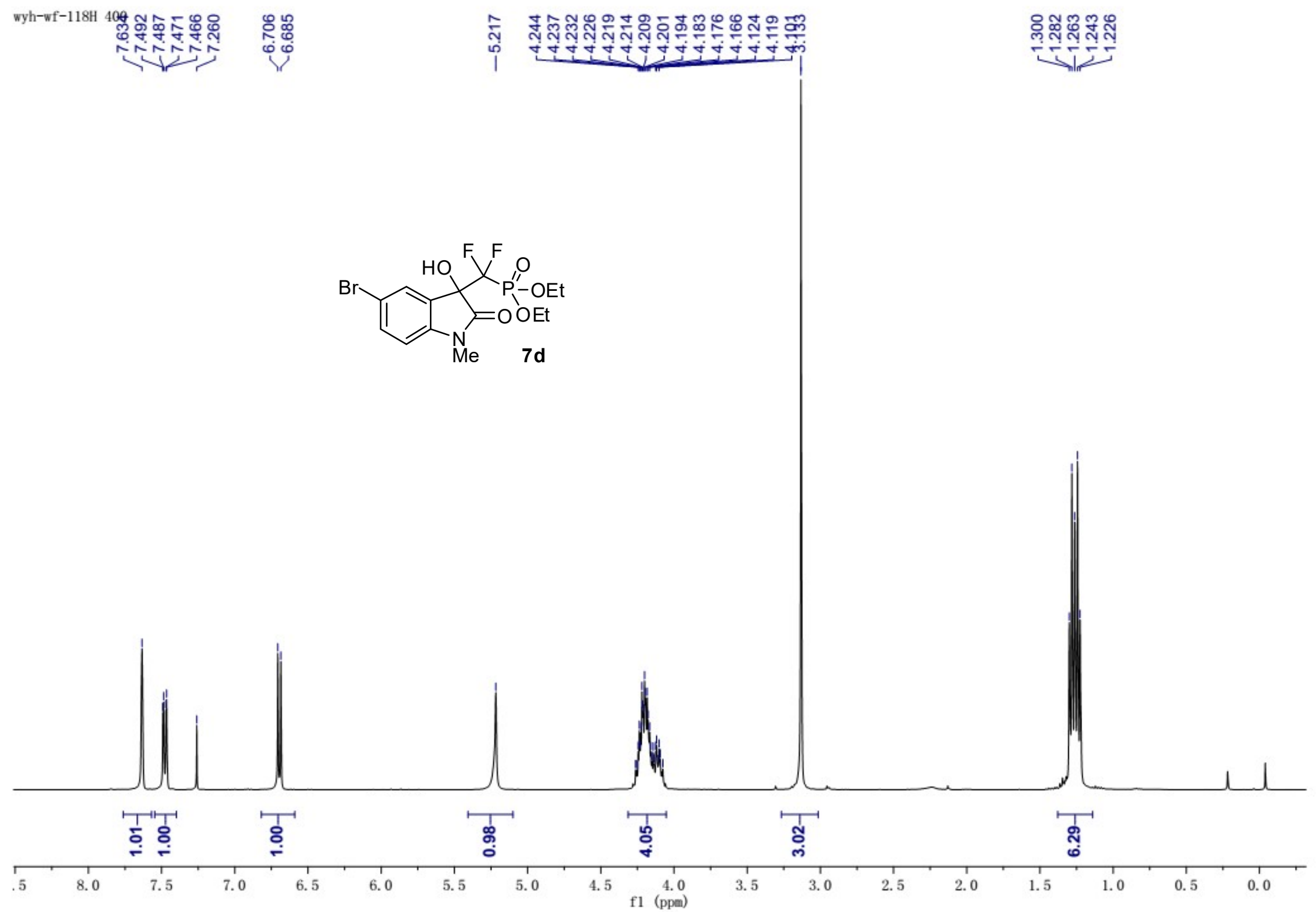




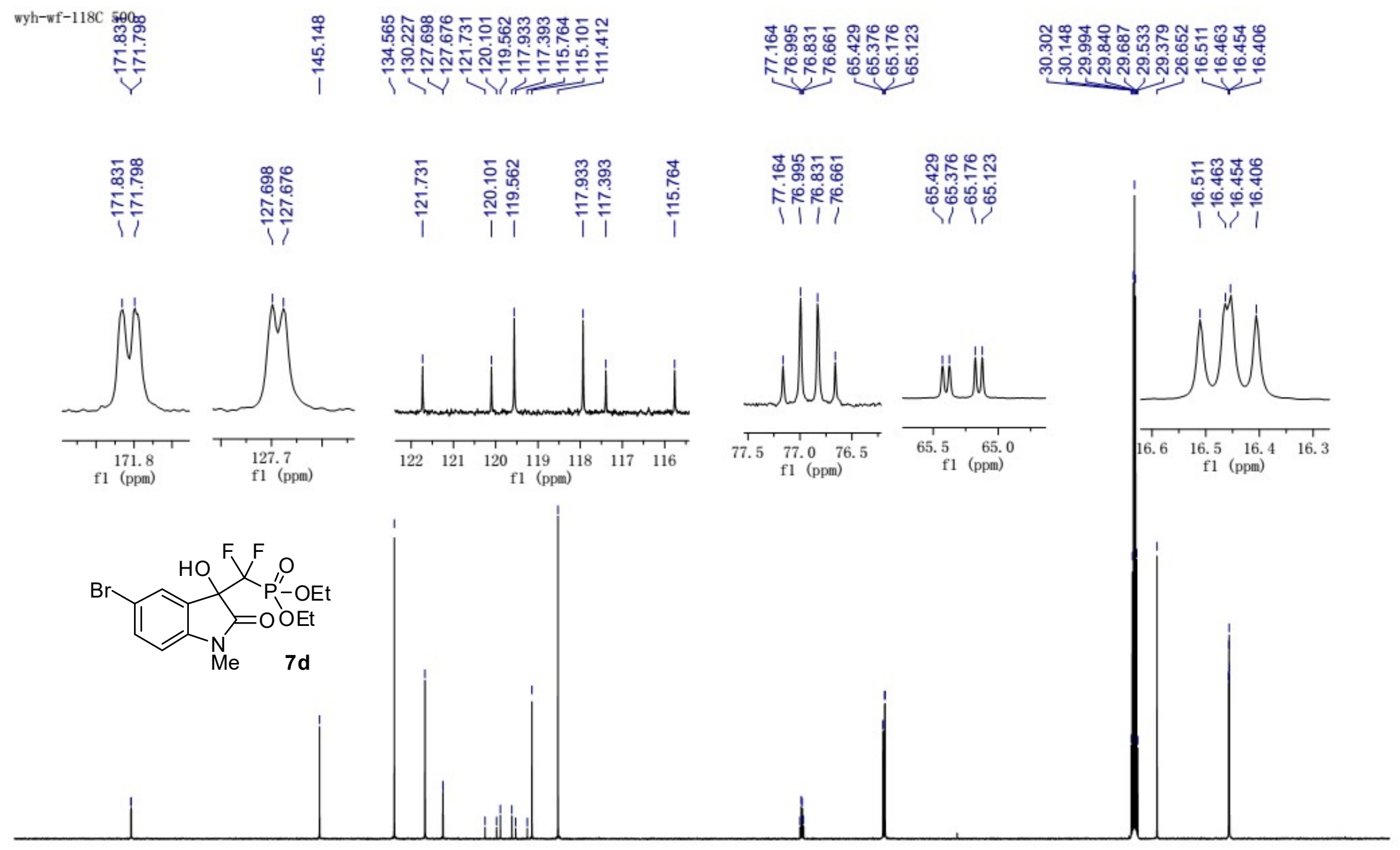

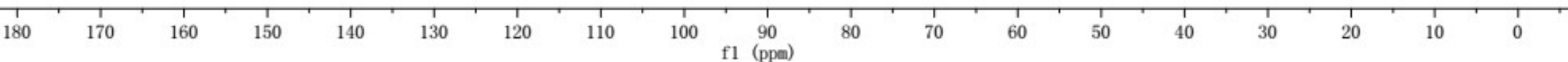



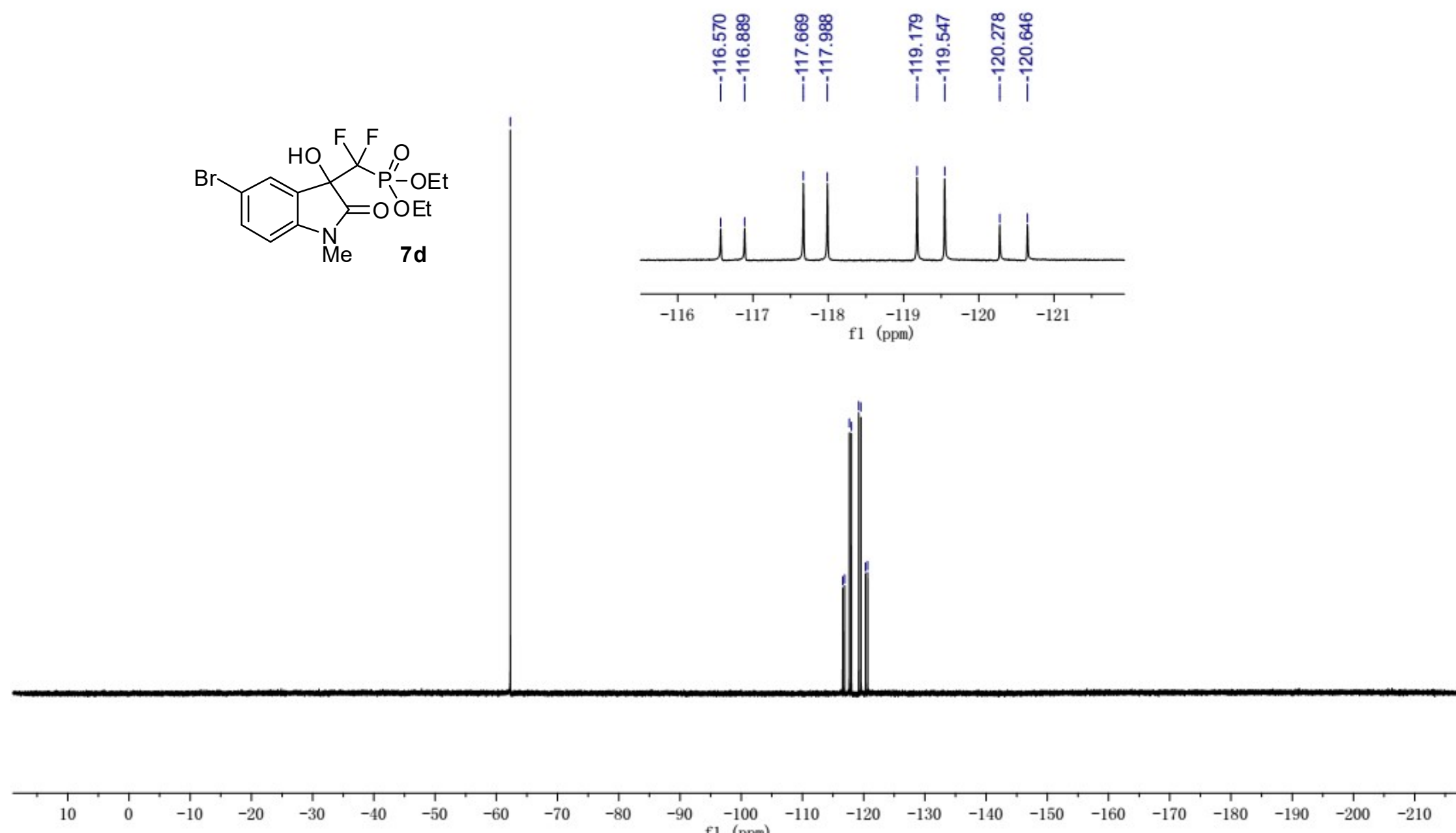

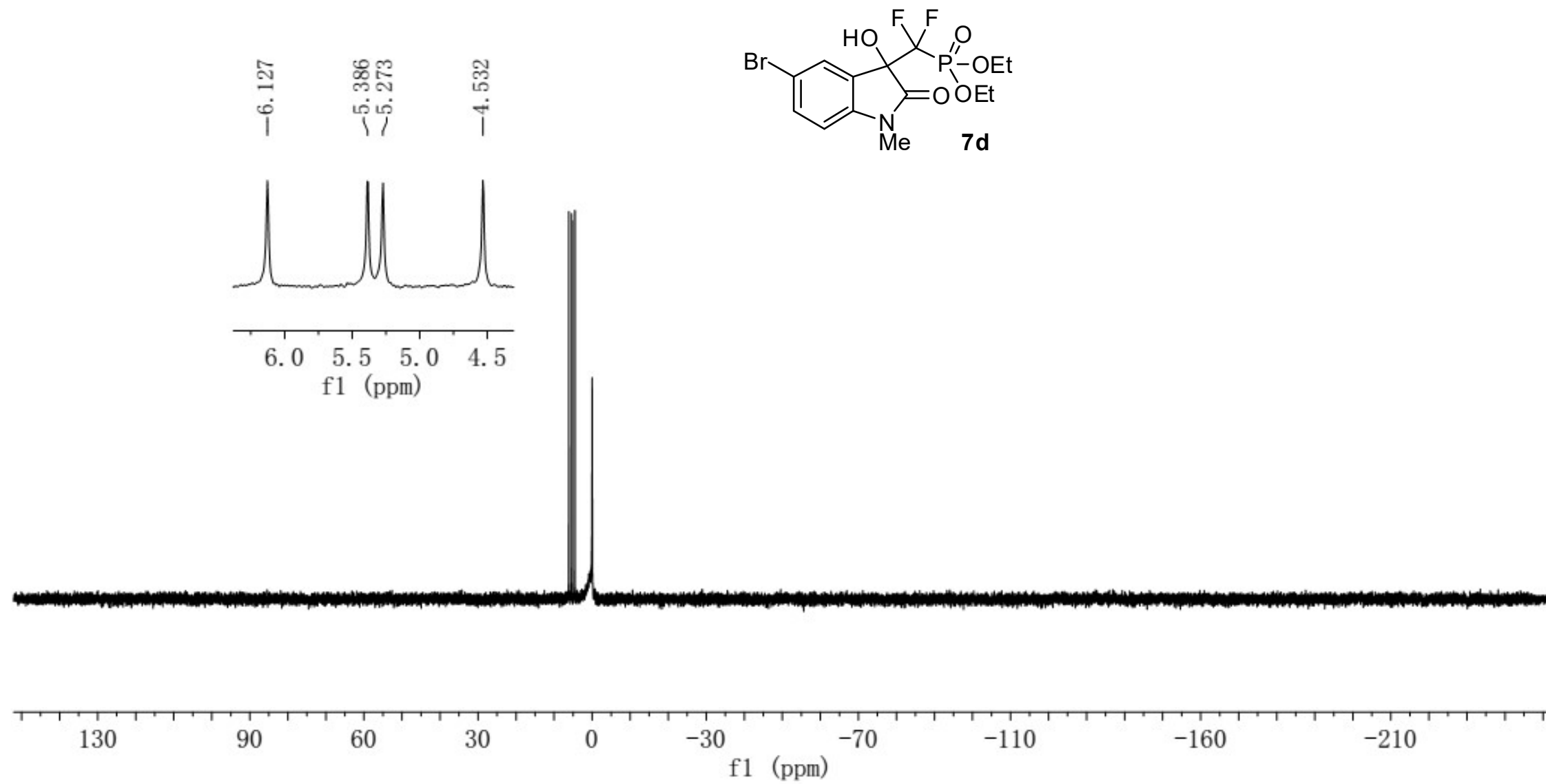


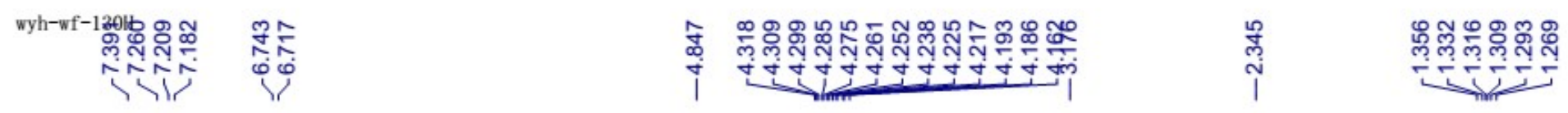

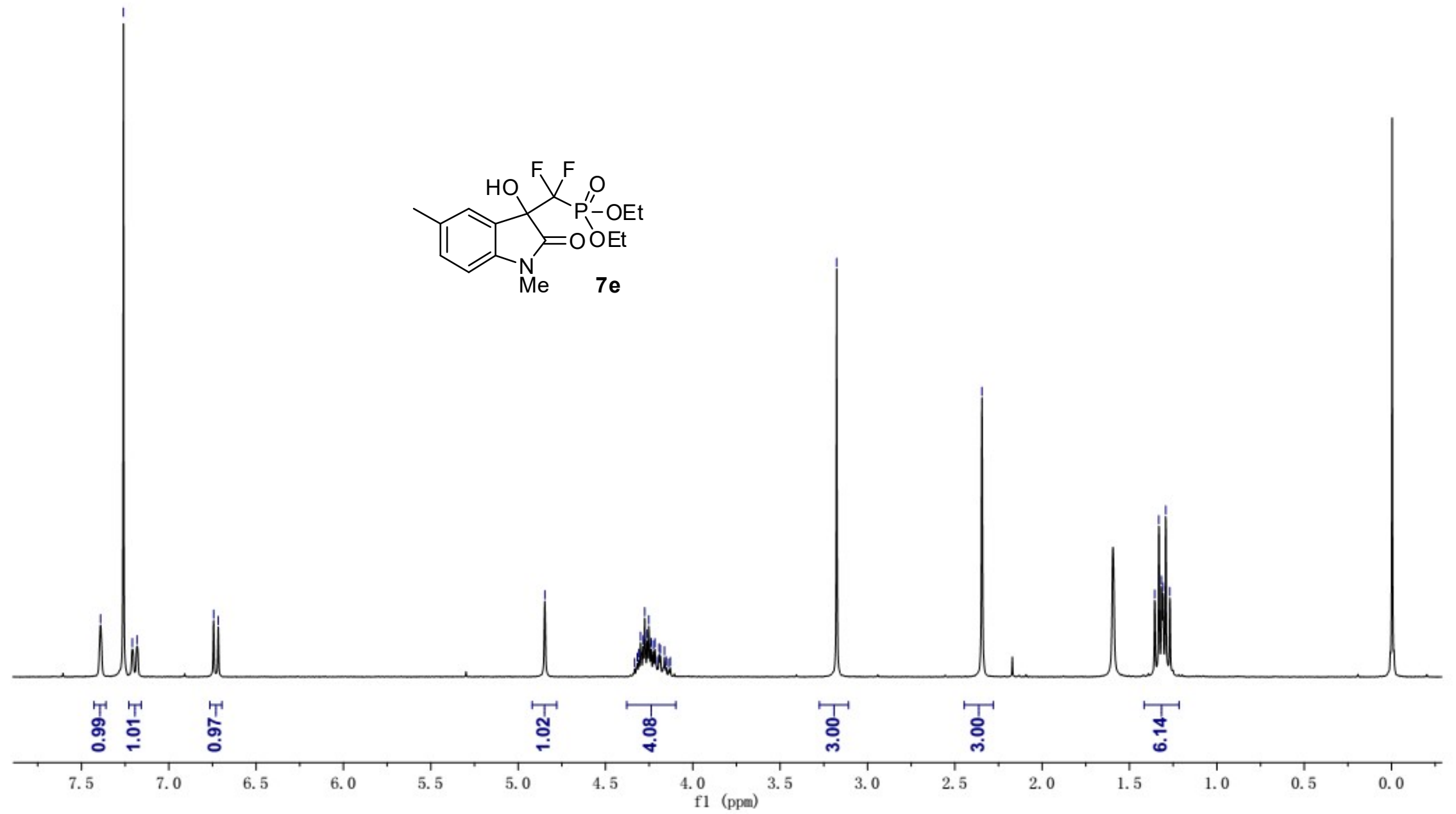



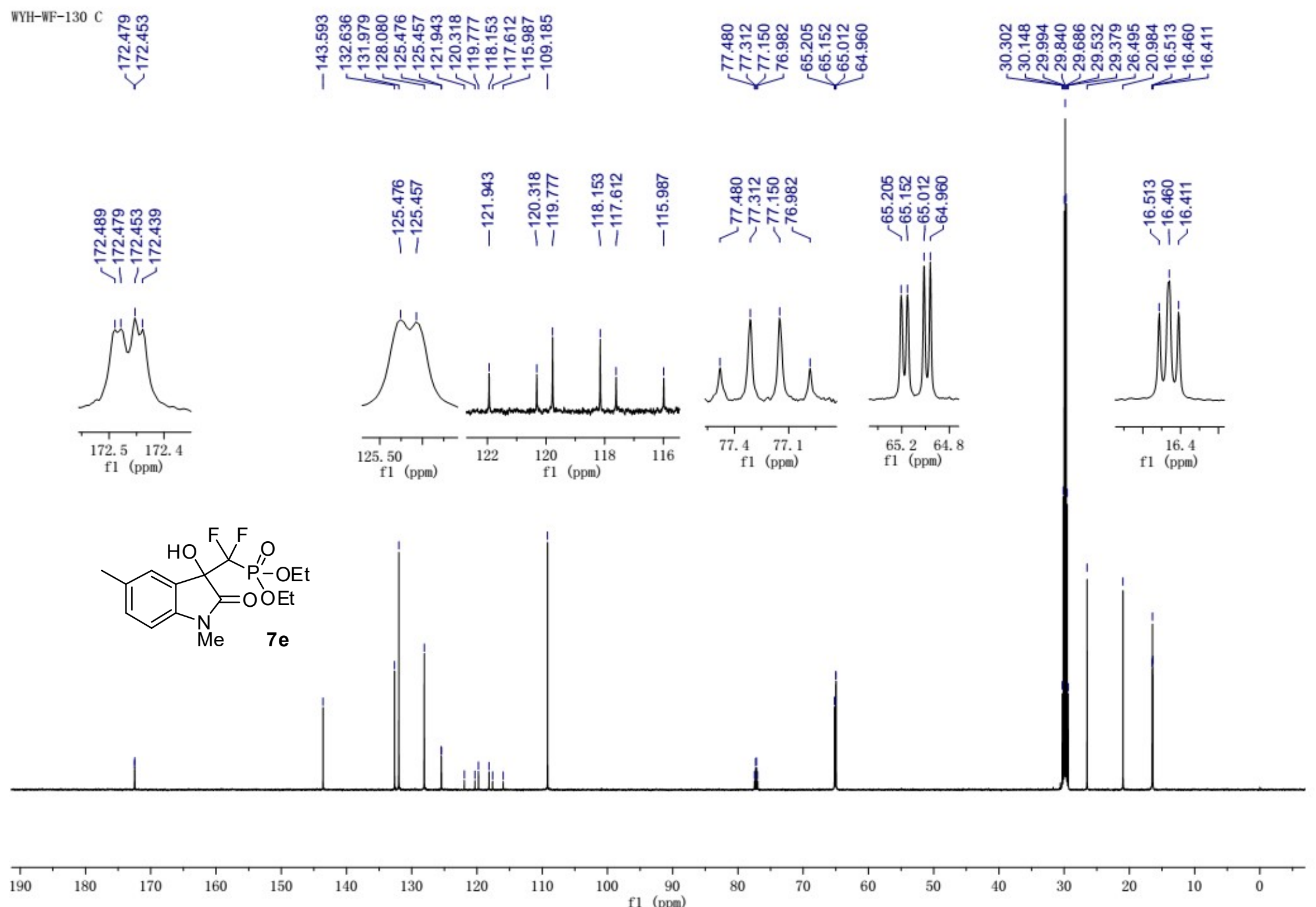


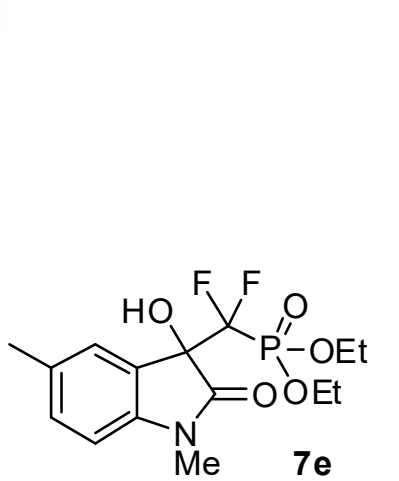

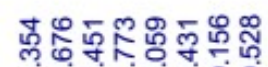

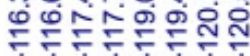

पini

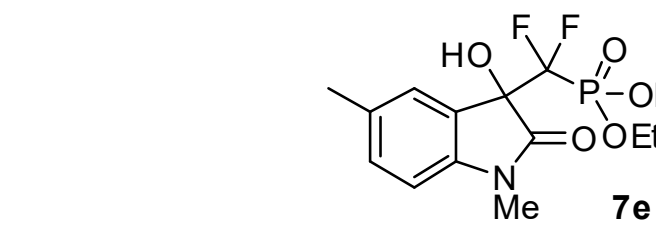

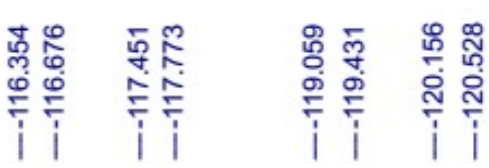
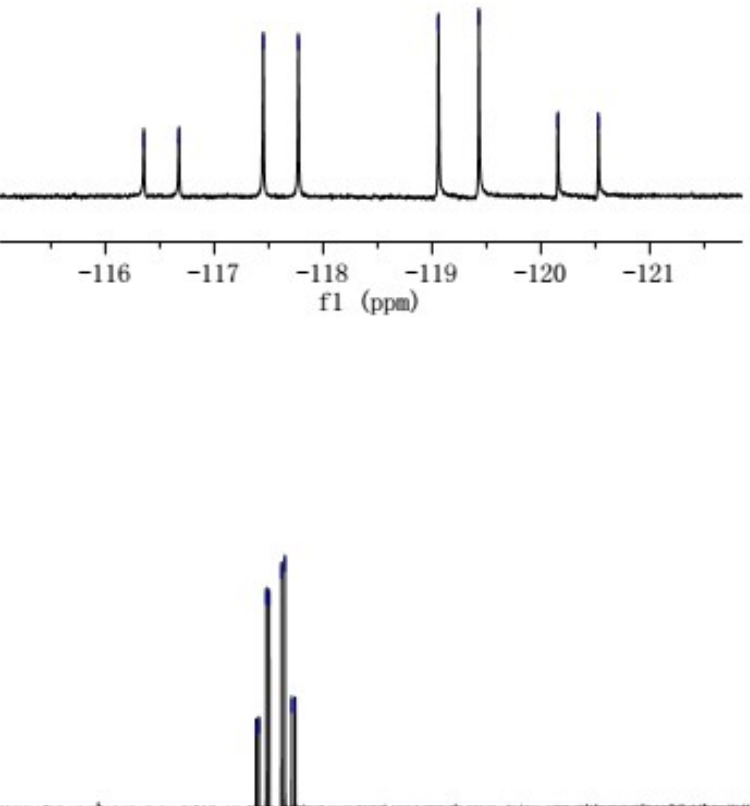

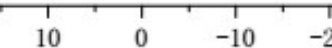

$-50 \quad-60$

$\underset{-70}{1} \quad \frac{1}{-80}$

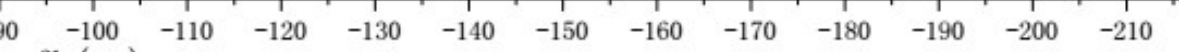



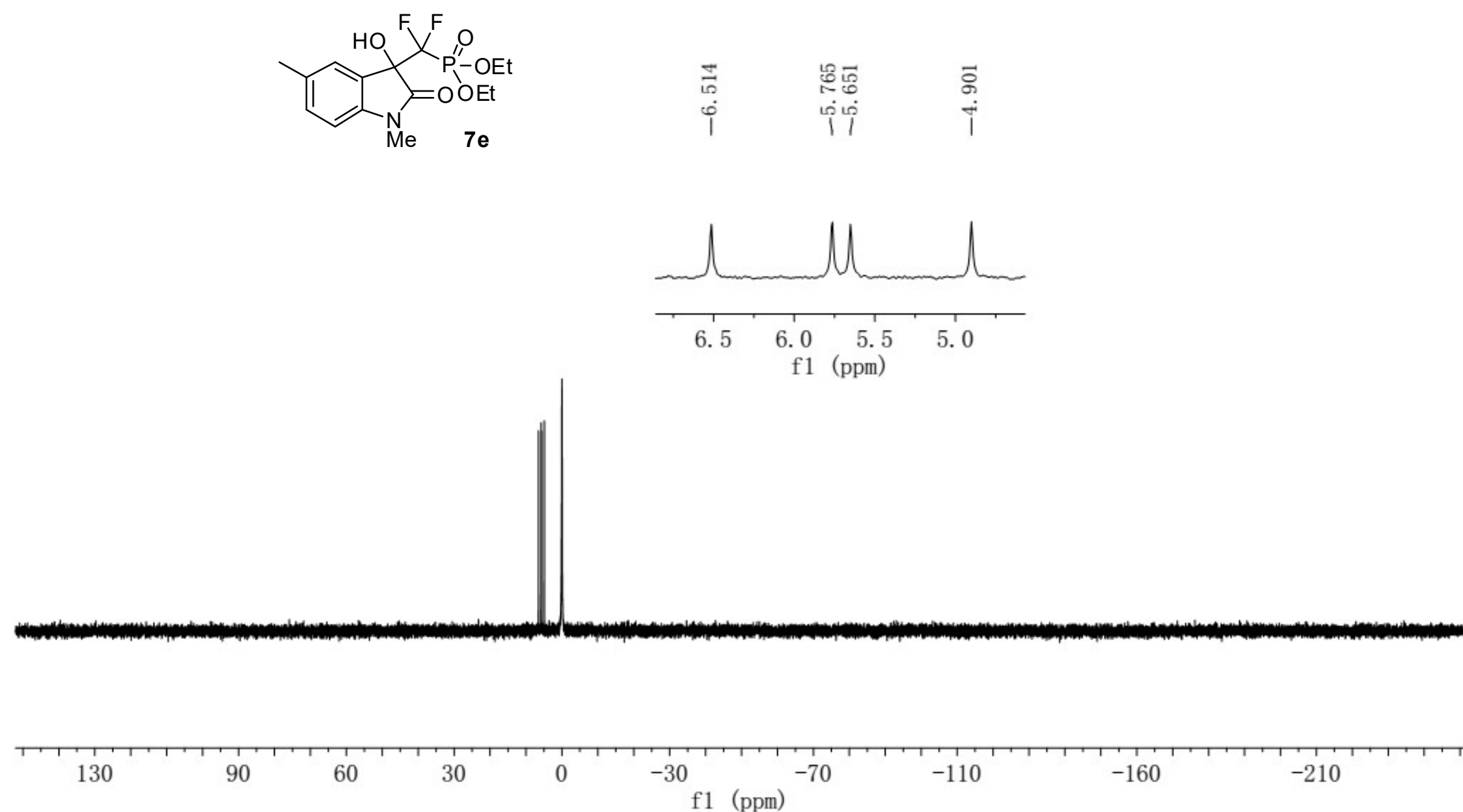


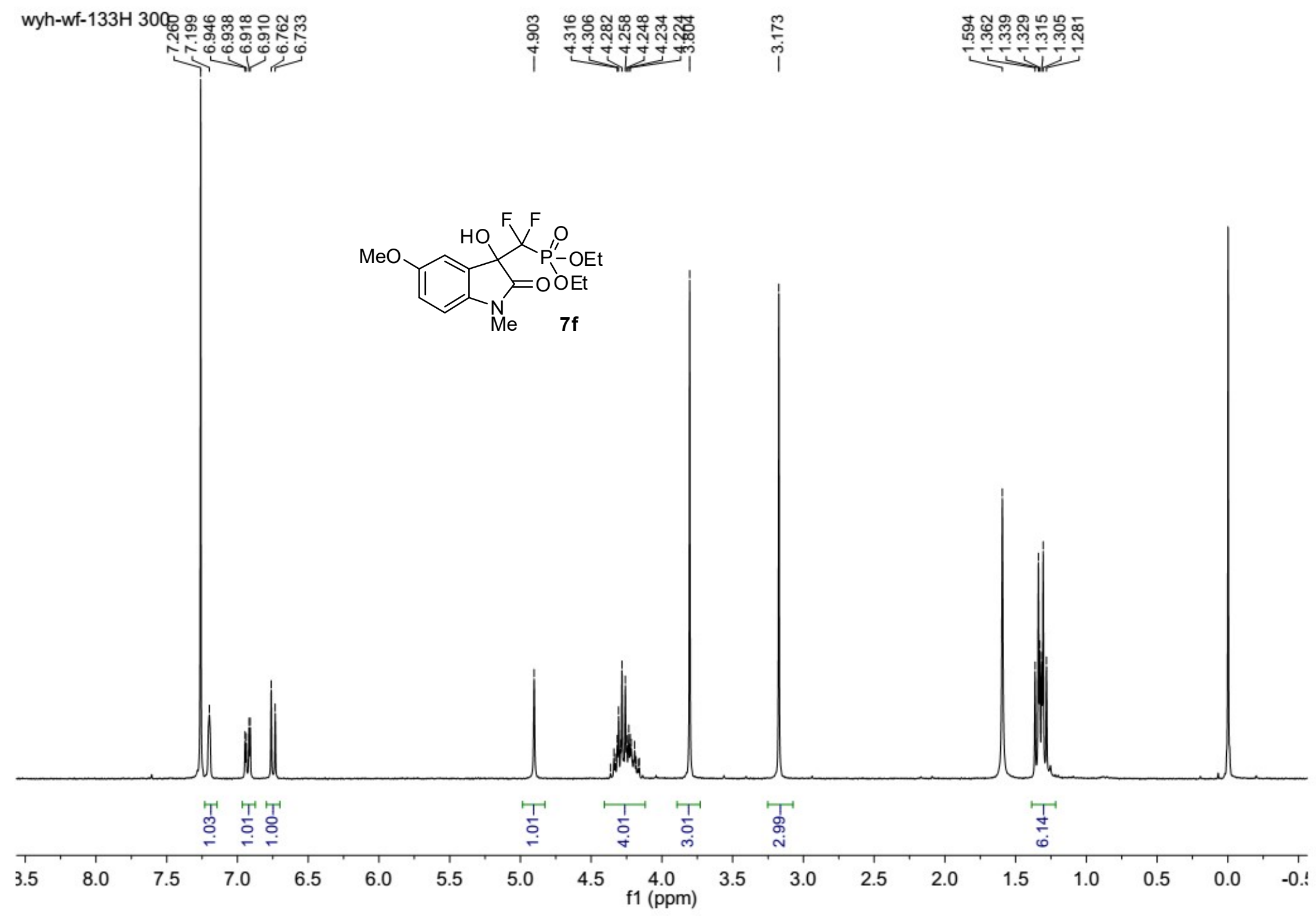



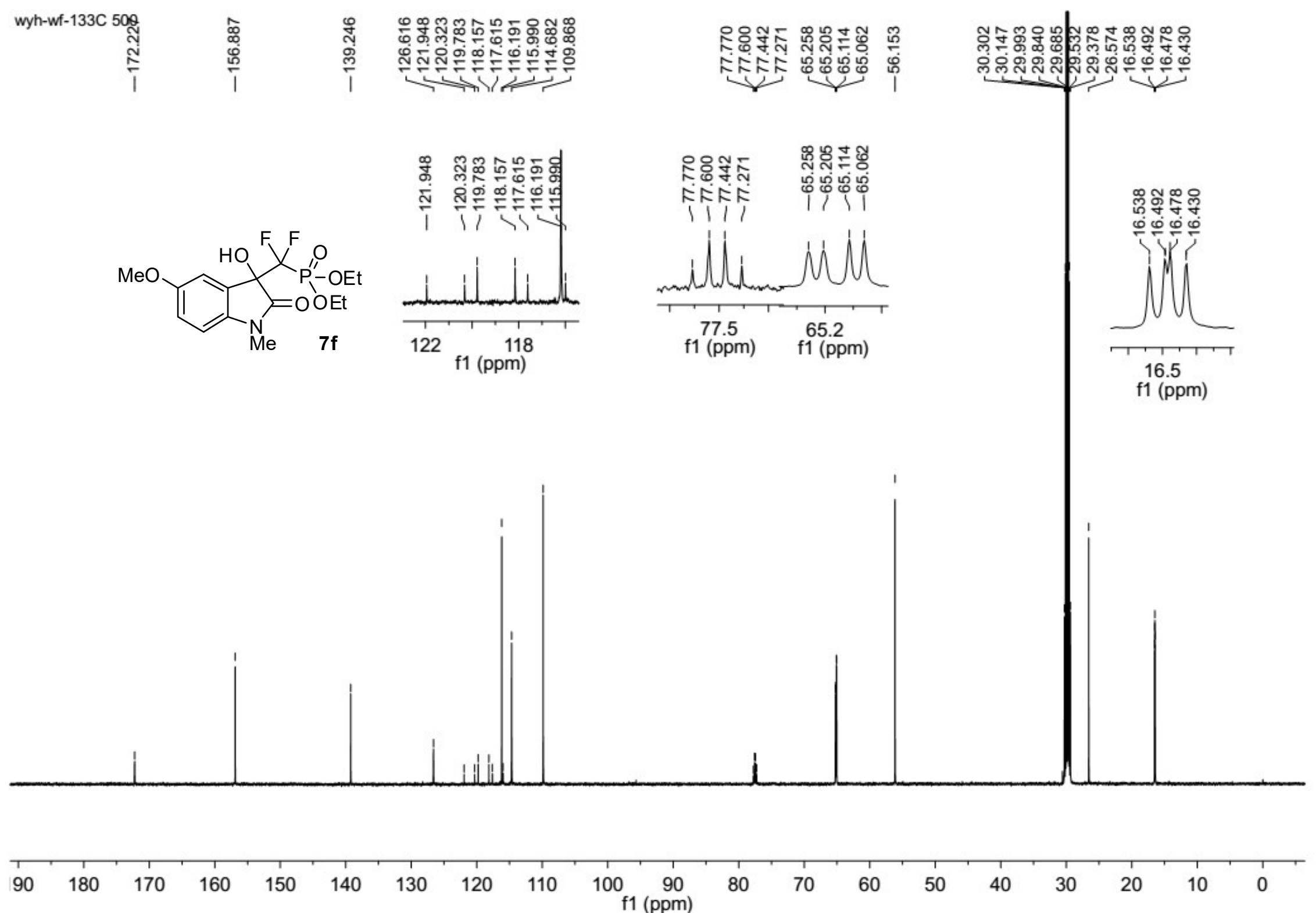

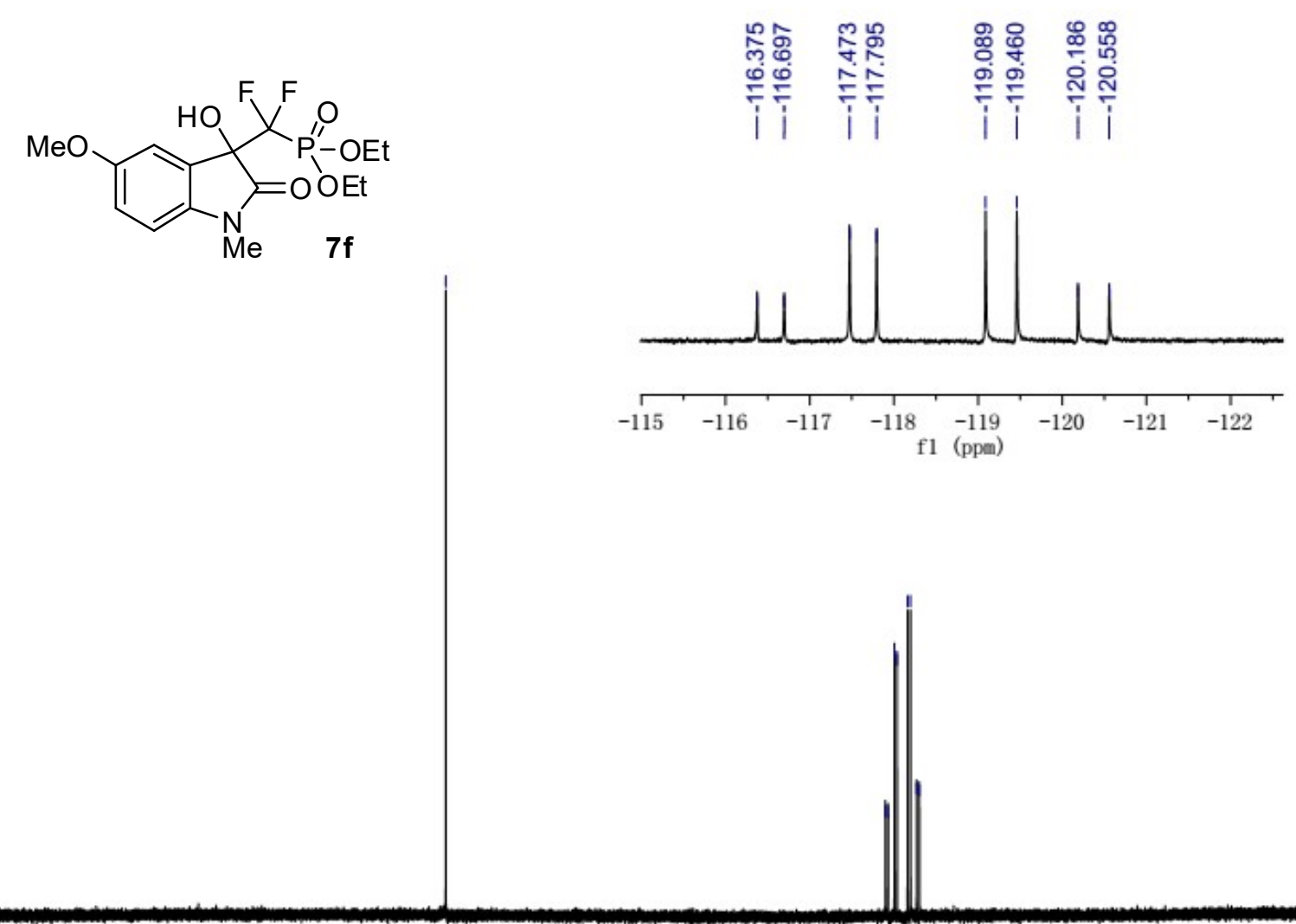

f1 $\quad \begin{aligned} & -100 \\ & \text { (ppm) }\end{aligned}$ 
wyh-wf-133P(H3PO4) 300

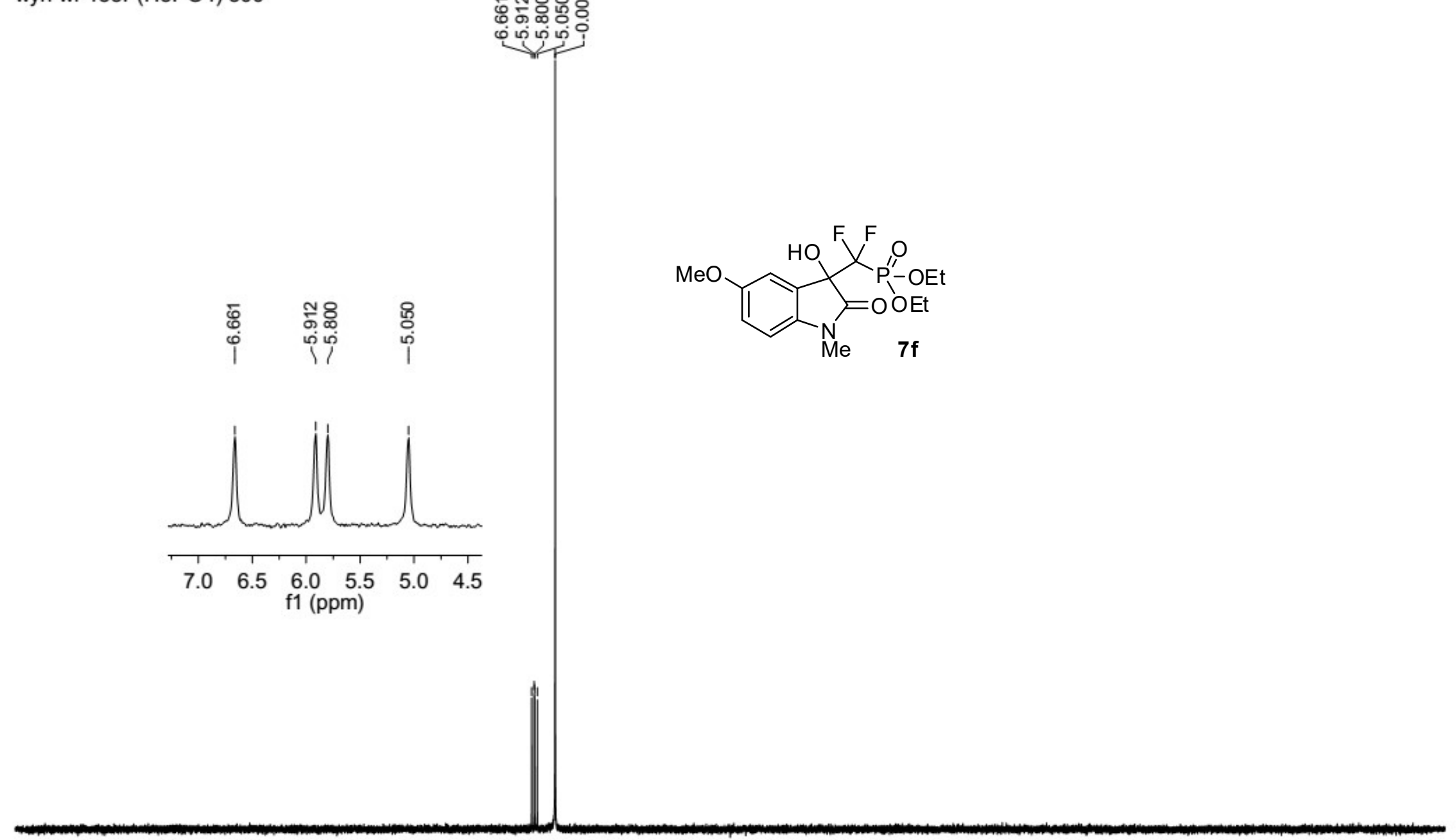

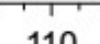

80

6040

20
$0 \quad-10$

-40
$\mathrm{f} 1(\mathrm{ppm})$

$-70$

$-100$

$-140$

$-180$

$-220$ 


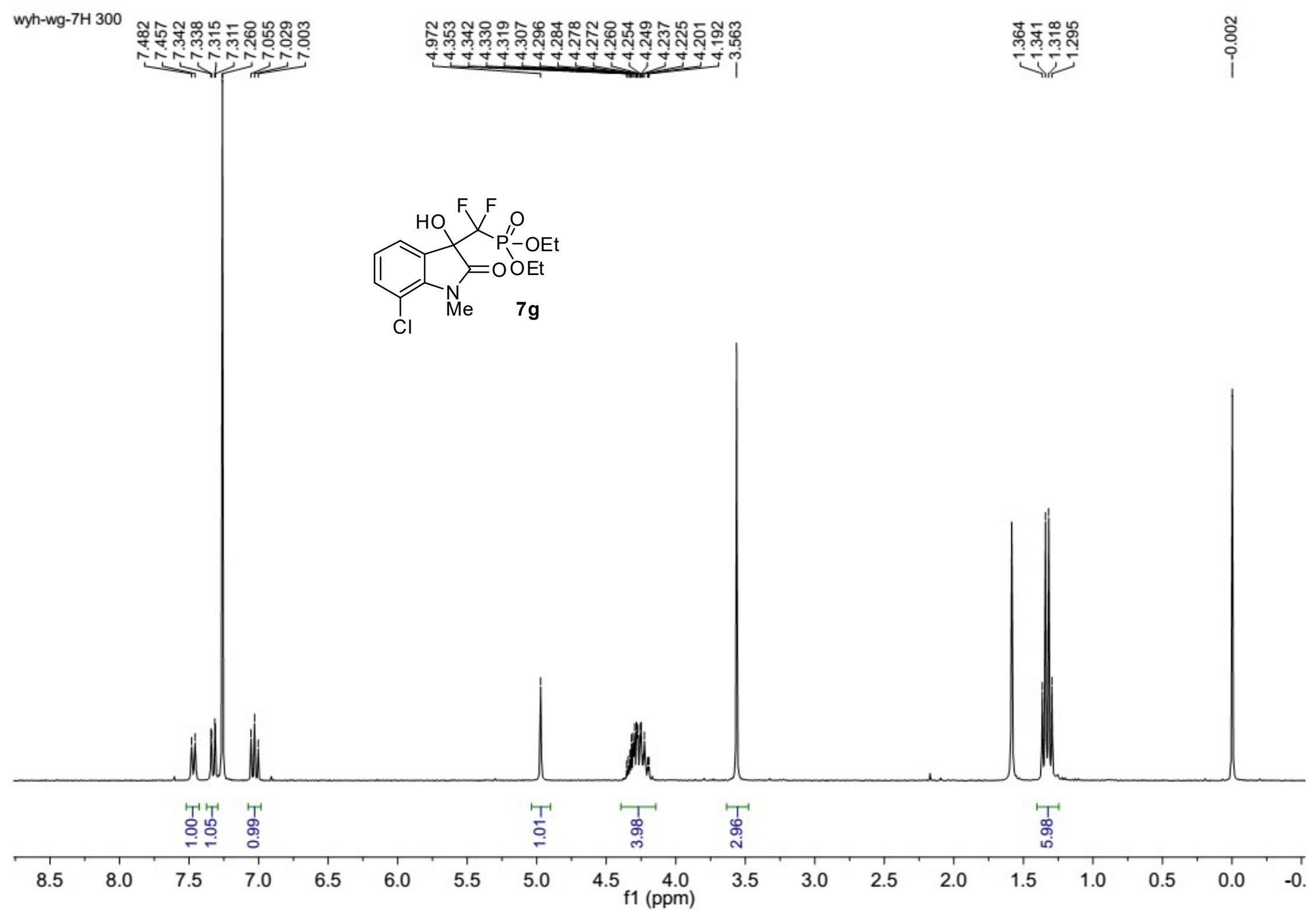



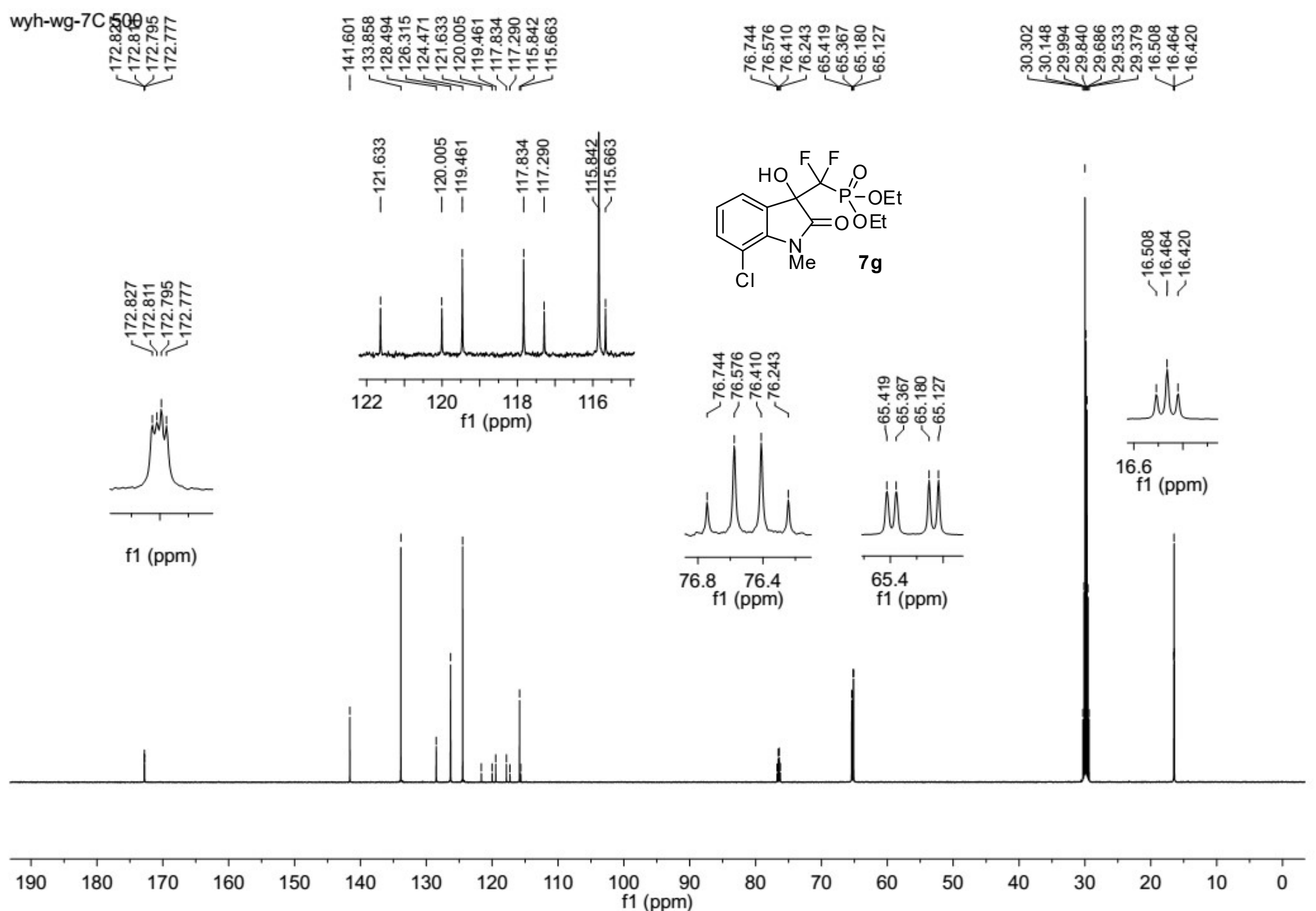
wyh-wg-7F(PhCF3) 300
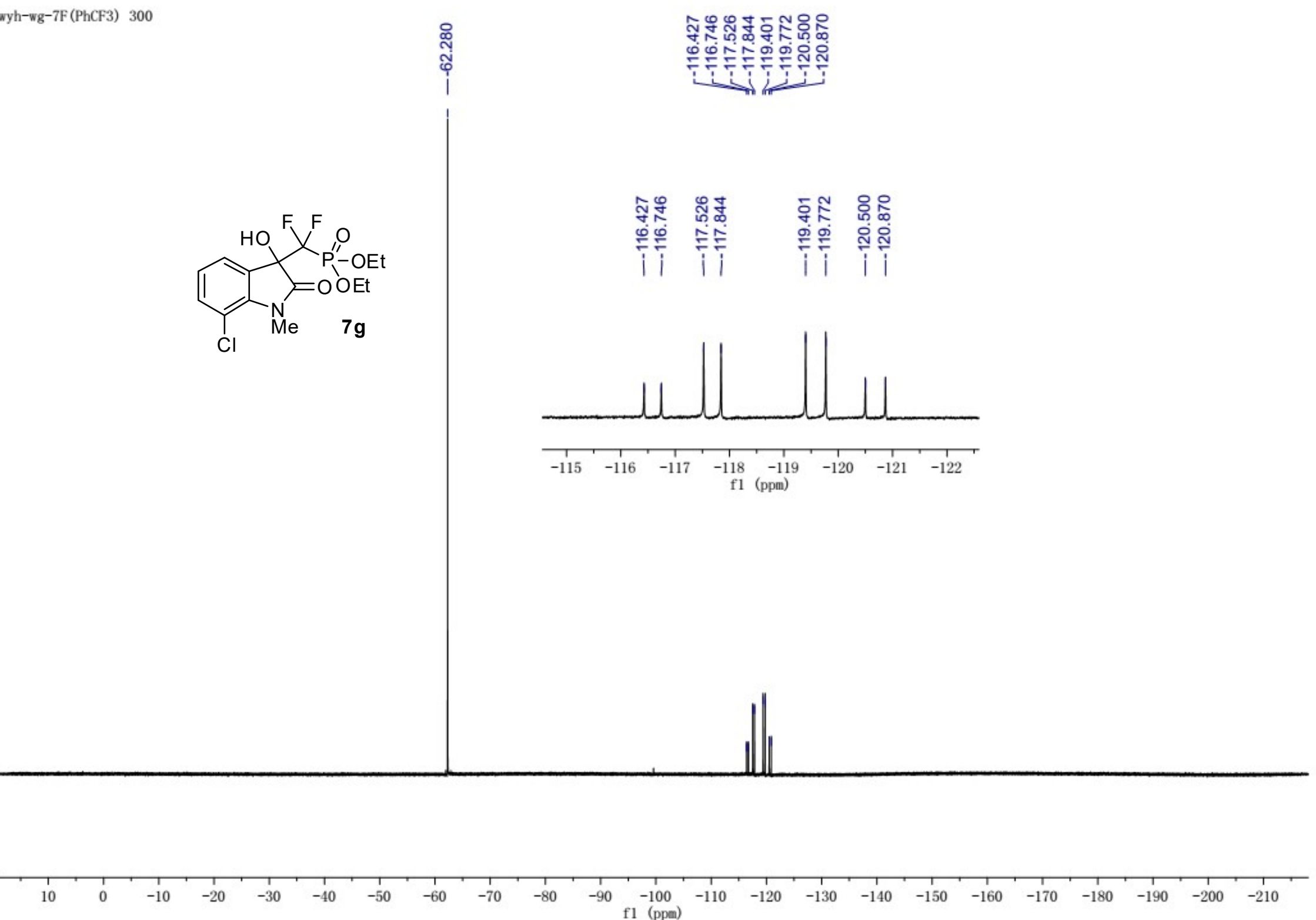

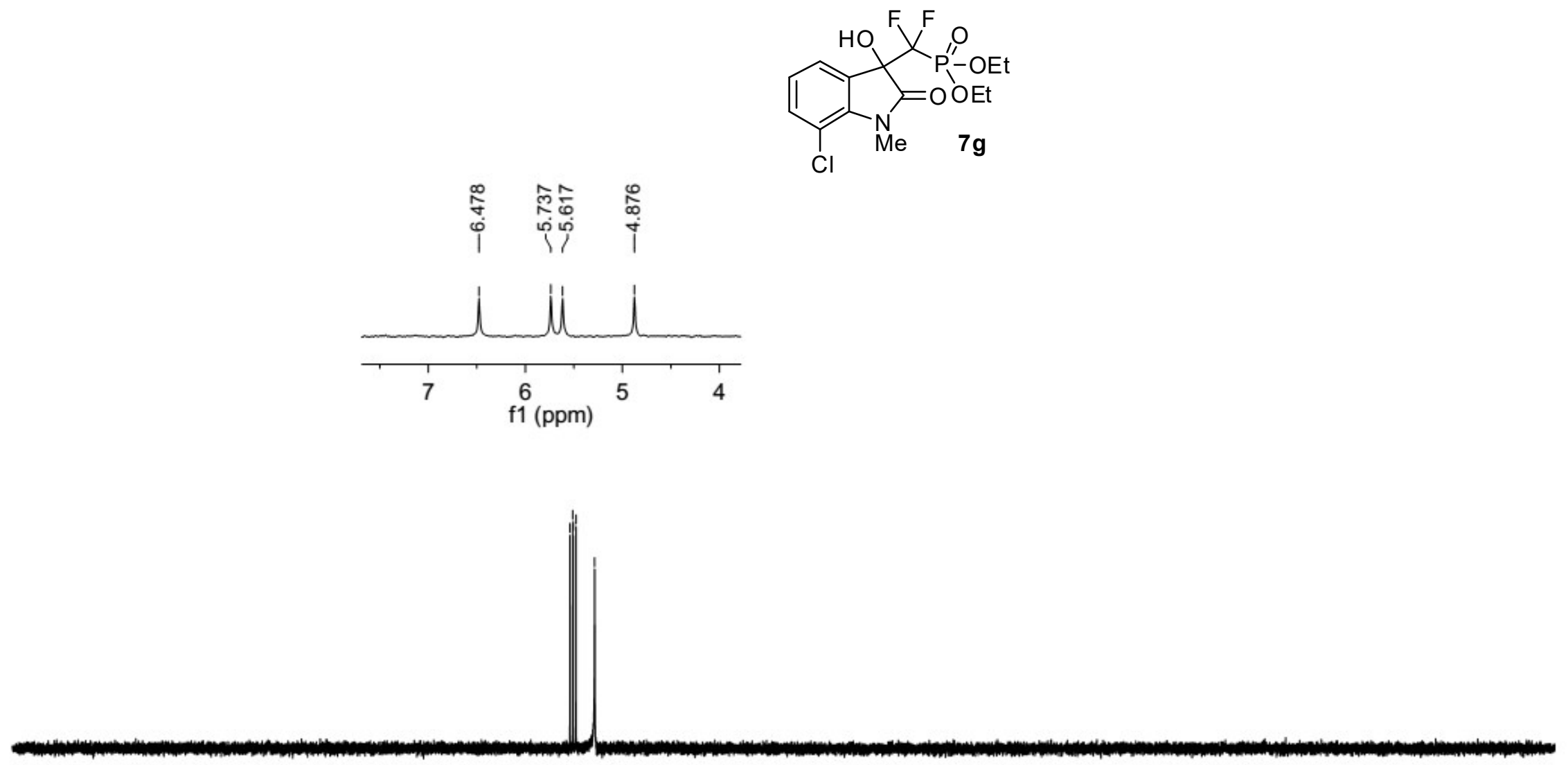


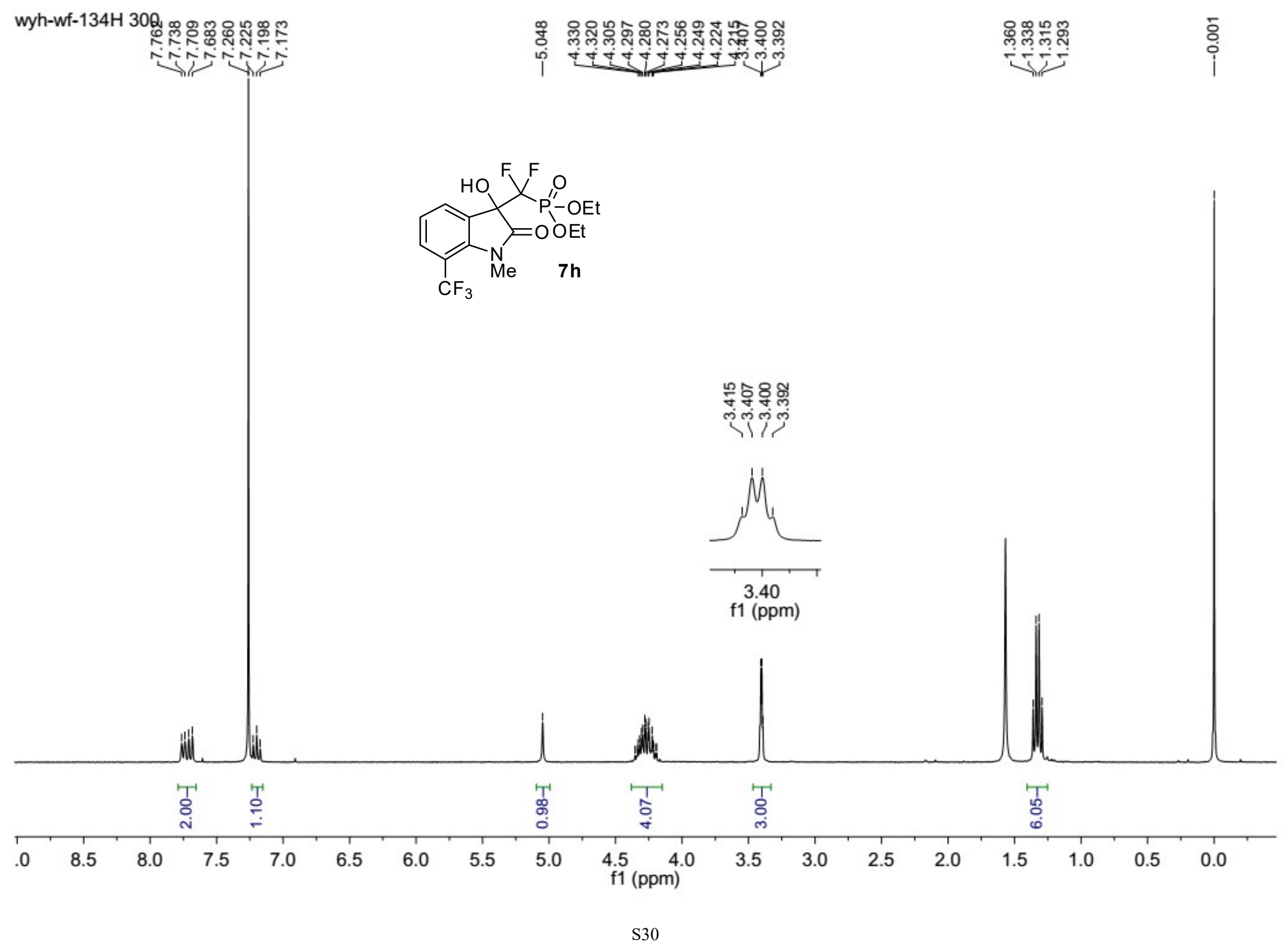



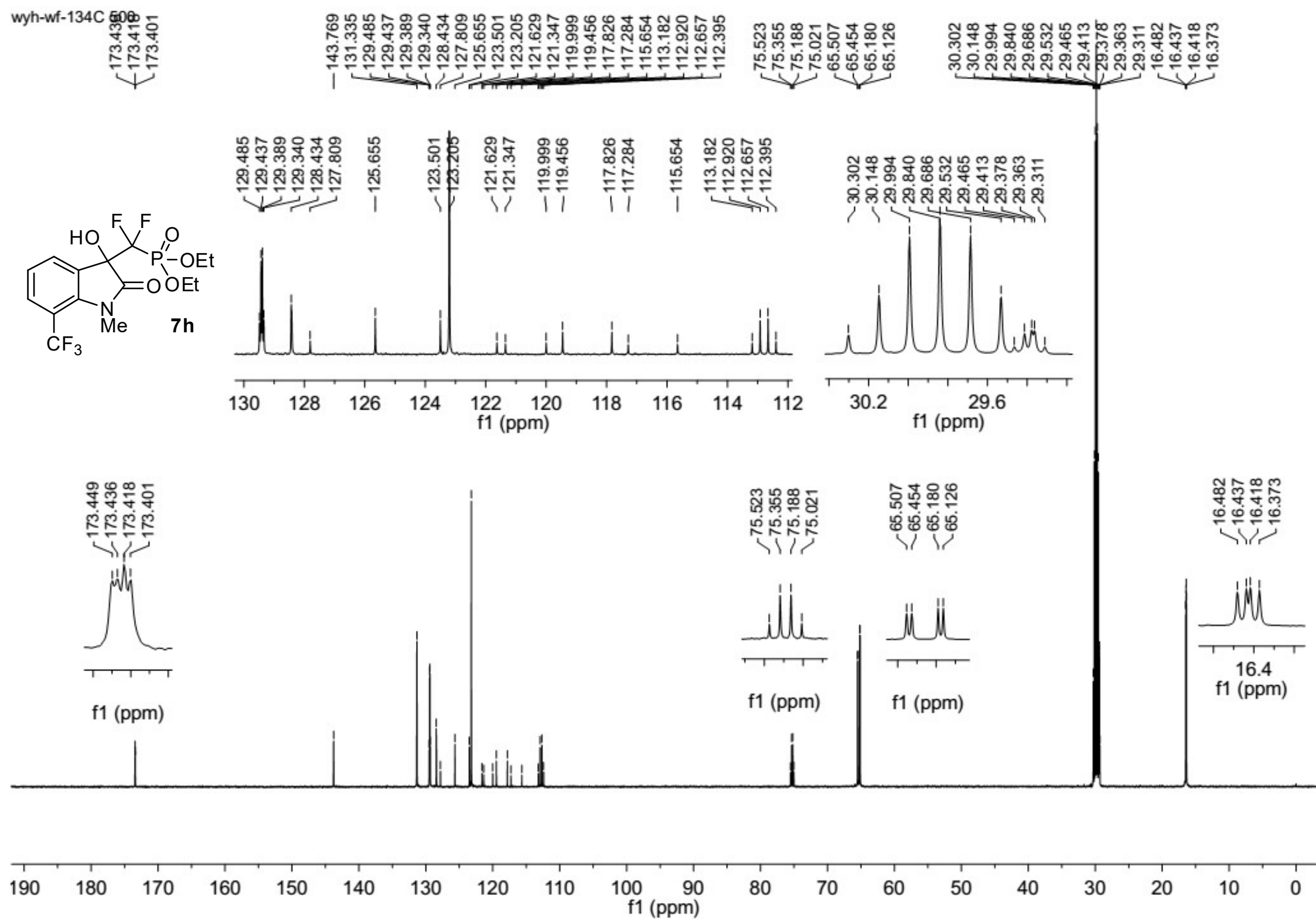


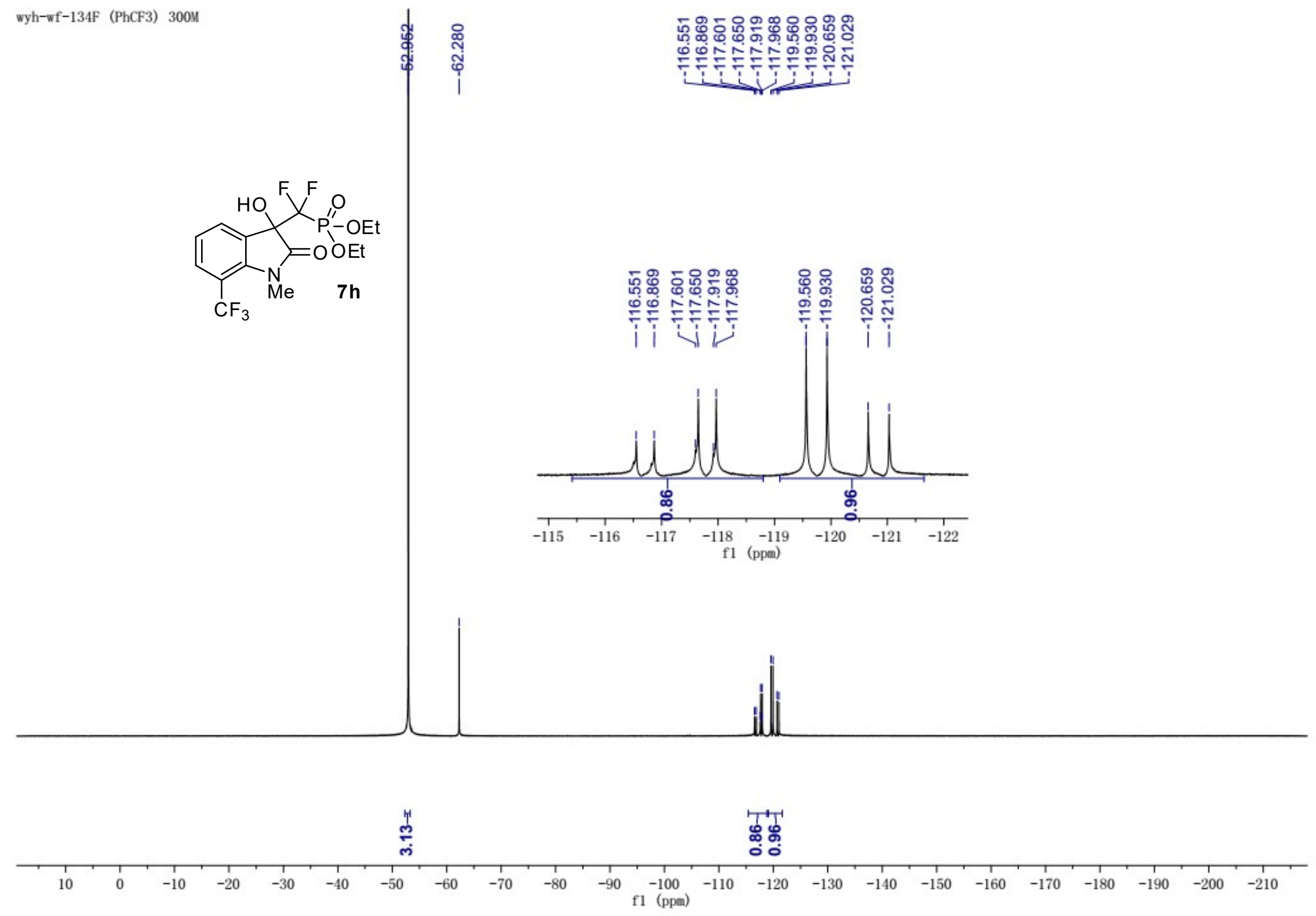



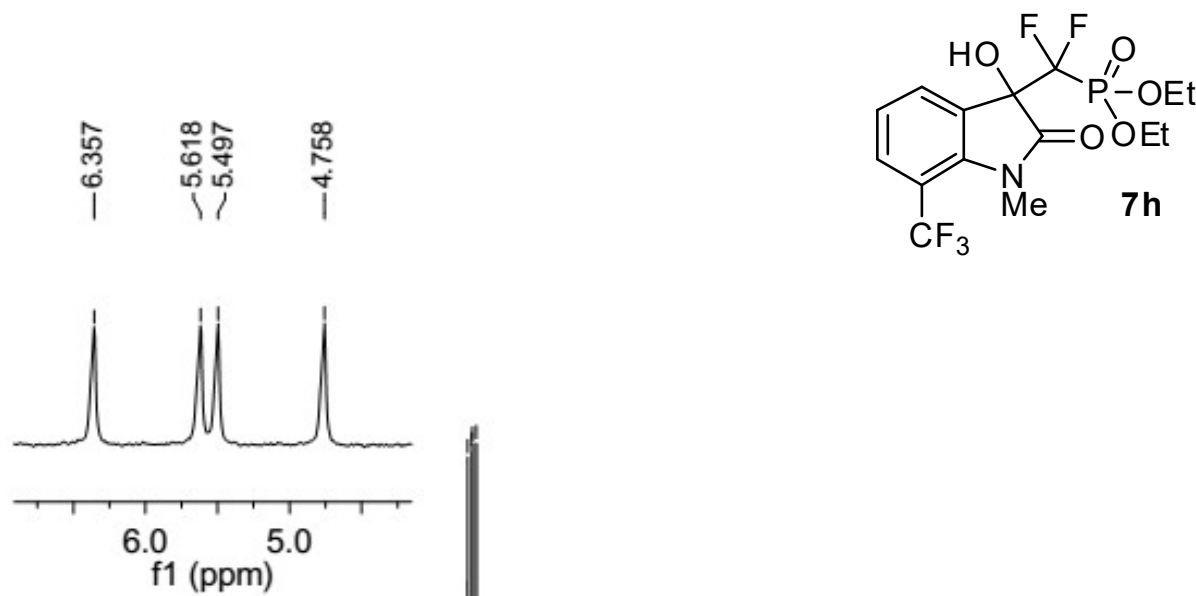


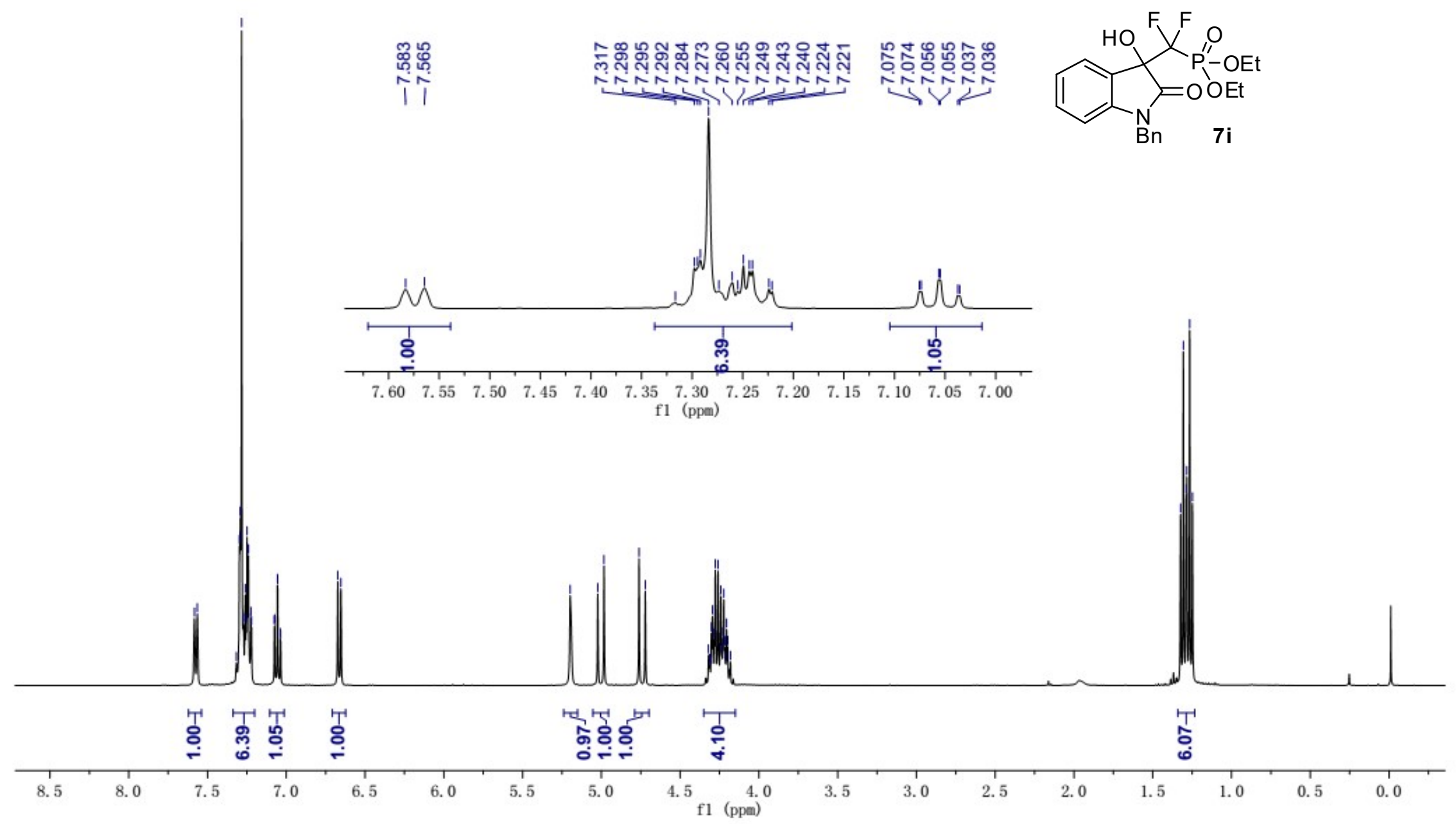




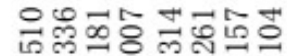

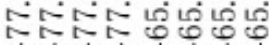

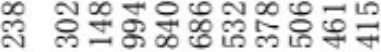

ษ Dें

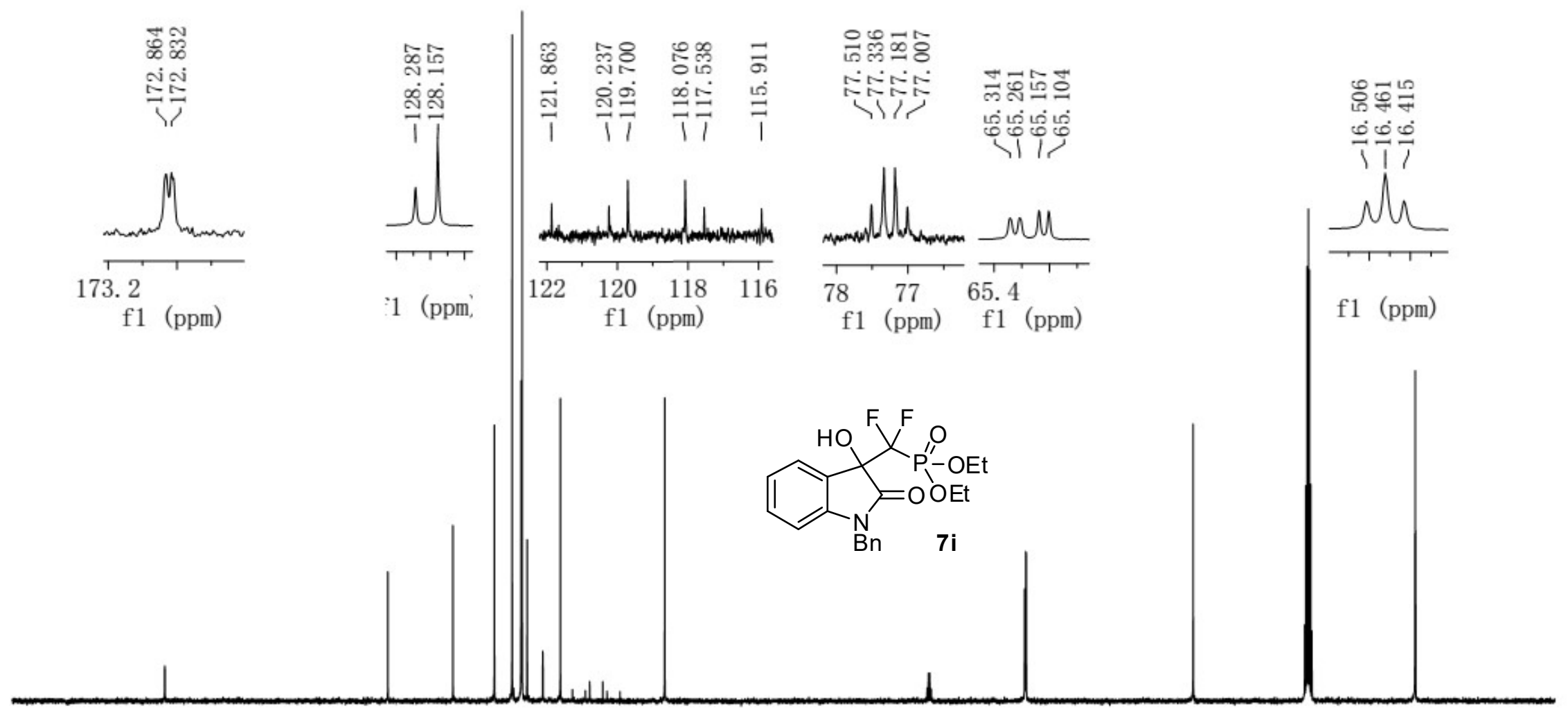

$\begin{array}{llllll}190 & 180 & 170 & 160 & 150 & 140\end{array}$
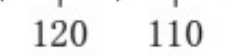

$100 \quad 90$

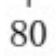

70

50

40

$30 \quad 20$

$10 \quad 0$ 
wyh-wf-120F (PhCF3) 300

ণัฒ
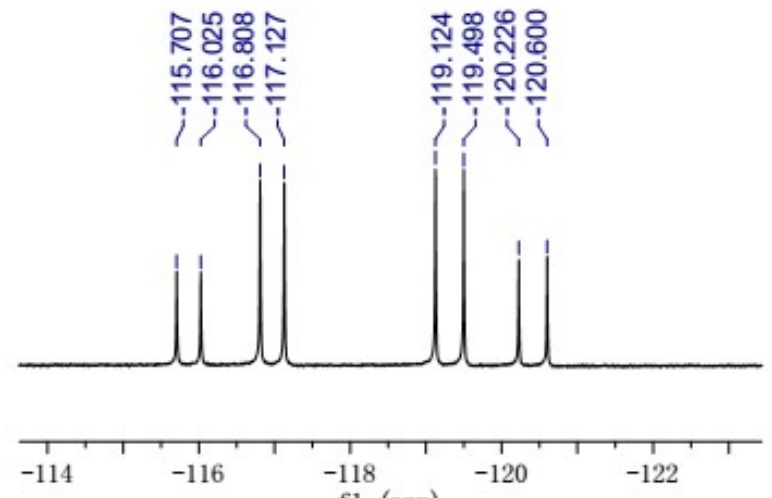

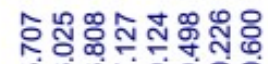

븐

isin

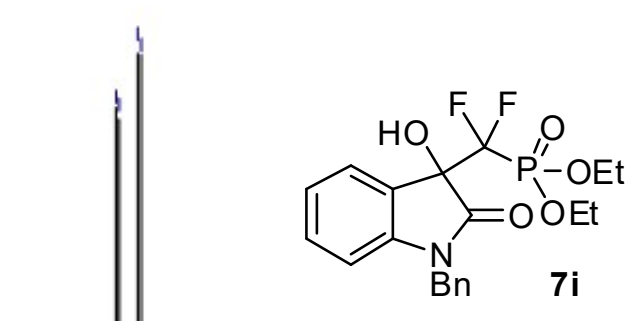

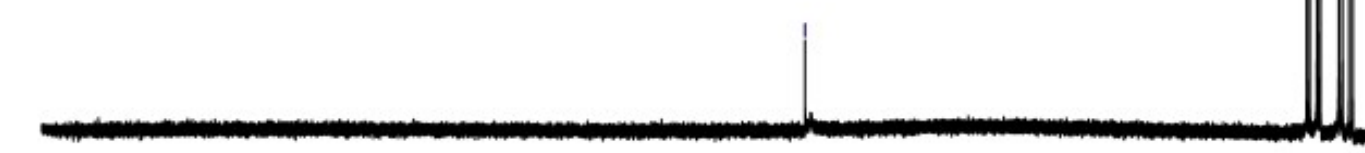

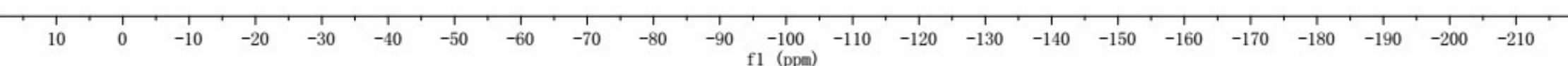



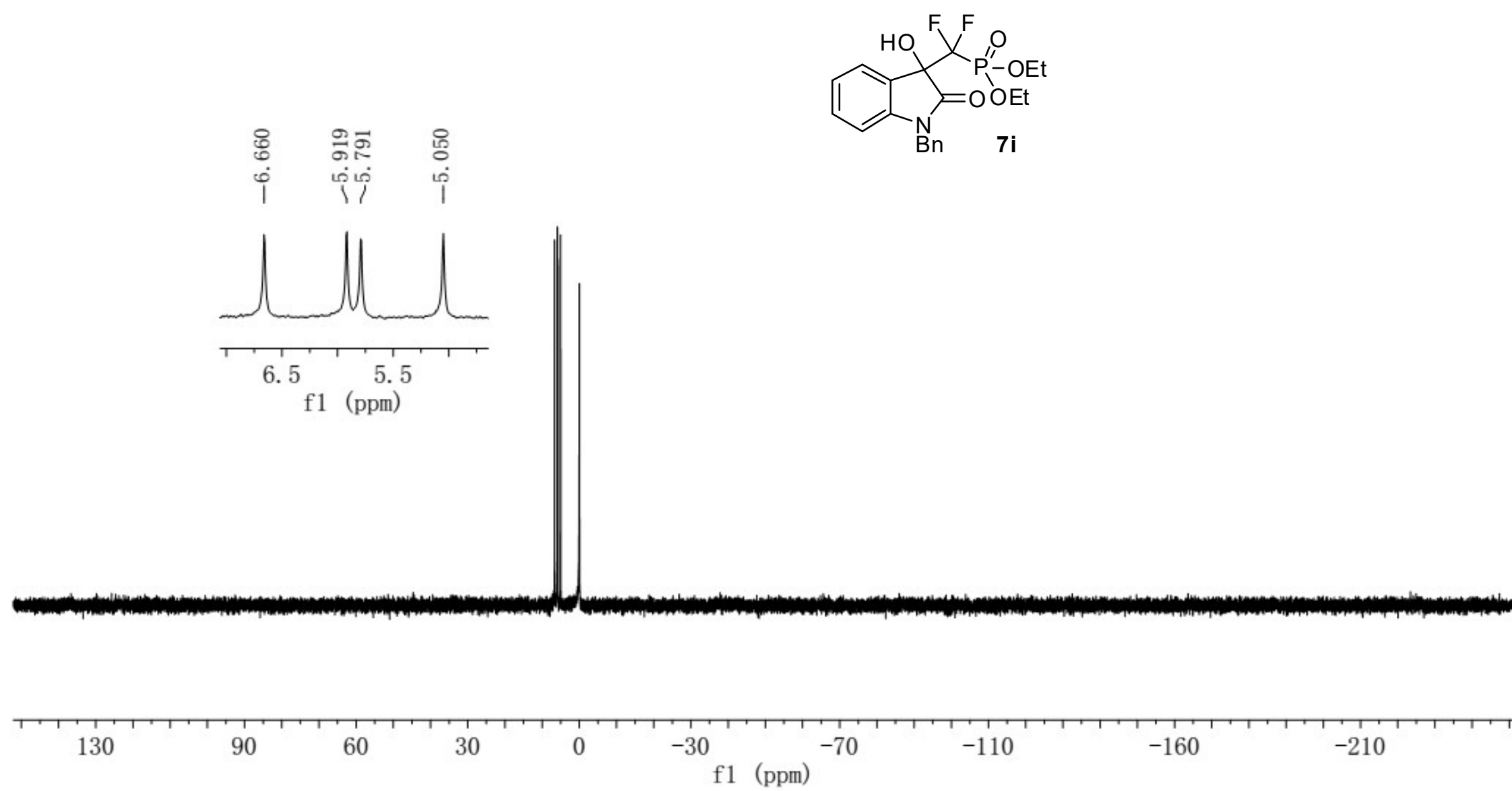
TMSO $\mathrm{O}$

$\underbrace{P}_{9 a} X_{F}^{P}$

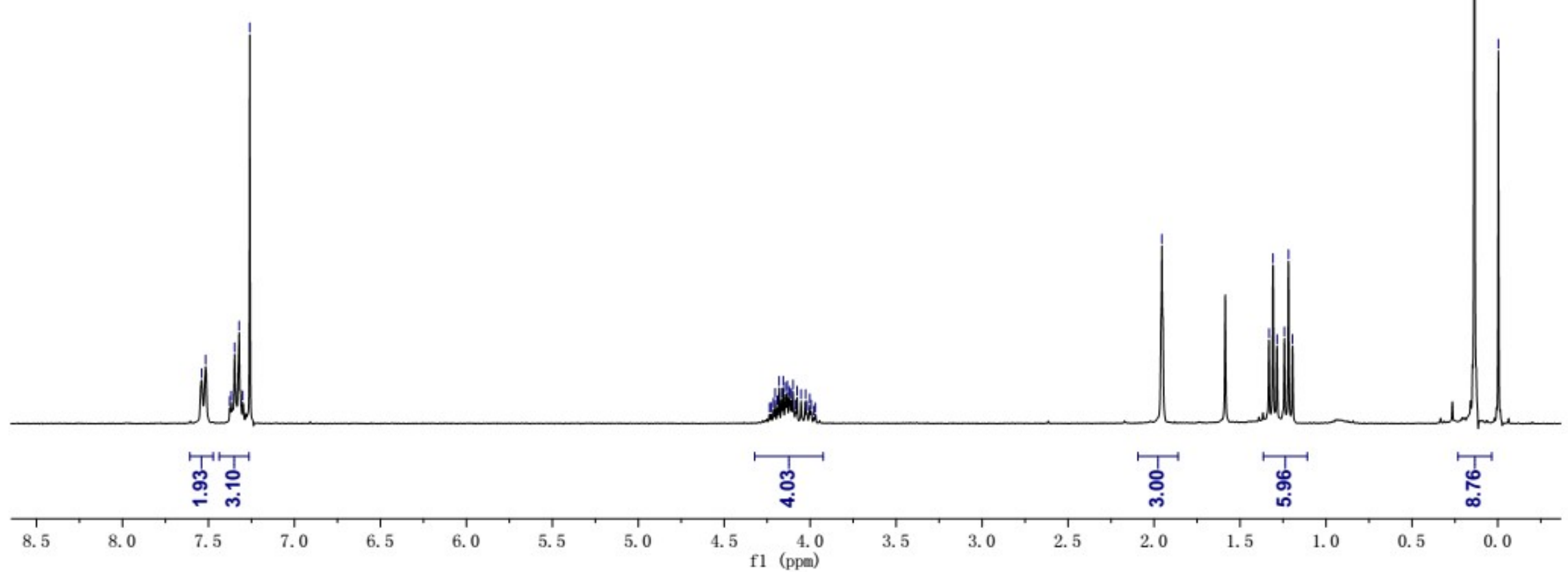



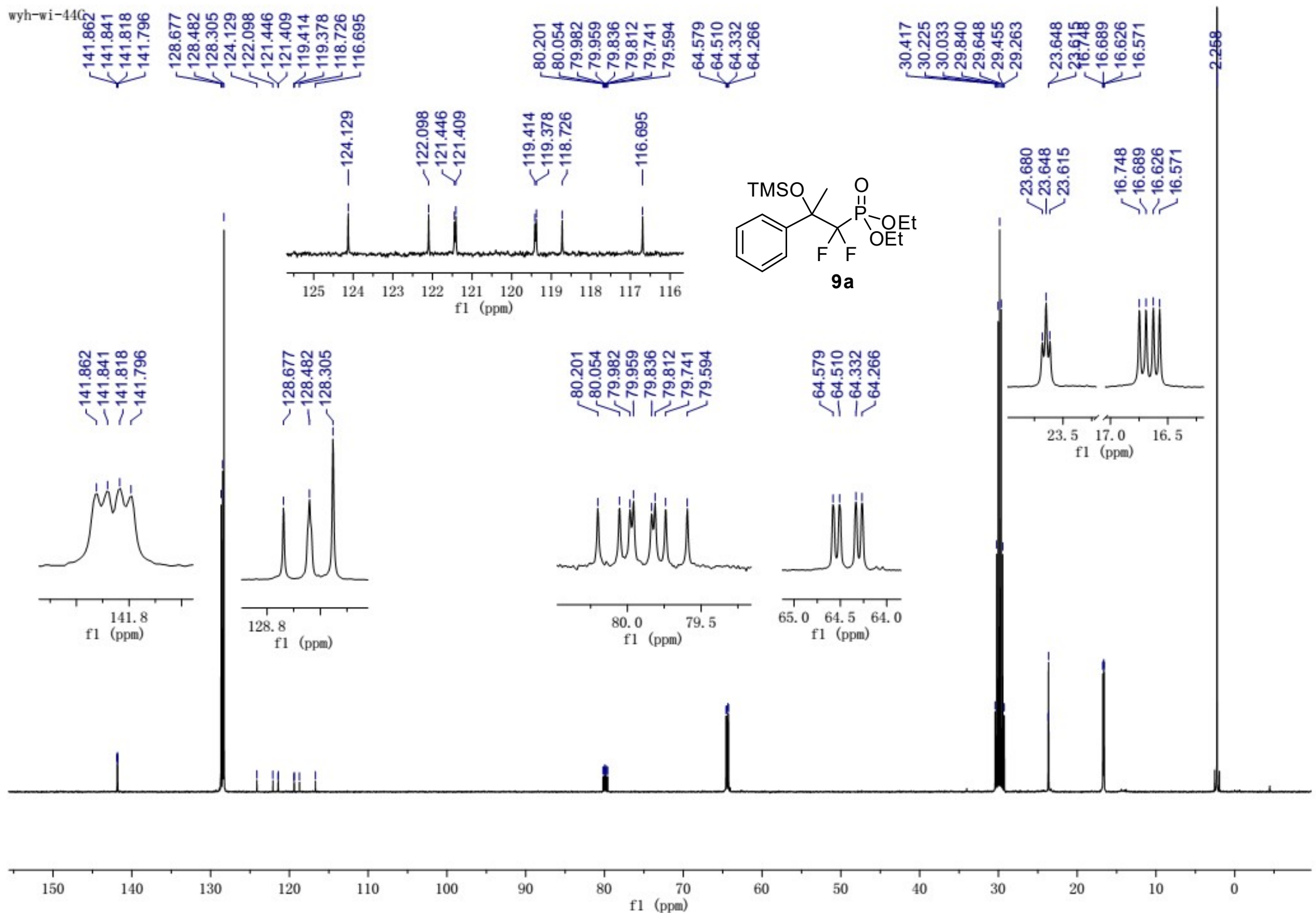

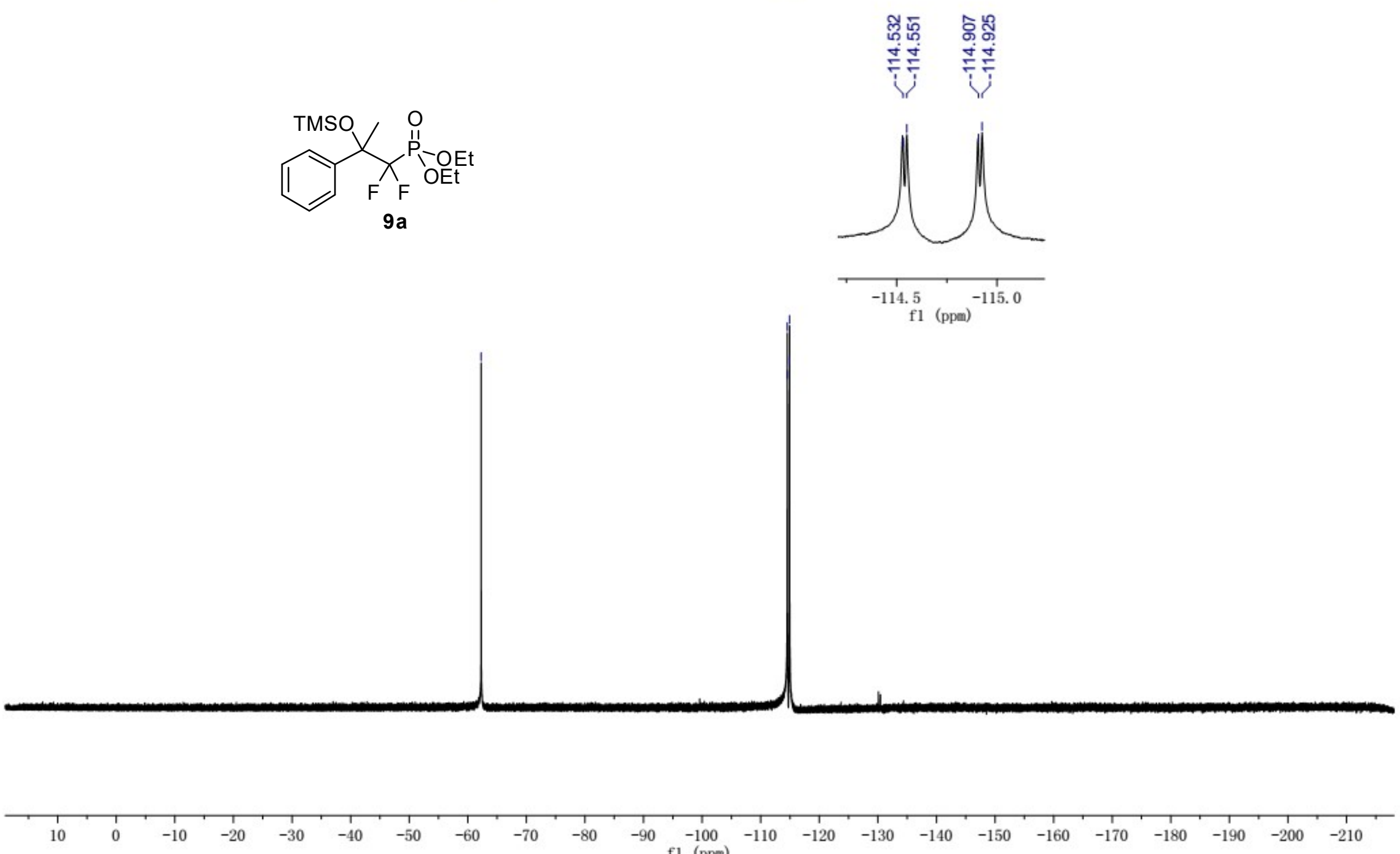


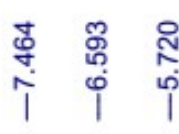

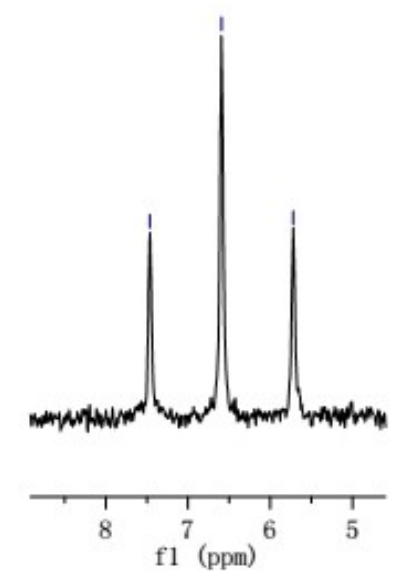

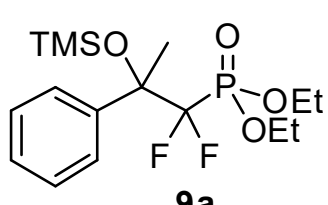




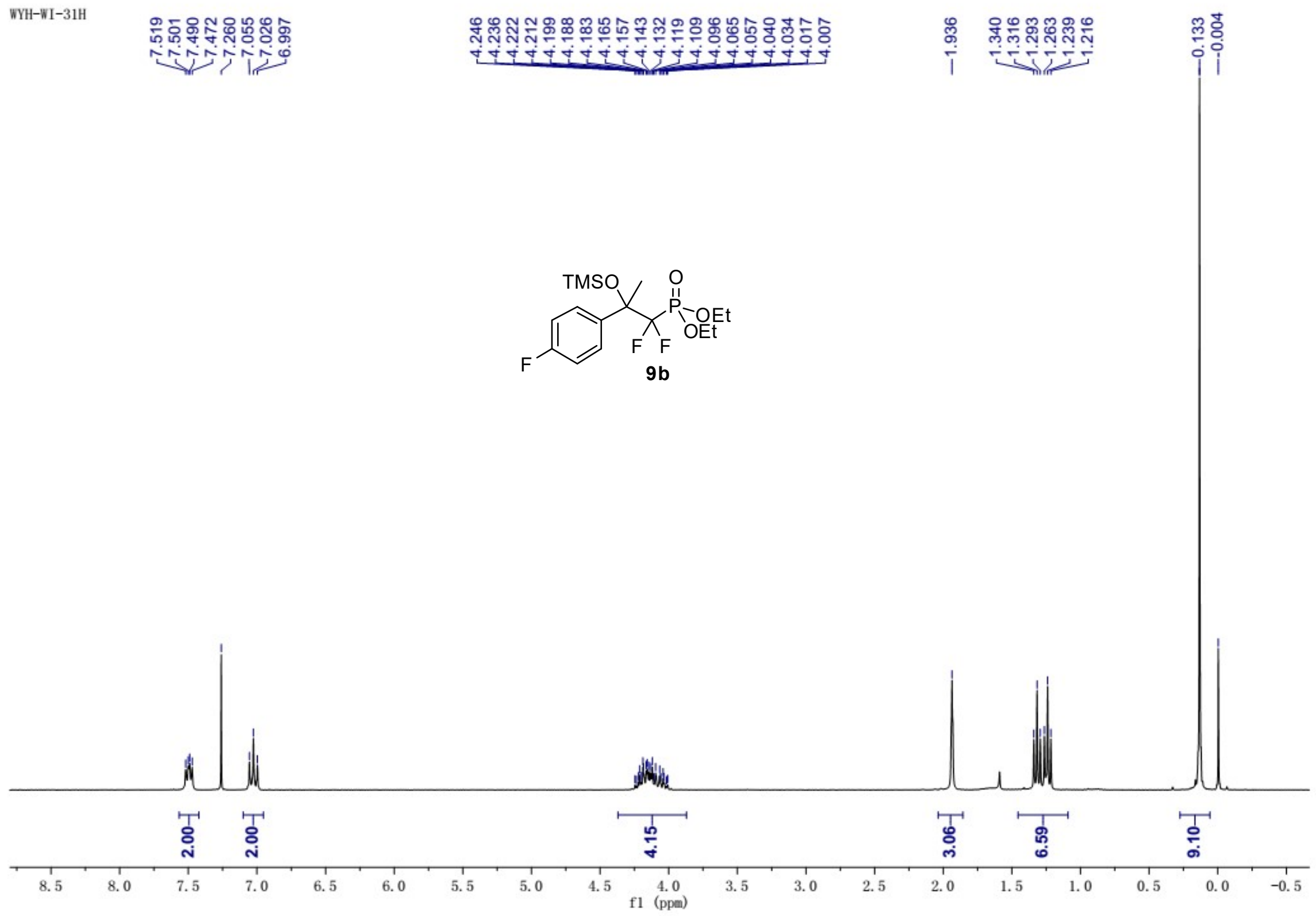



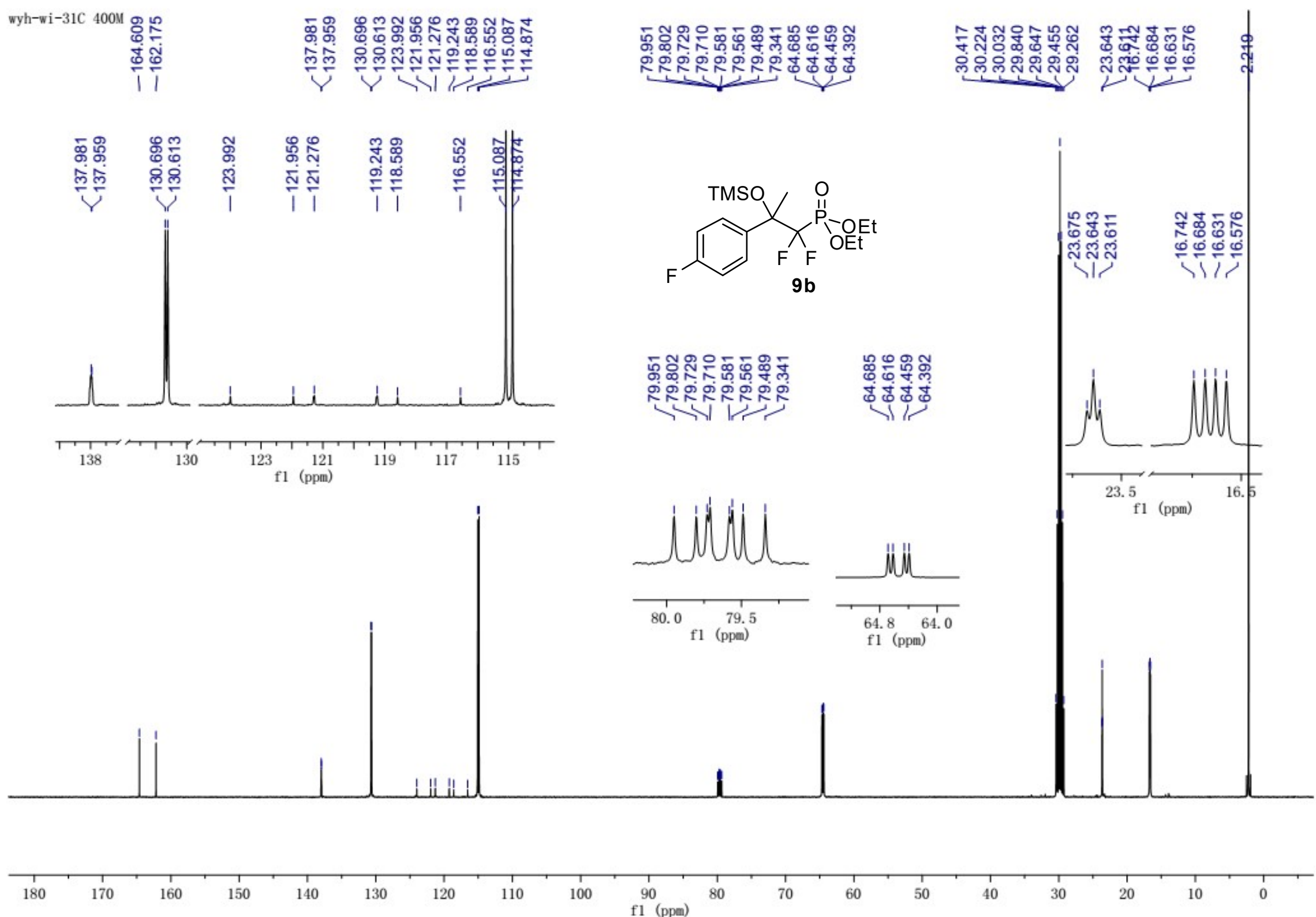
资

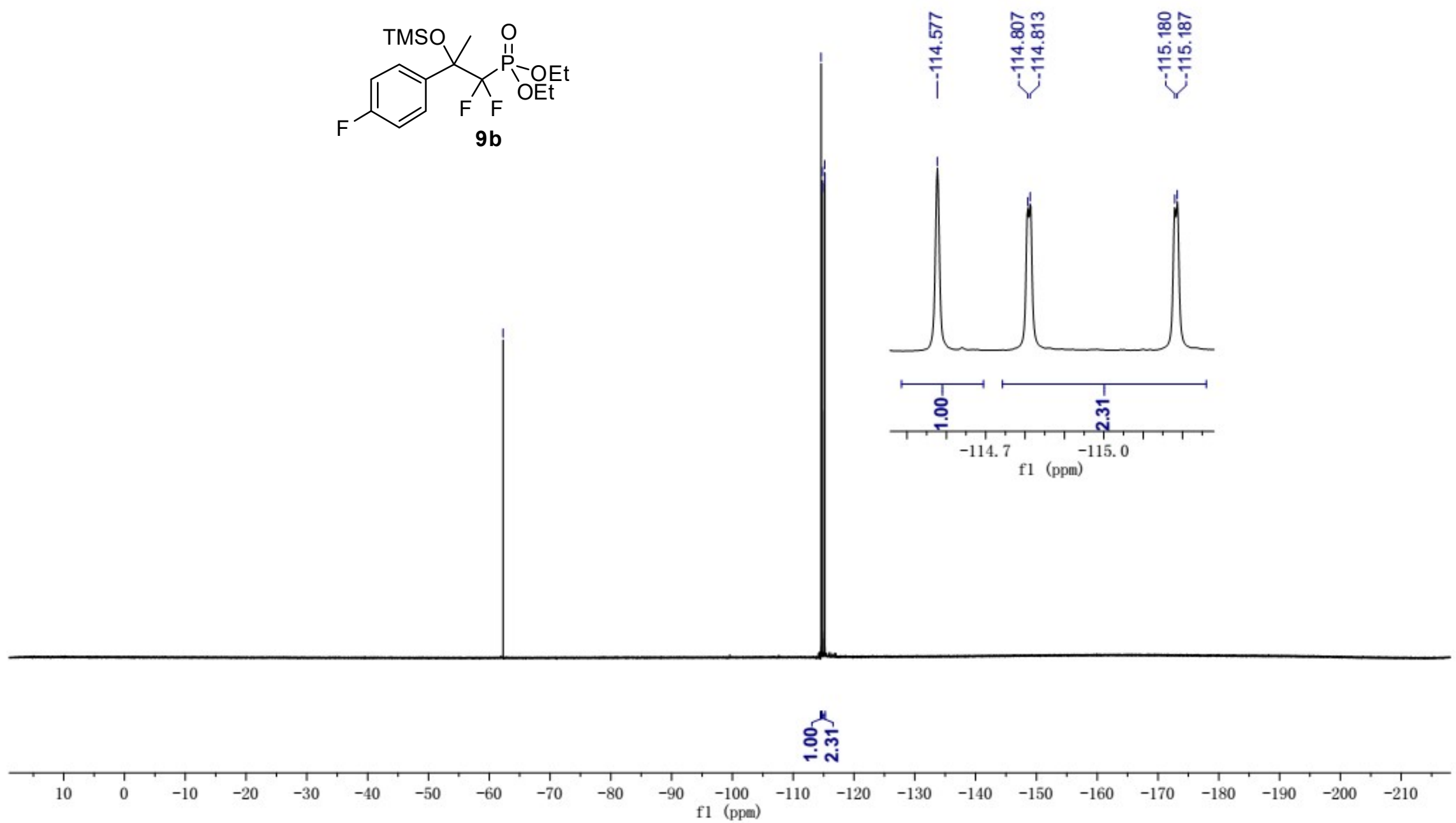




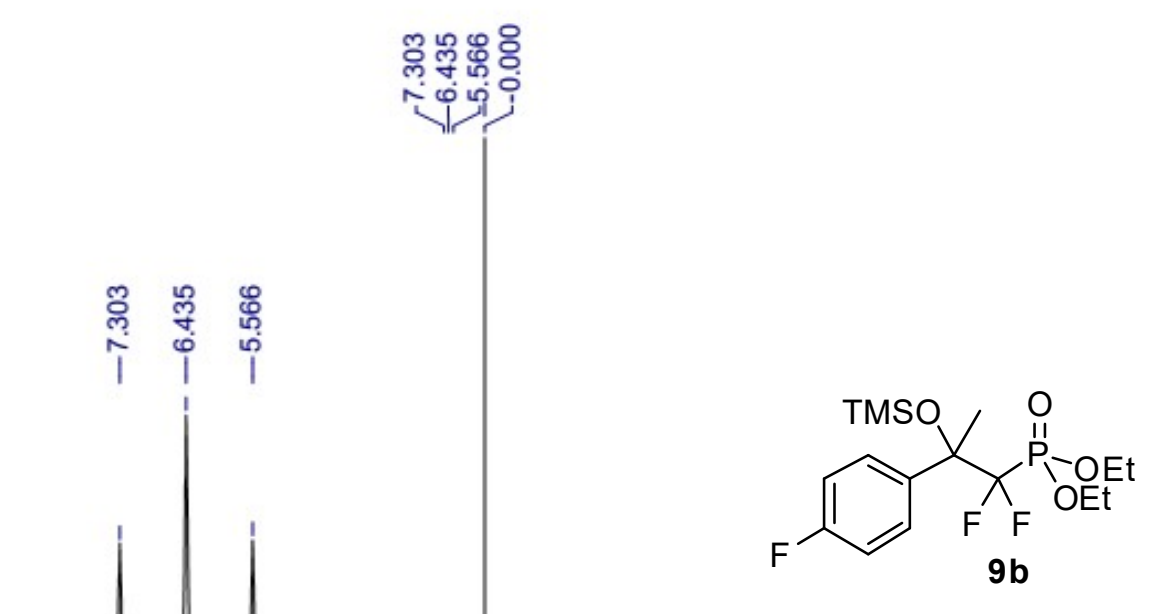




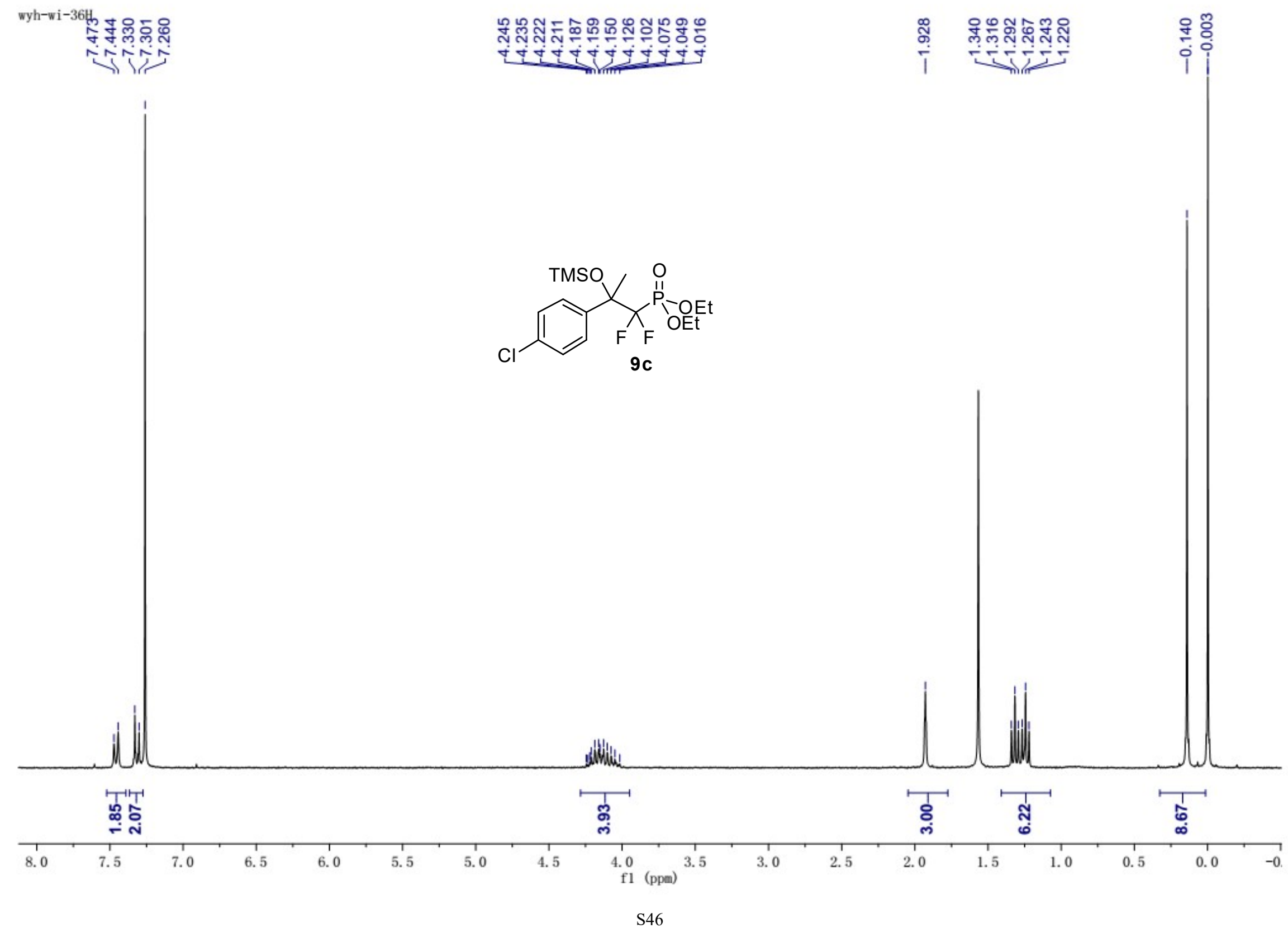



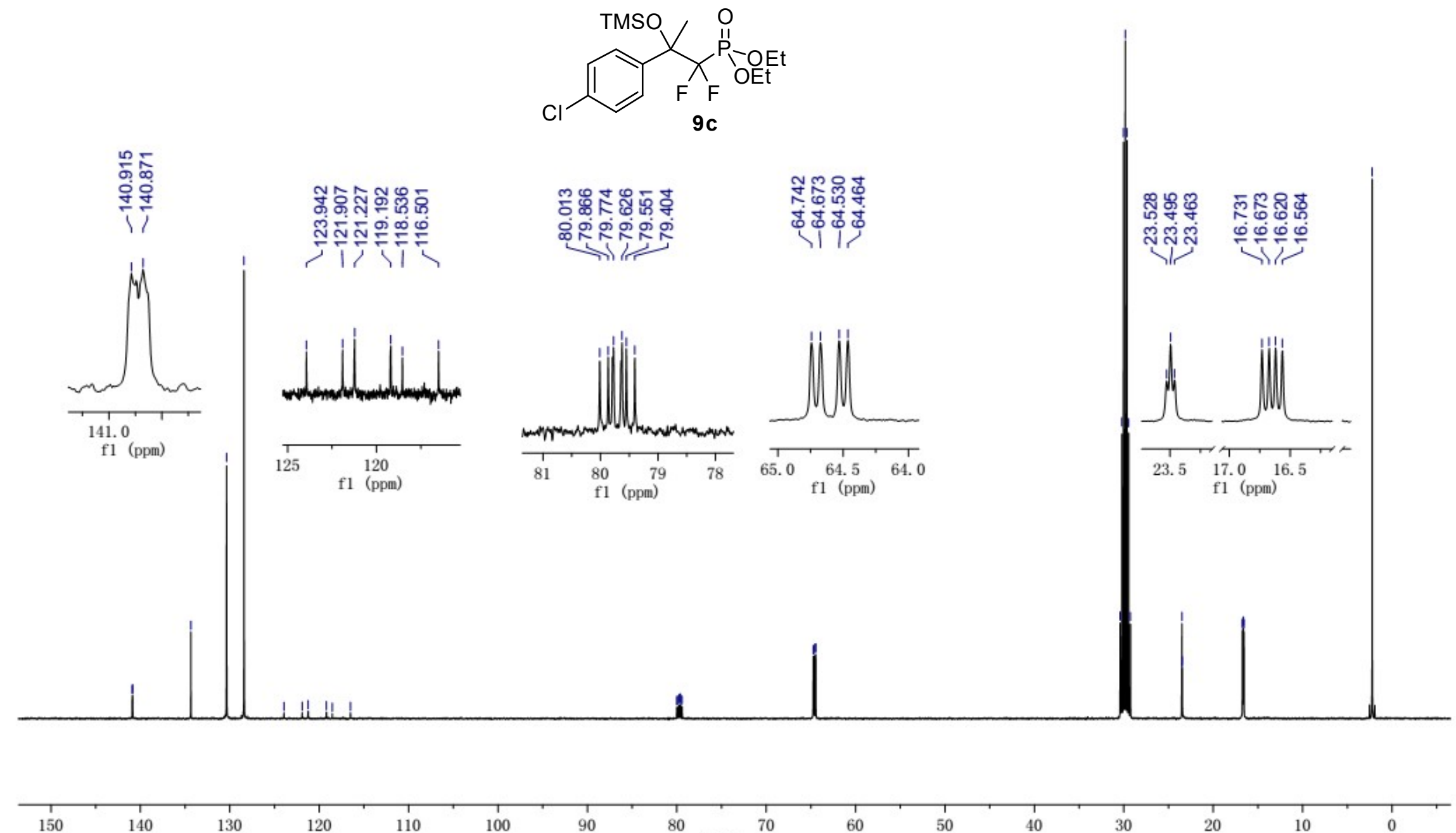

90

$80 \quad 70$

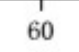

50

40

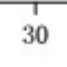

20 

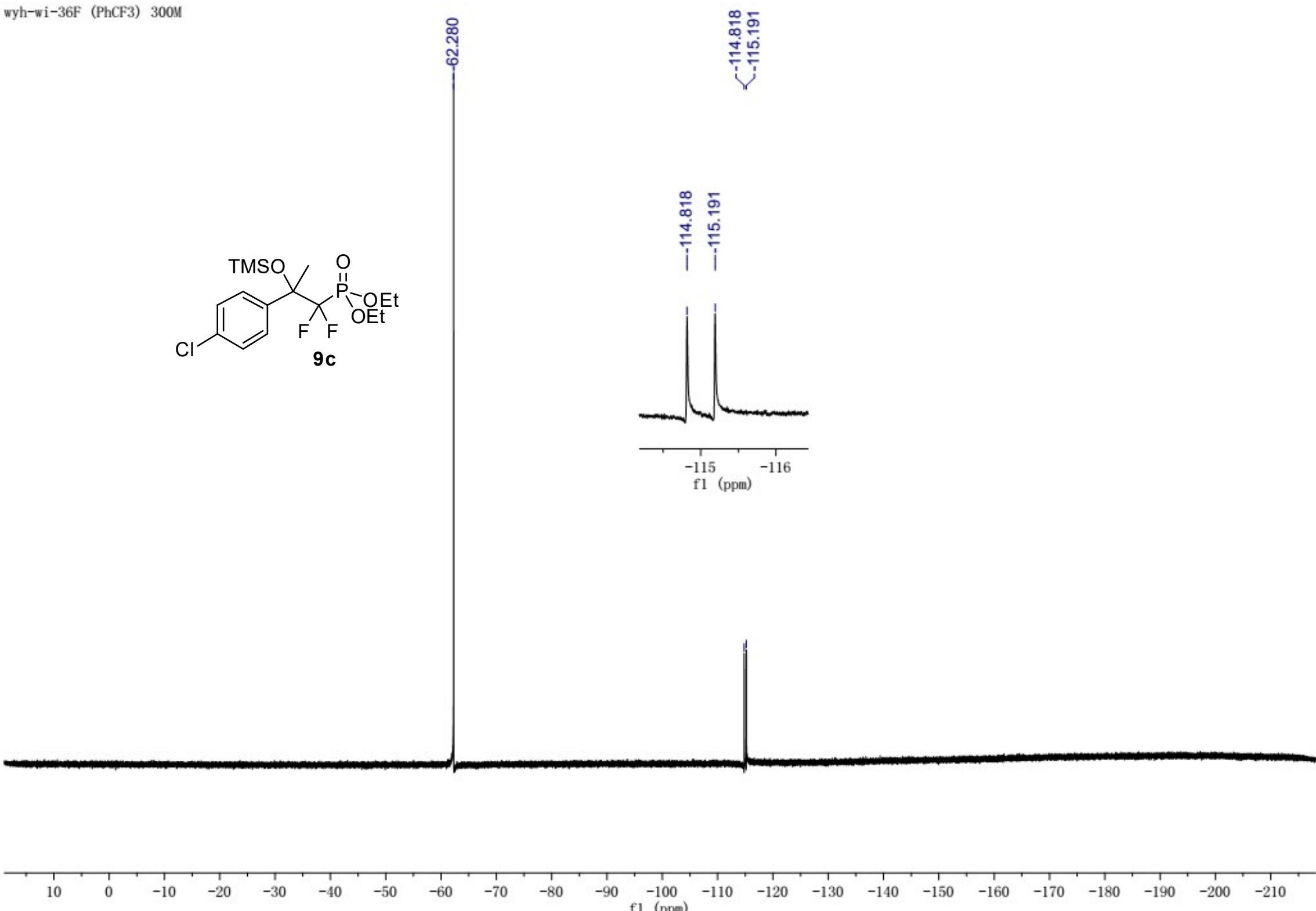


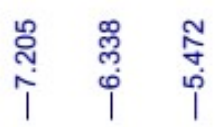

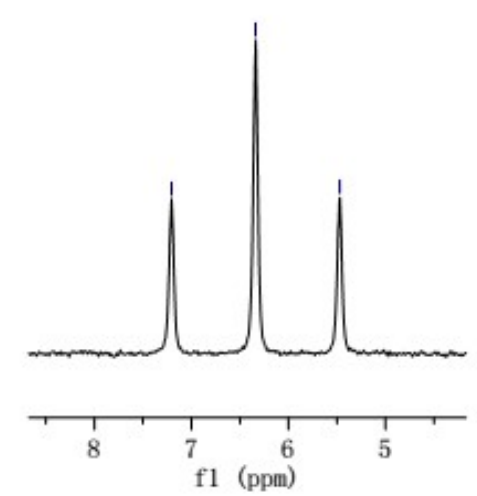

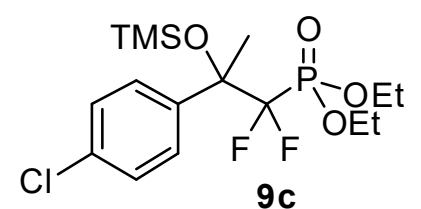



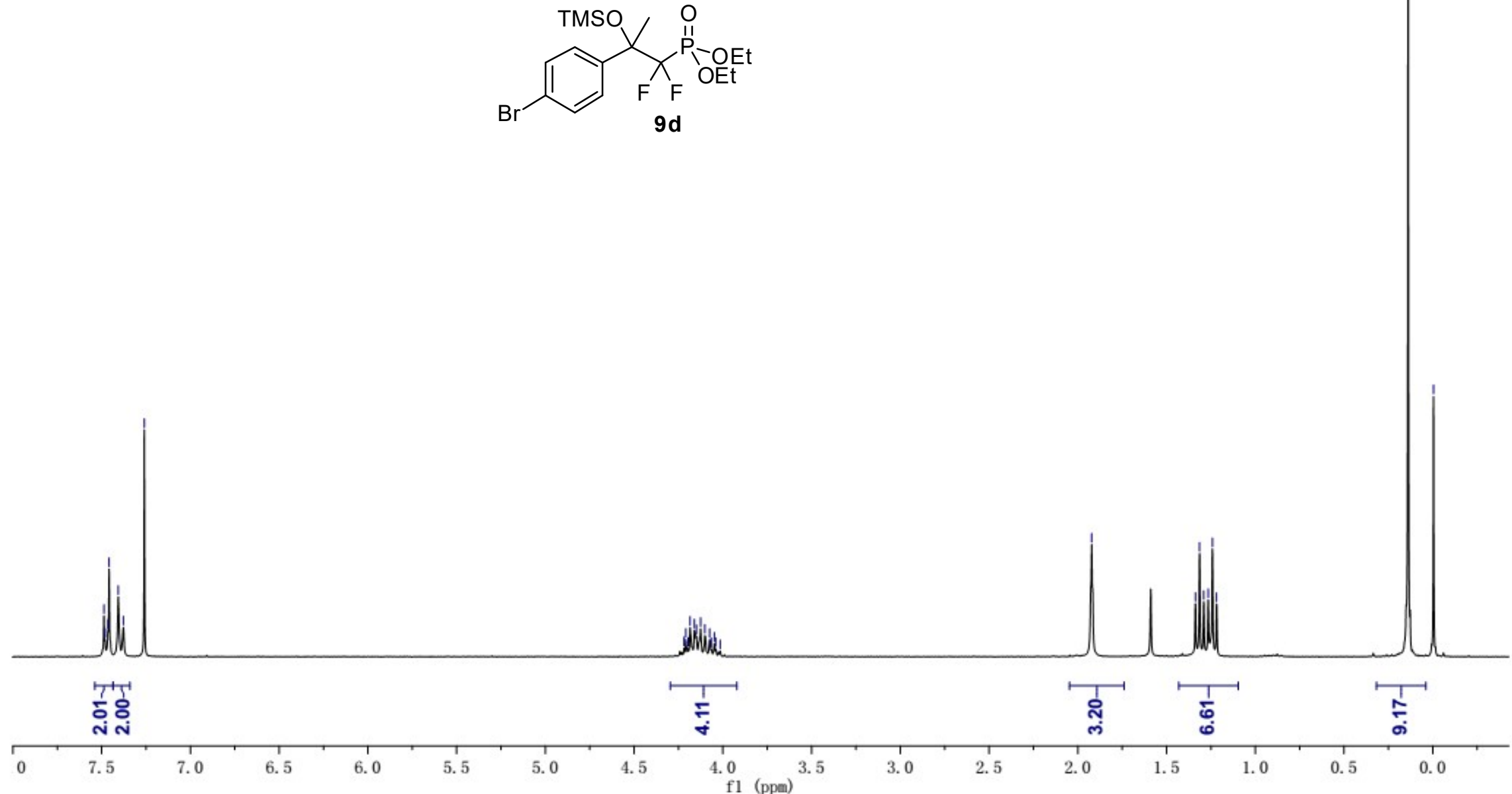

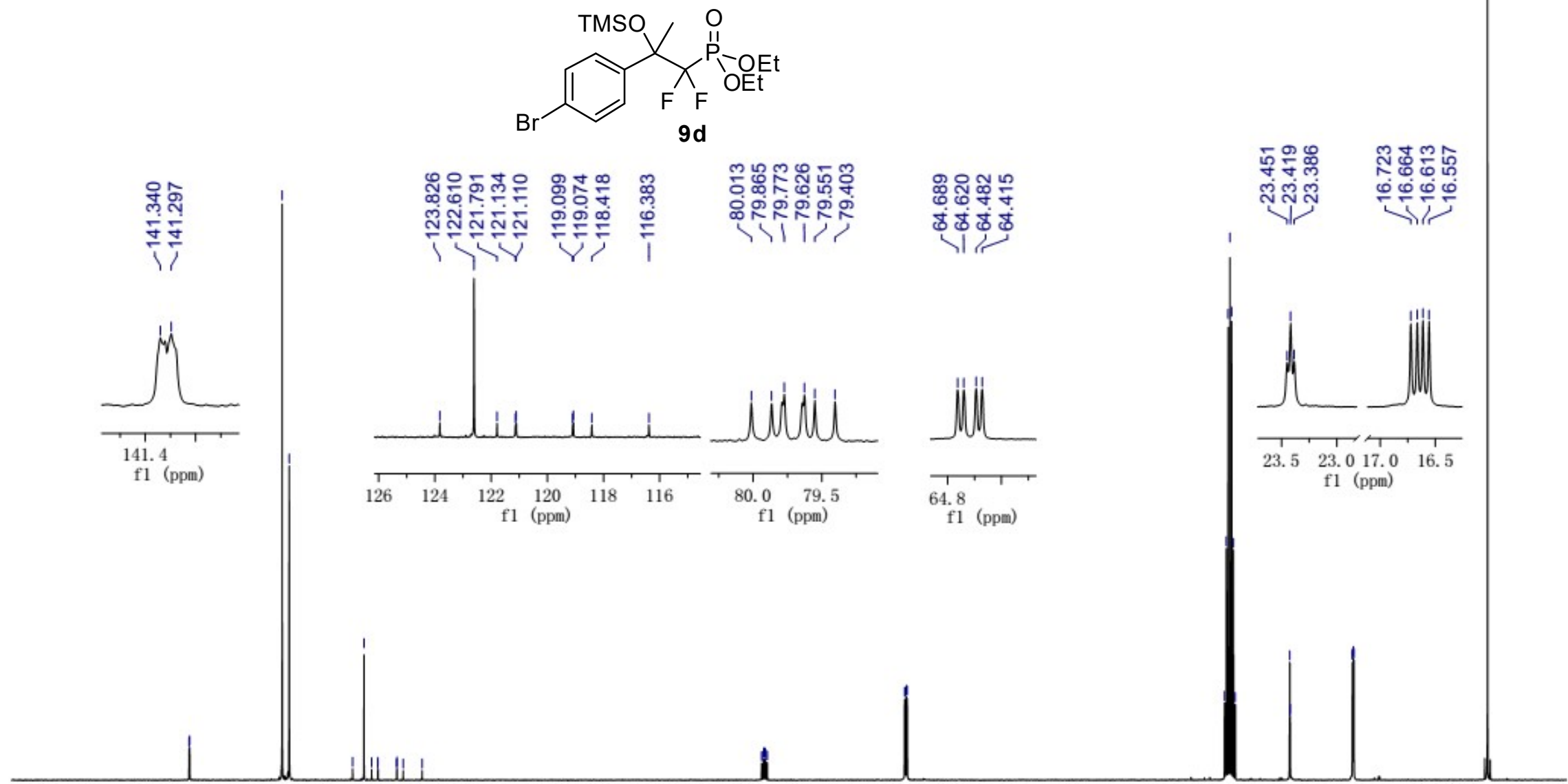

60

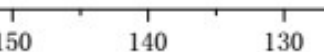

120

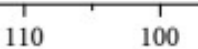

$100 \quad 90$

80
f1 $(\mathrm{ppm})$ 

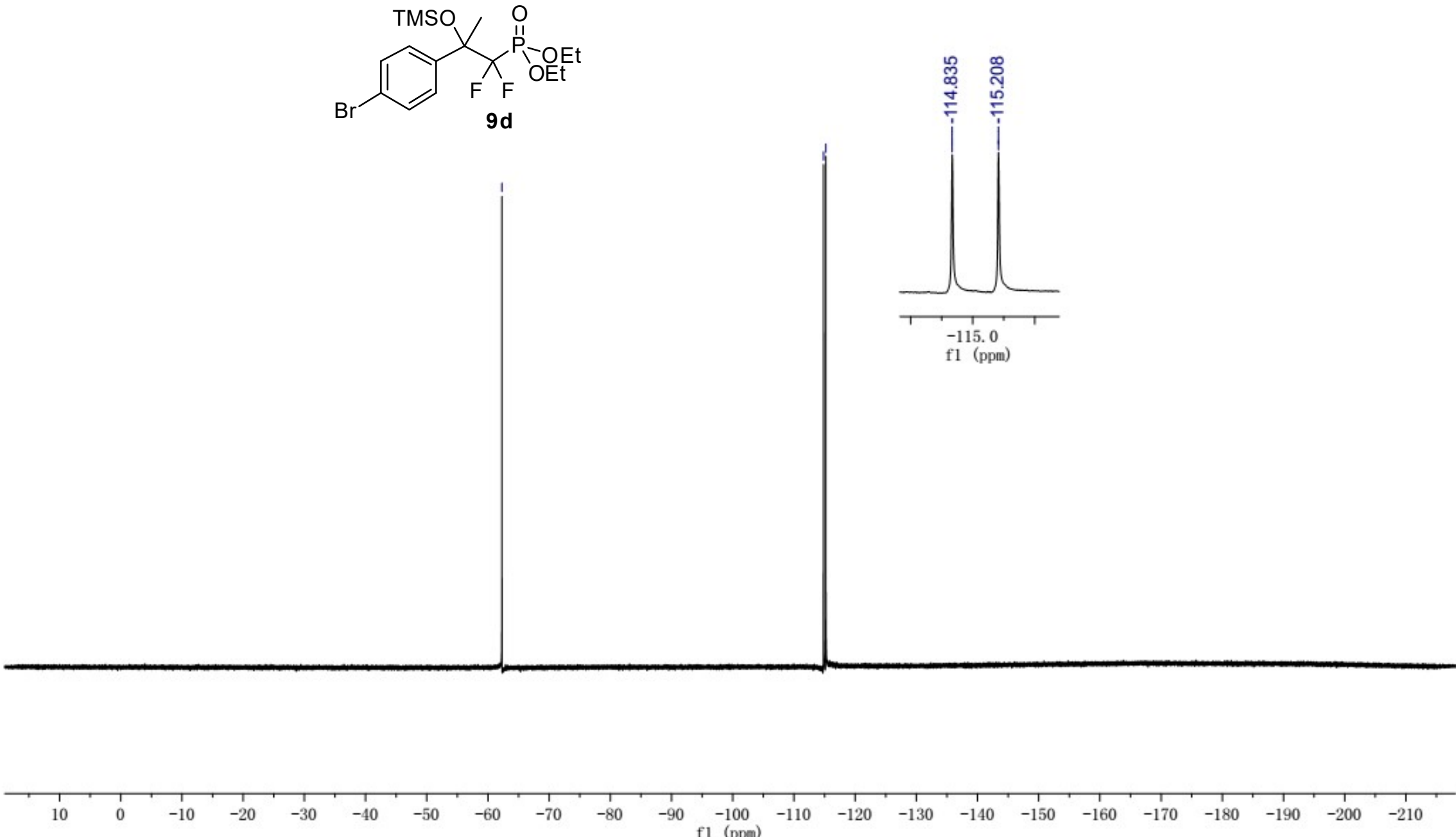


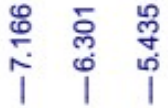
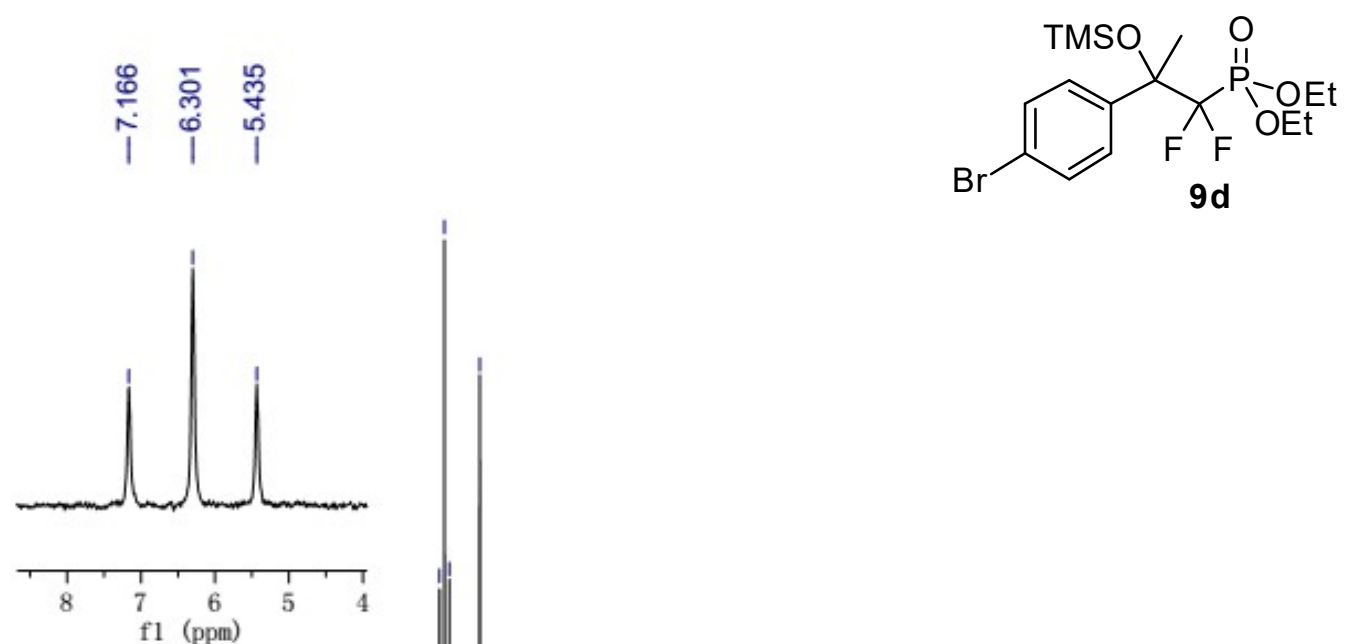


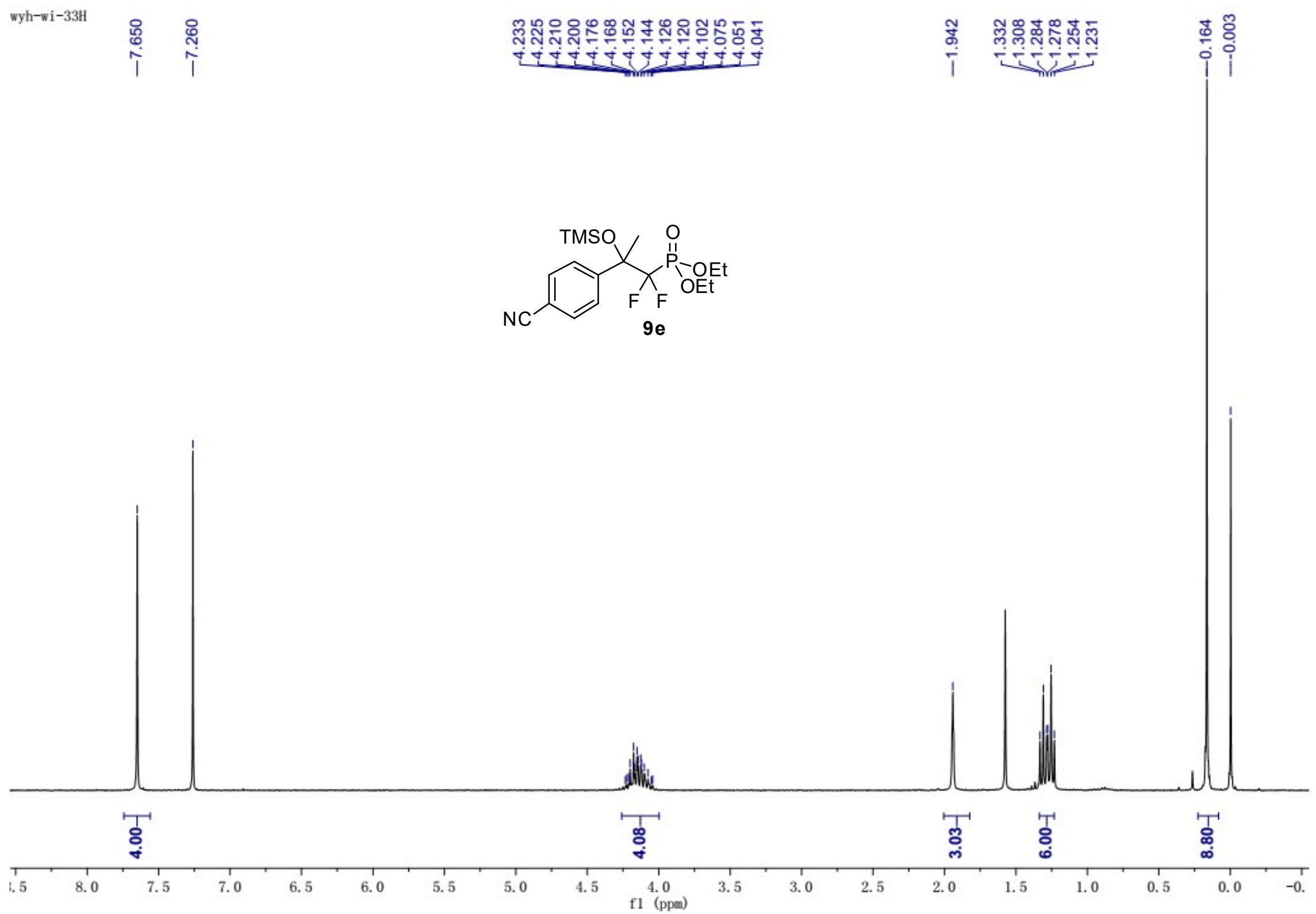



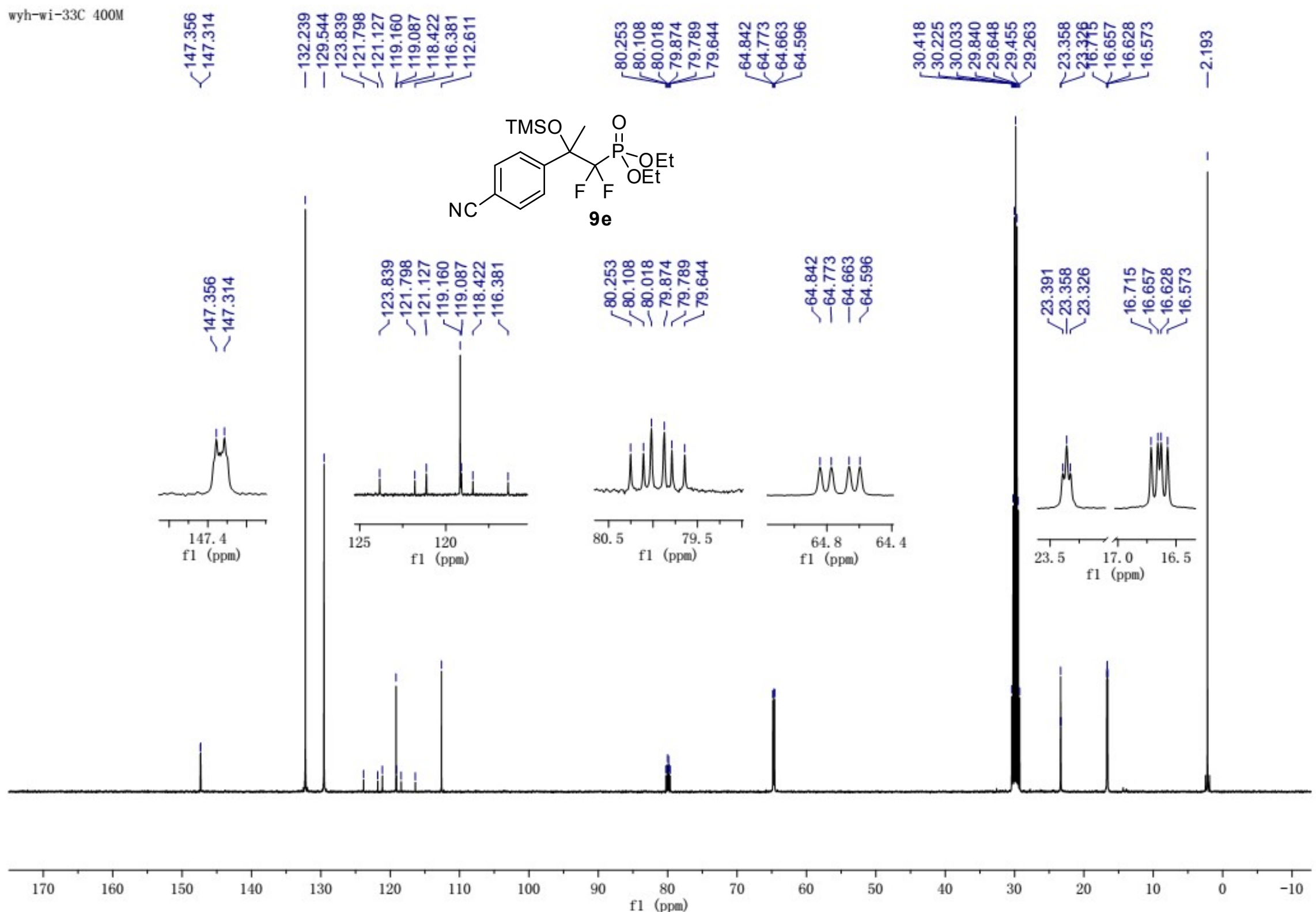


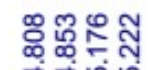

훅둔
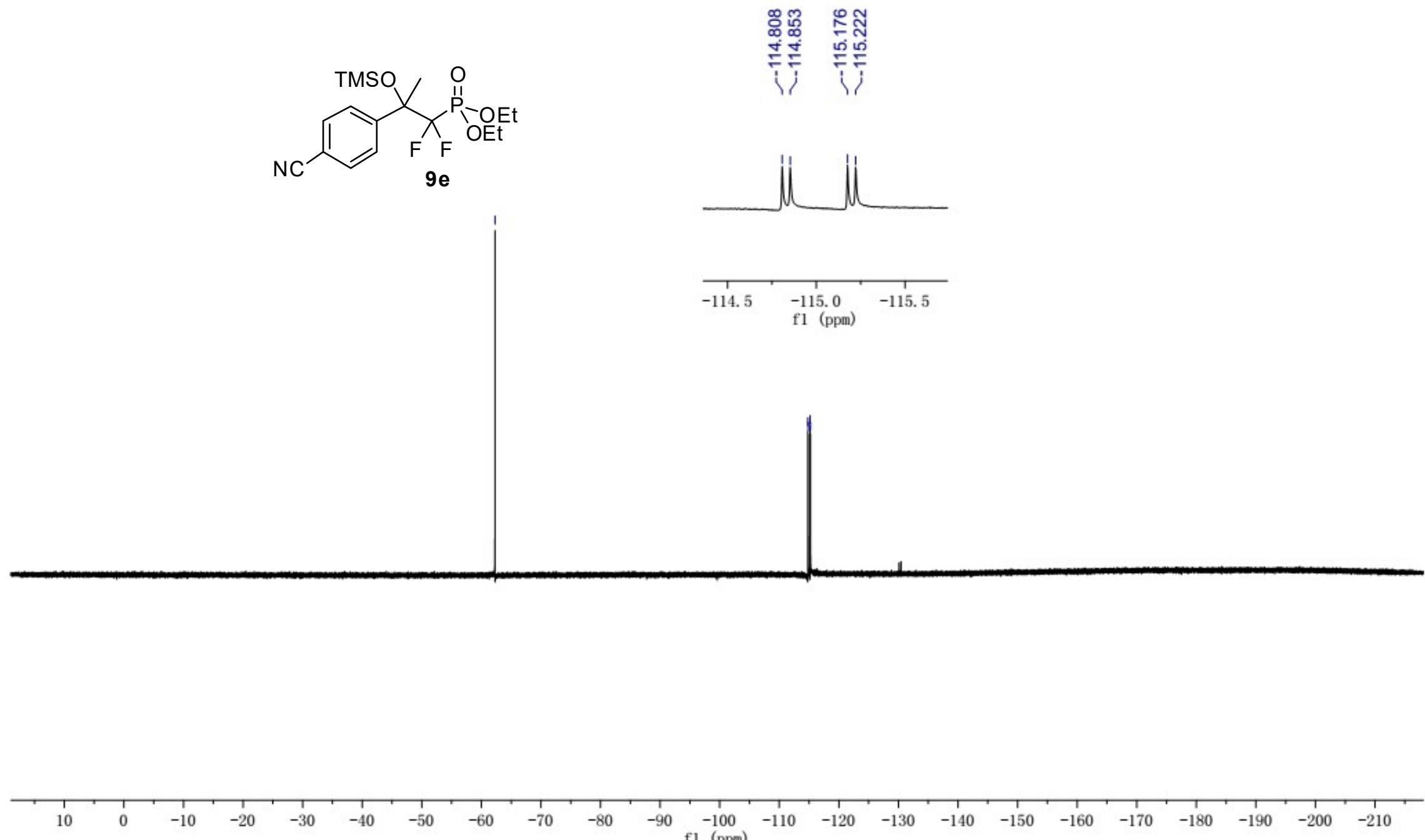

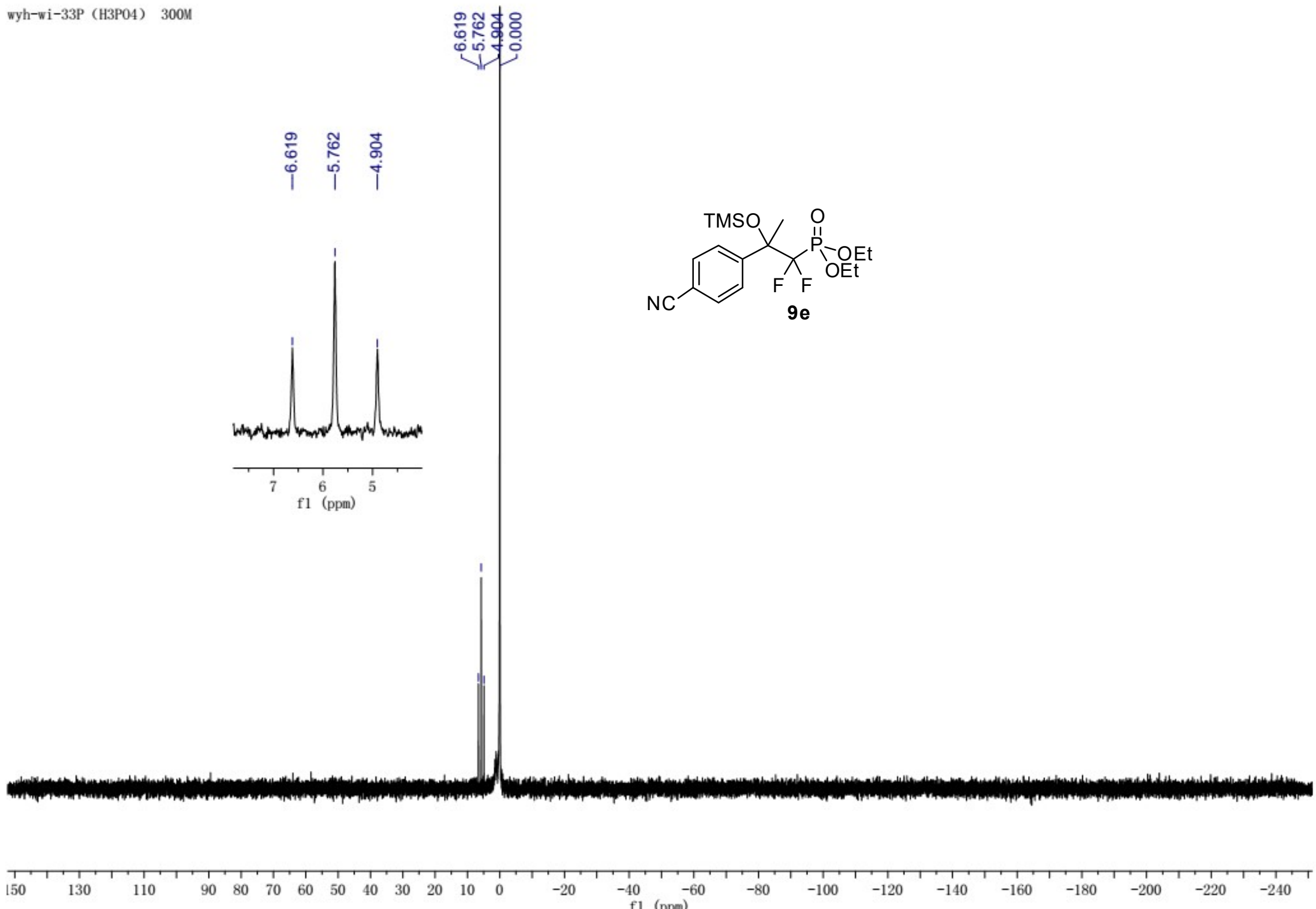


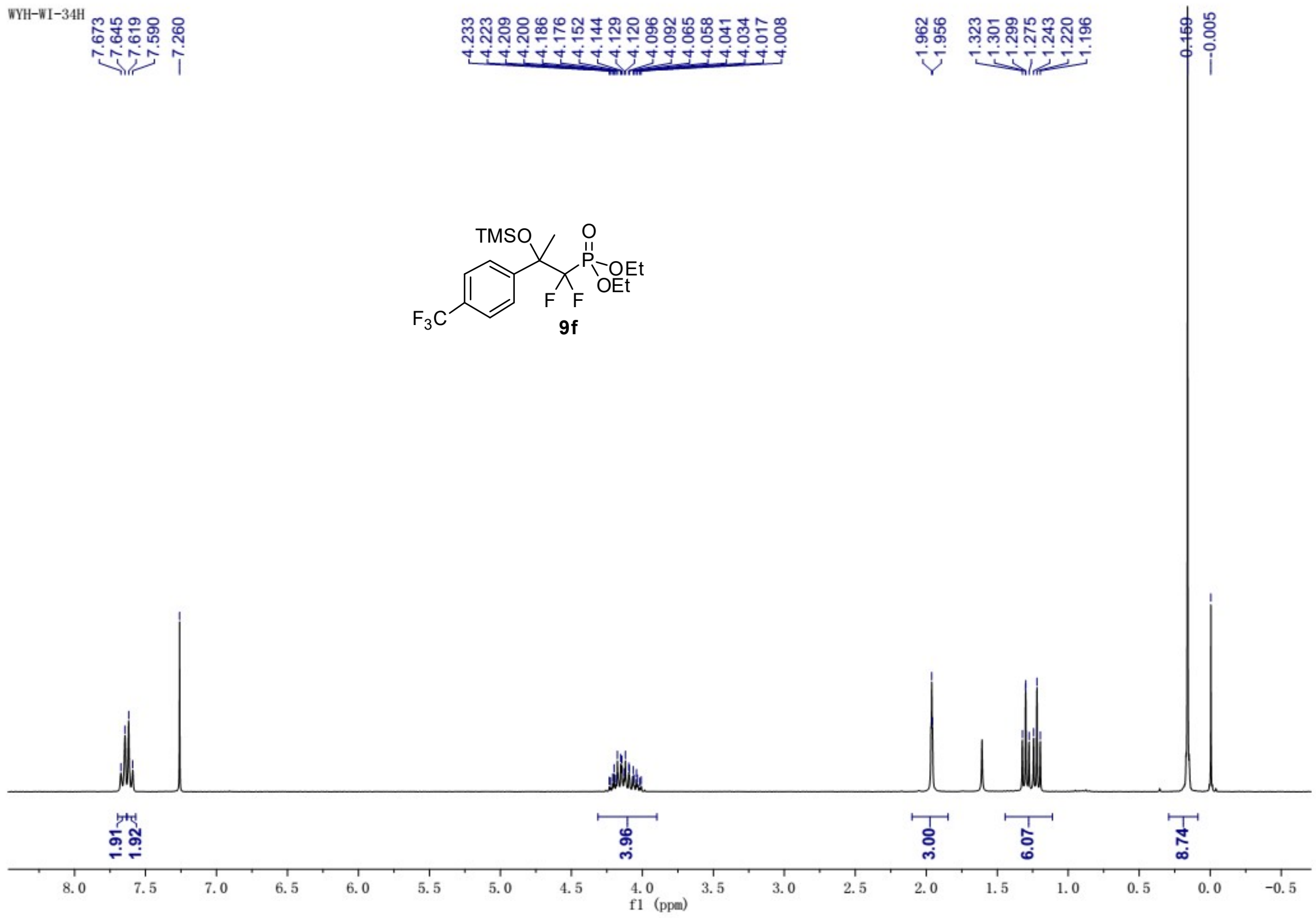



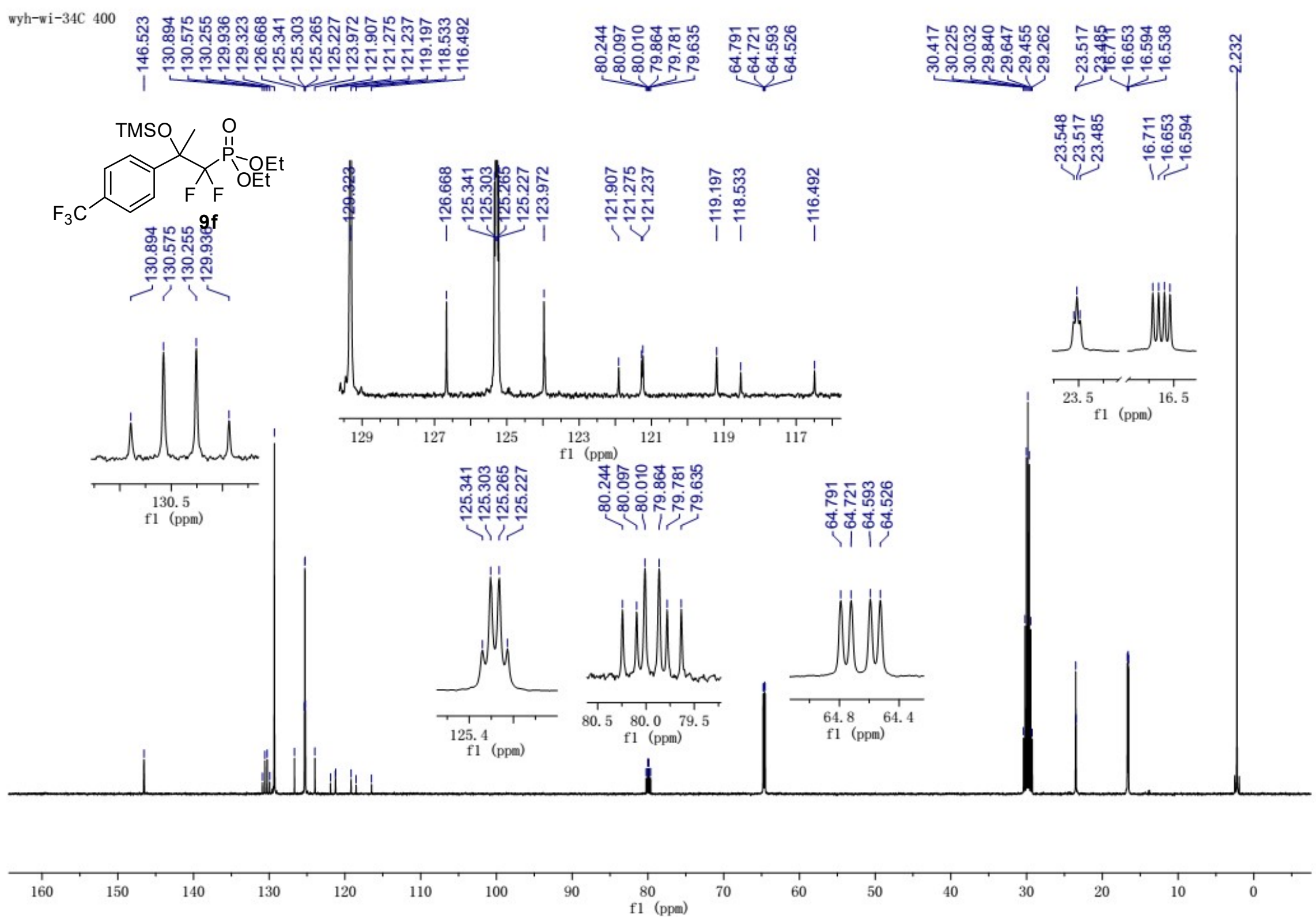


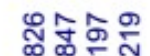

过馆
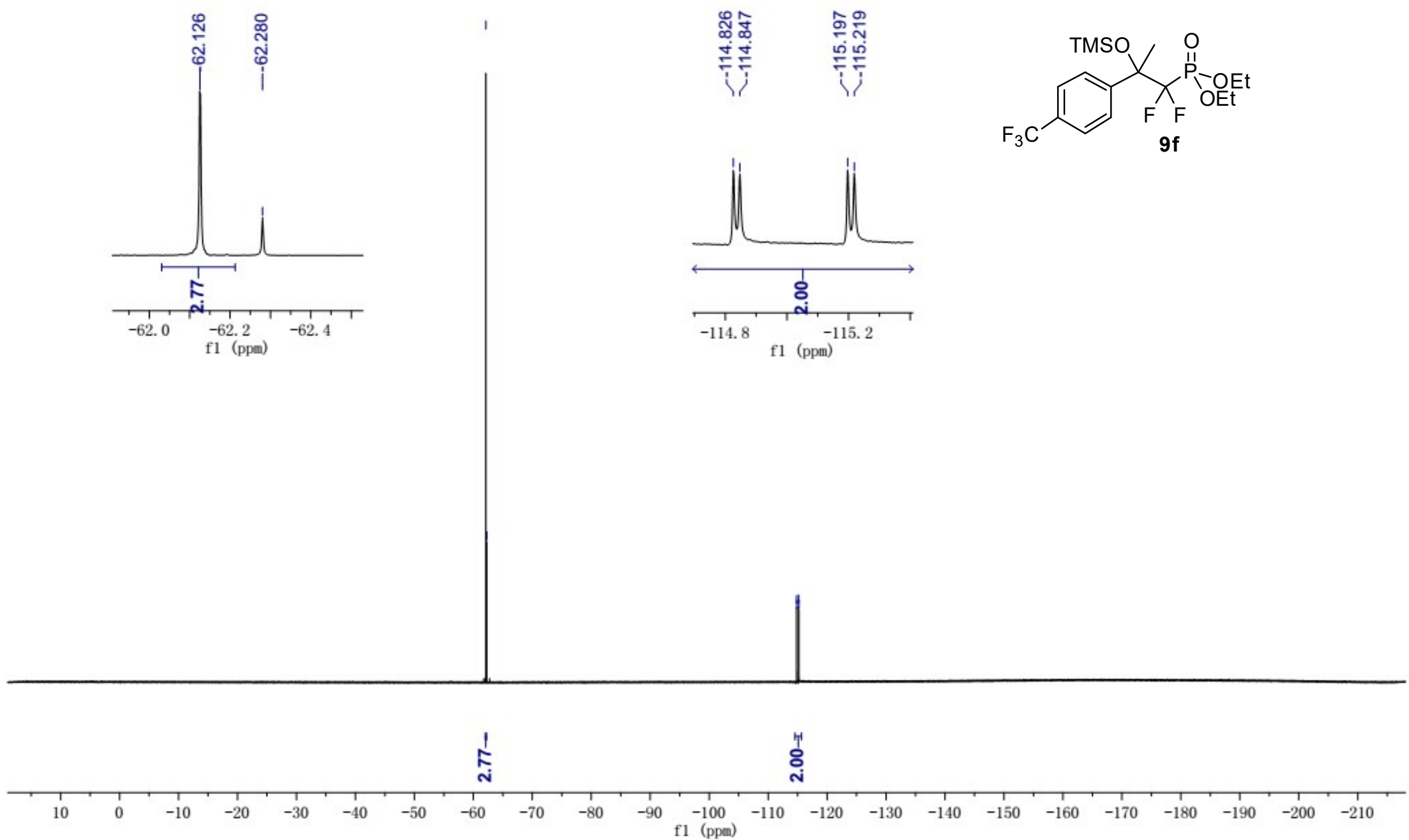


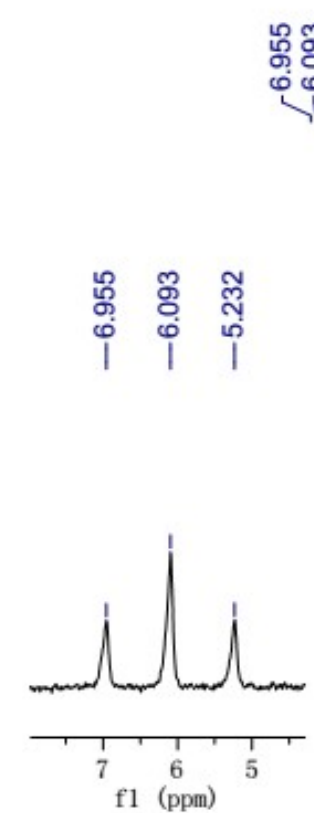

fl (ppm)
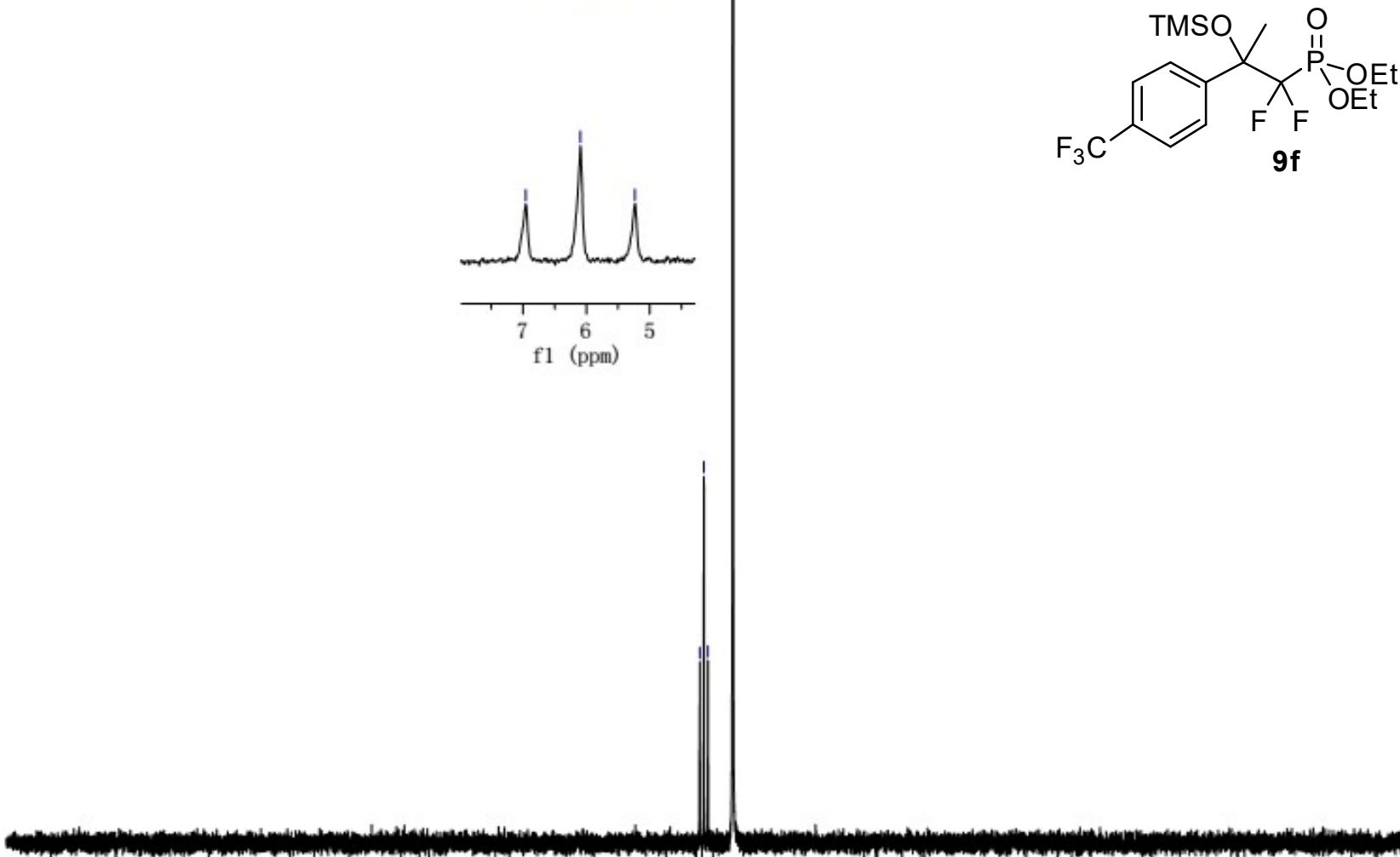

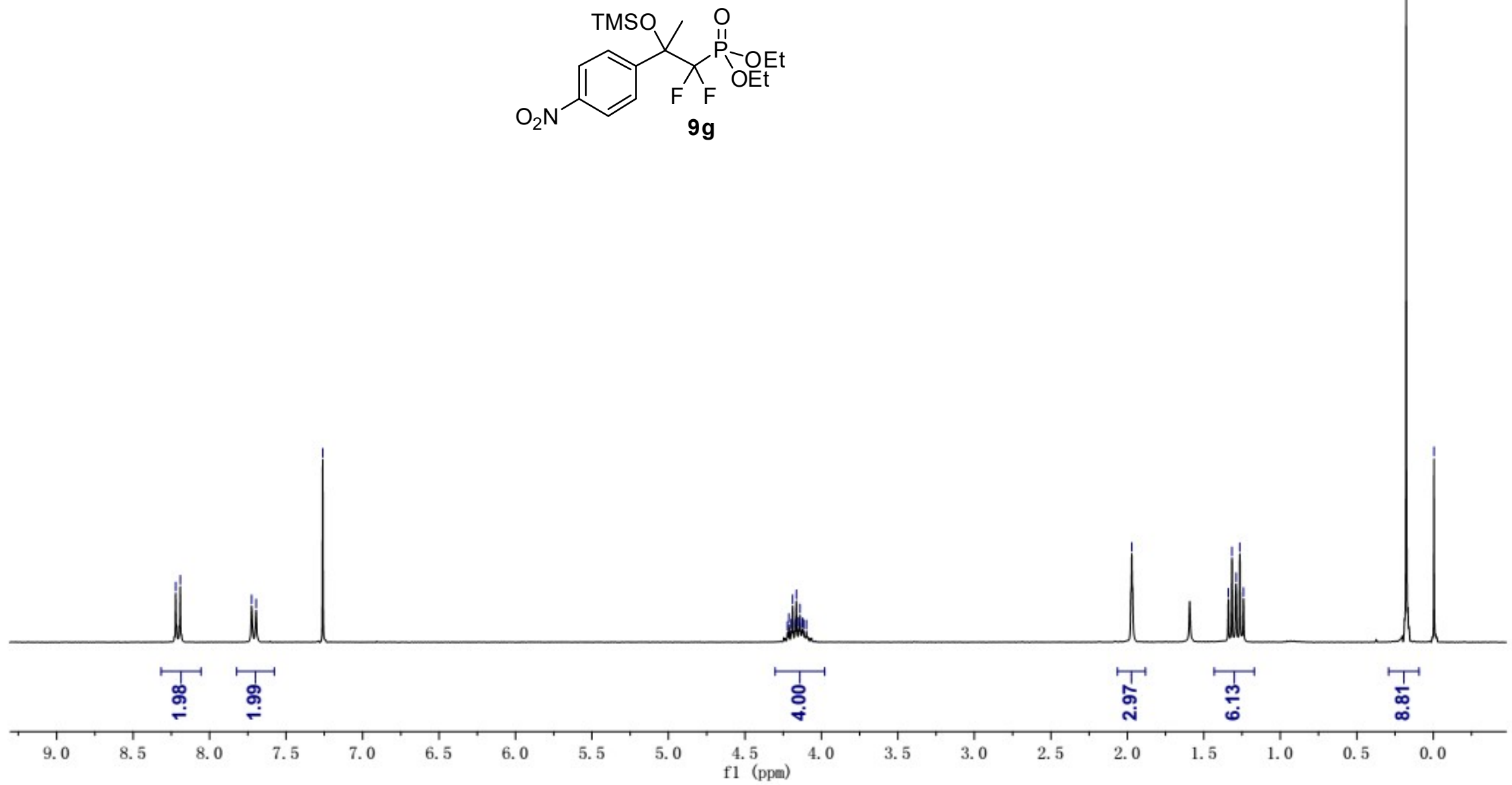


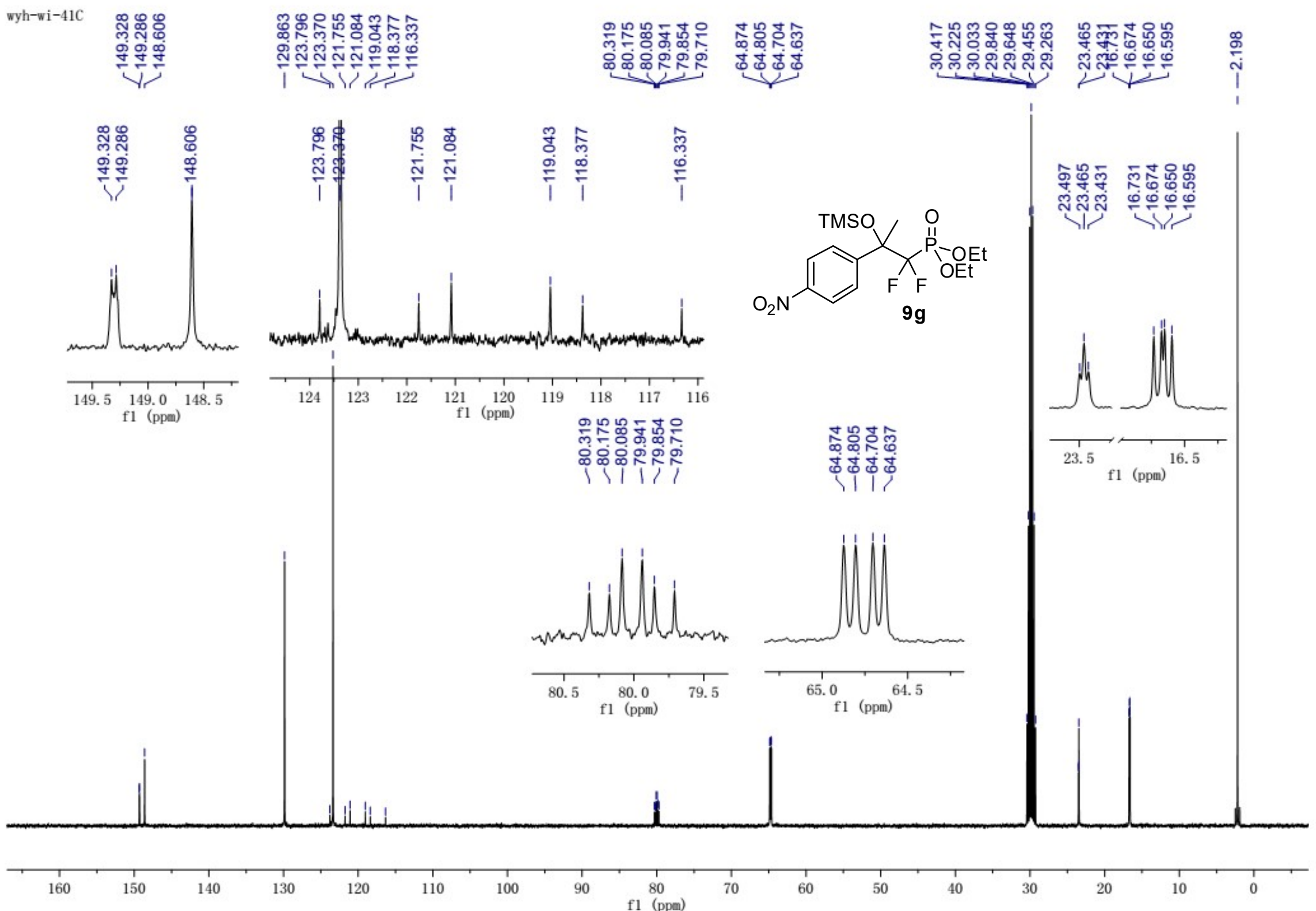



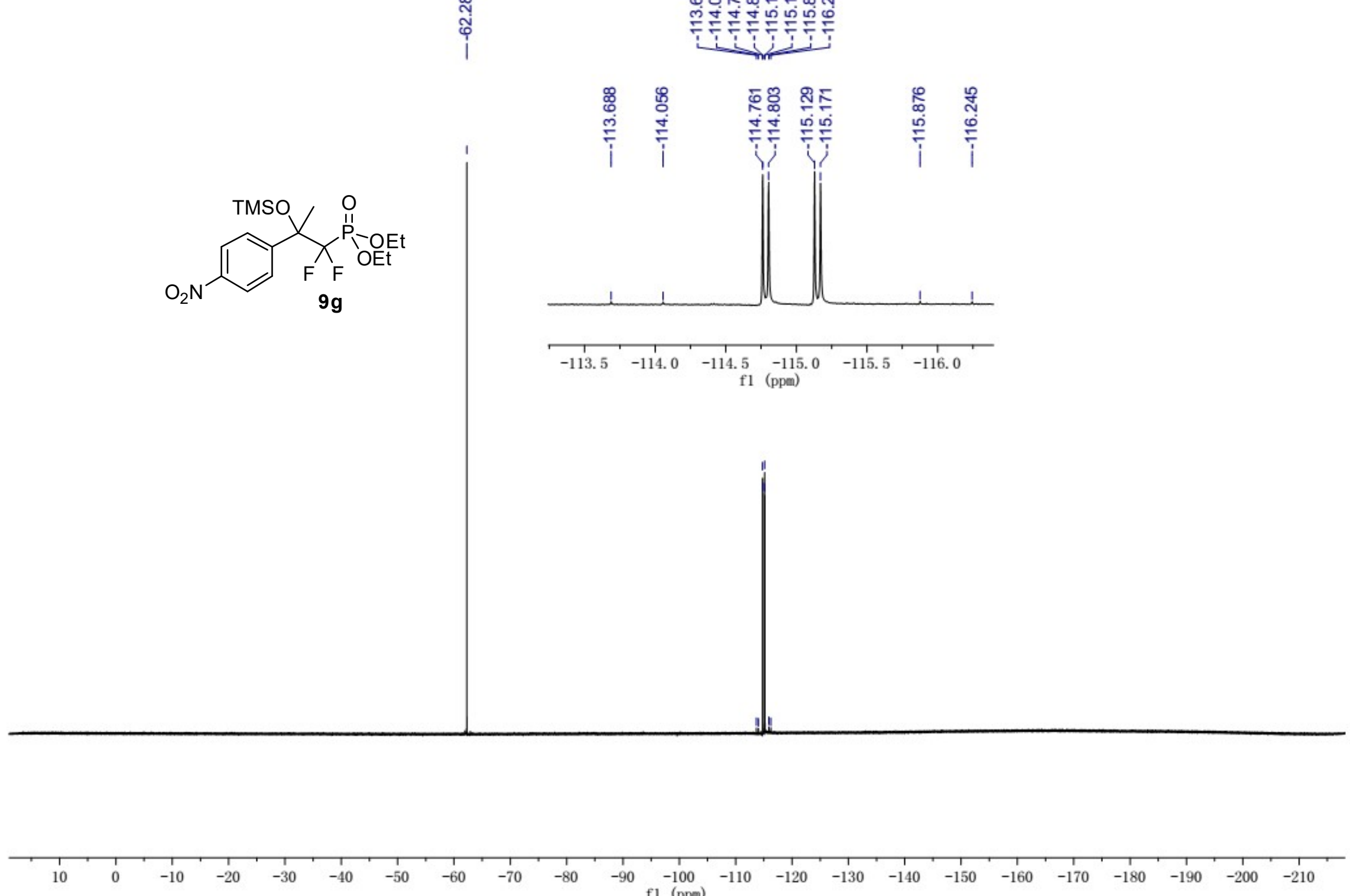


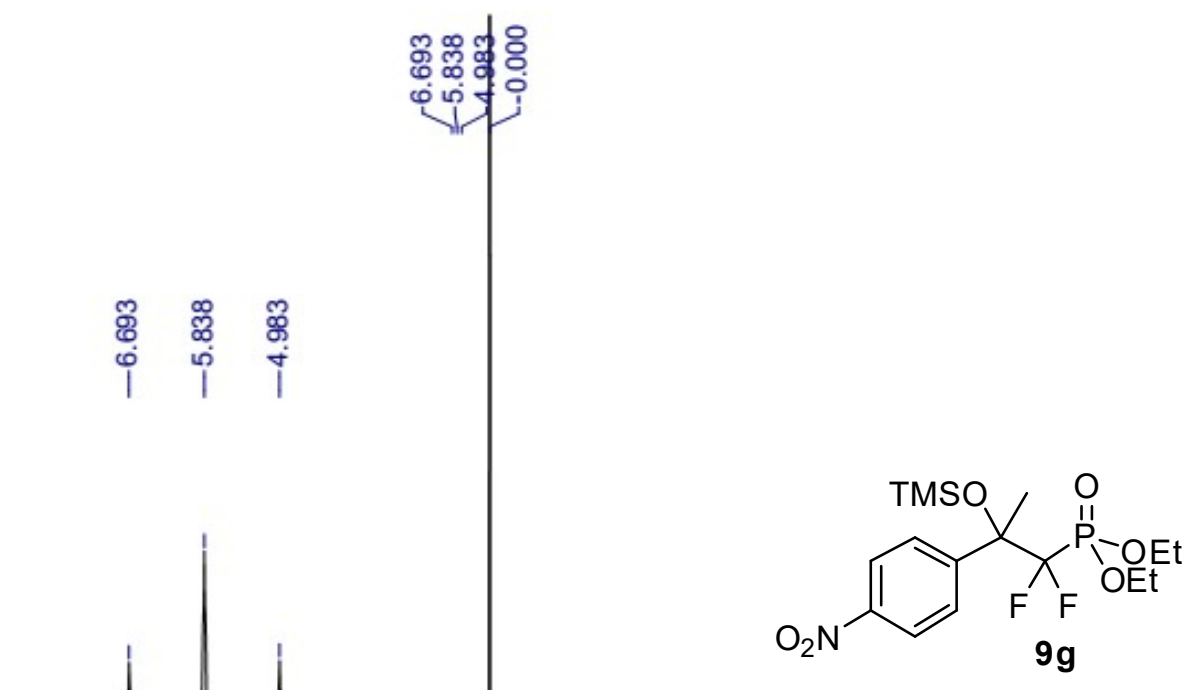

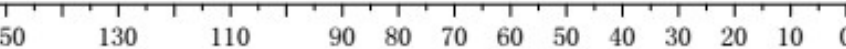

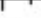

f1 (ppm)
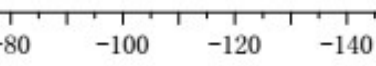

$-160$

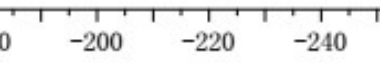


wyh-wi-27H

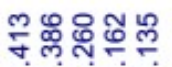

نत许

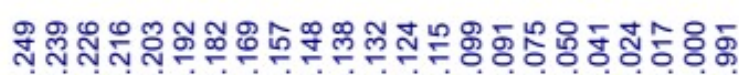

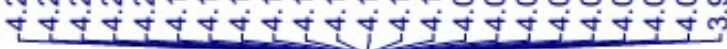

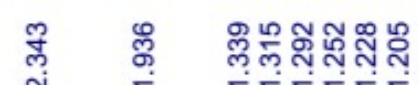

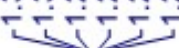
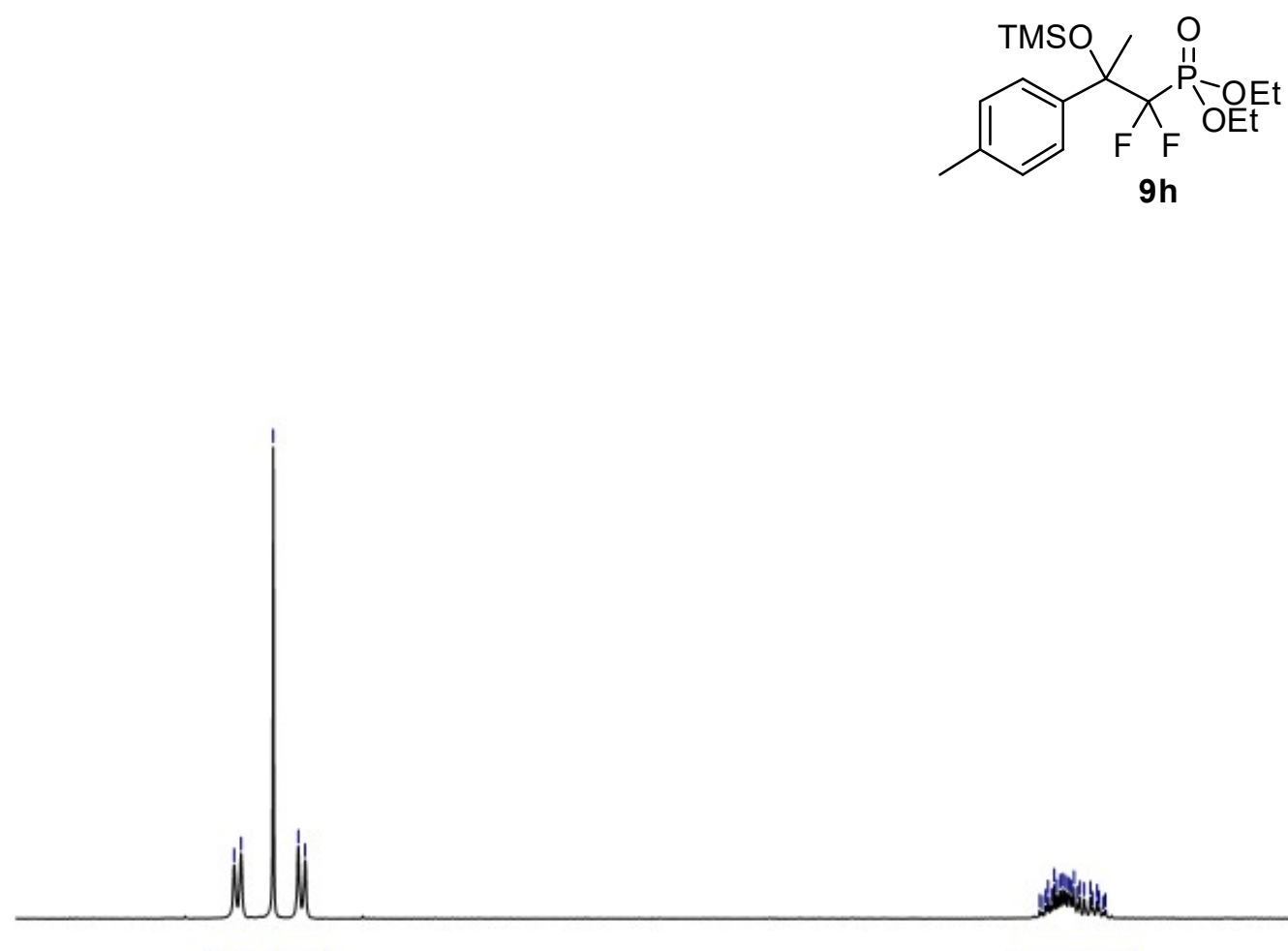

गे है

Whathe

$9 \mathrm{~h}$

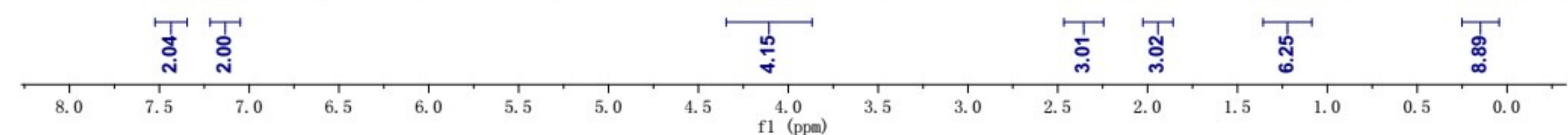



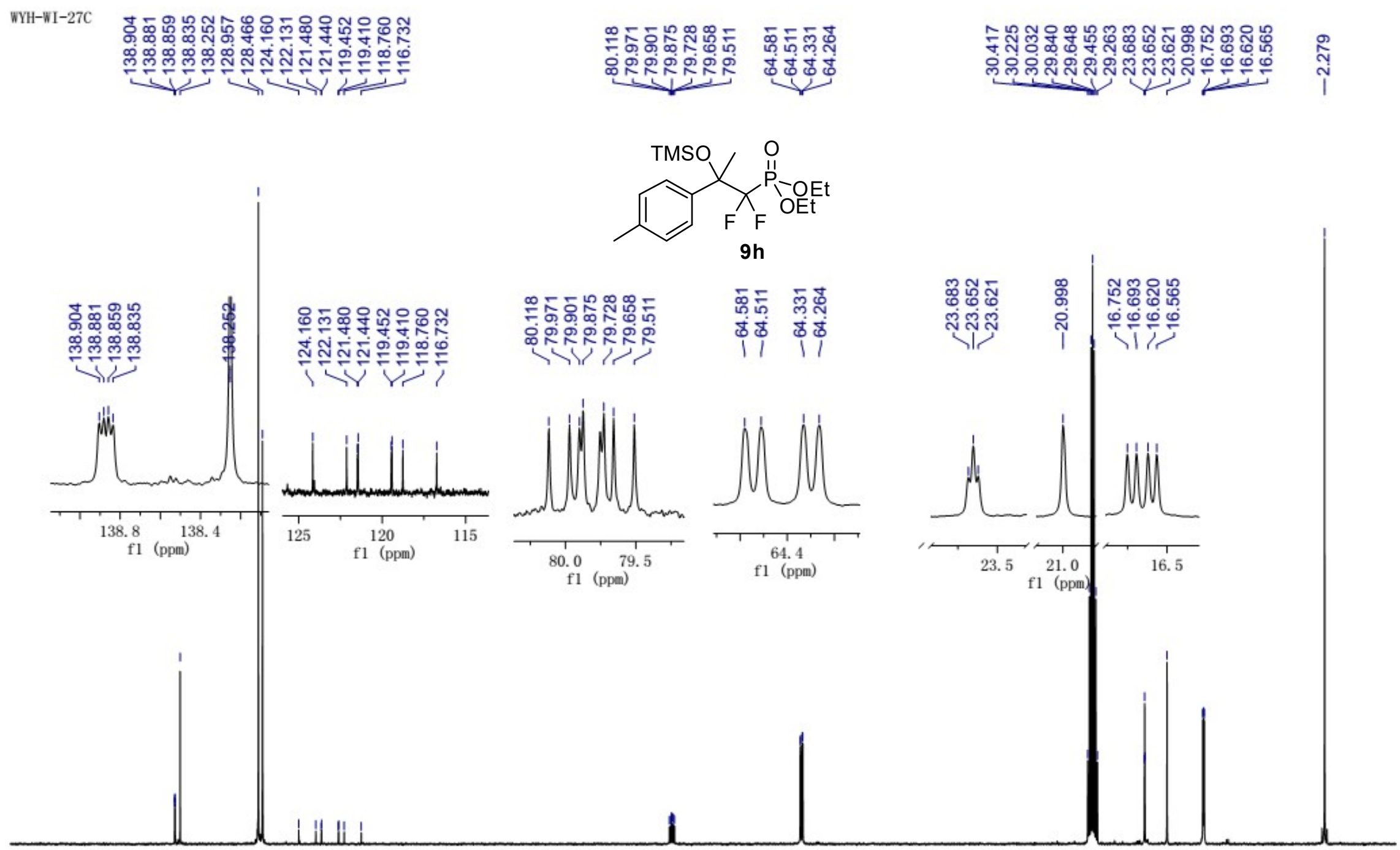
年

1

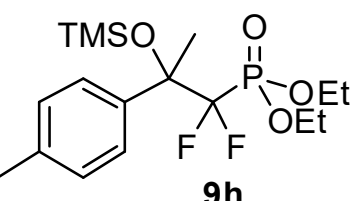

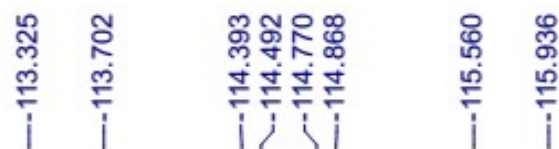
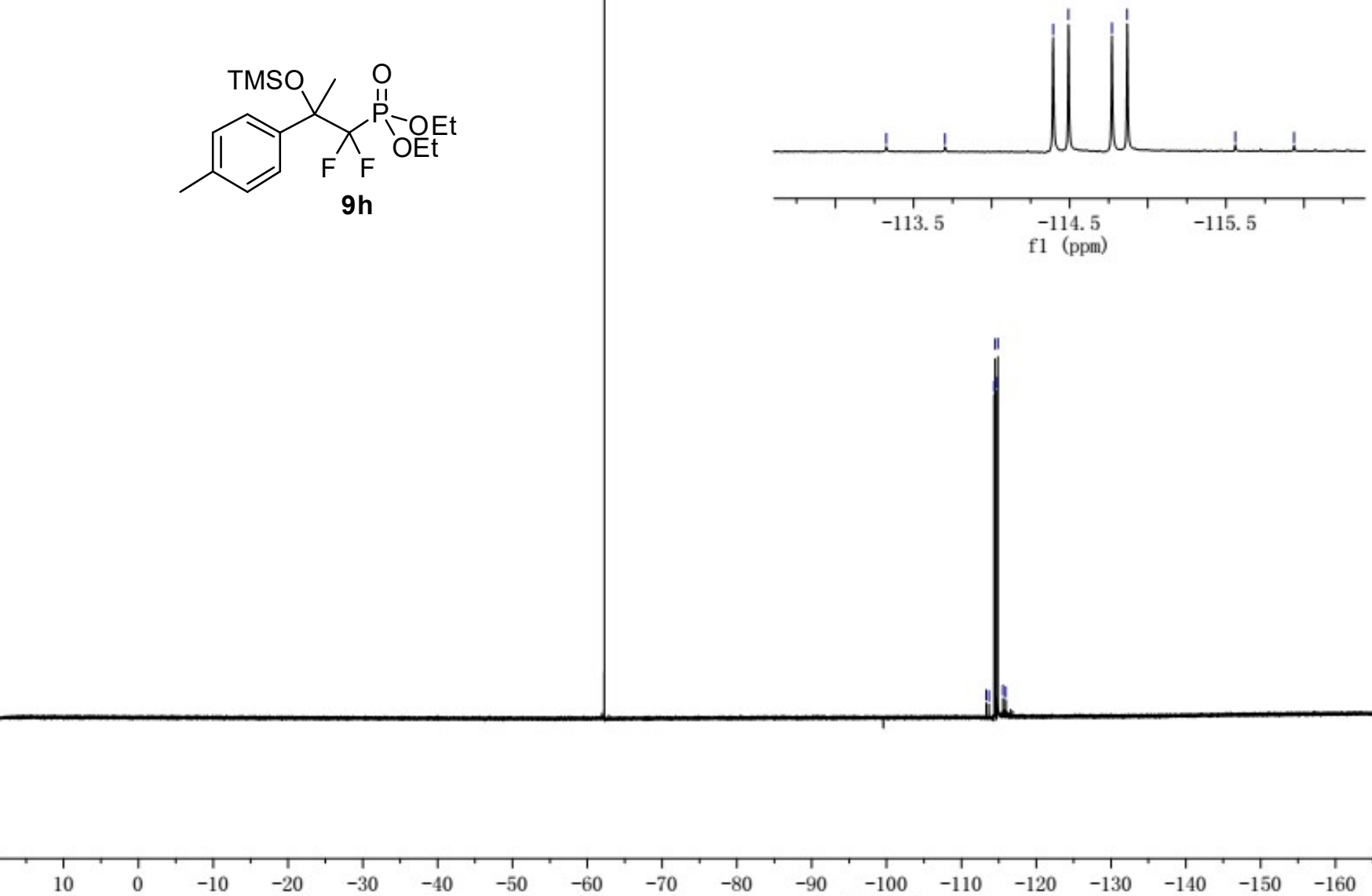

$-90 \quad-100$ 

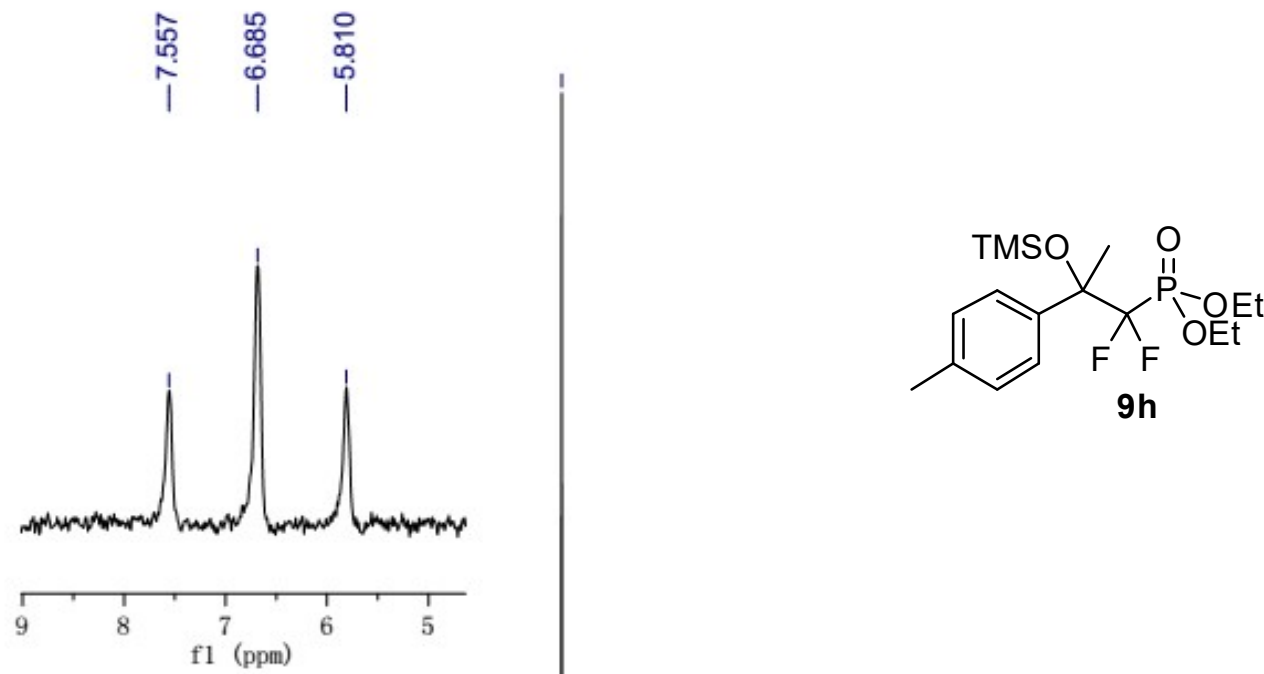

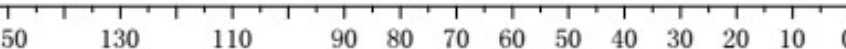

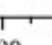

$-40(-60$

$9 \mathrm{~h}$

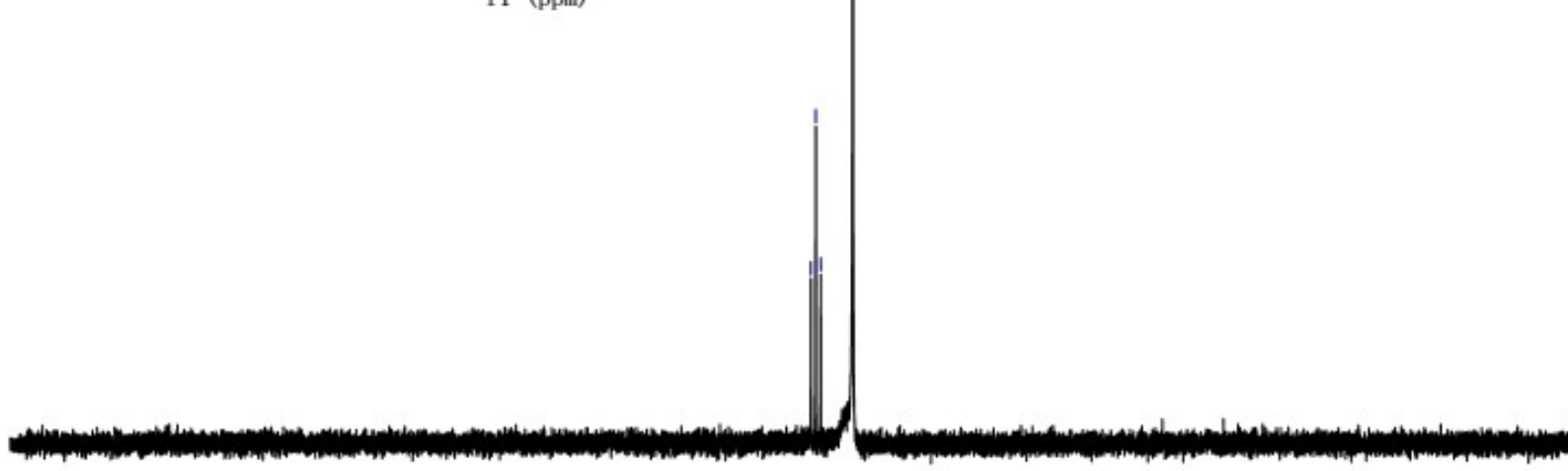



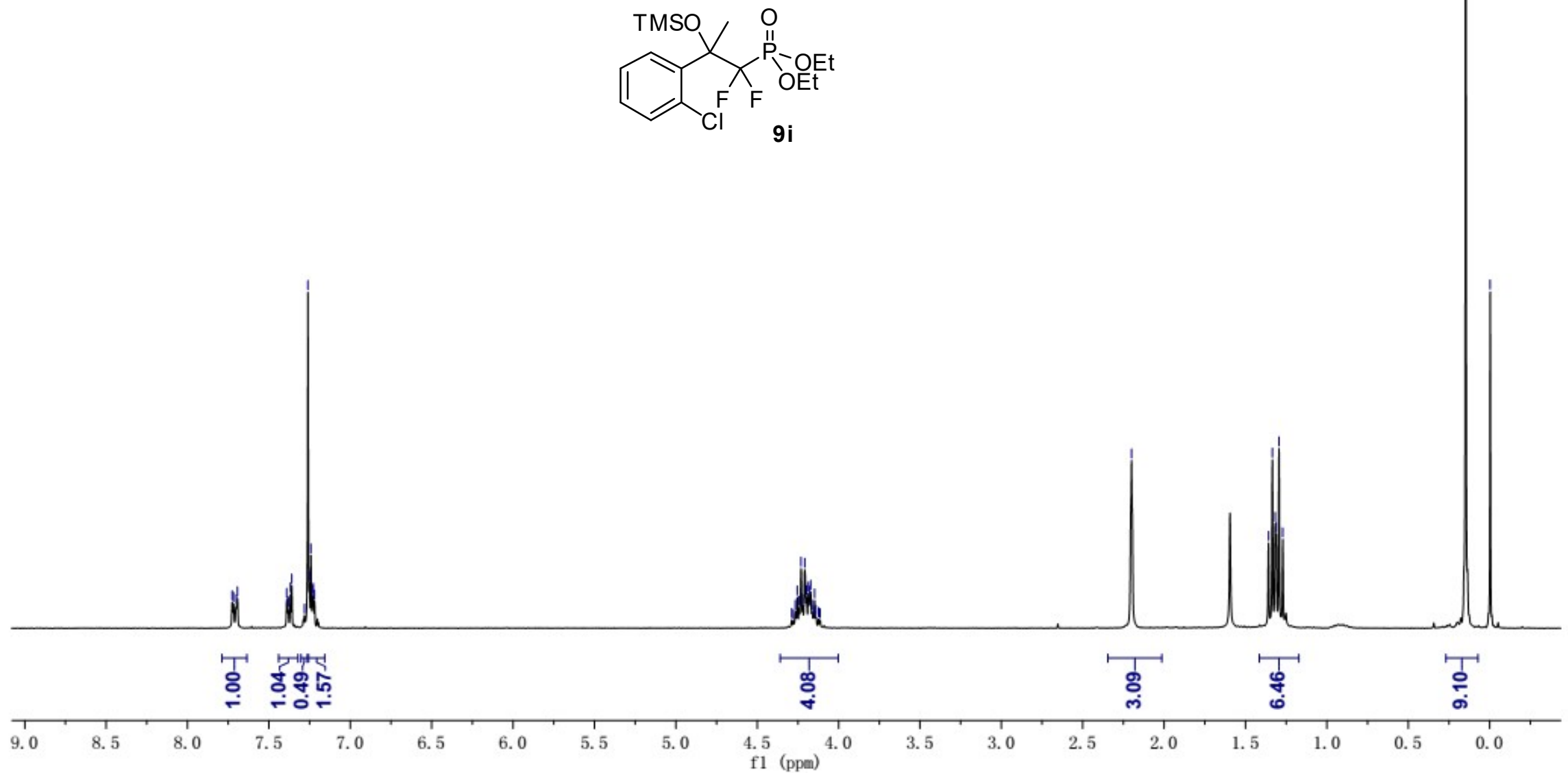
wyh-wi-38c 400 ம o.

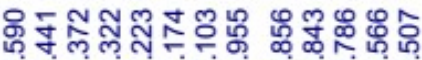
ए人.

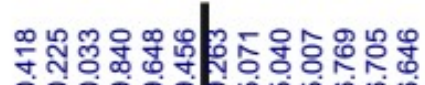

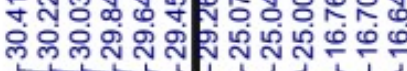

$\longrightarrow$ - 11111
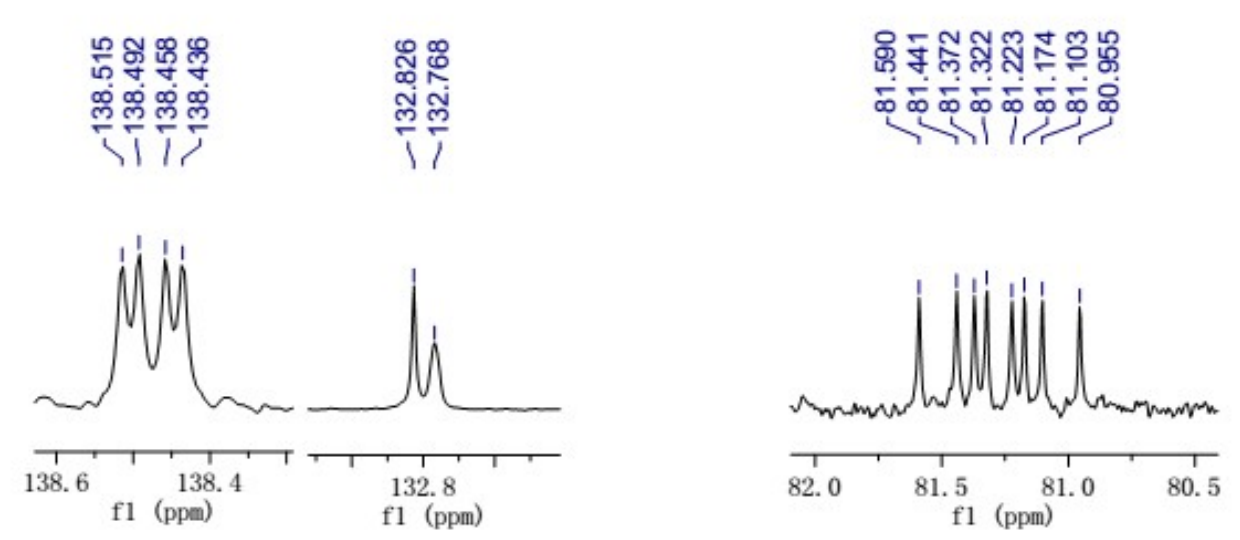

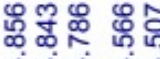

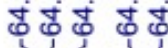

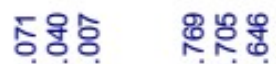

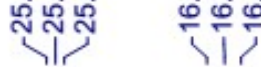

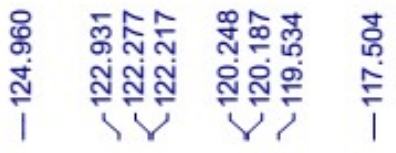
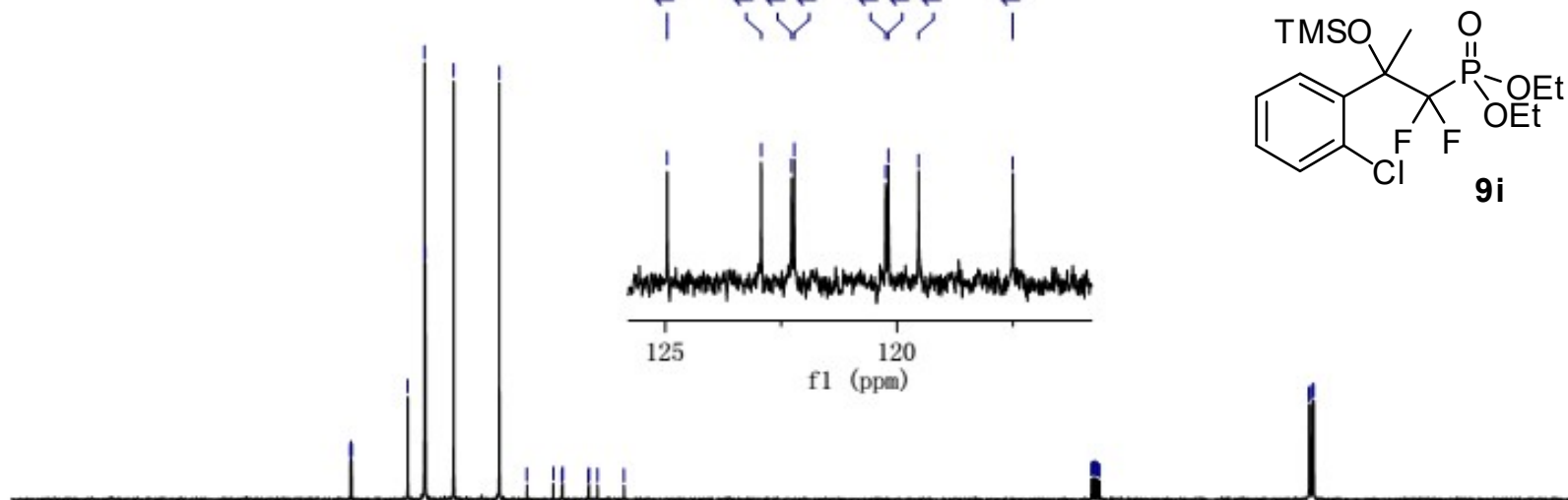

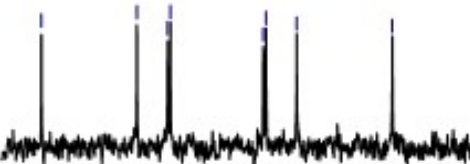
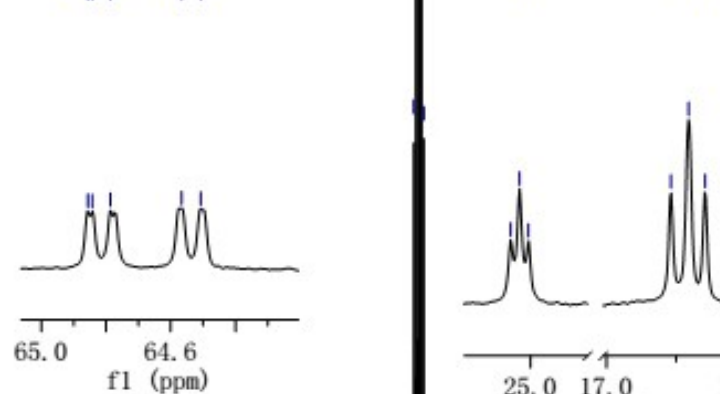

7125

f1 $\begin{array}{r}120 \\ \text { (ppm) }\end{array}$

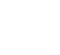

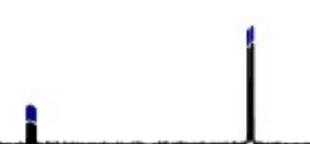




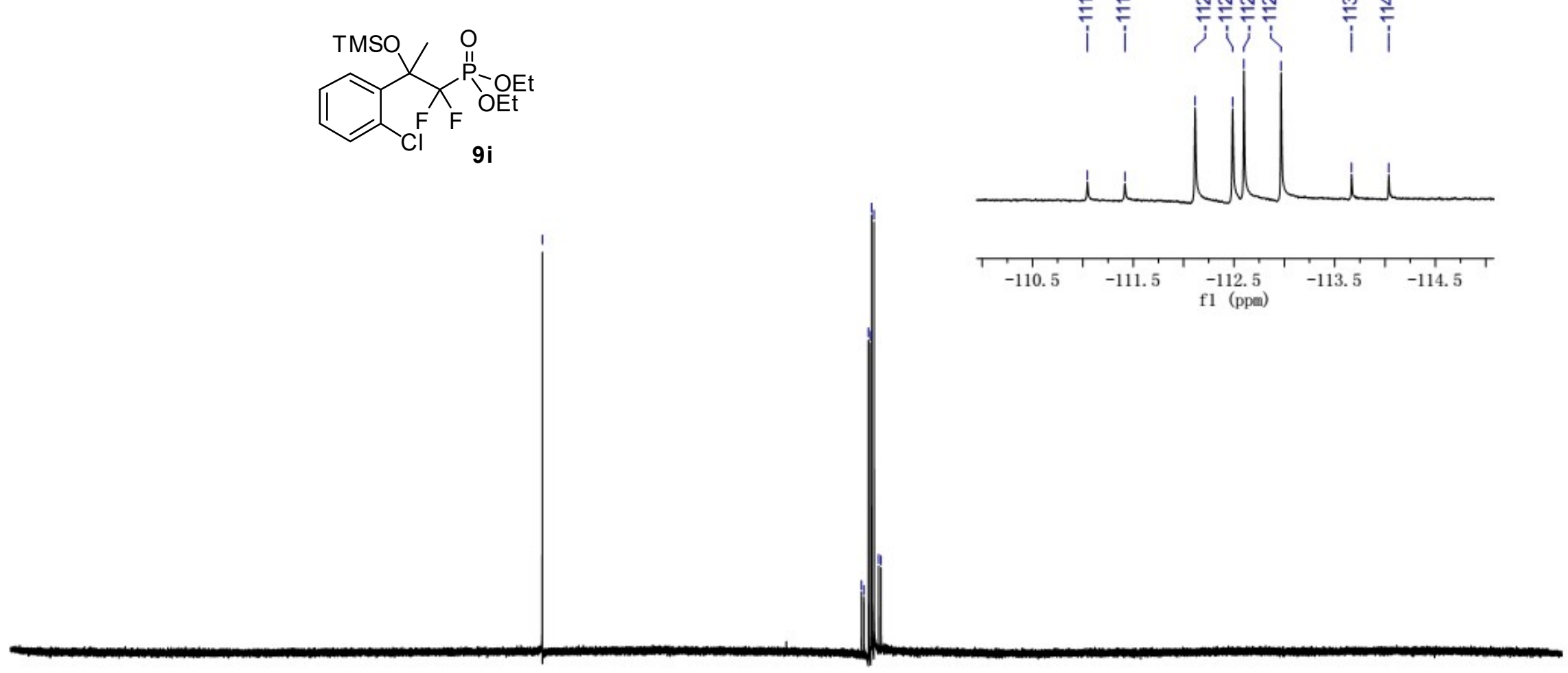

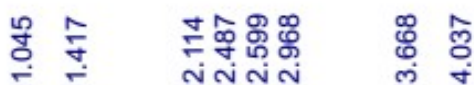

产

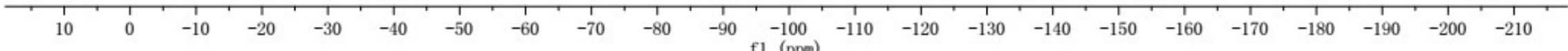



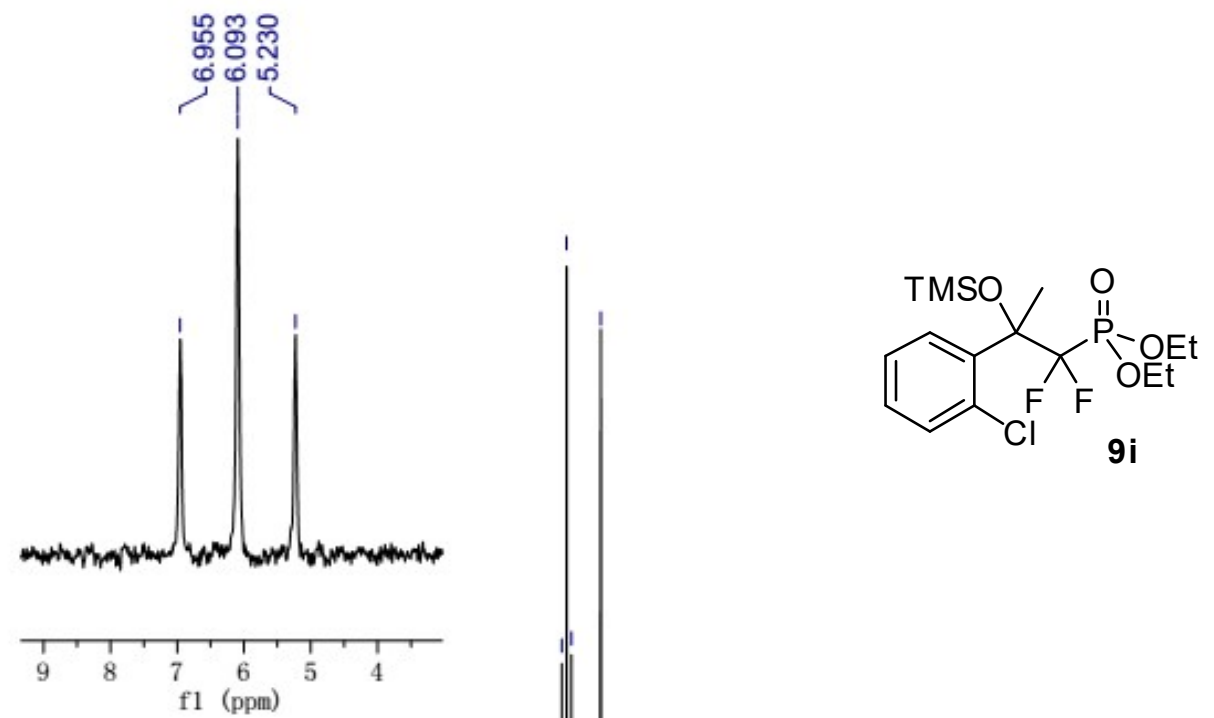

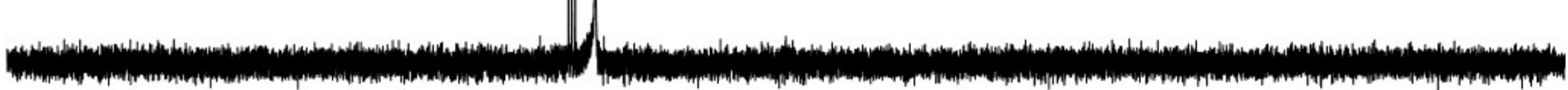
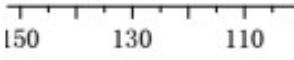

$\begin{array}{lllllllllll}90 & 80 & 70 & 60 & 50 & 40 & 30 & 20 & 10 & 0\end{array}$

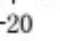

$-60$ 

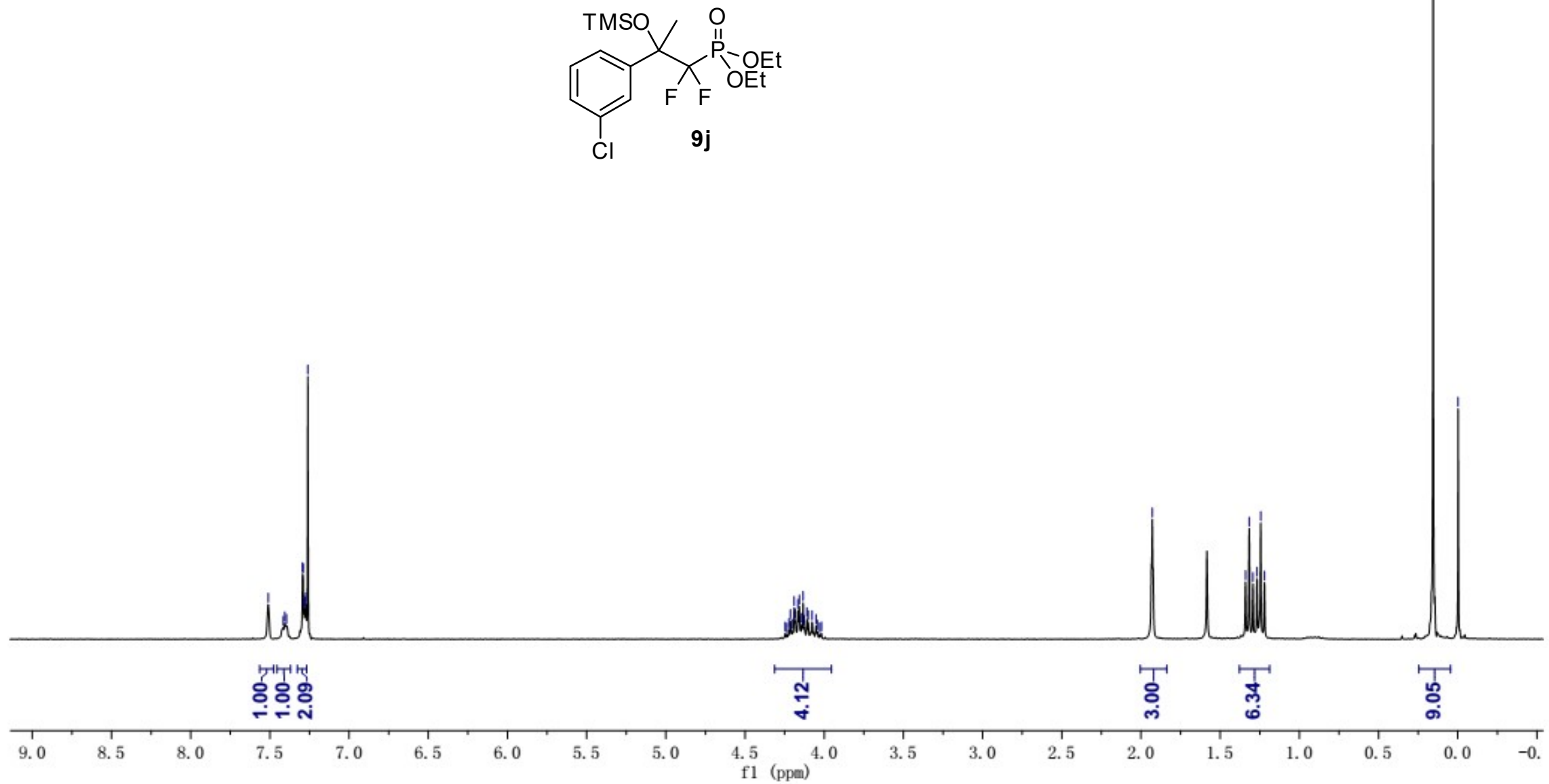

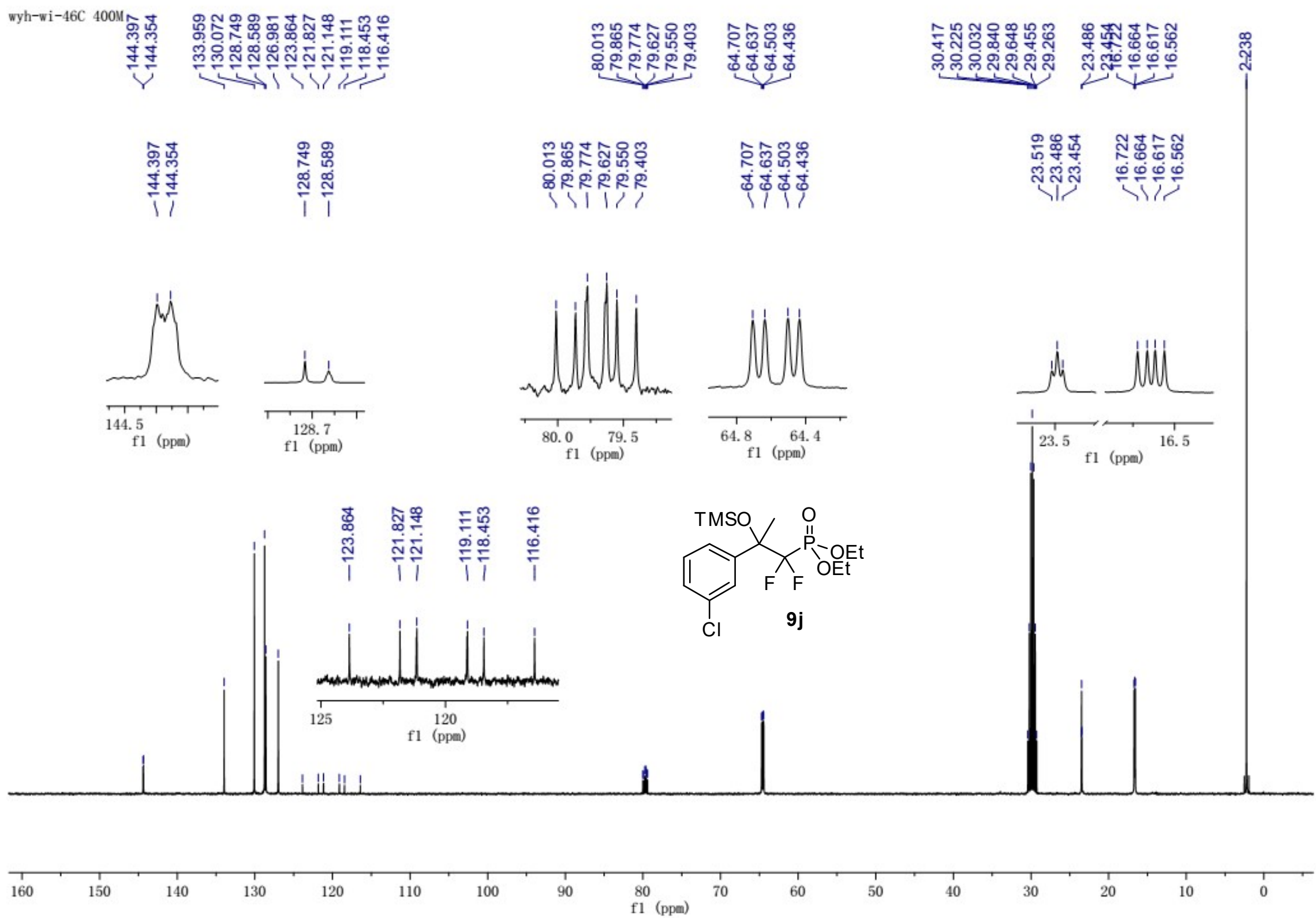

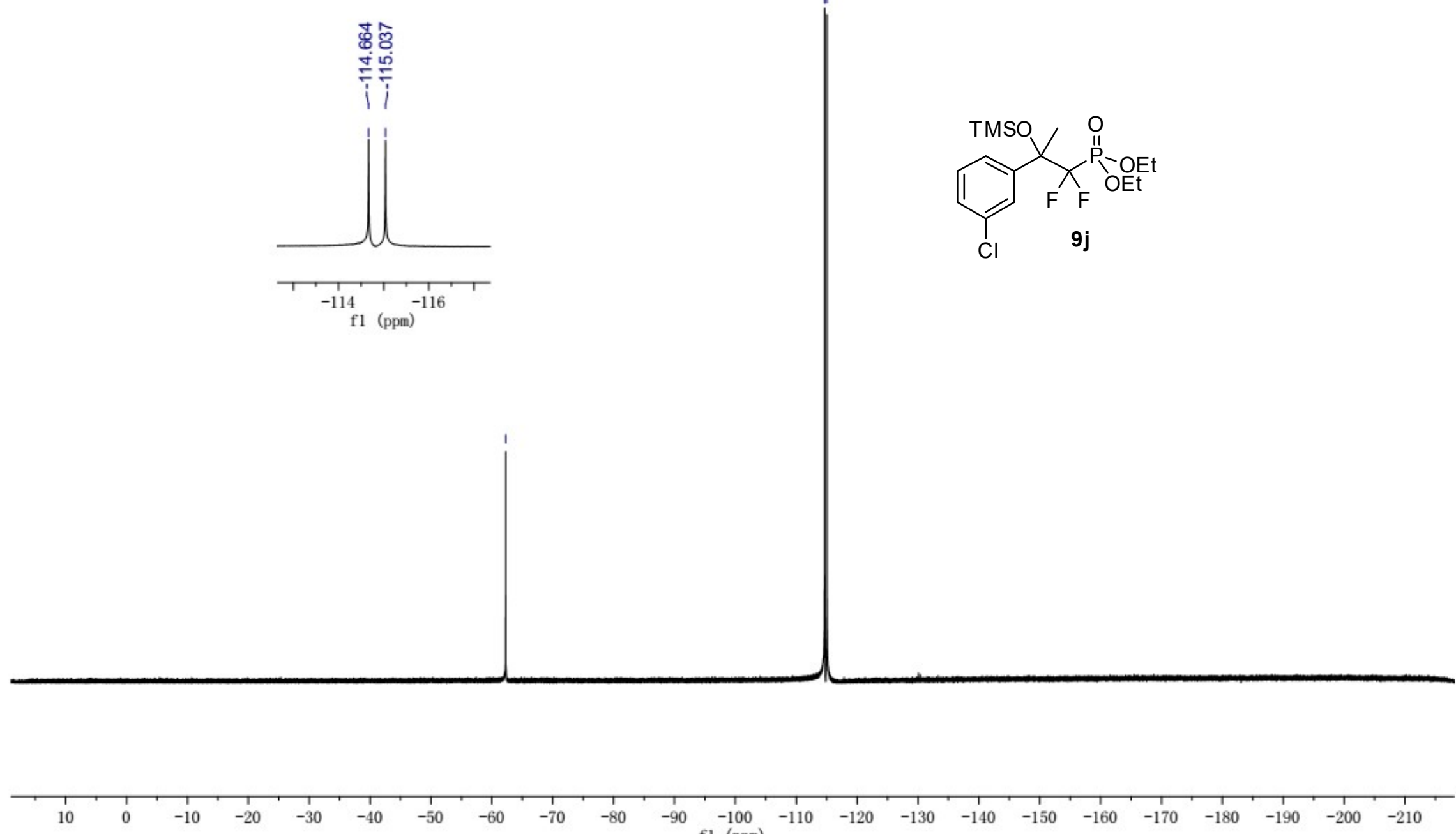
f1 (ppa) 


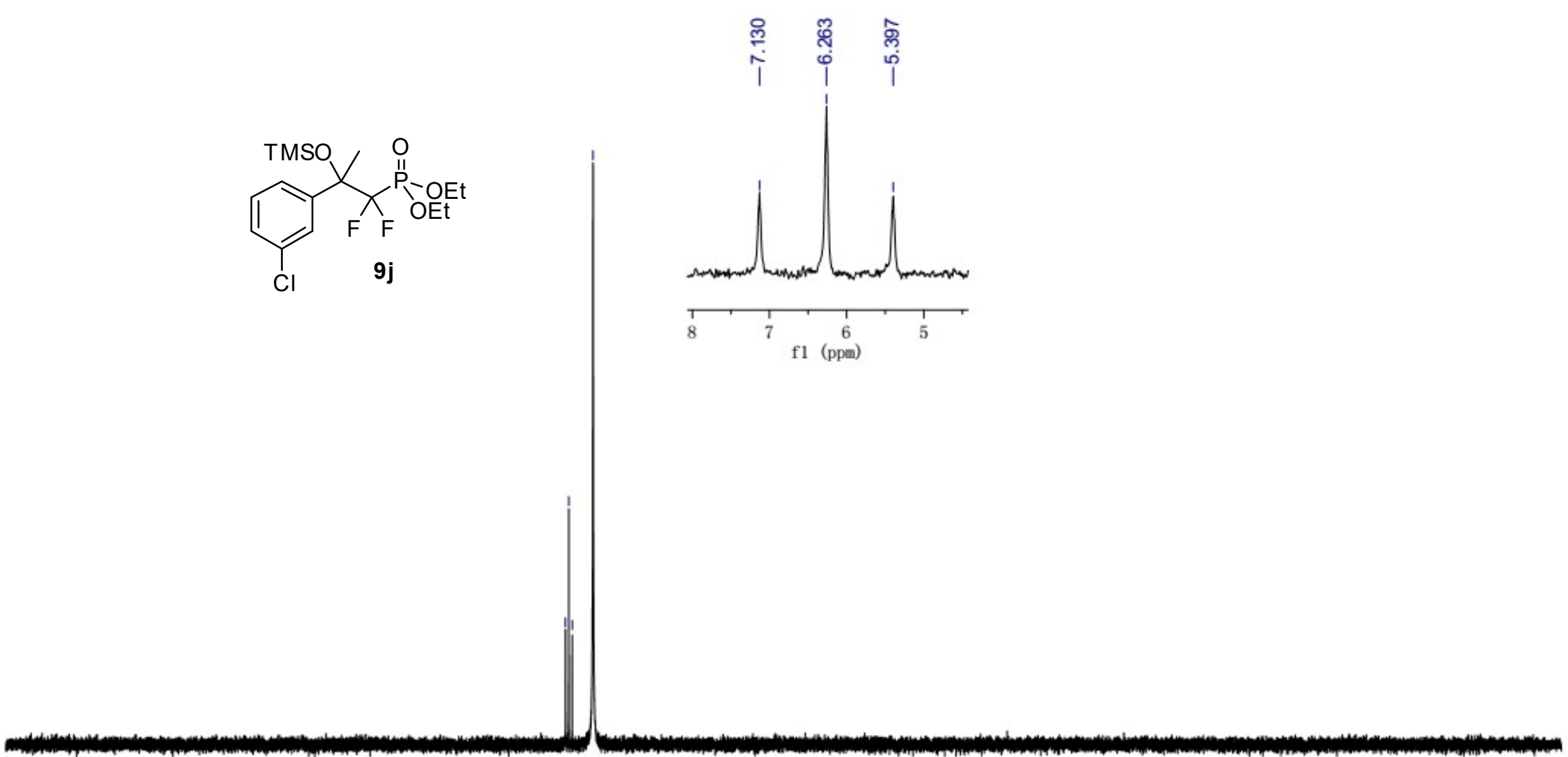




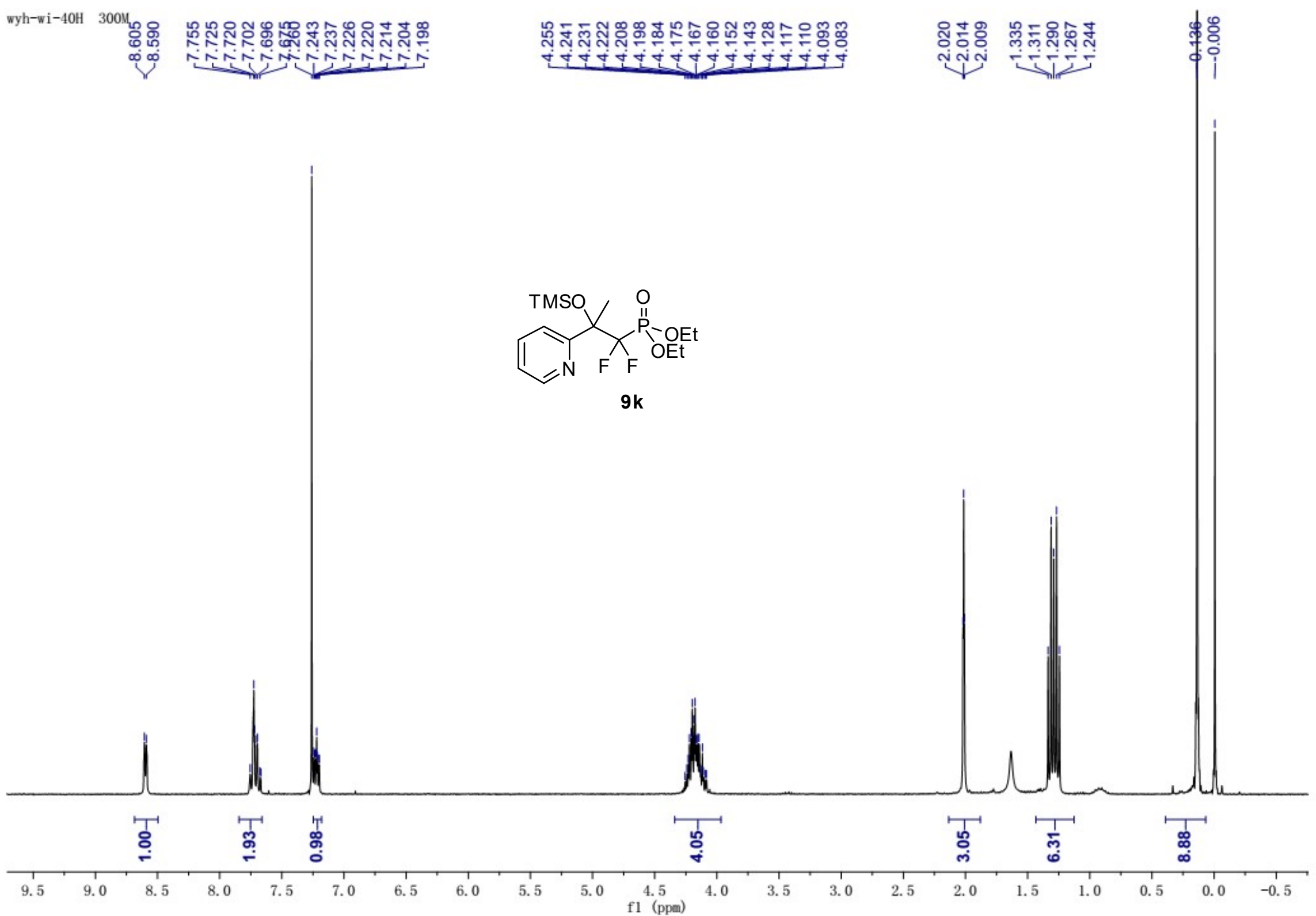



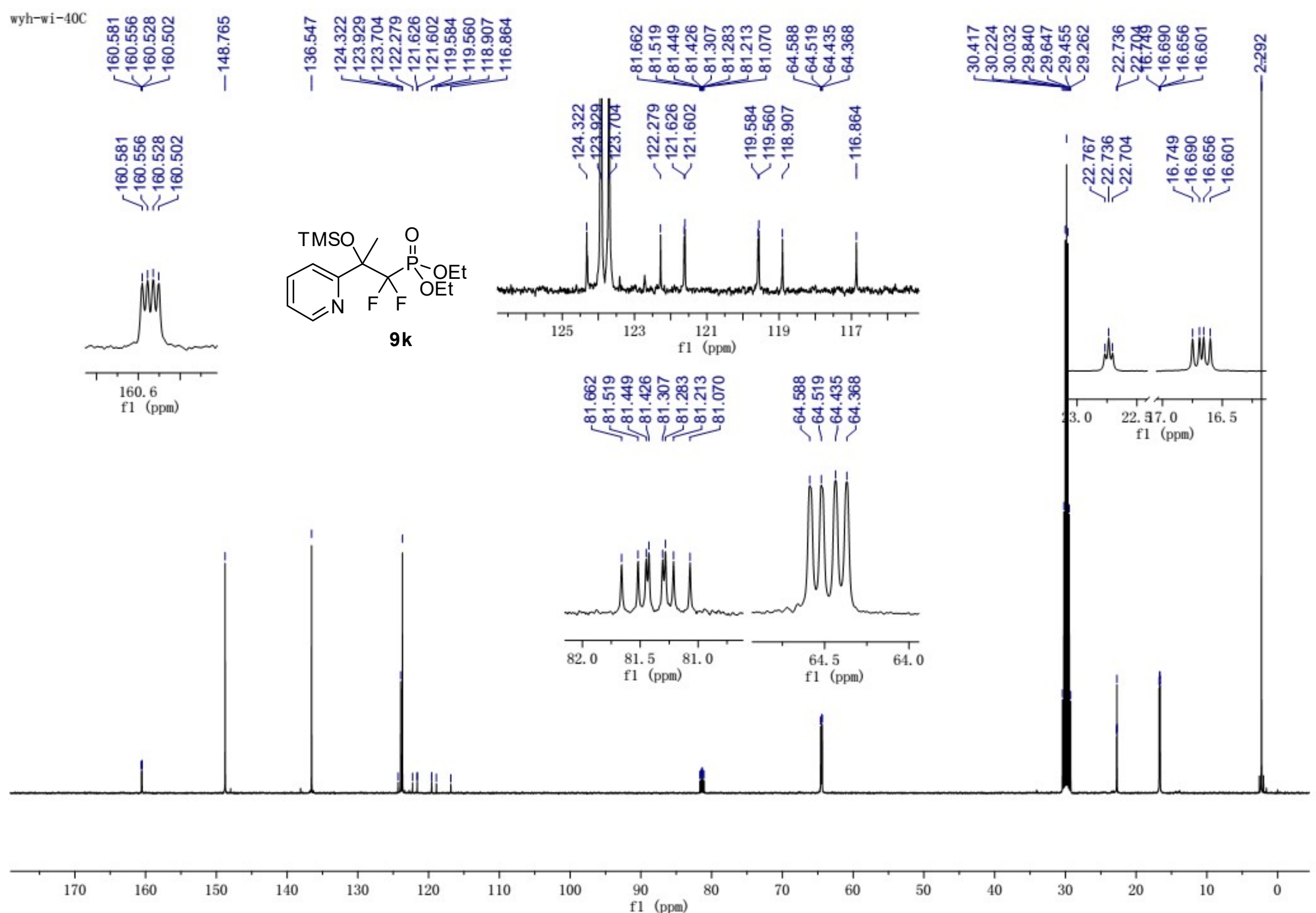


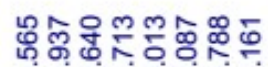

1

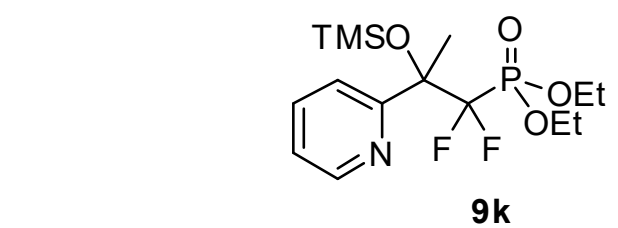

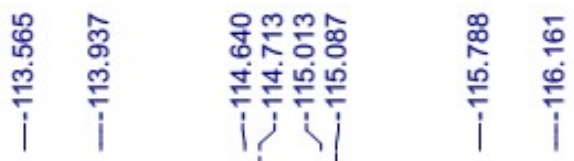
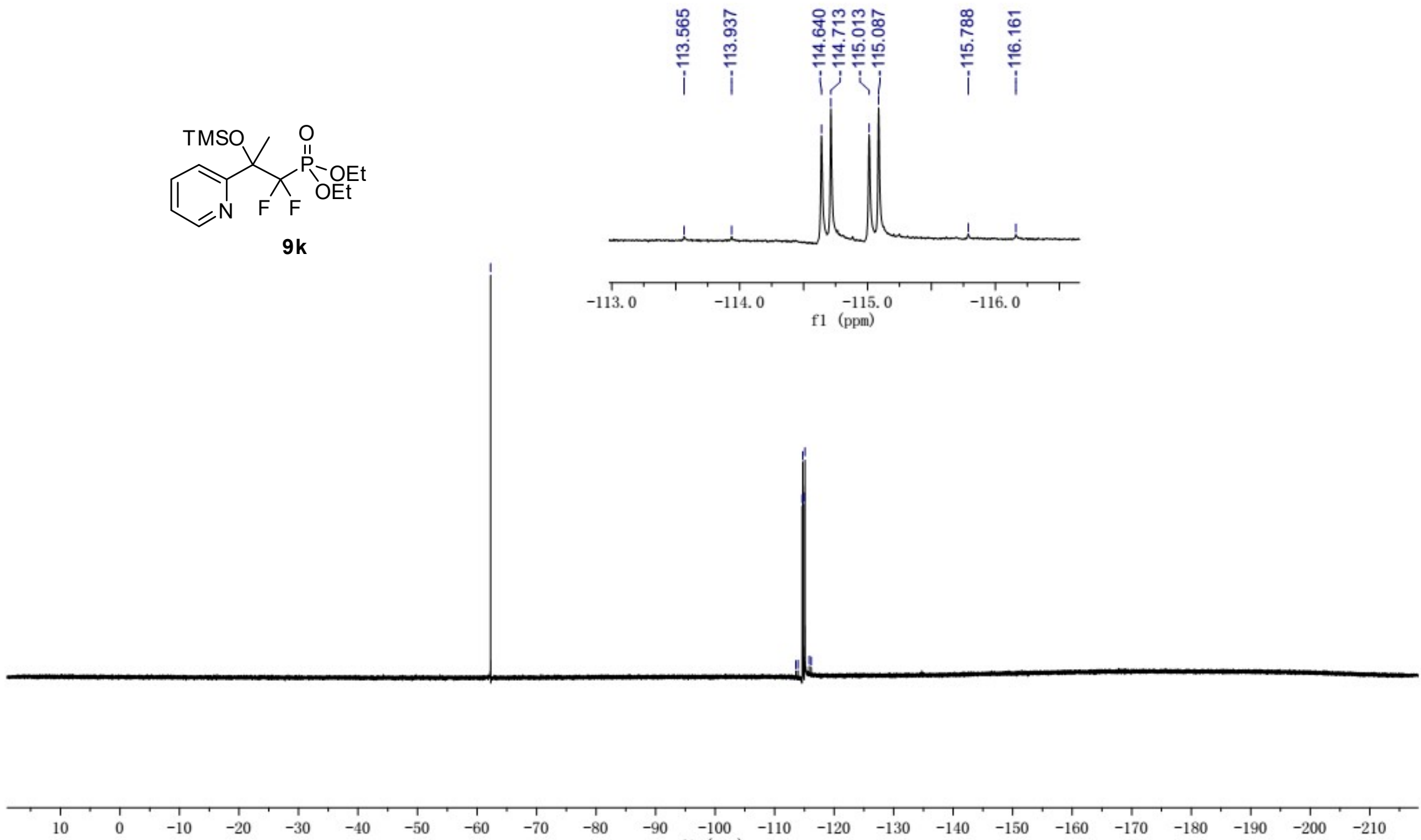

f1 $\stackrel{-100}{(\mathrm{ppm})}$ 


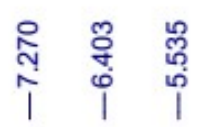
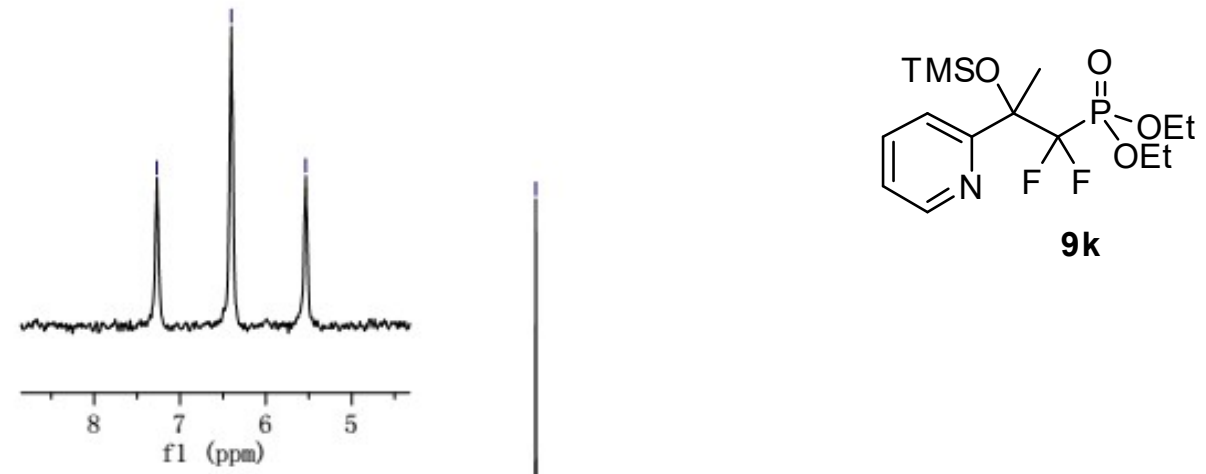

$\stackrel{T}{150} 130 \quad 110$ $\begin{array}{lllllllllll}90 & 80 & 70 & 60 & 50 & 40 & 30 & 20 & 10 & 0\end{array}$ 


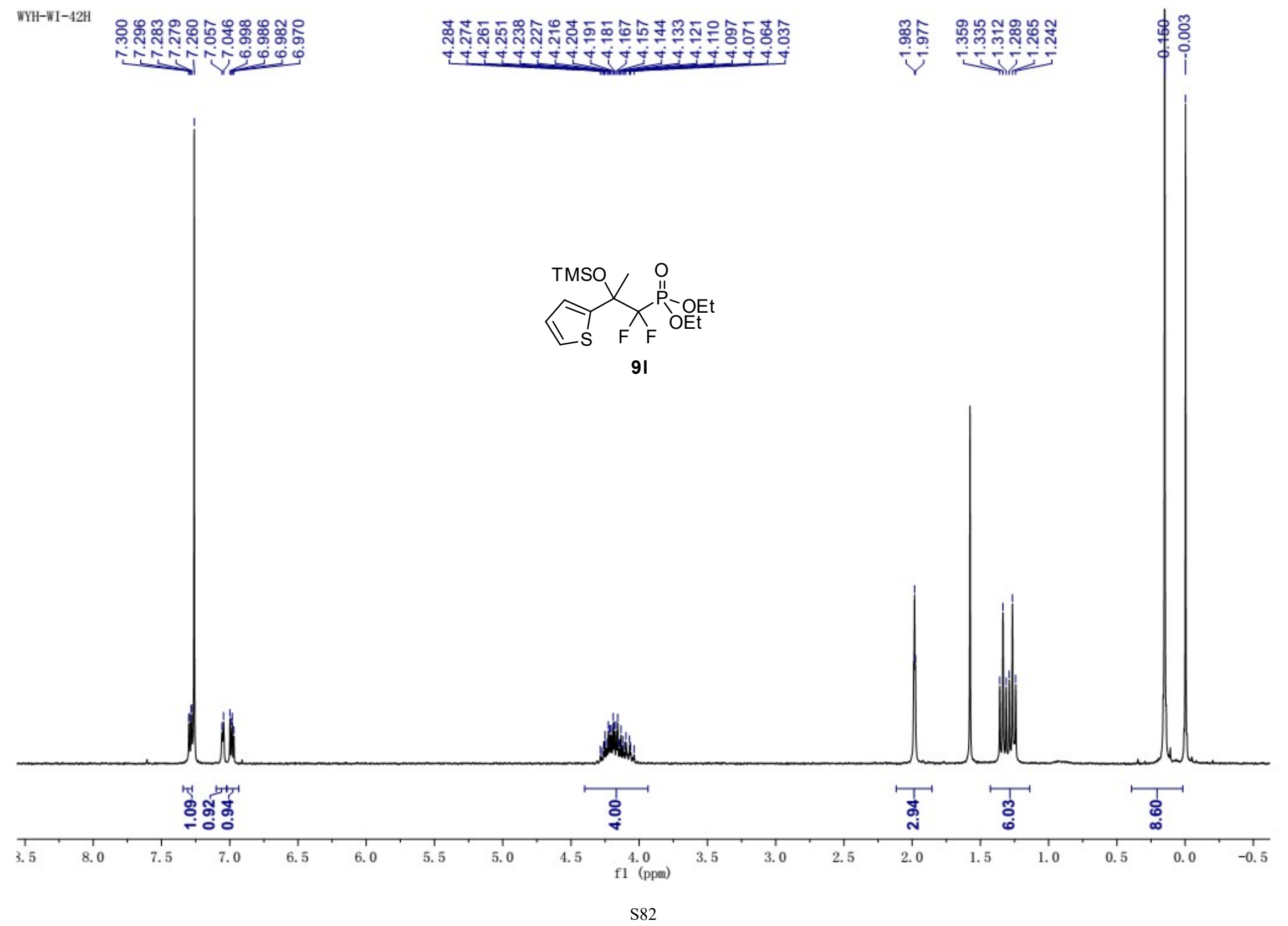



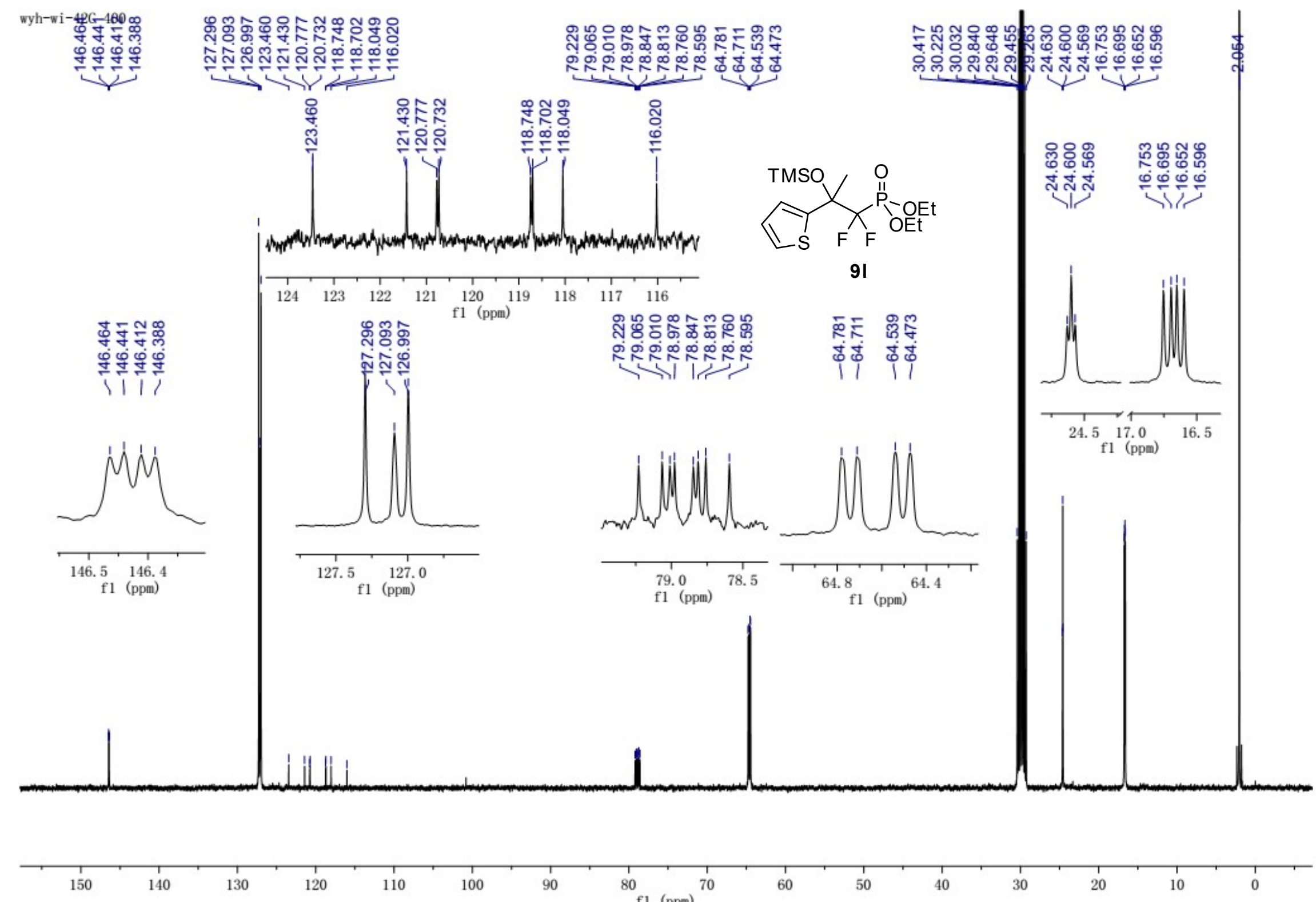

S83 
年
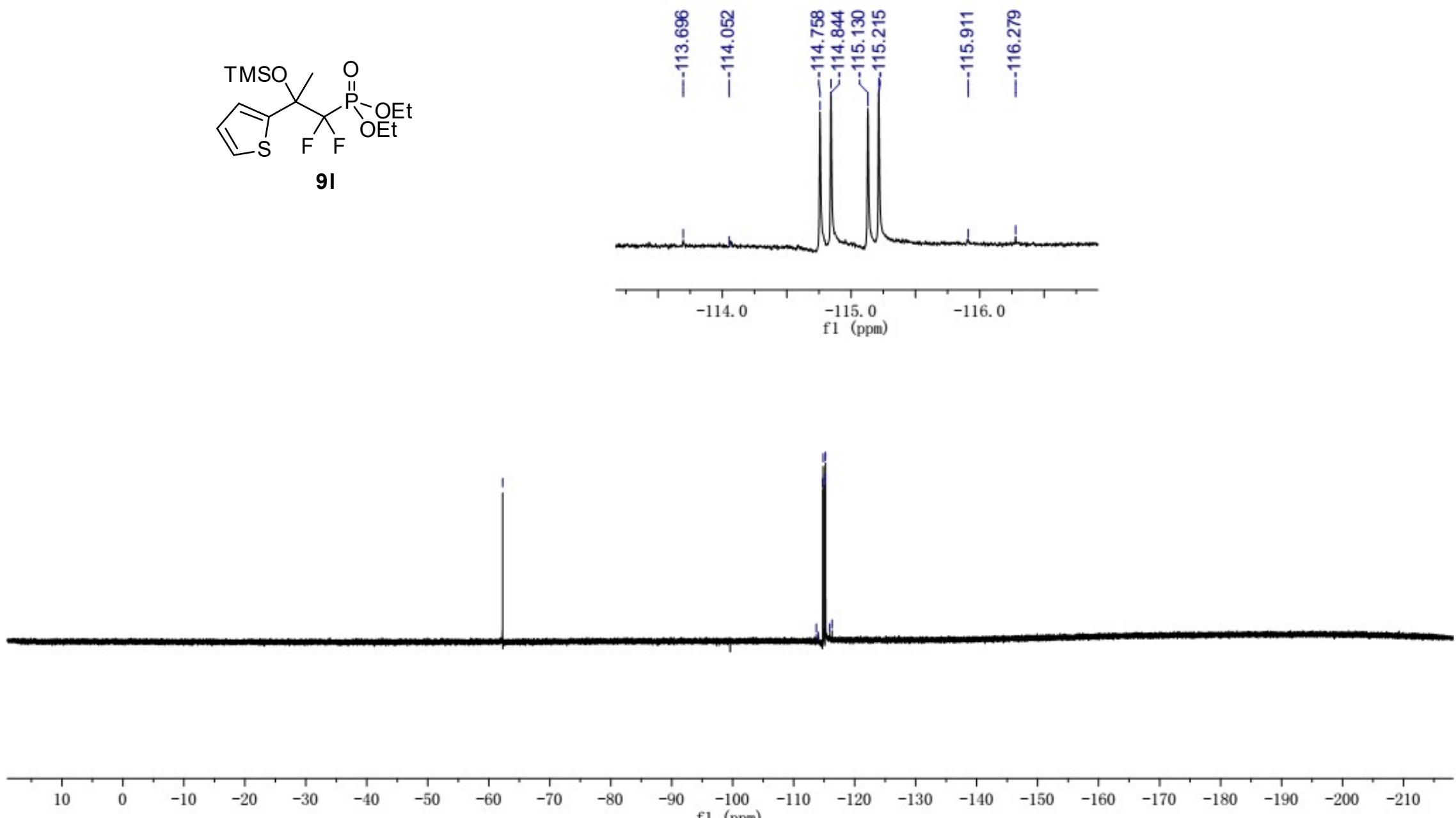


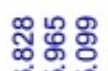

i ம
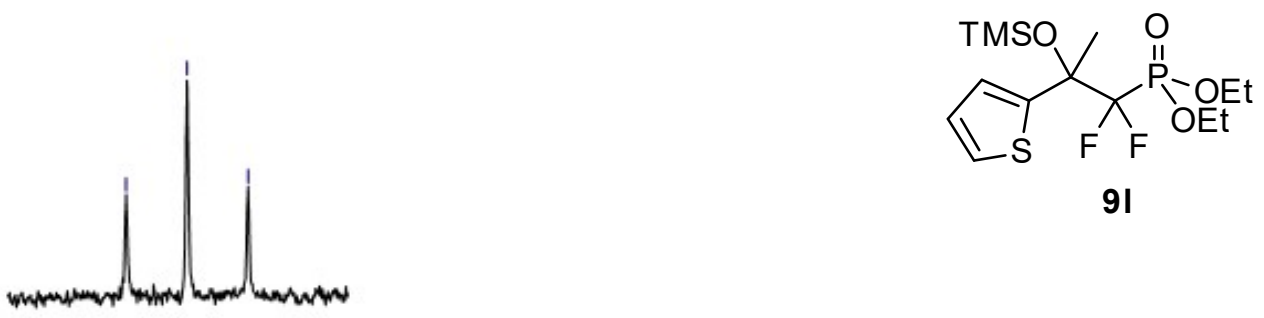

9l
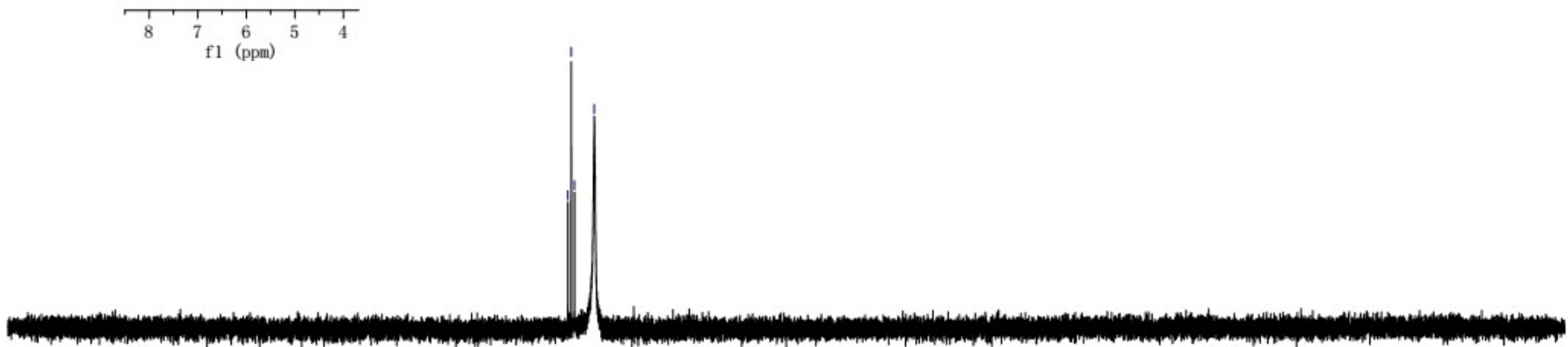

$T_{50}^{1}+130+110$ $\begin{array}{llllllllll}90 & 80 & 70 & 60 & 50 & 40 & 30 & 20 & 10 & 0\end{array}$ 
wyh-wi-50H

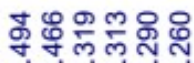

inivi

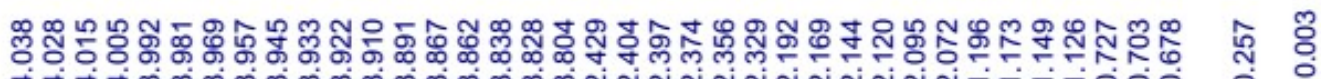

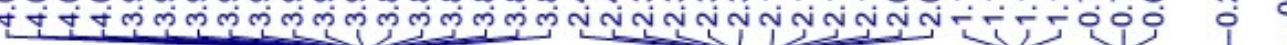

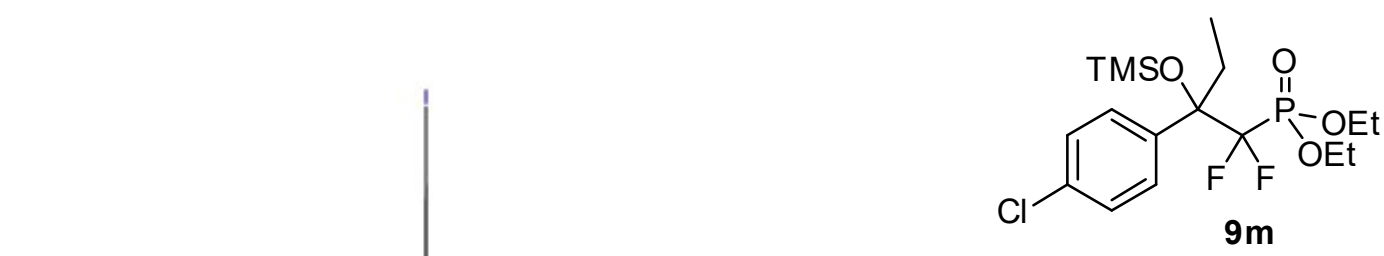

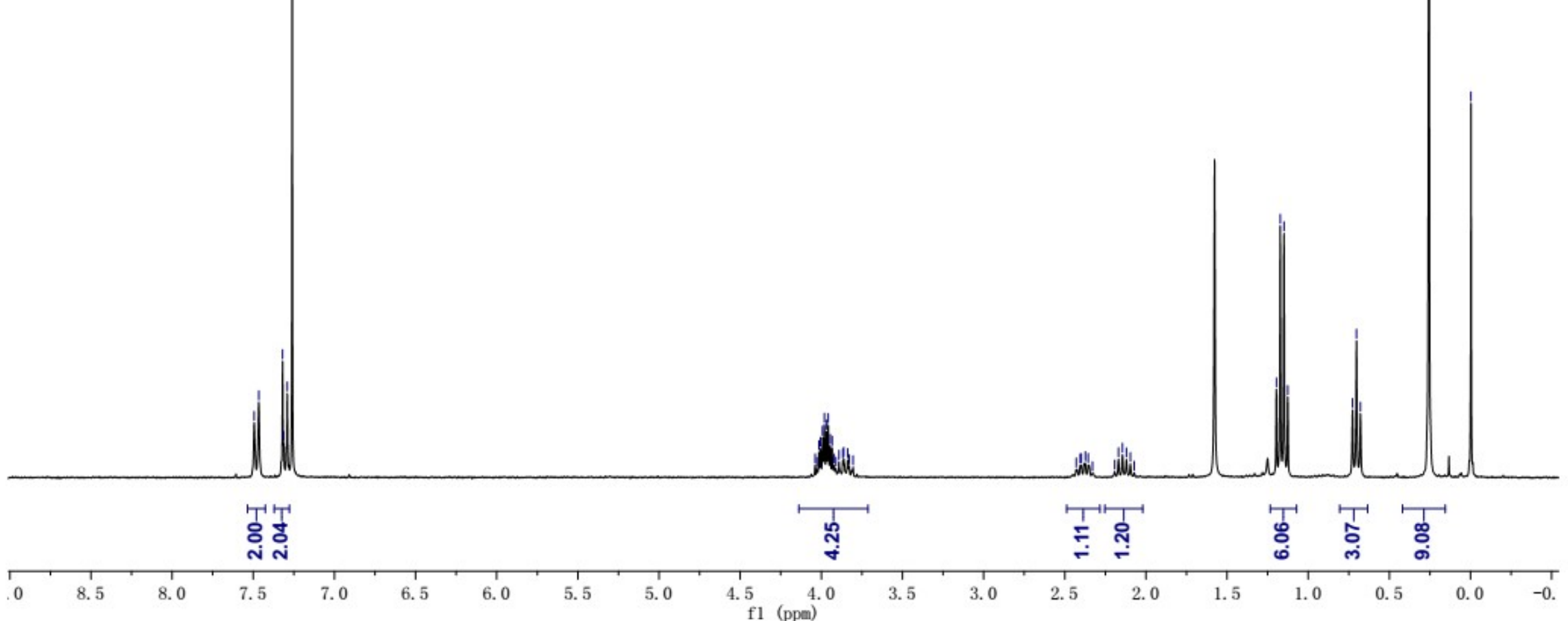

S86 


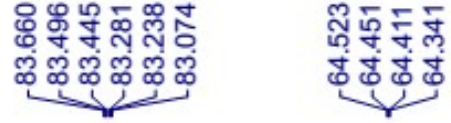

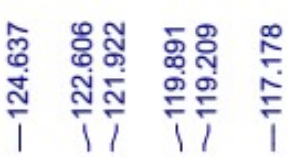

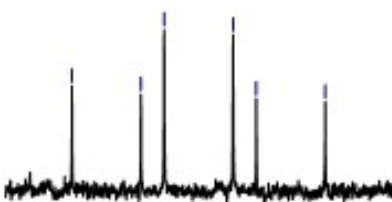

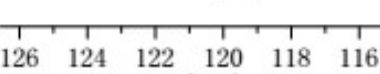

f1 (ppm) 18

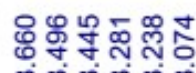
留留留留算留

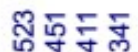

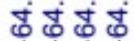
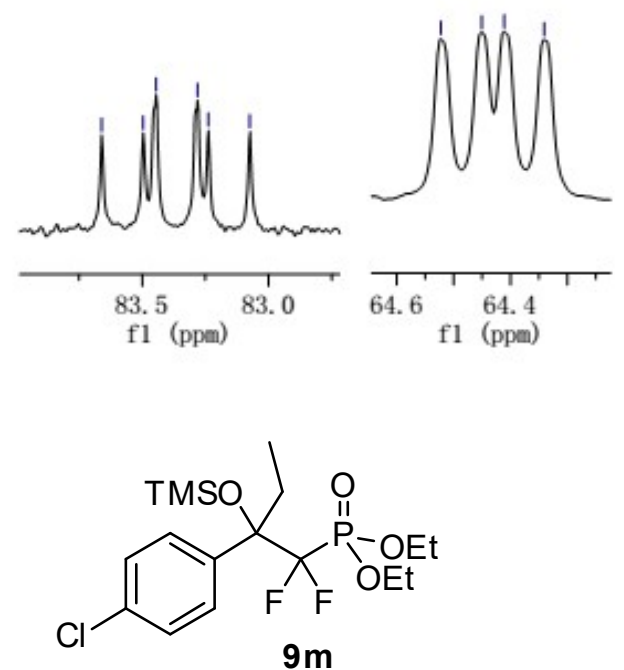

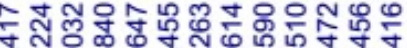
잉.

近i

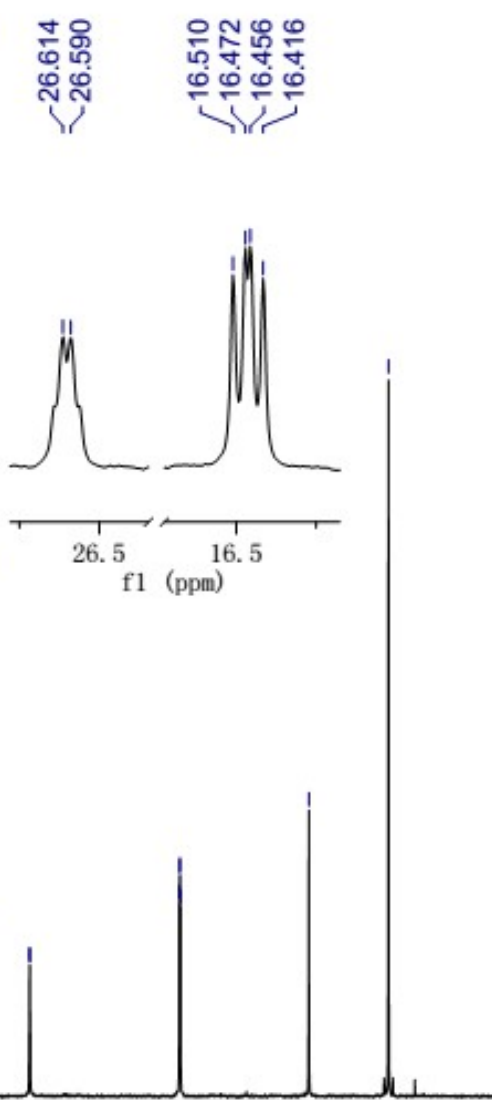

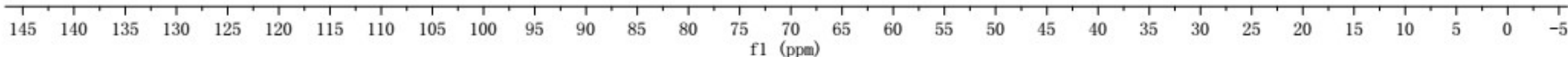




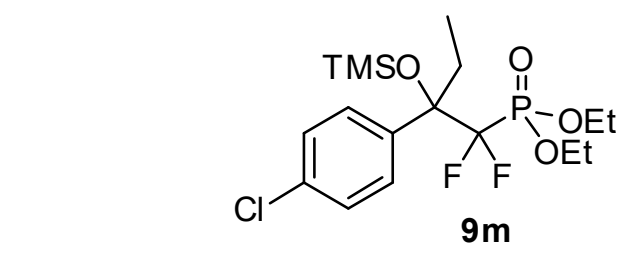

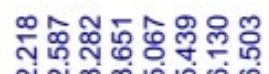

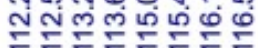

运证

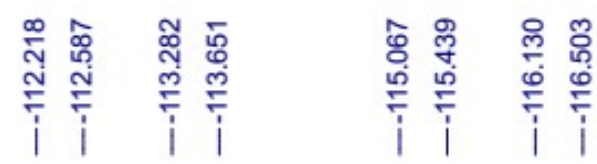
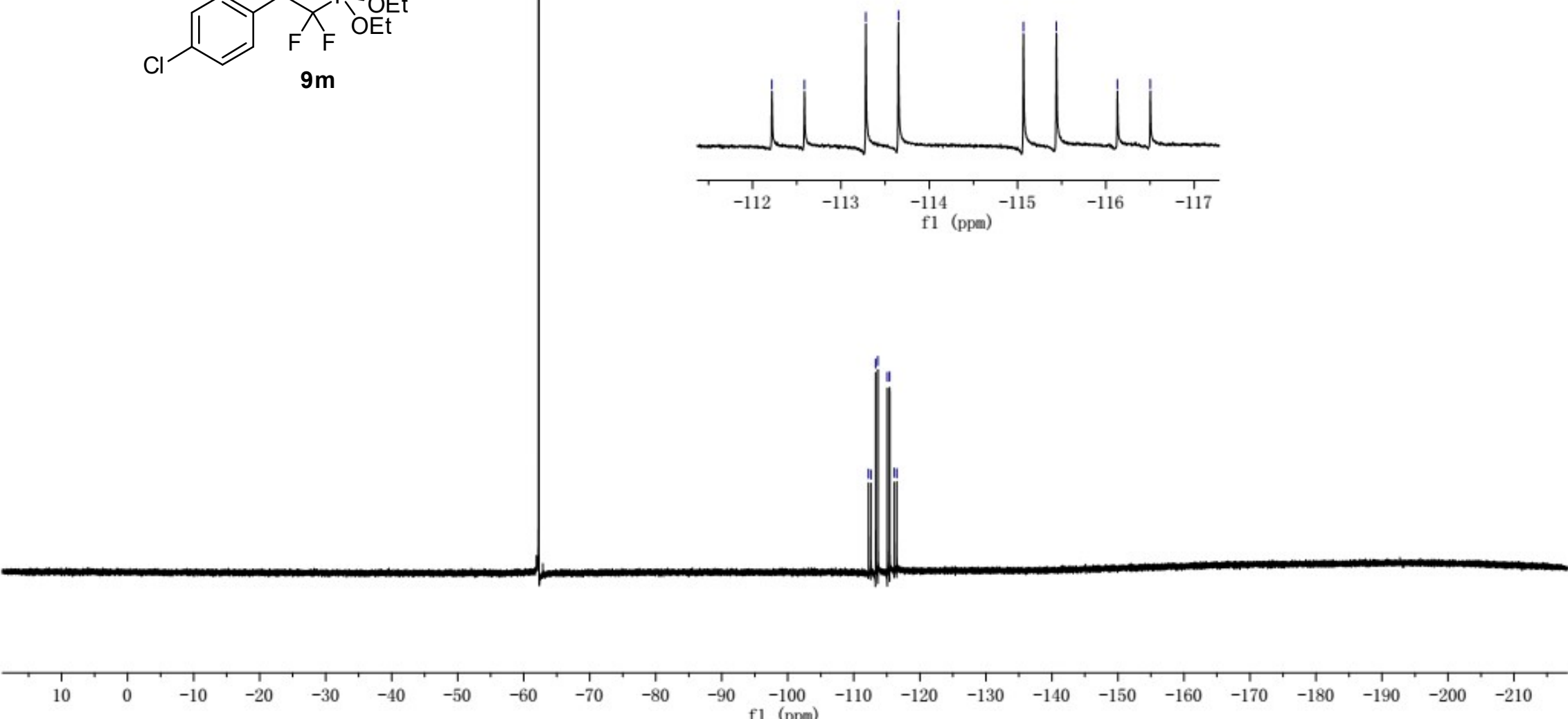

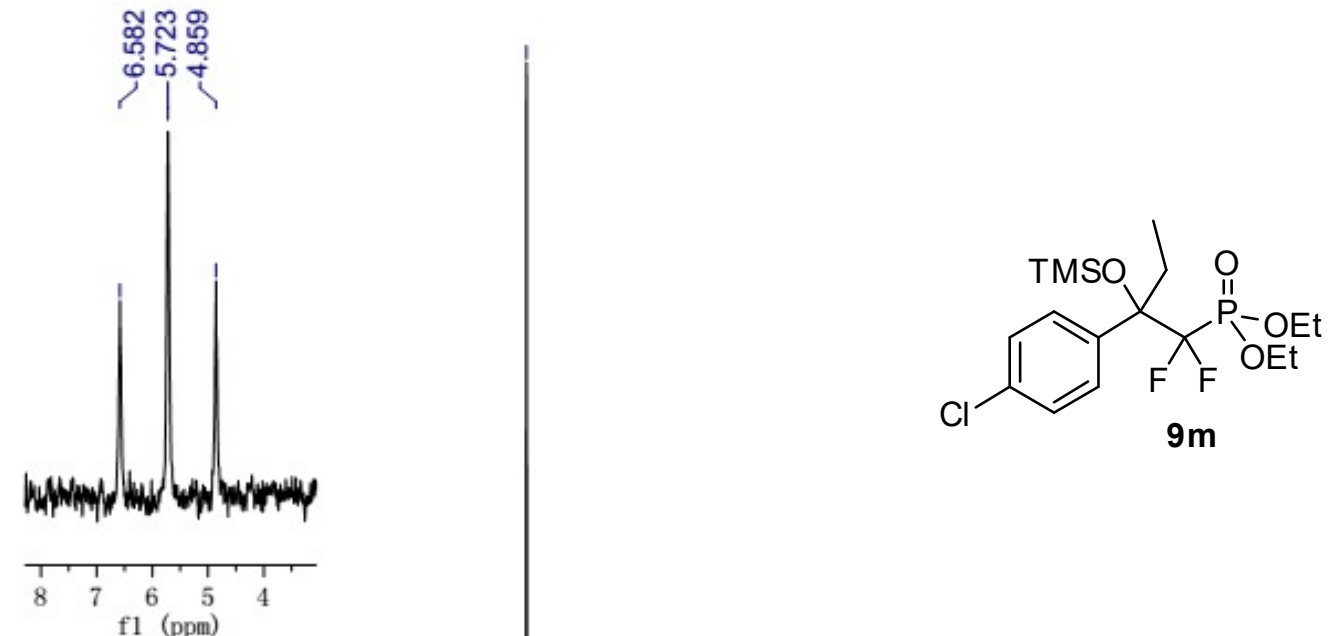

$9 \mathrm{~m}$ 

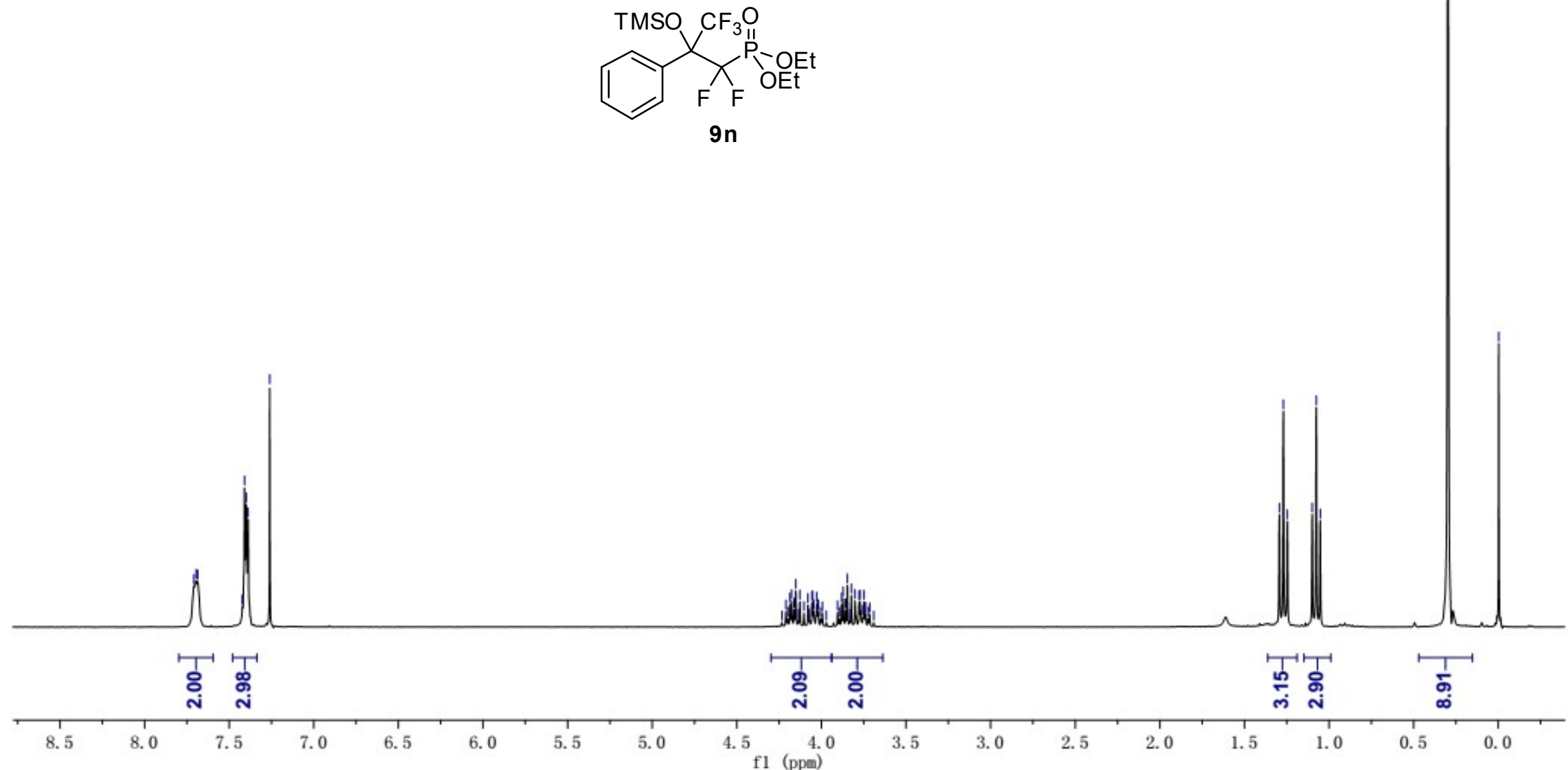


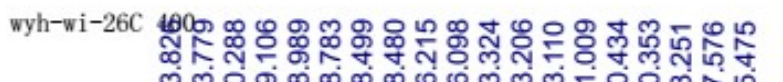

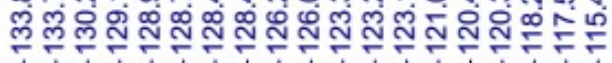

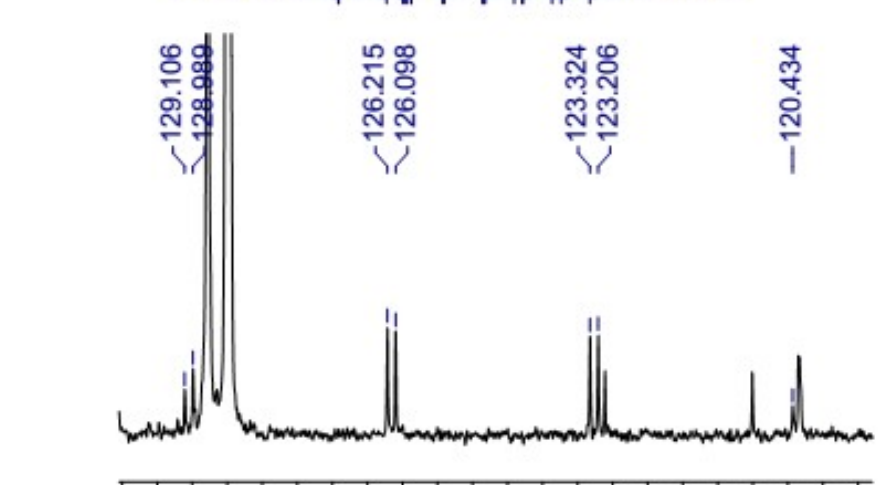

\begin{tabular}{cccccccccccc}
\hline & 130 & 129 & 128 & 127 & 126 & 125 & 124 & 123 & 122 & 121 & 120
\end{tabular} $\begin{array}{lllllll}130 & 129 & 128 & 127 & 126 & 125 & 124 \\ \text { f1 (ppm) }\end{array}$

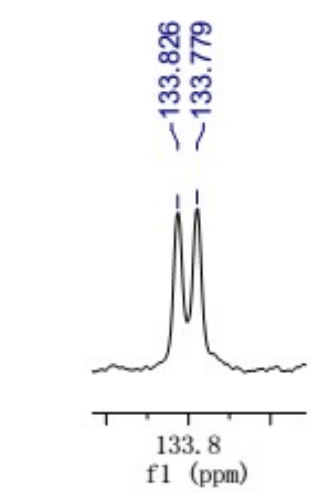<smiles>CCOP(=O)(OCC)C(F)(F)C(F)(c1ccccc1)C(F)(F)F</smiles>

9n

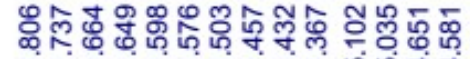

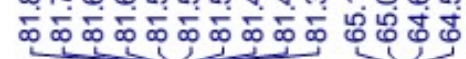

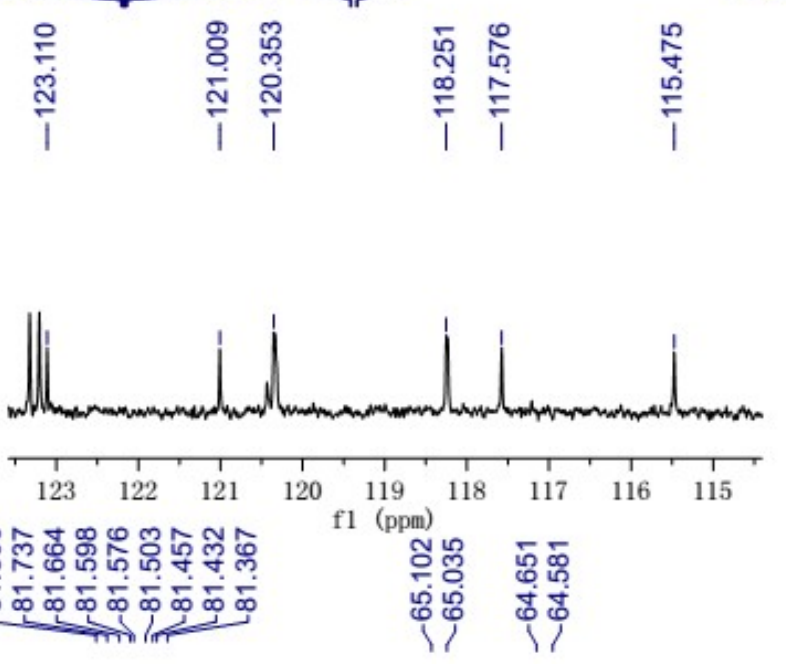

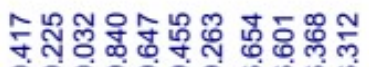

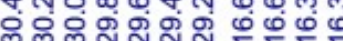

$\frac{10}{1}$

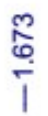
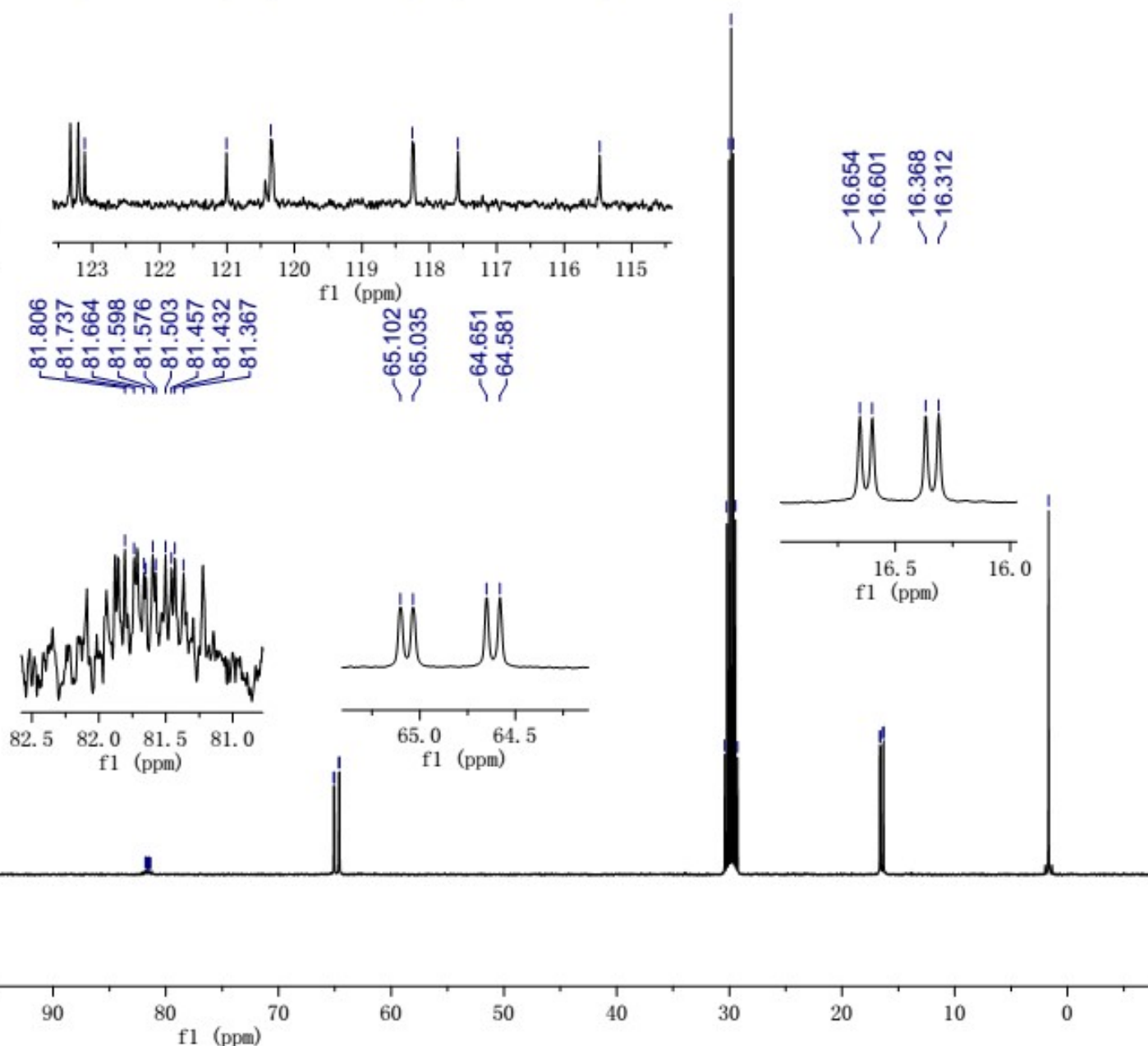

60

50 


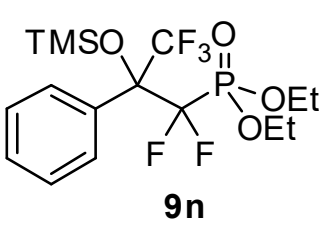

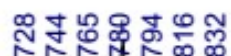
@

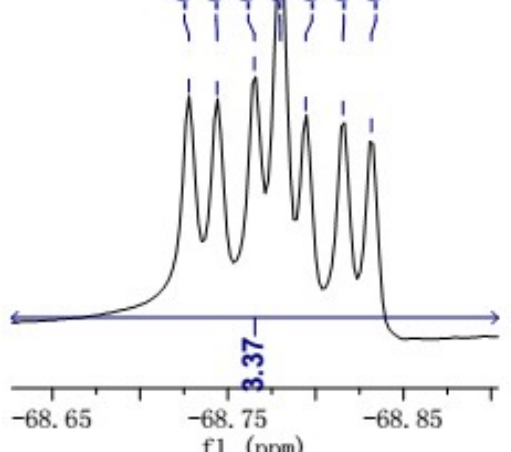

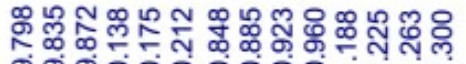

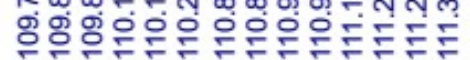

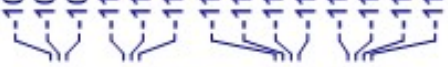

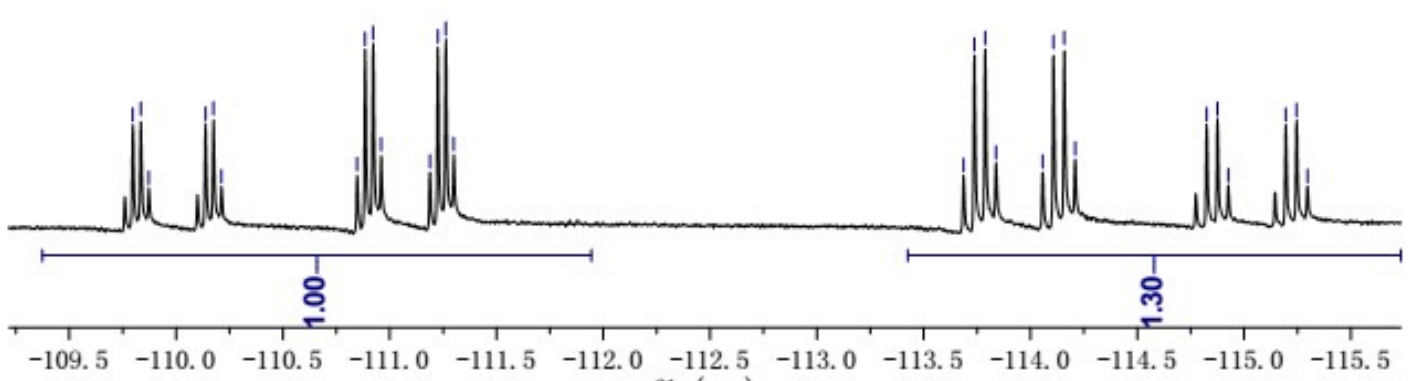

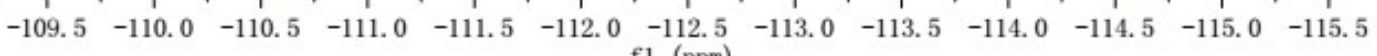
f1 (ppm)

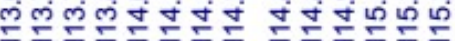
计行拧

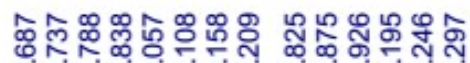

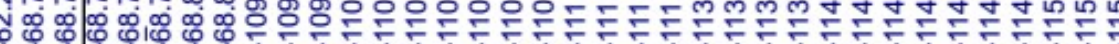

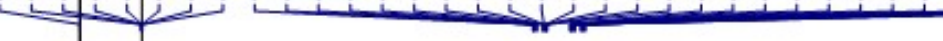

$$
\text { fl (ppm) }
$$

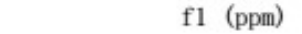




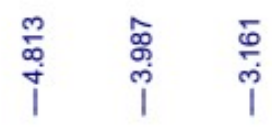

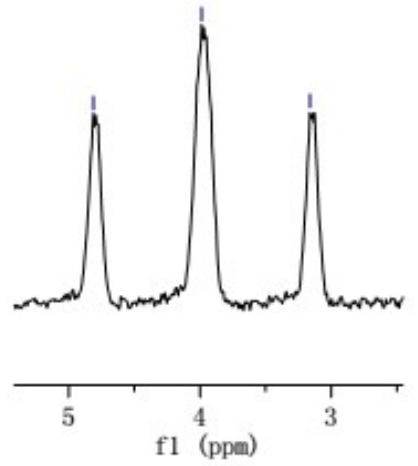

TMSO $\mathrm{CF}_{3} \mathrm{O}$

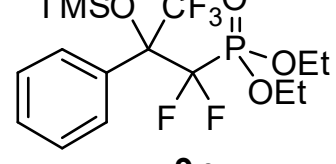




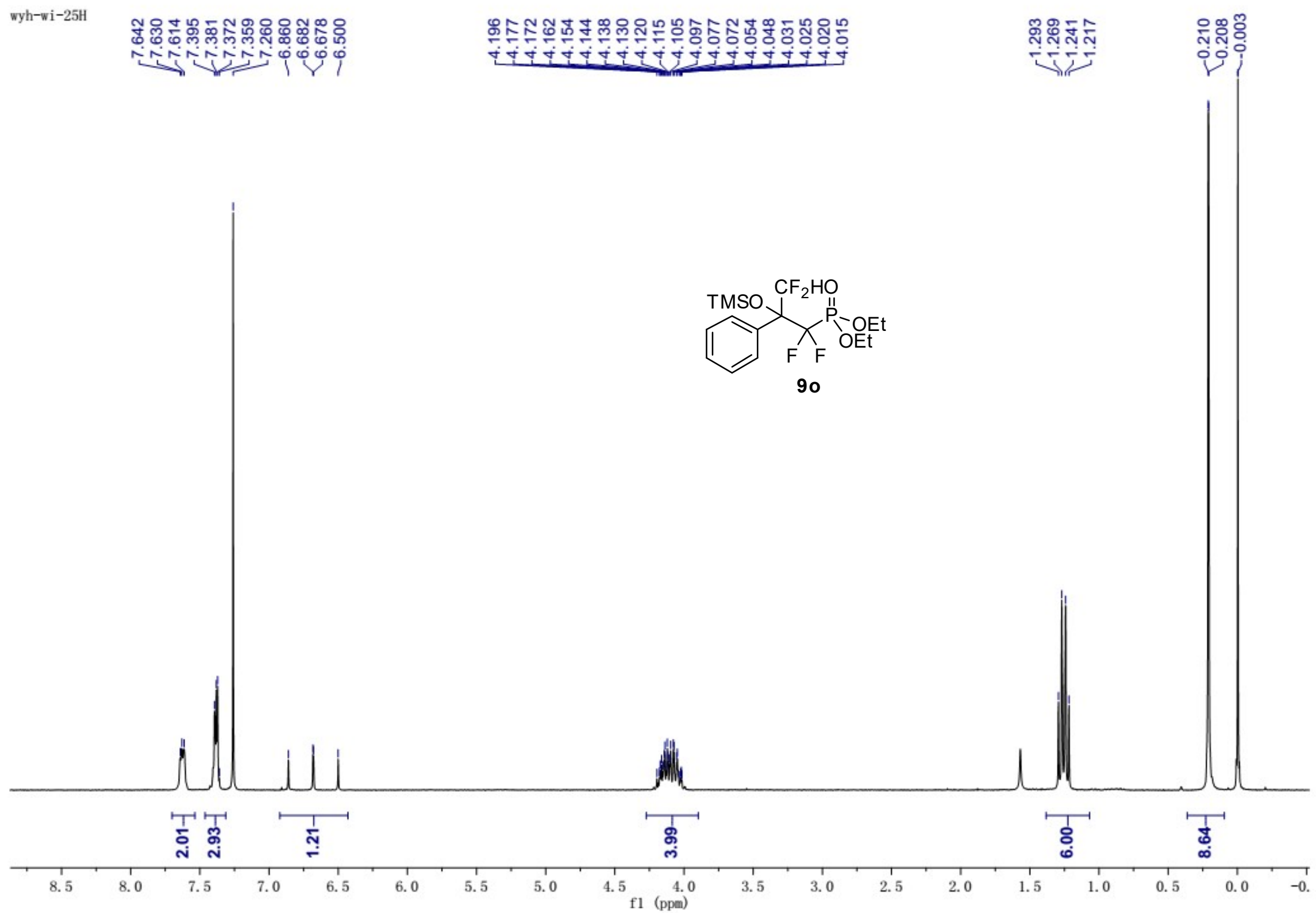



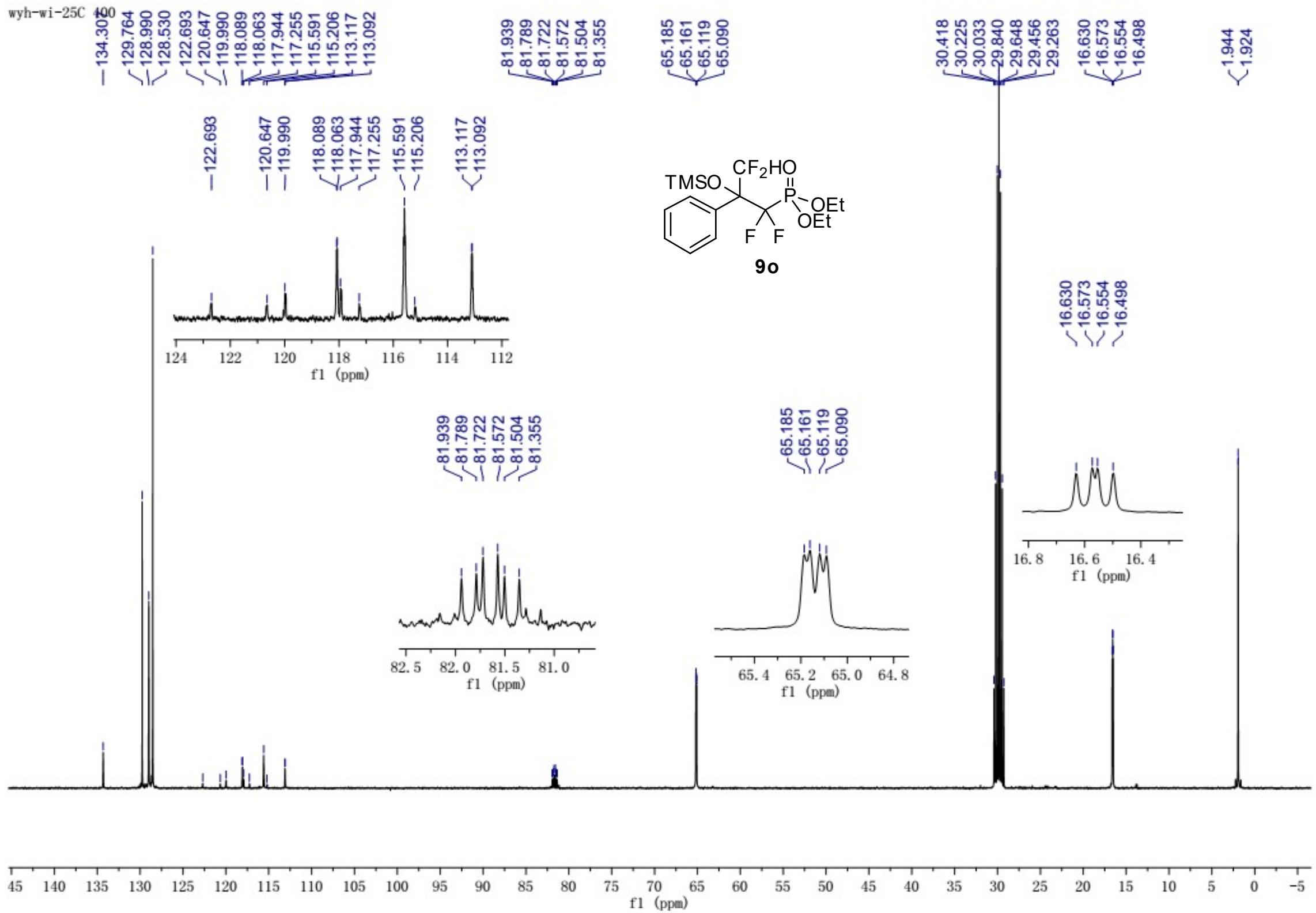


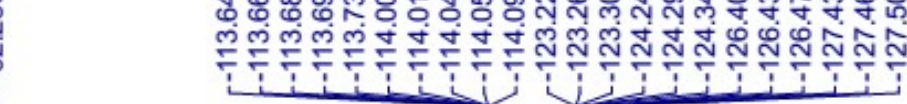
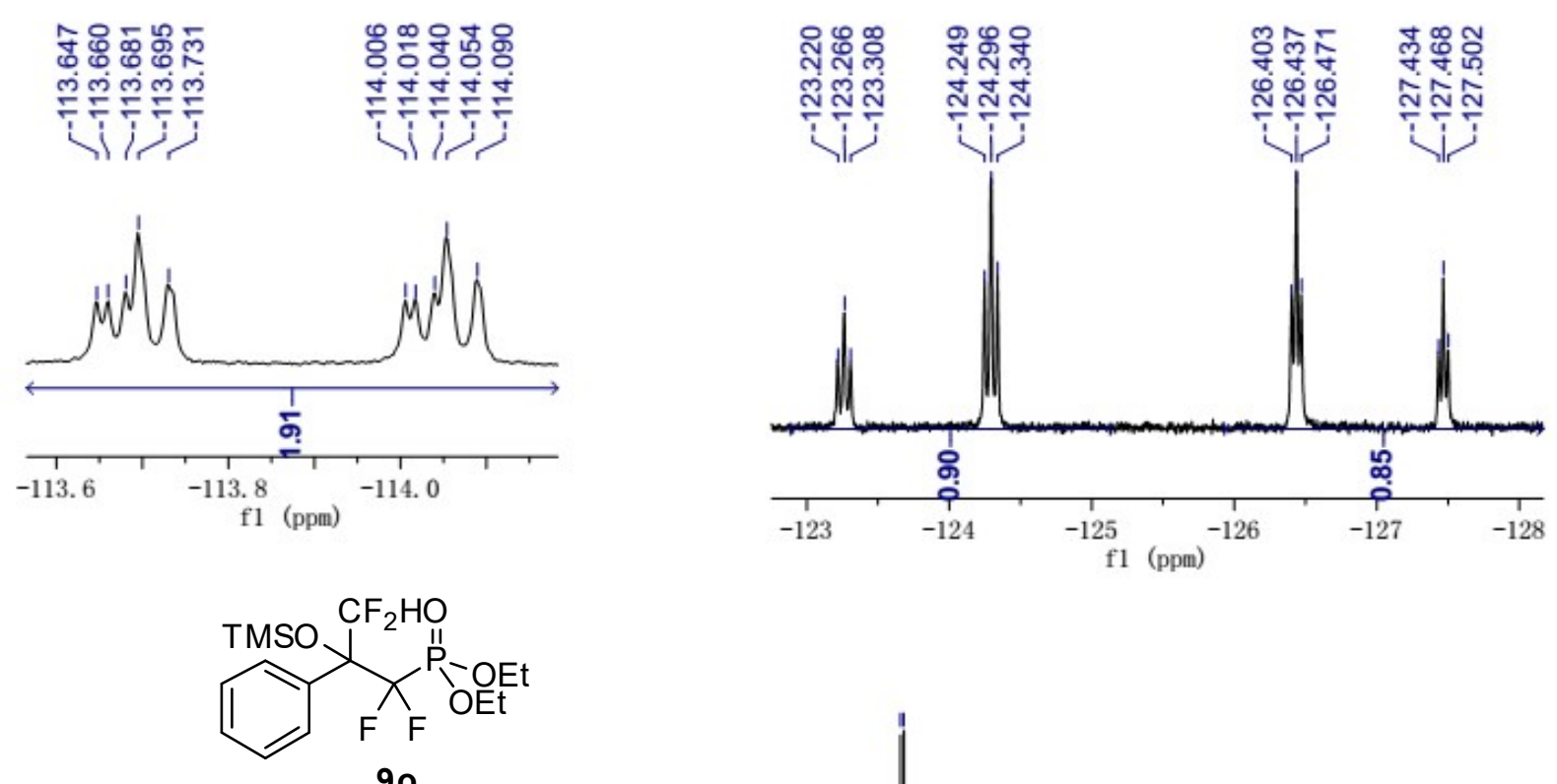

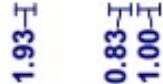

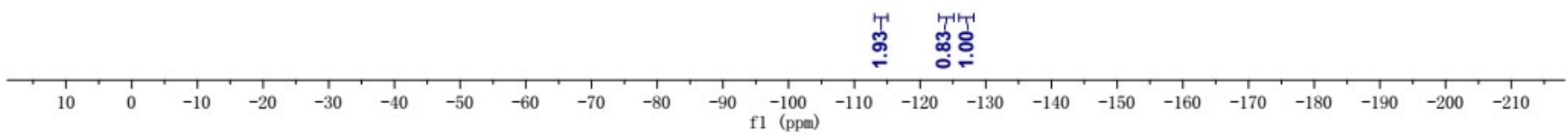


章量

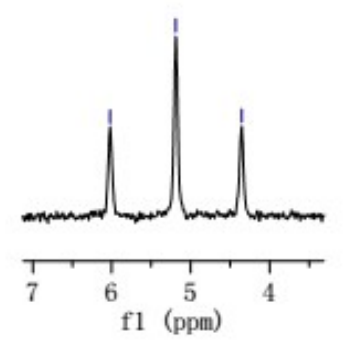

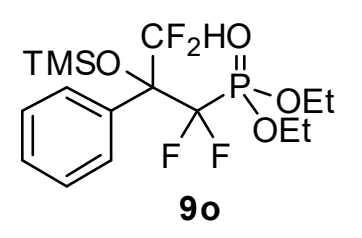

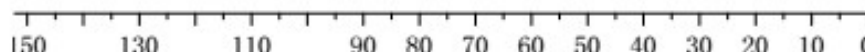

-40 (pm) 

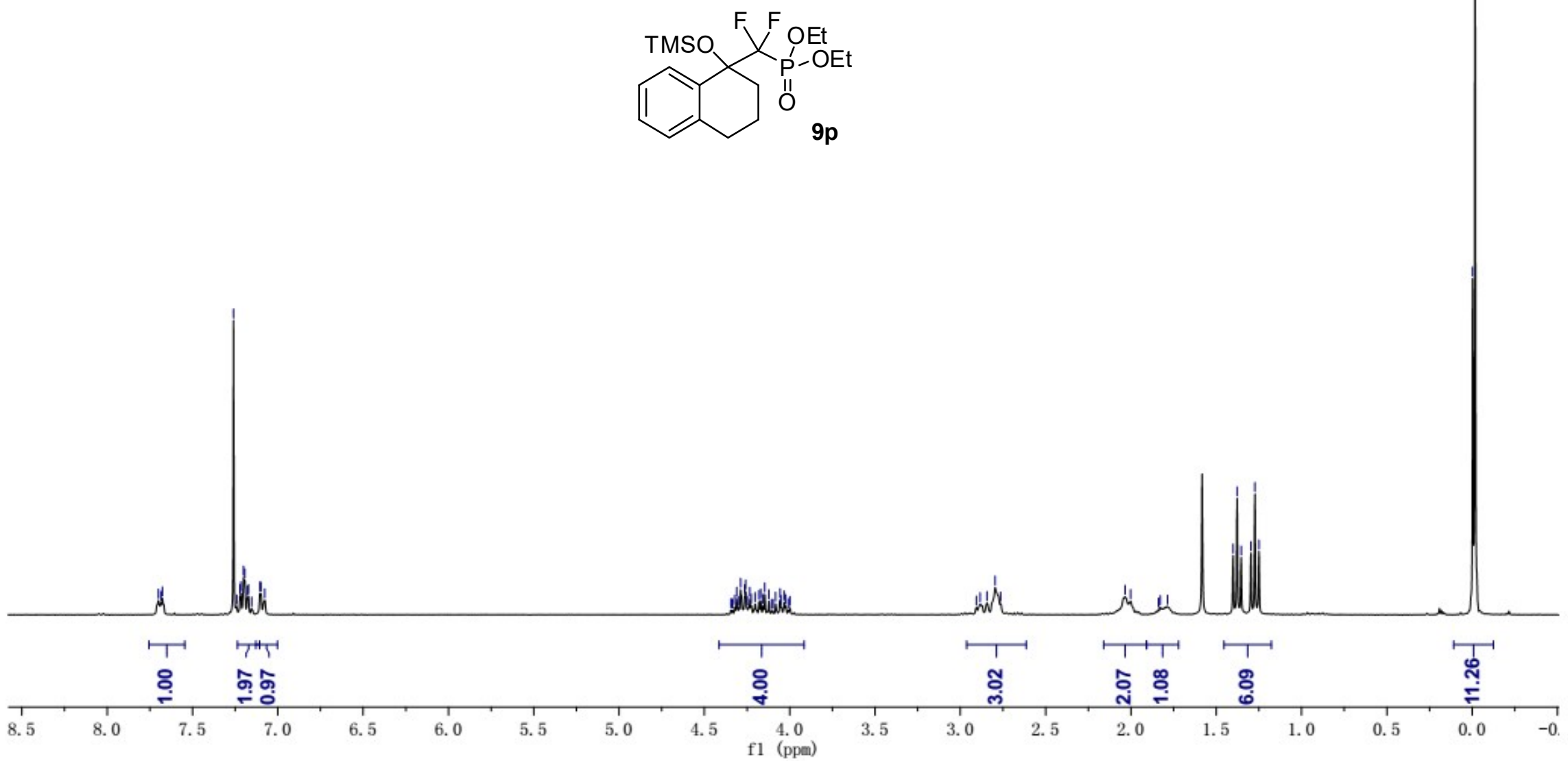


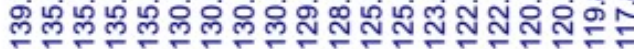
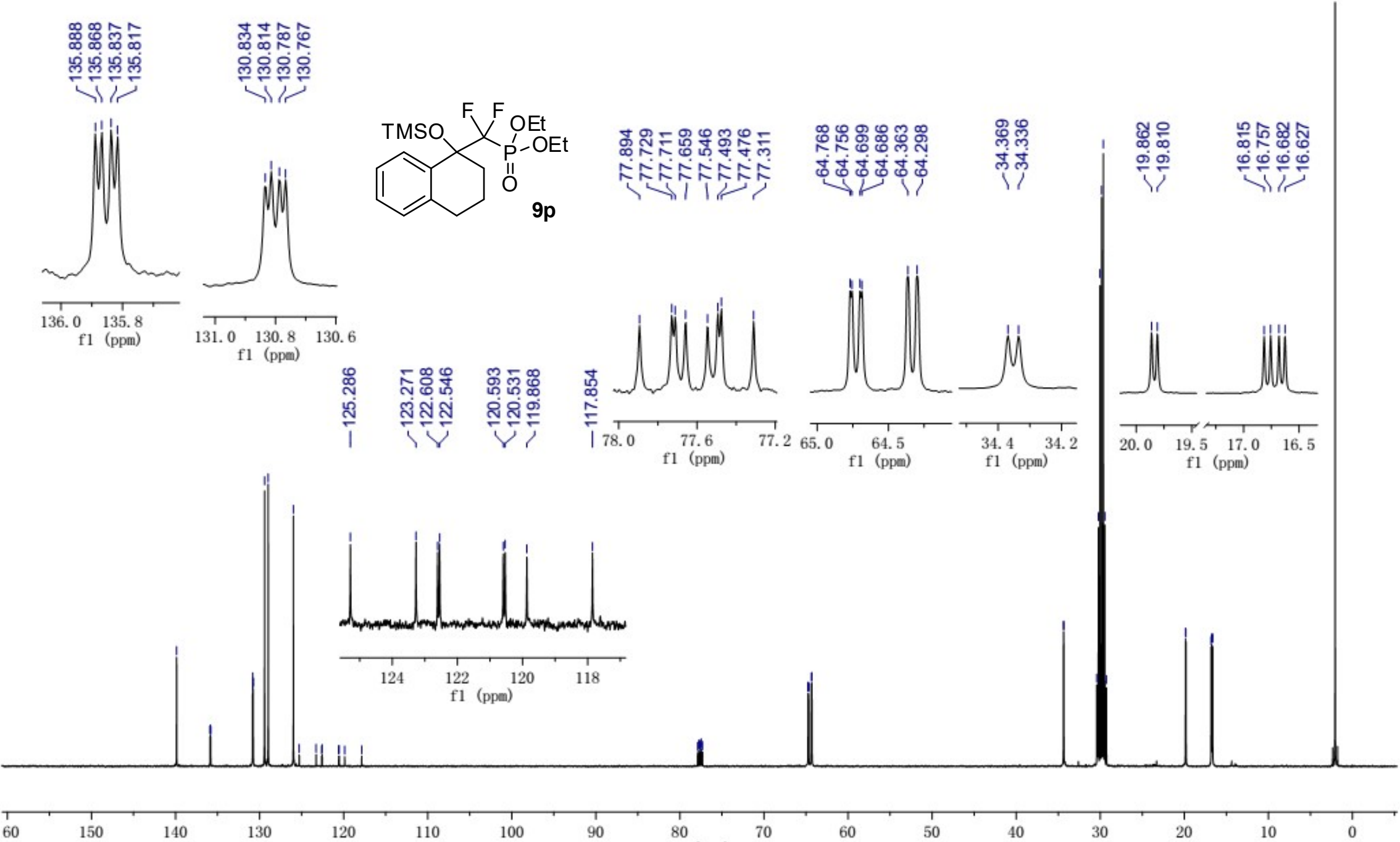

120

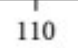

100

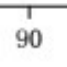

80

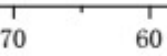

S99 


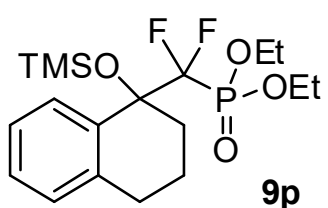

$9 p$
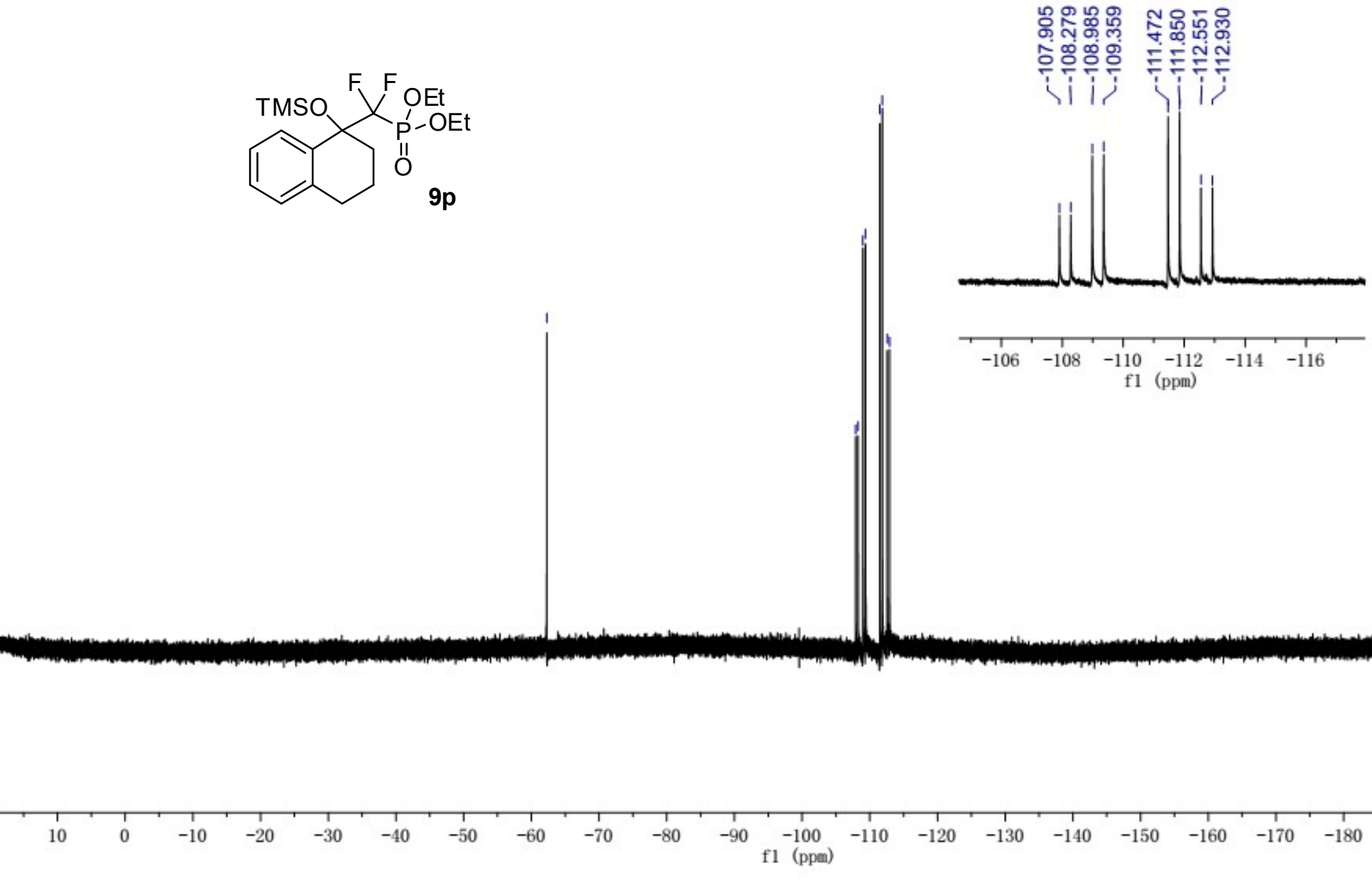


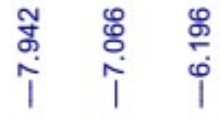
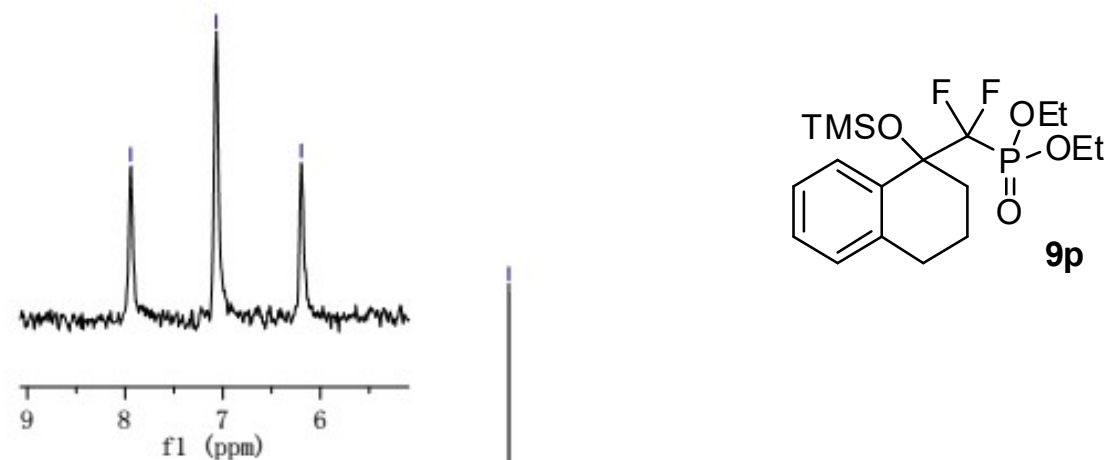


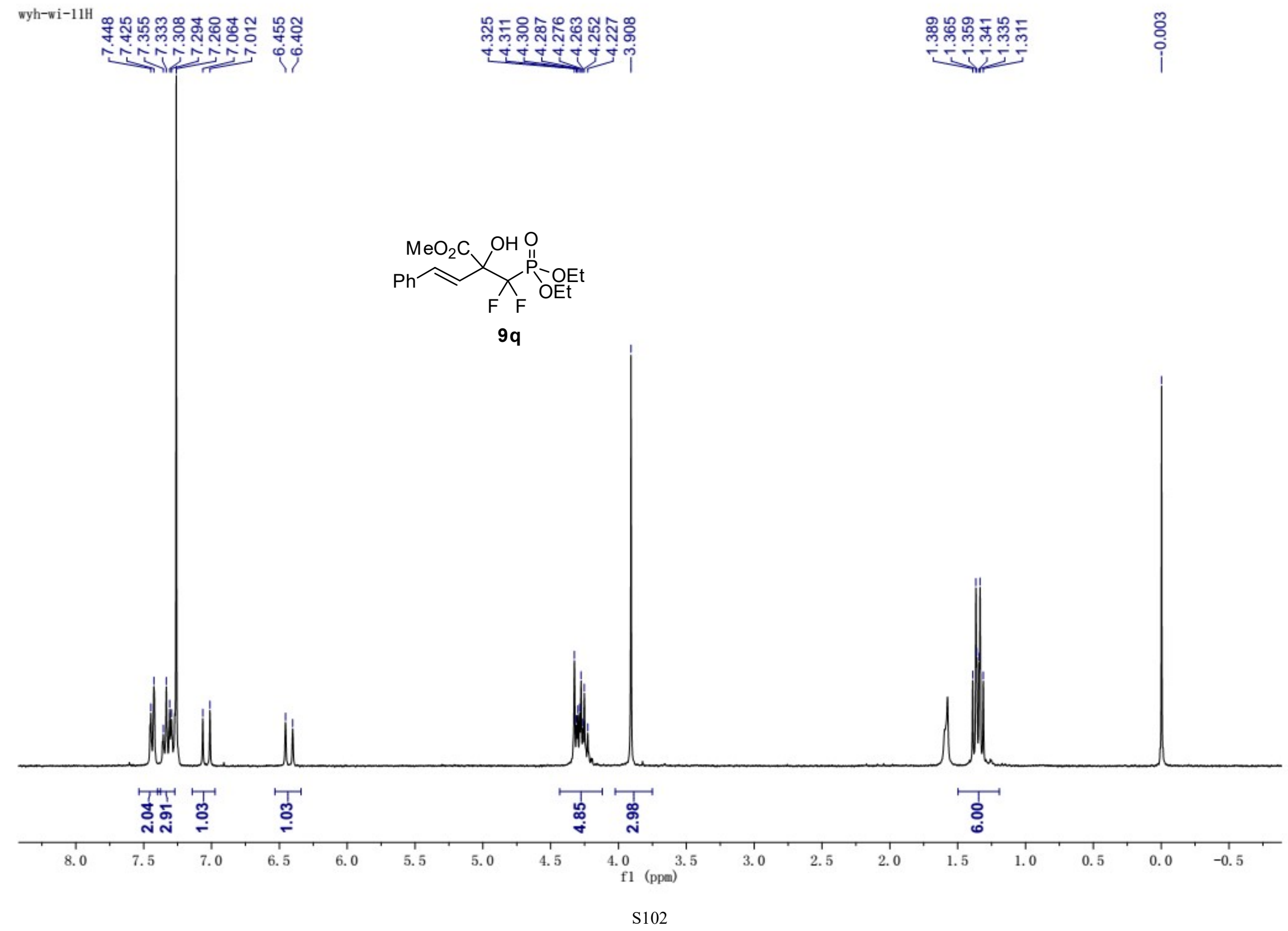



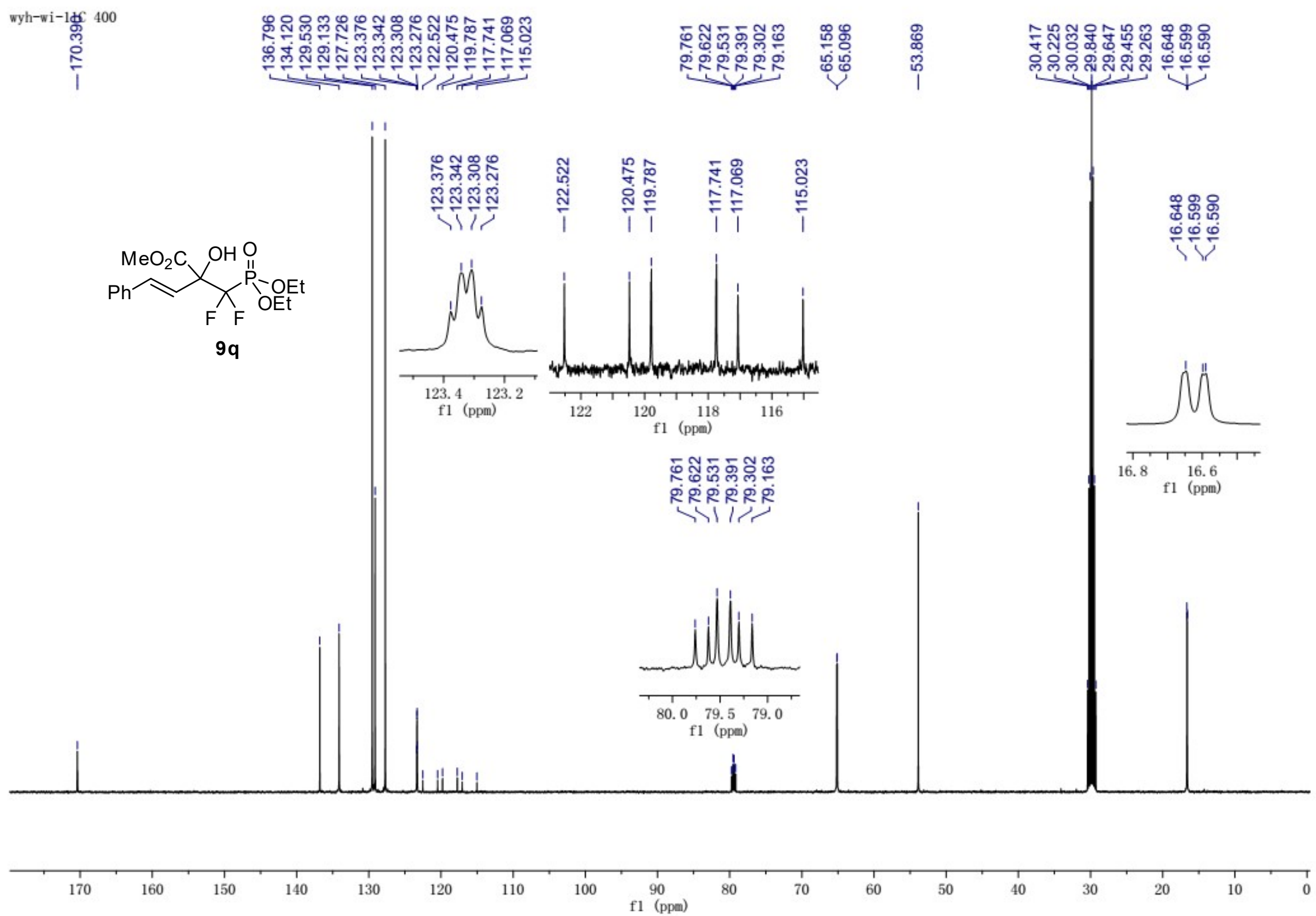


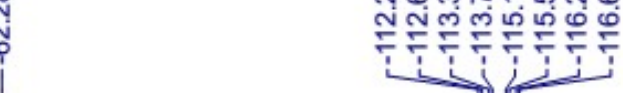

$\mathrm{MeO}_{2} \mathrm{C} \mathrm{OH}^{\mathrm{O}}$ $\underbrace{P}_{F F} P_{\mathrm{OEEt}}^{\mathrm{P}}$

9q

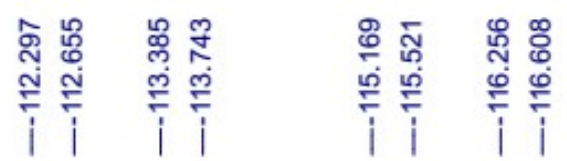
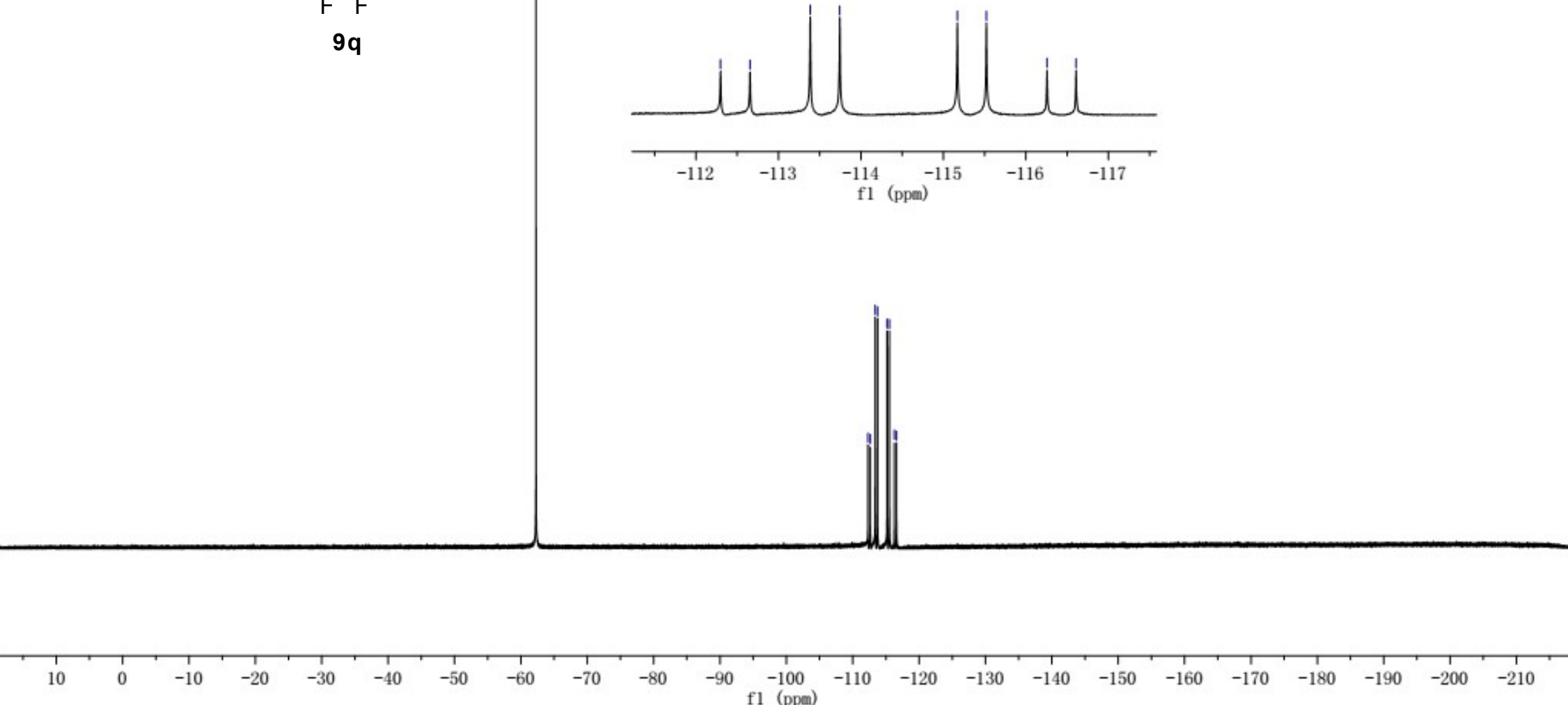

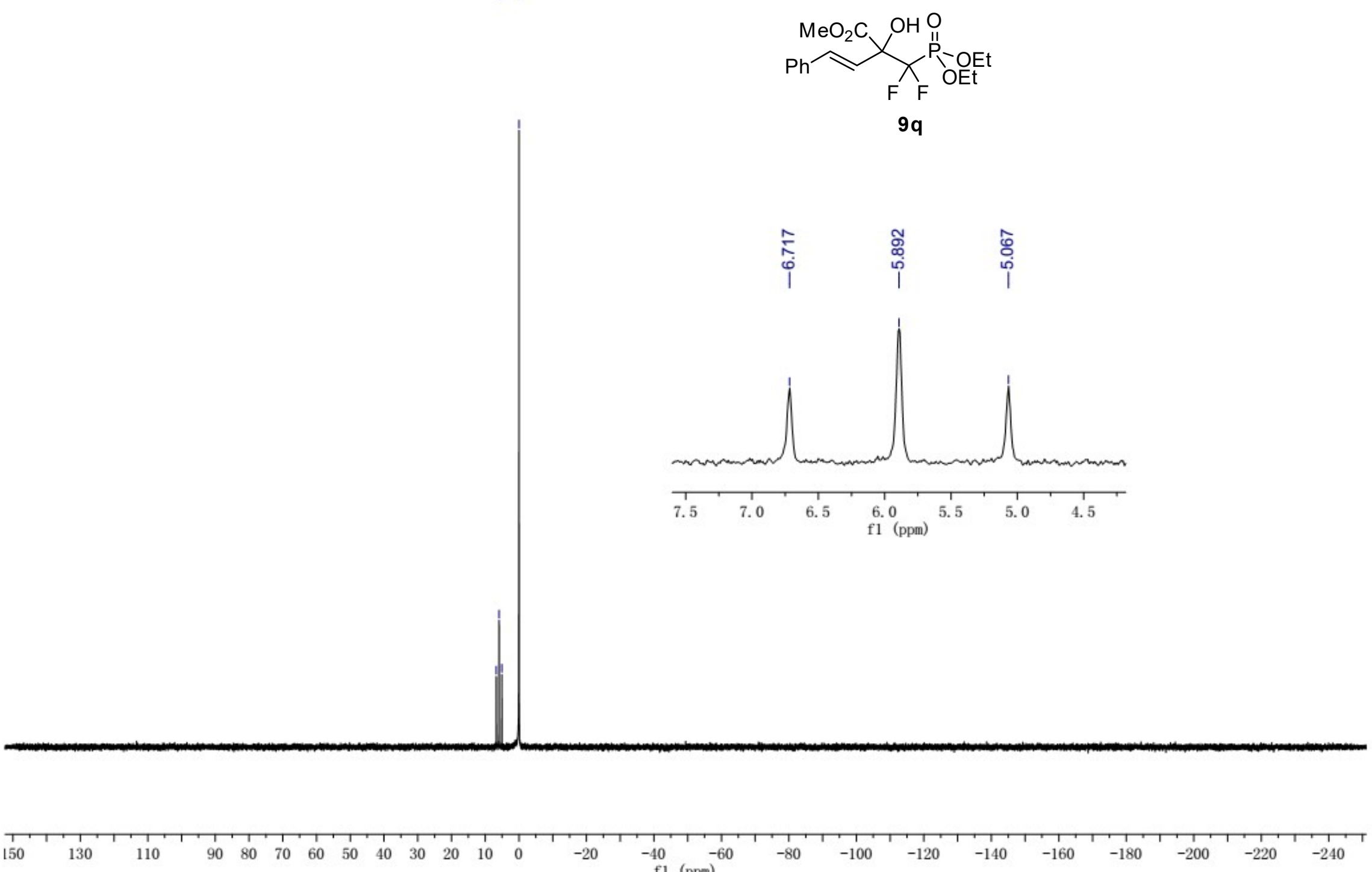
wyh-wi-10H

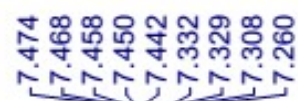

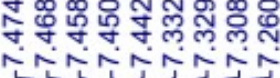

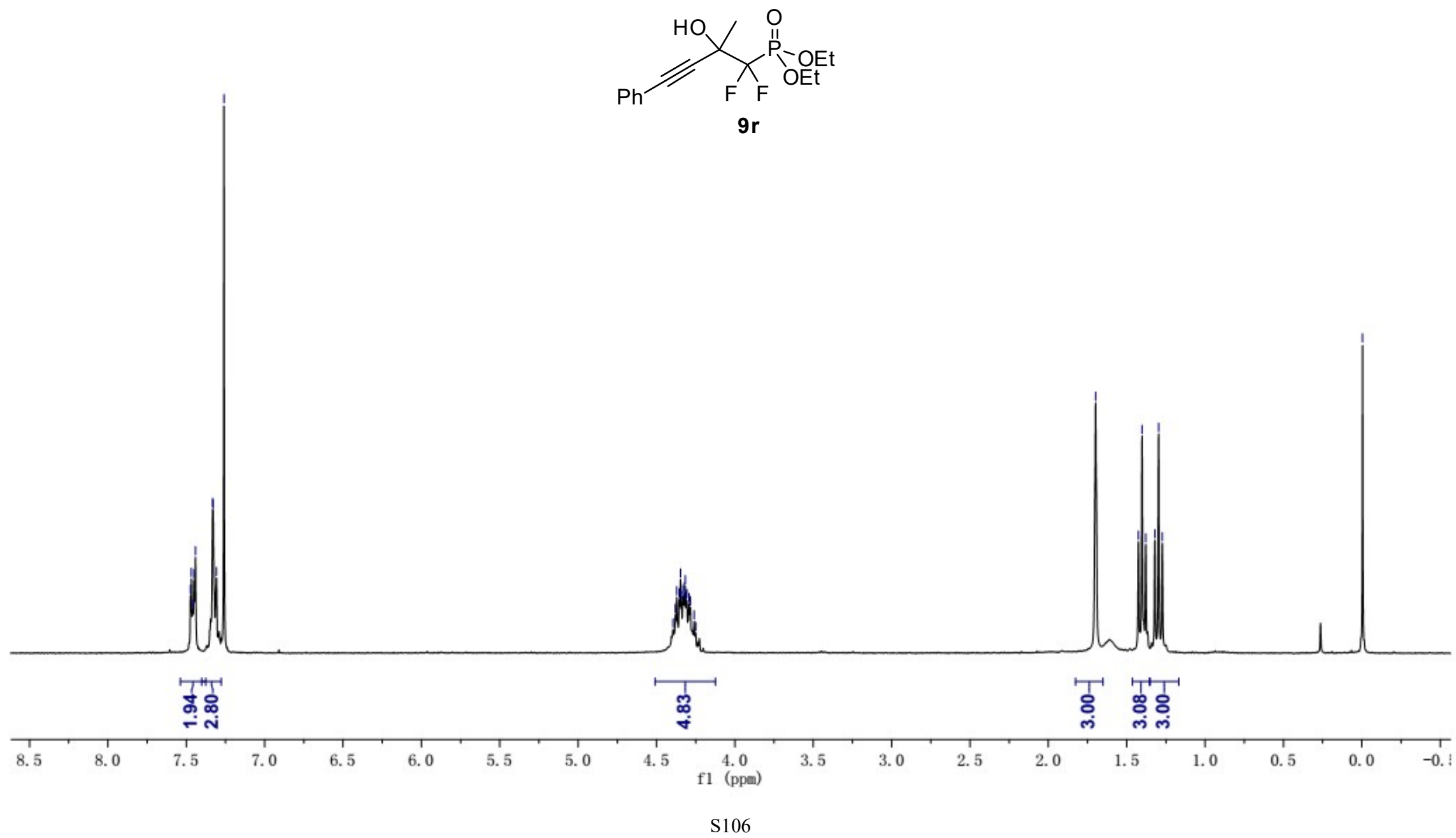

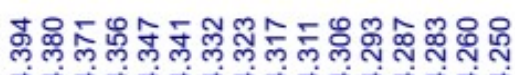

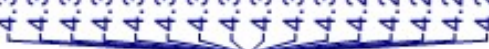

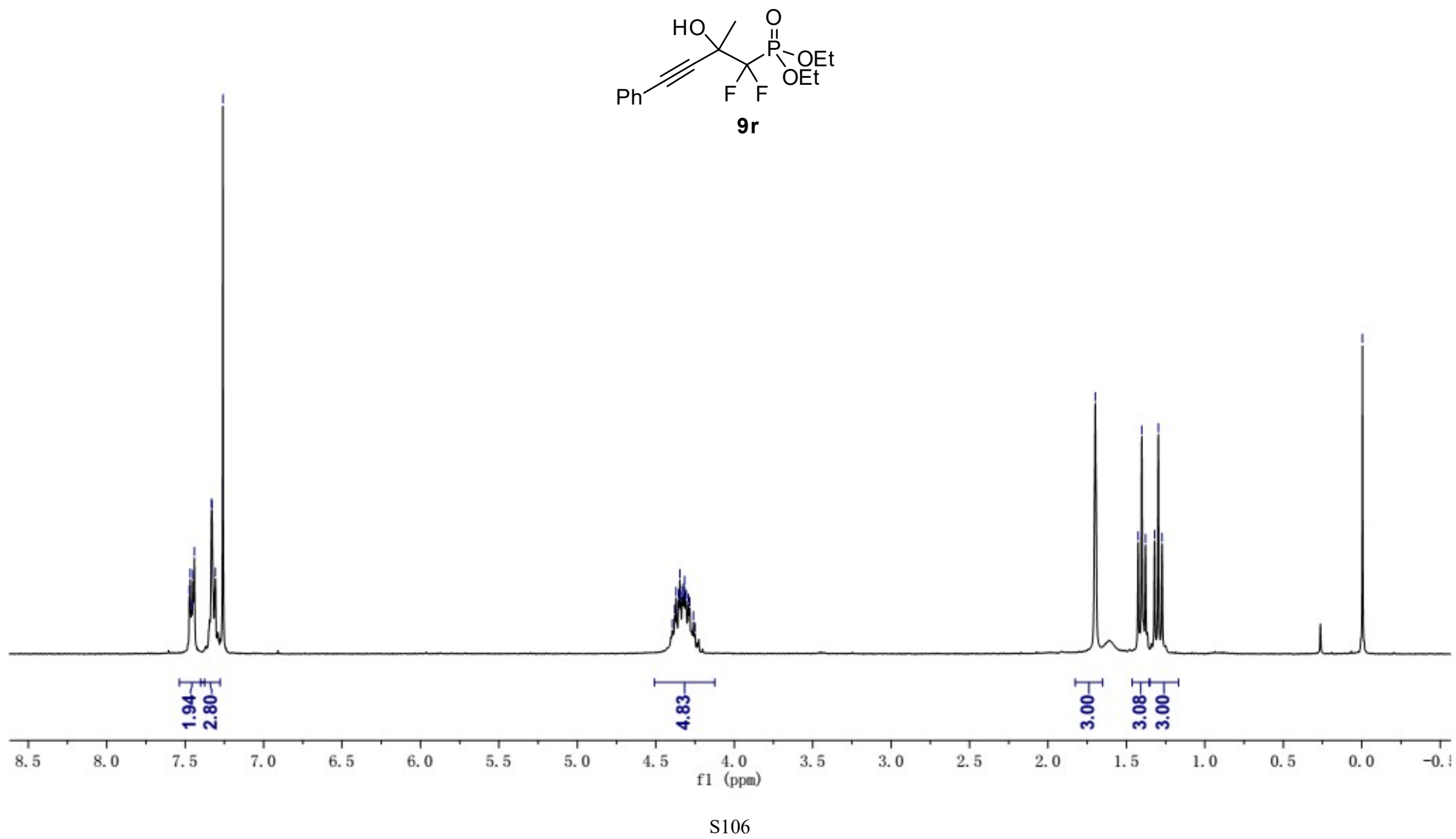

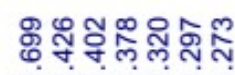

证毕 


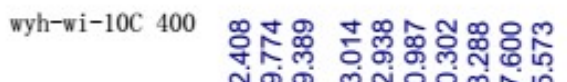

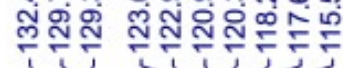

र पiाए

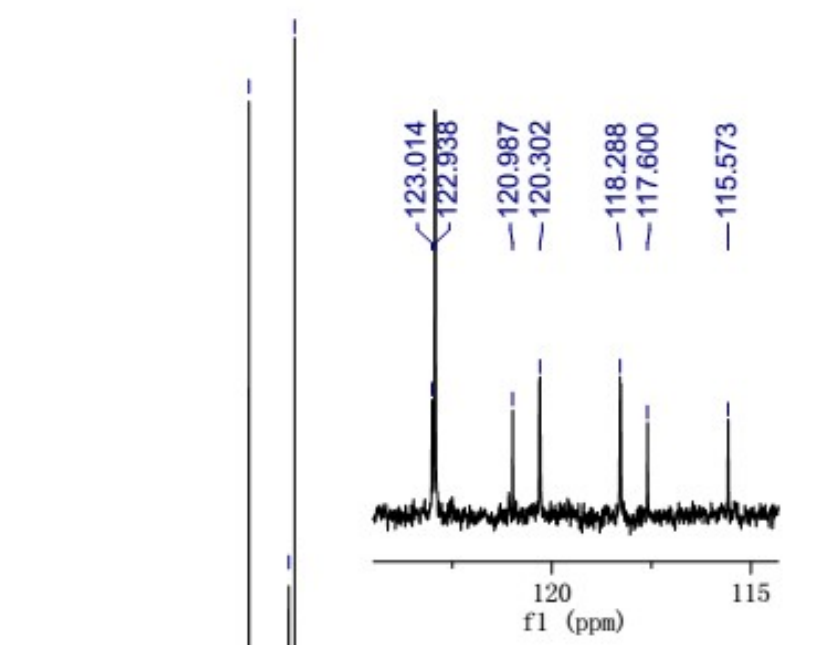

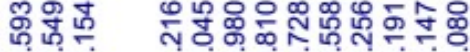

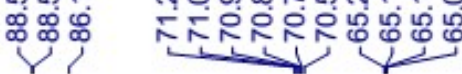

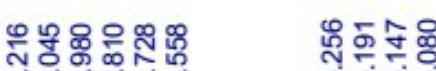

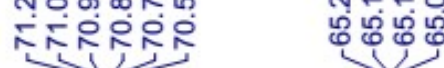

(n)

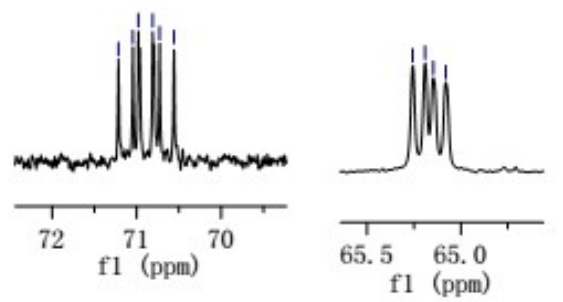

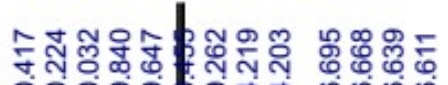

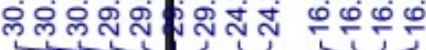

遇遇哭

$\div$

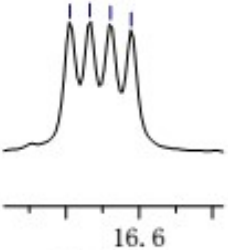

f1 $\begin{array}{r}16.6 \\ \text { ppm) }\end{array}$
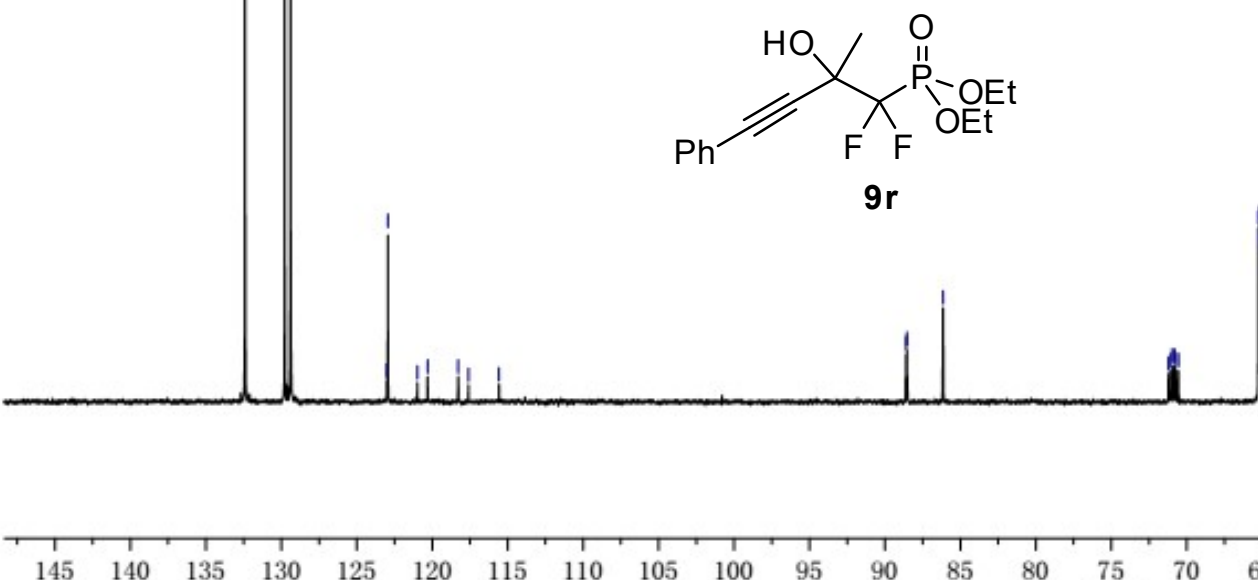

7570

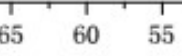

45
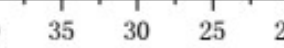

$\begin{array}{lllll}15 & 10 & 1 & 1 \\ & & & \end{array}$ 
wyh-wi-10F (PhCF3) 300

$$
\text { ণัฒ }
$$

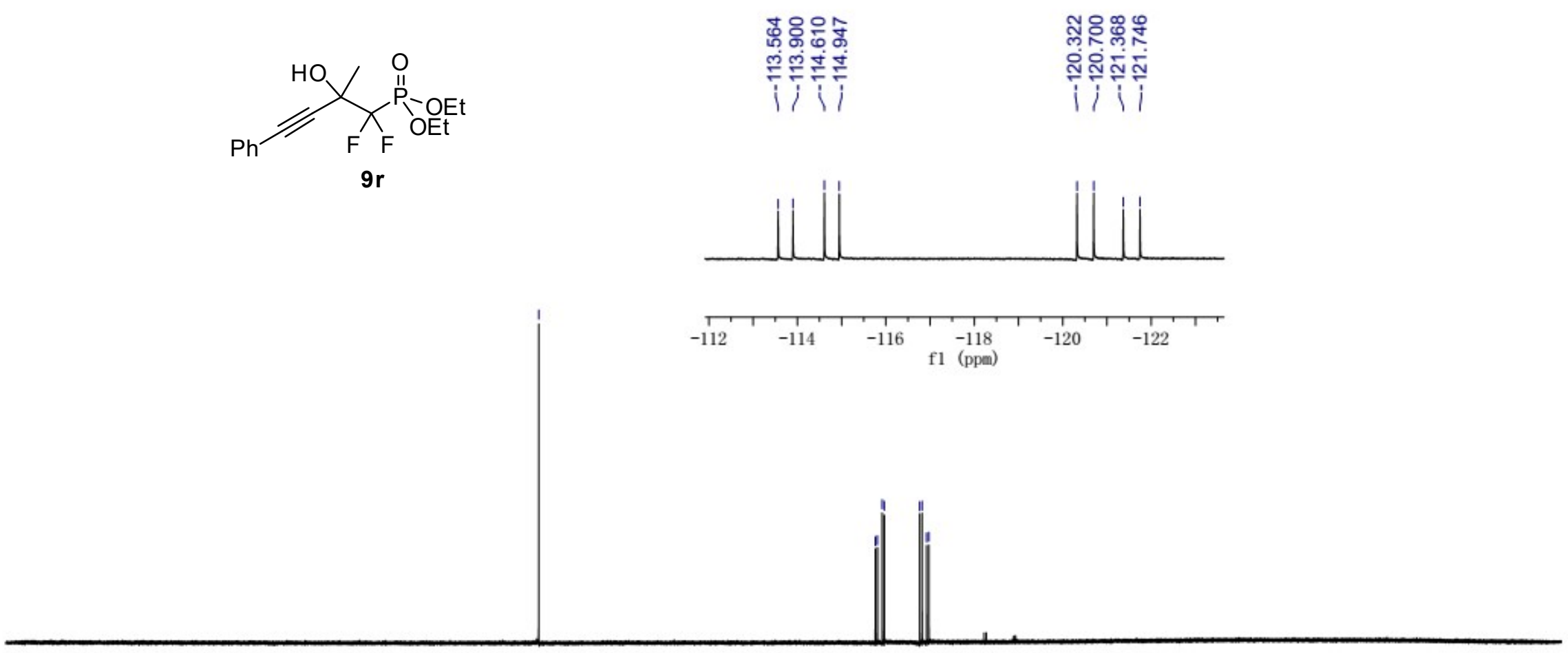

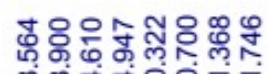

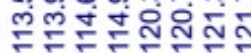

i

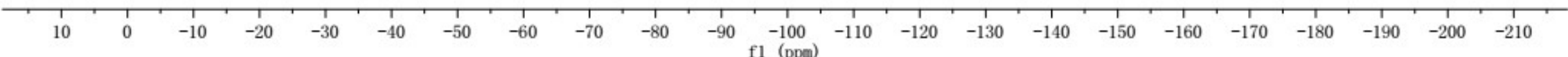




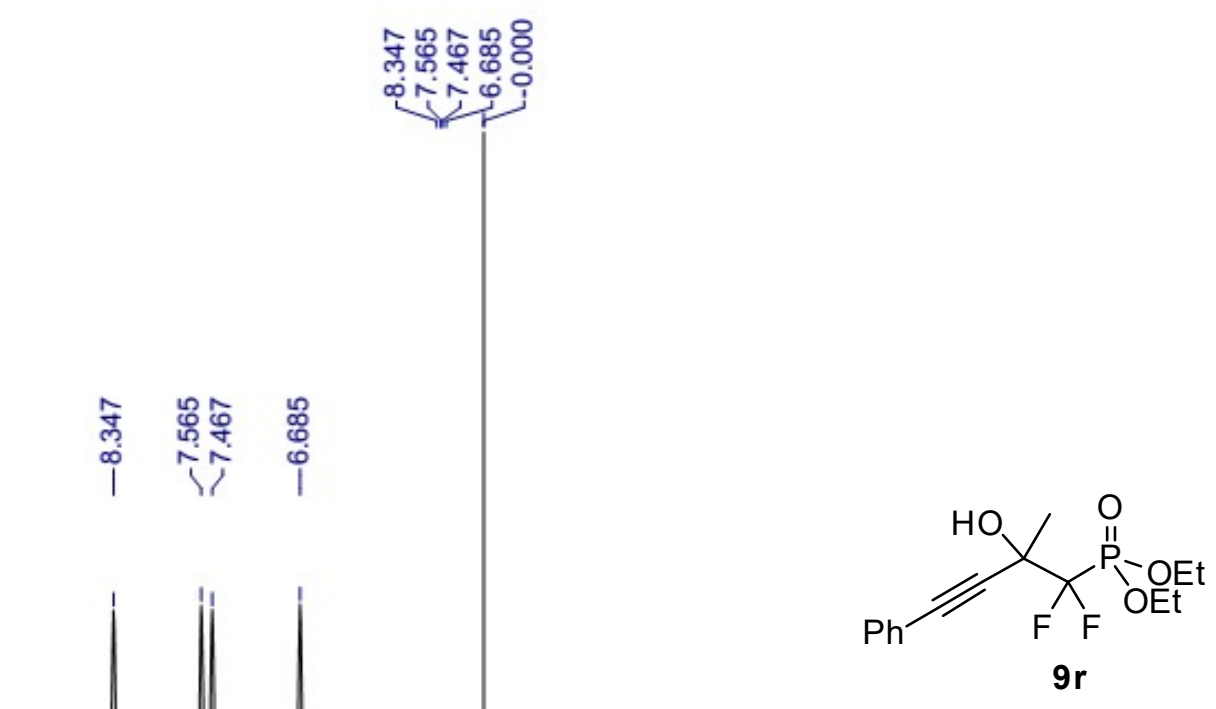




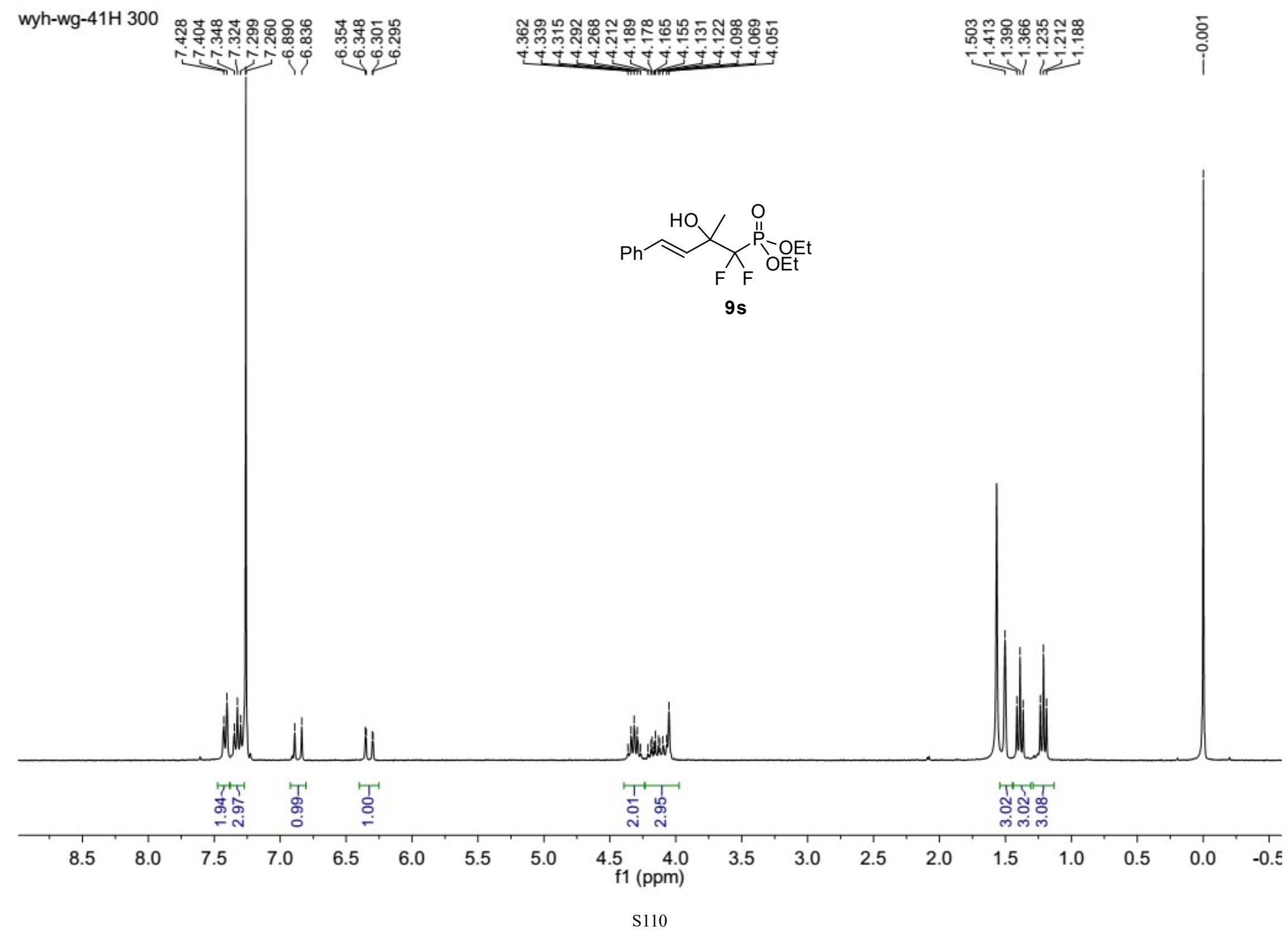




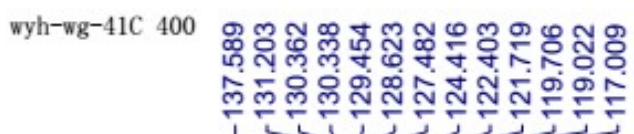

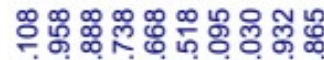

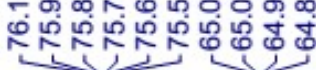

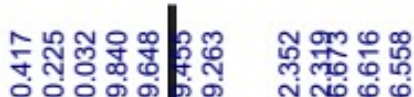
ठำ

1 ता

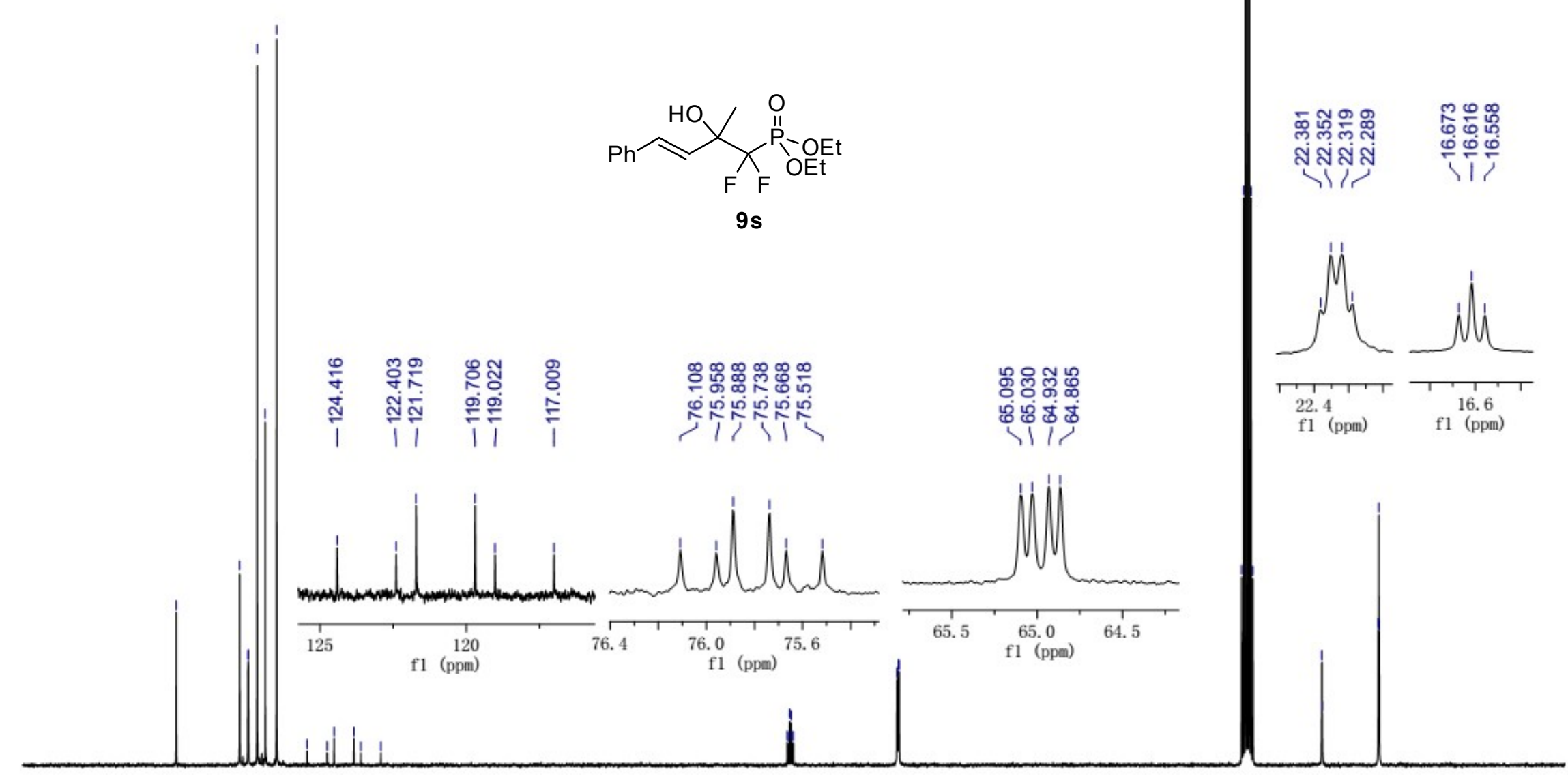




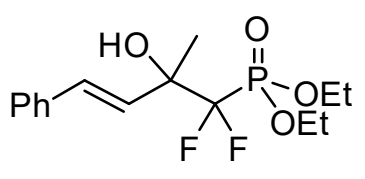

9s
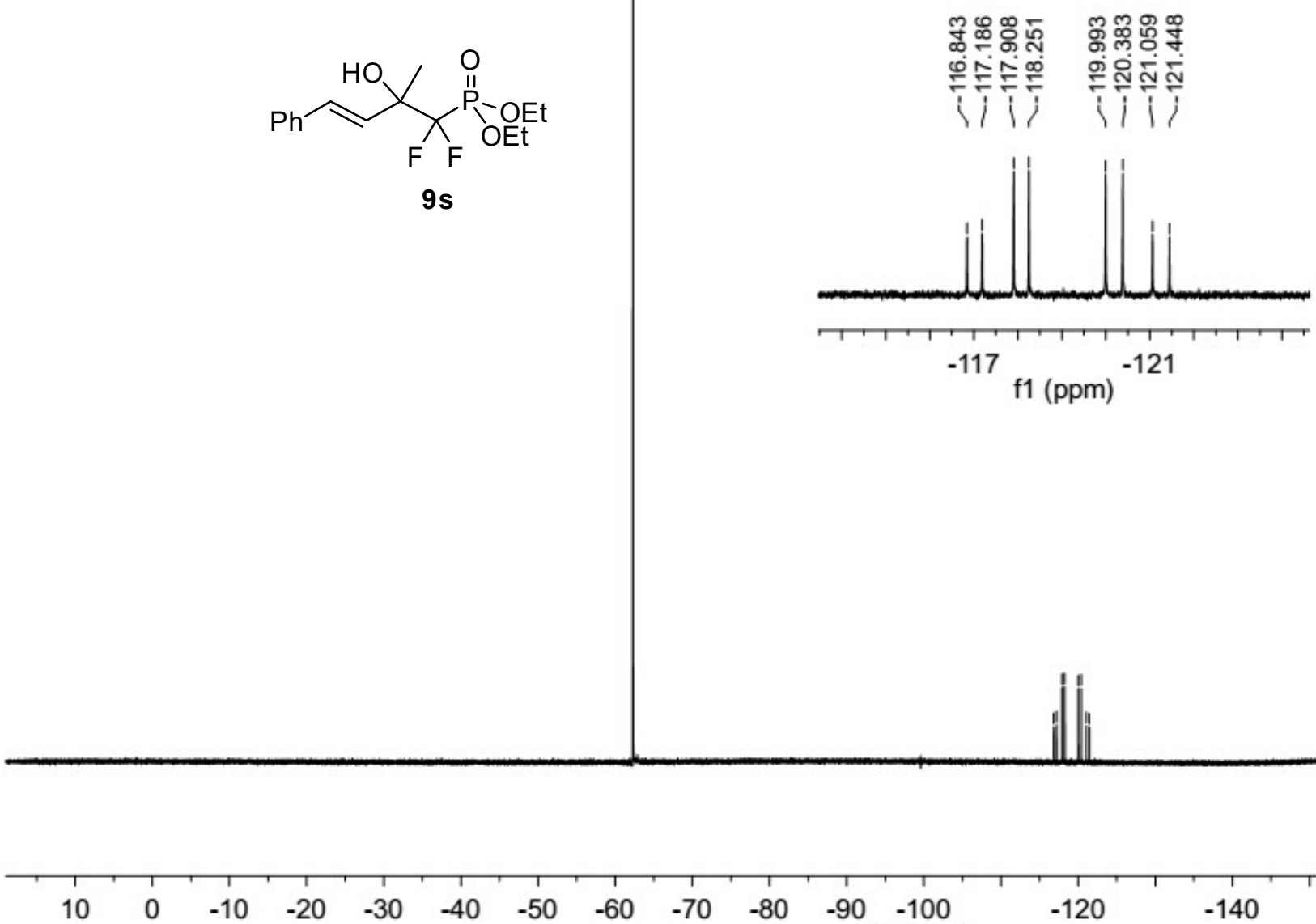

$\begin{array}{llllllllllll}0 & 0 & -10 & -20 & -30 & -40 & -50 & -60 & -70 & -80 & -90 & -100\end{array}$

$-120$

$-140$

$-160$

$-180$

$-200$ 

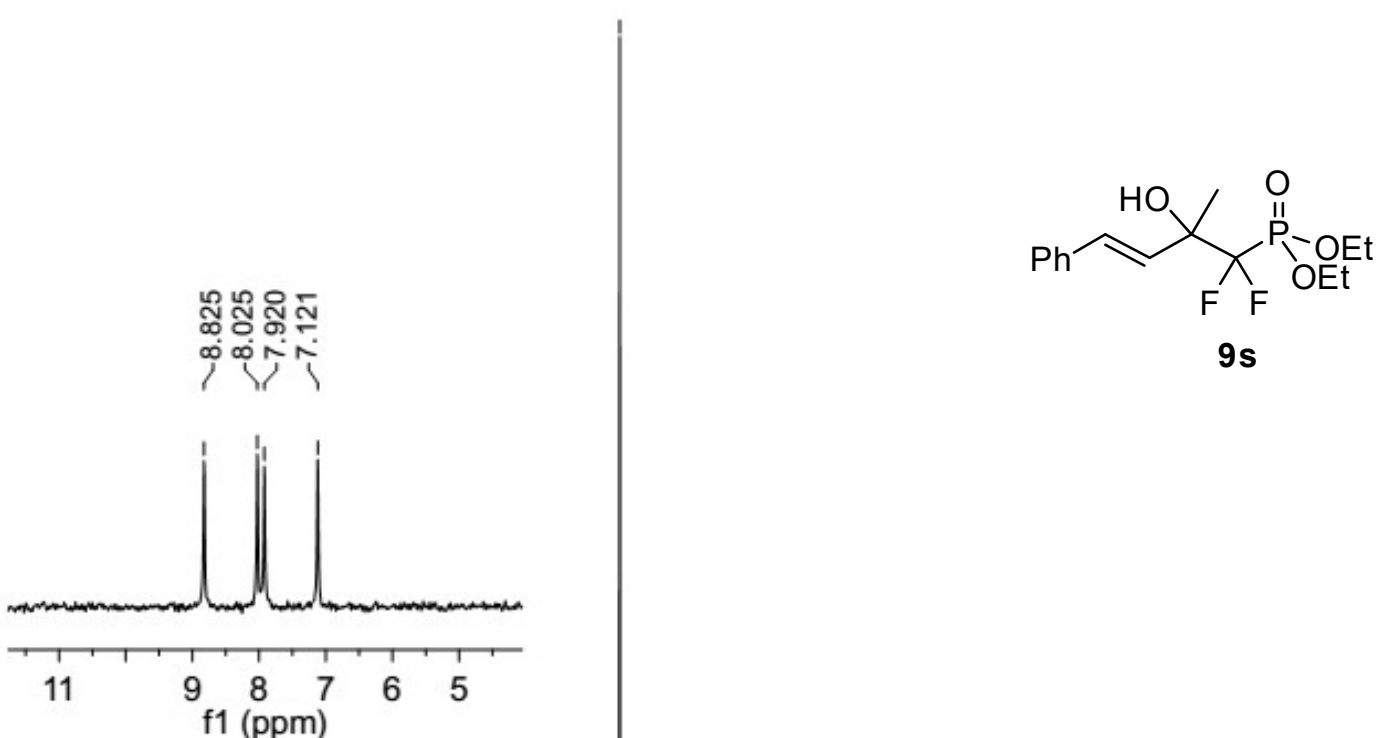

9s

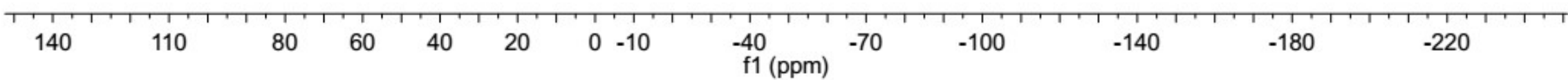




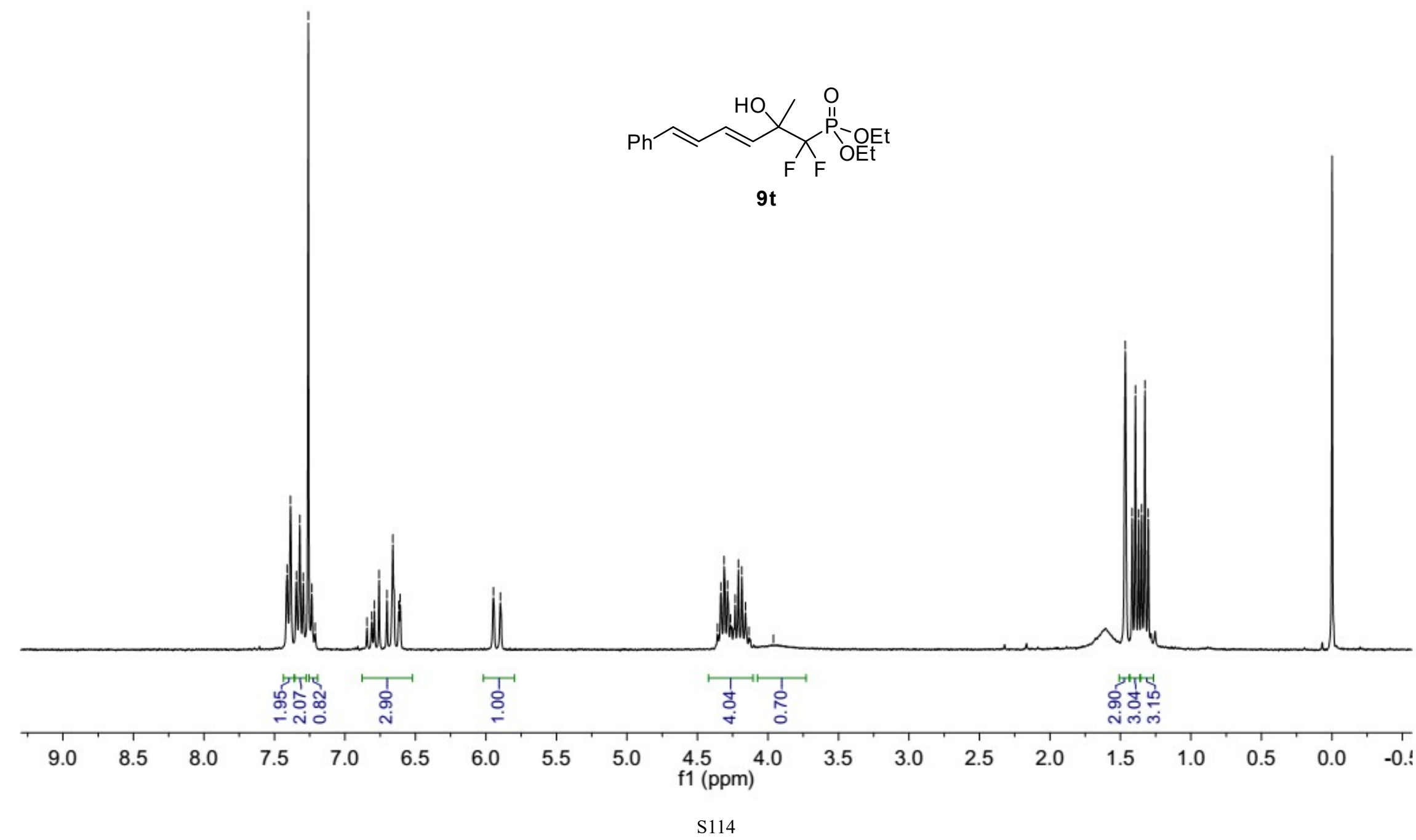




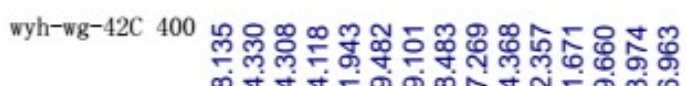

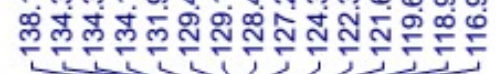

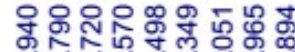

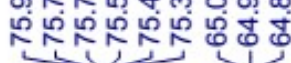

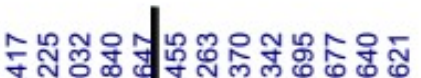

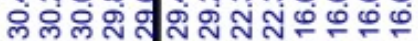

1)

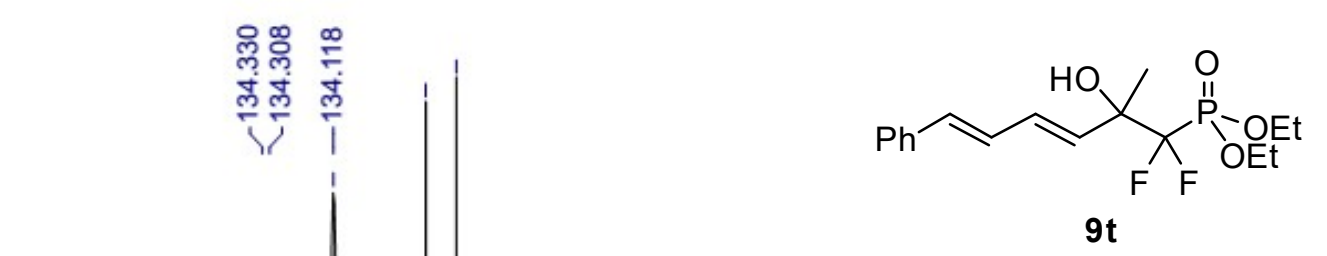

$$
\text { 9t }
$$

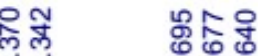

สู่
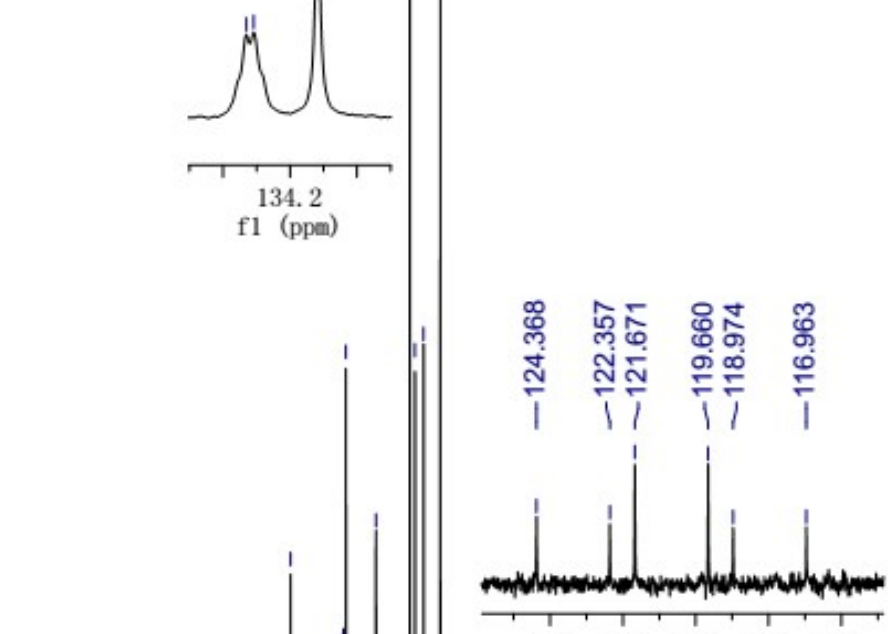

$\begin{array}{lllll}124 & 122 & 120 & 118 & 116\end{array}$

f1 (ppm)

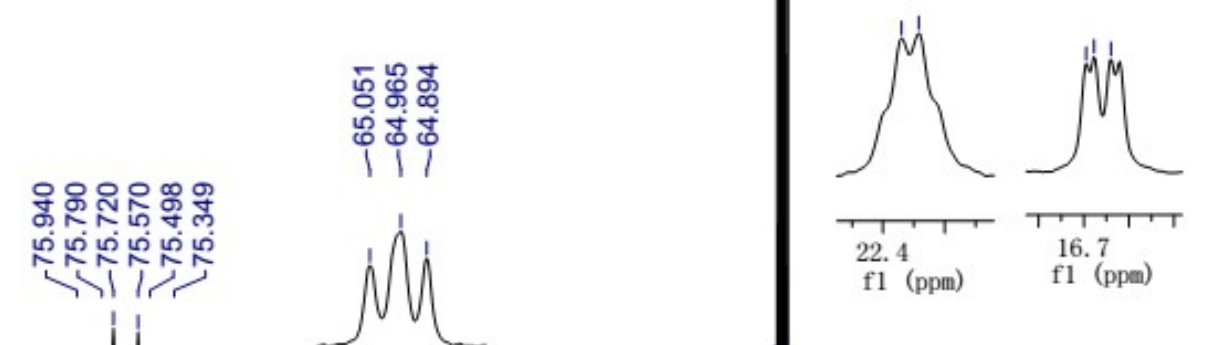



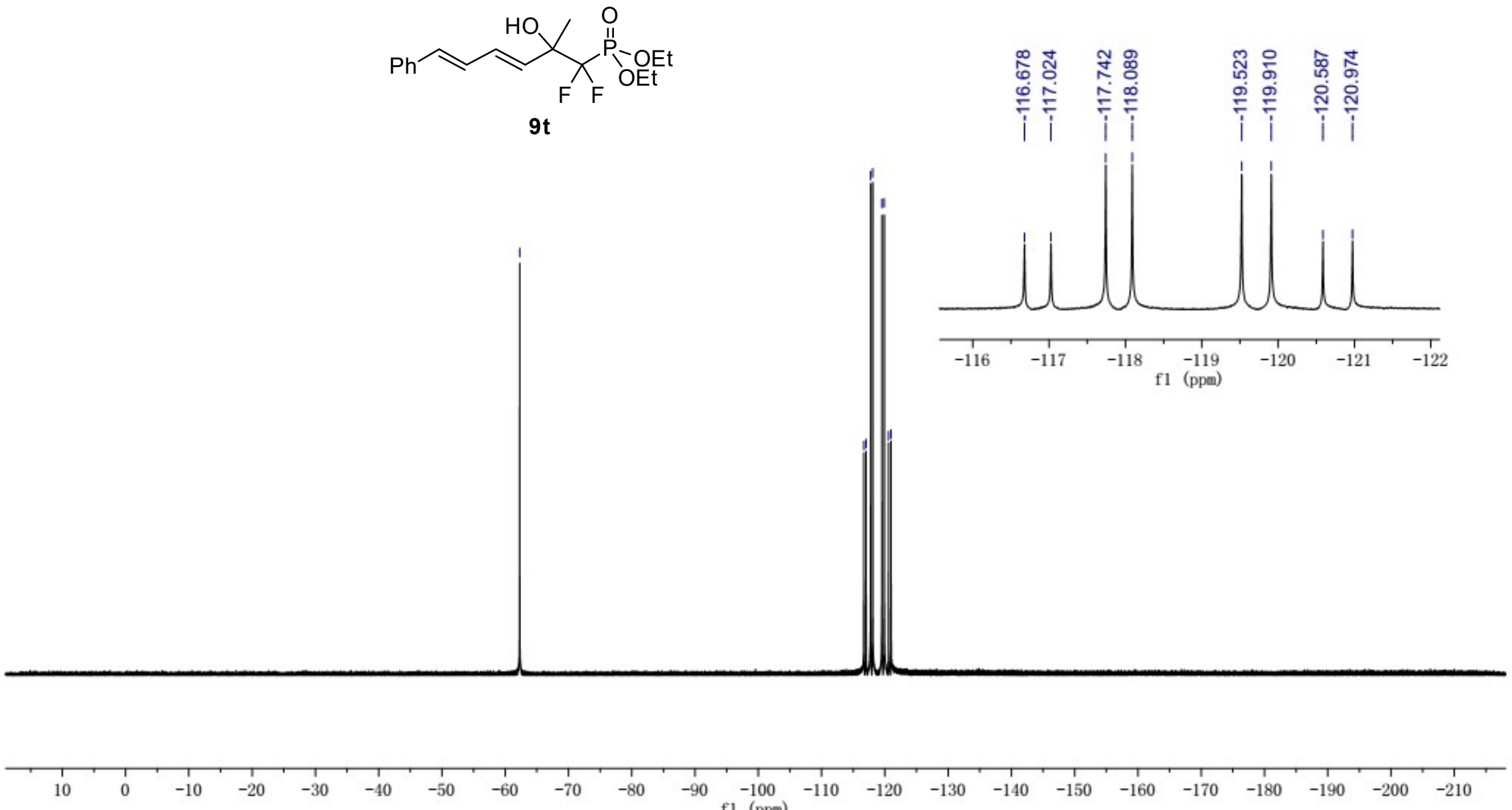

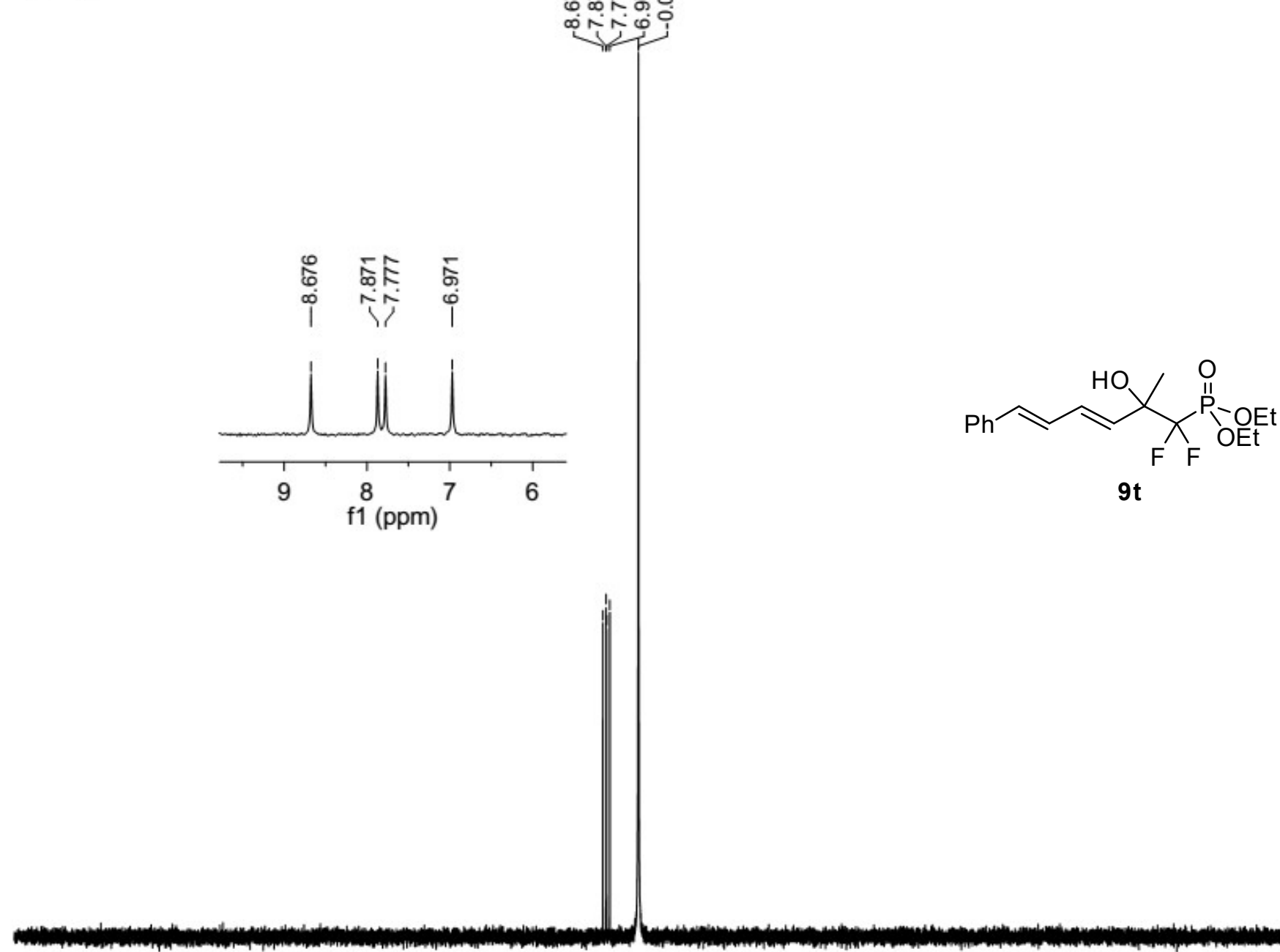

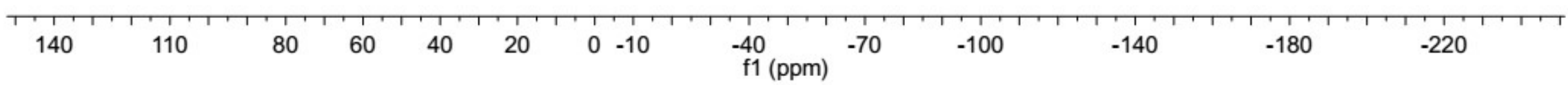




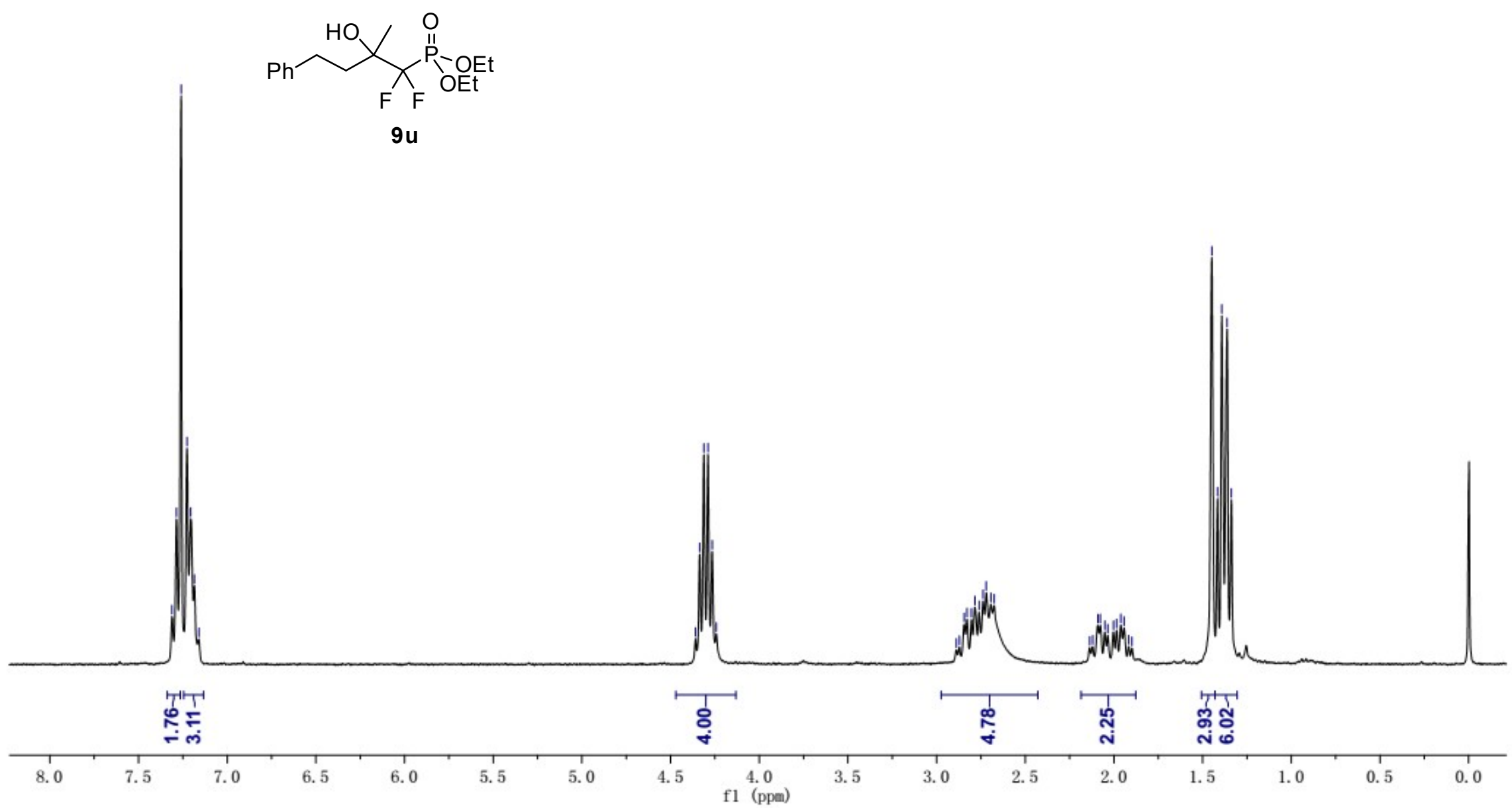



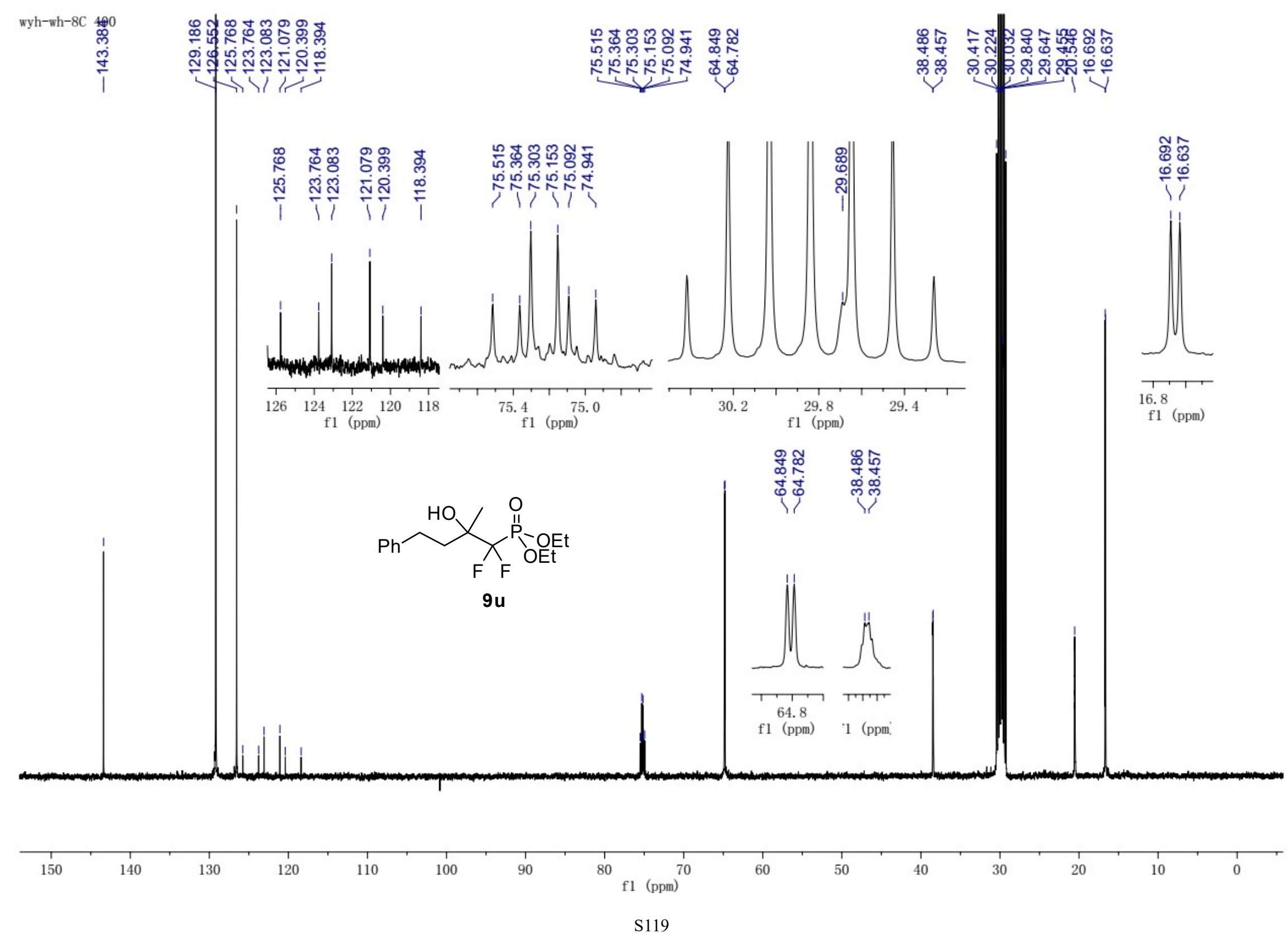

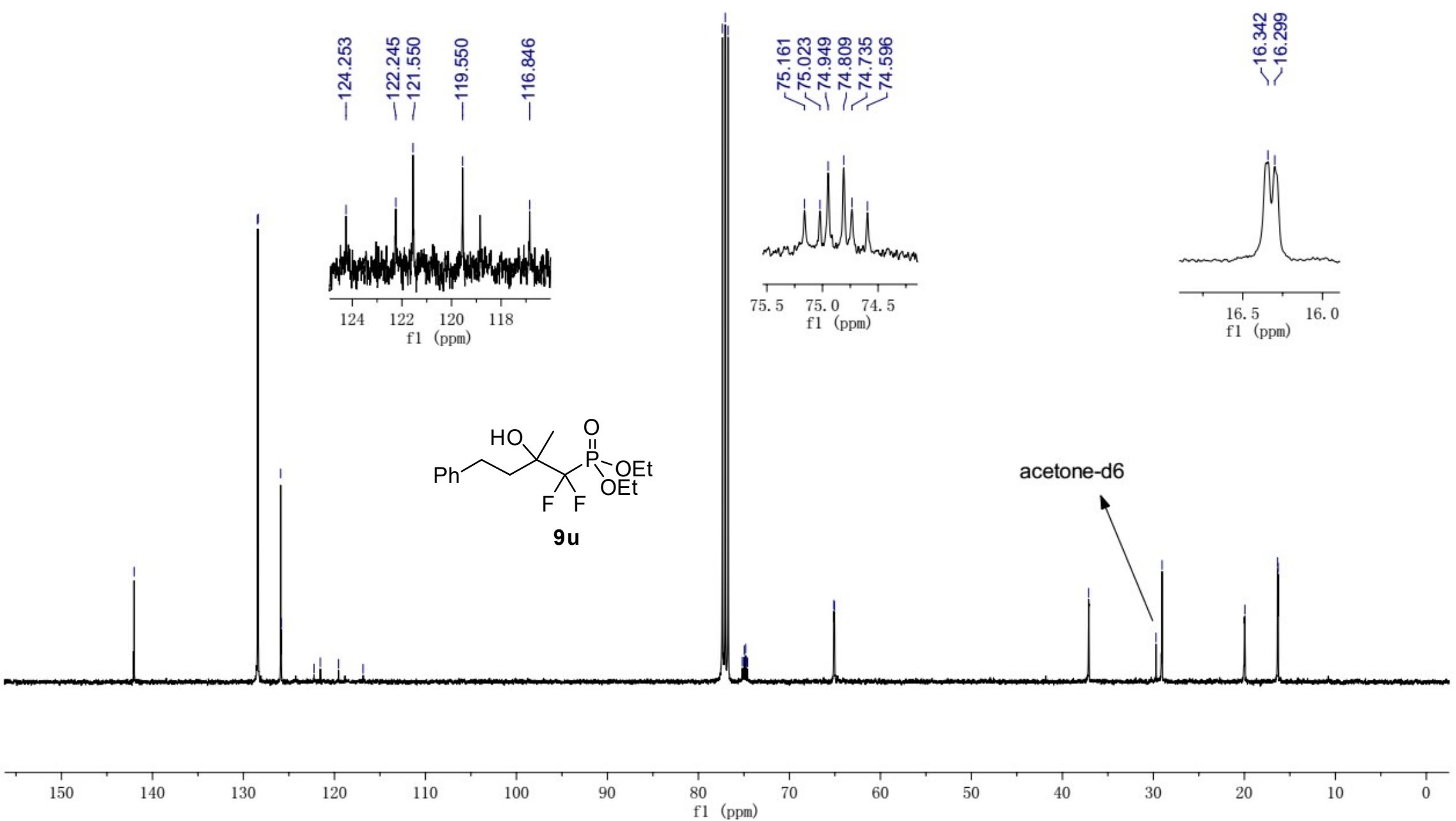

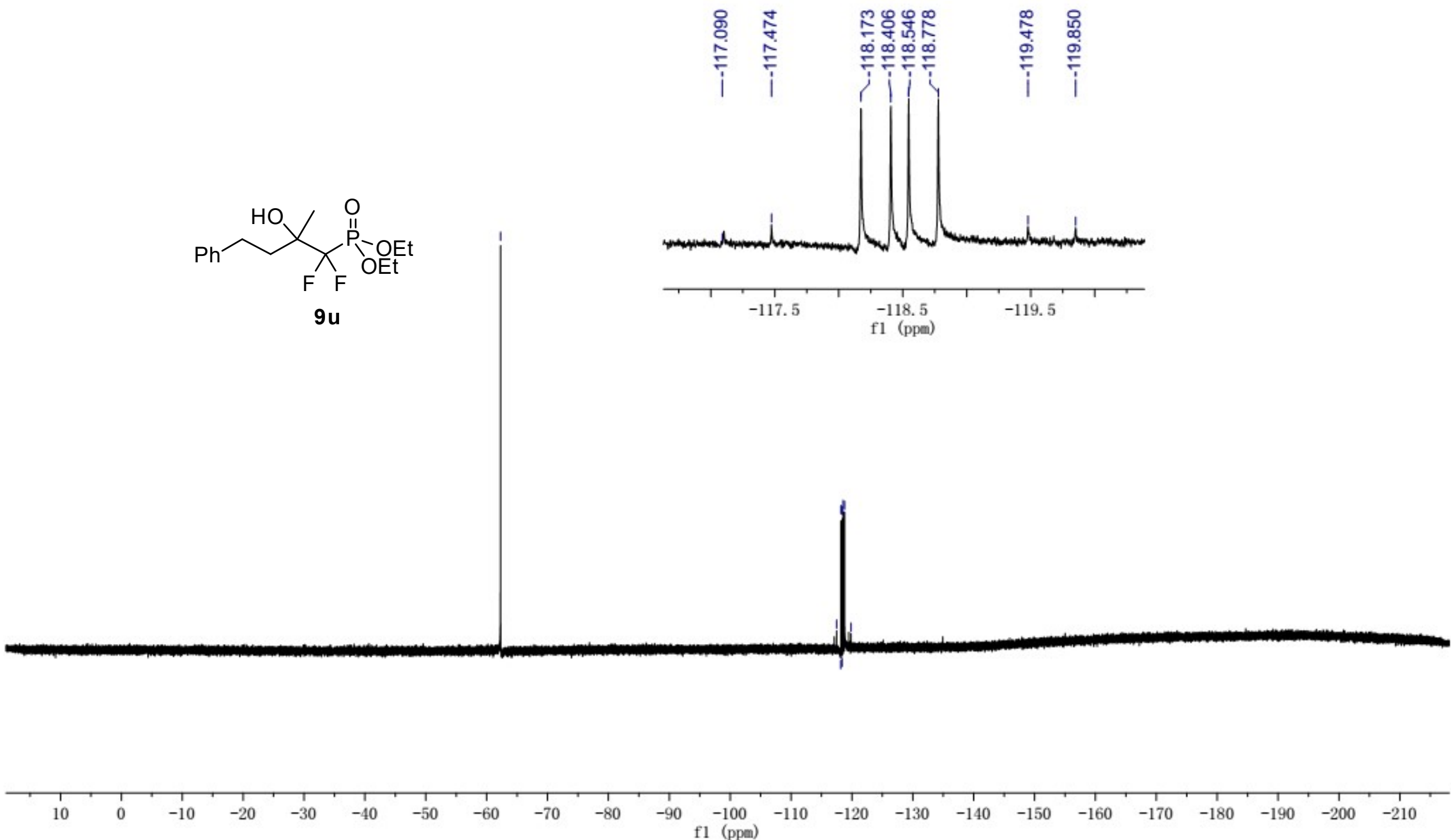


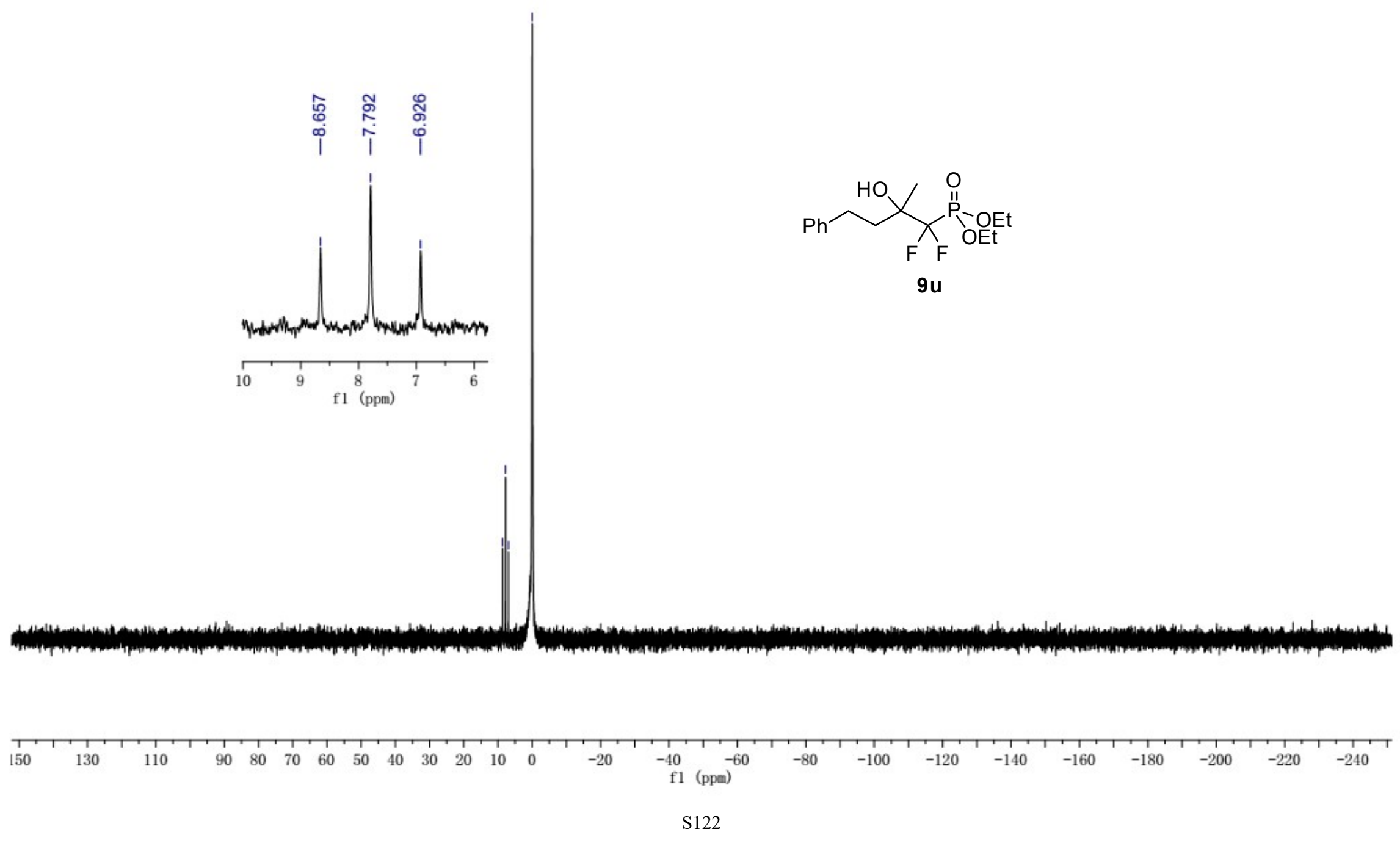




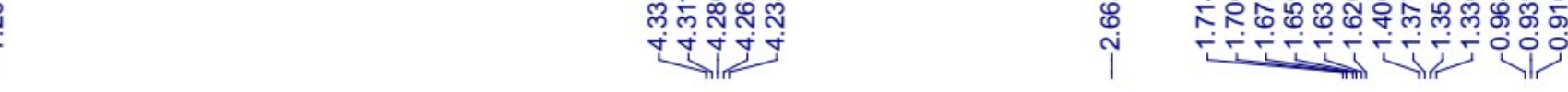

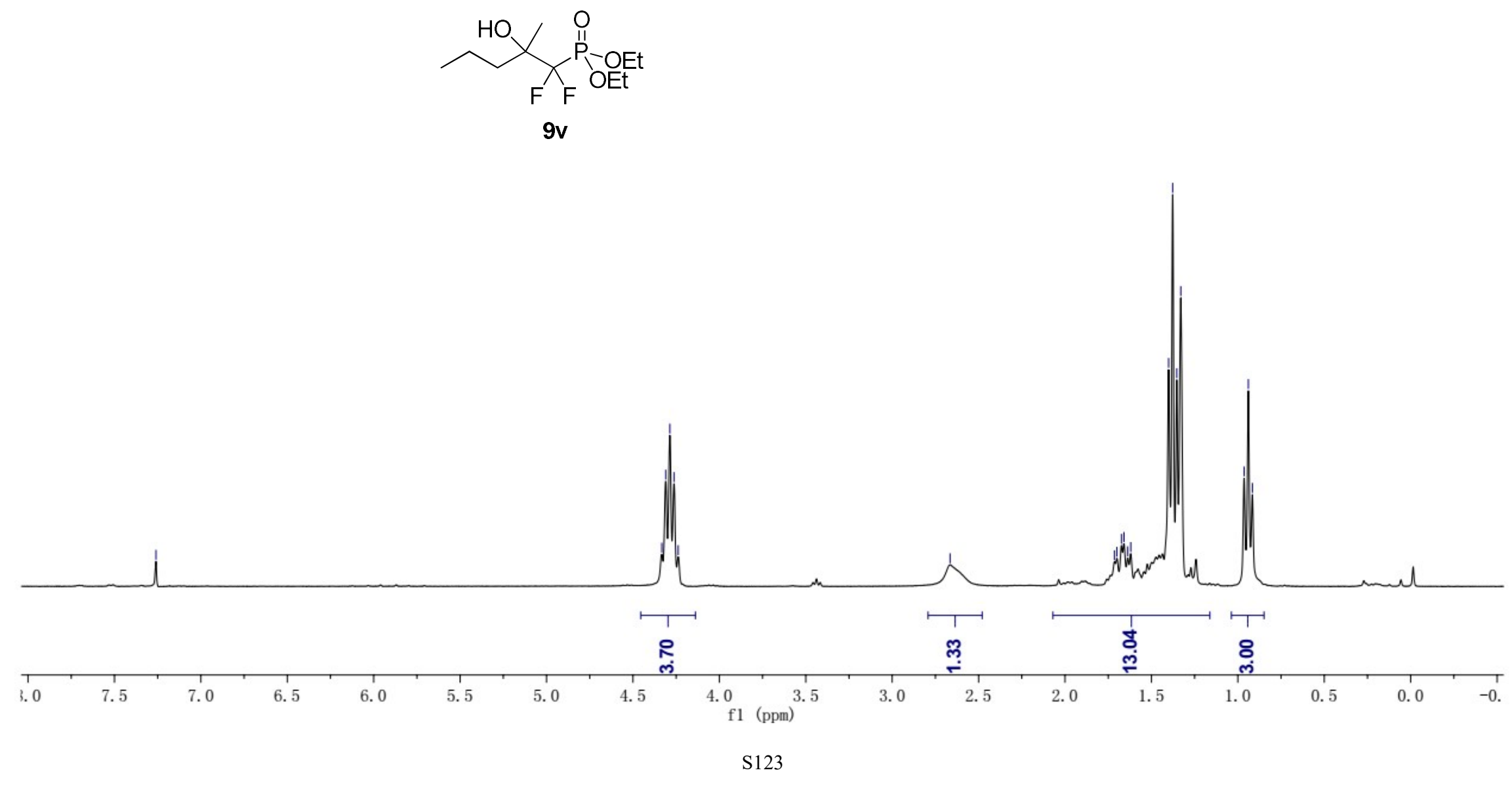




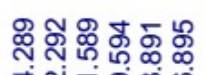

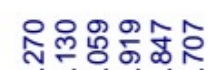

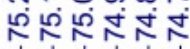

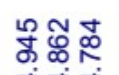

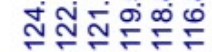

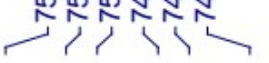

छ̛ं छீ

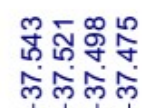

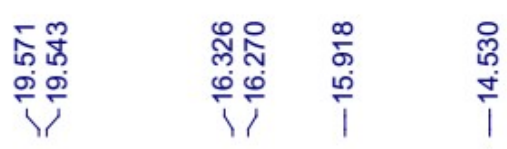
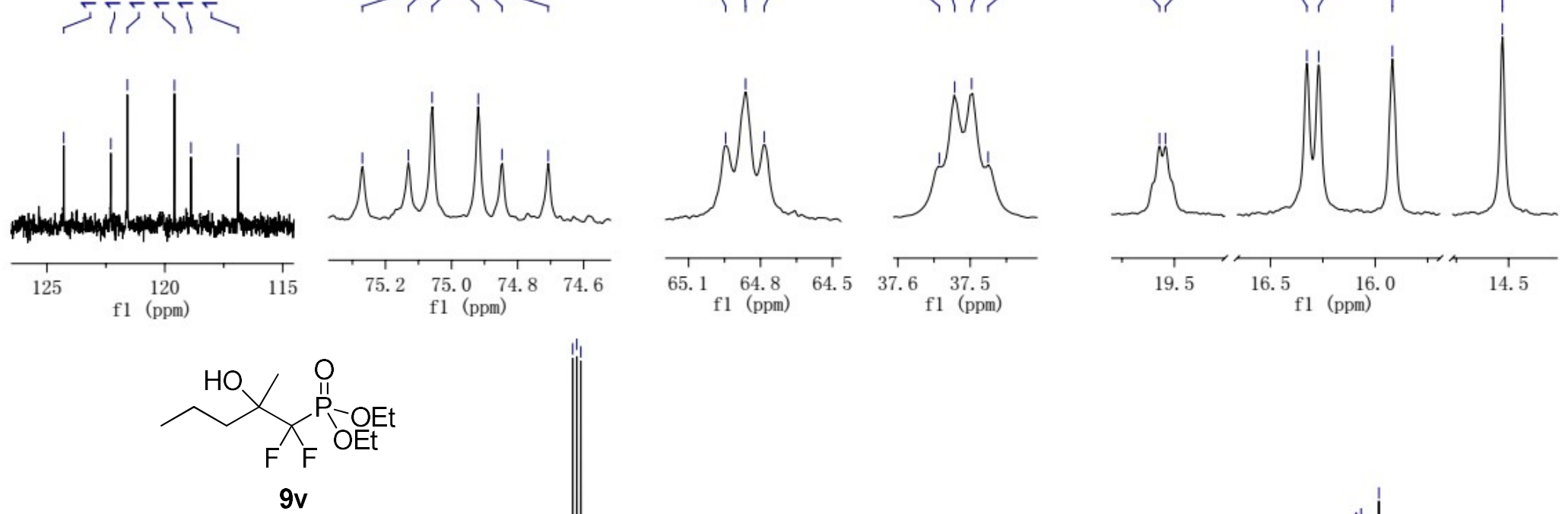

9v

Hilin

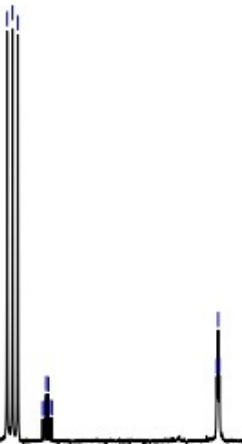

$\begin{array}{lllllll}125 & 120 & 115 & 110 & 105 & 100 & 95\end{array}$

95

$80 \quad 75$

$\begin{array}{lr}65 & 60 \\ \text { fl } & (\mathrm{ppm})\end{array}$

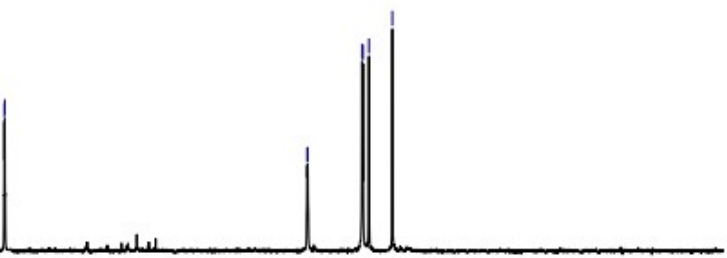


1

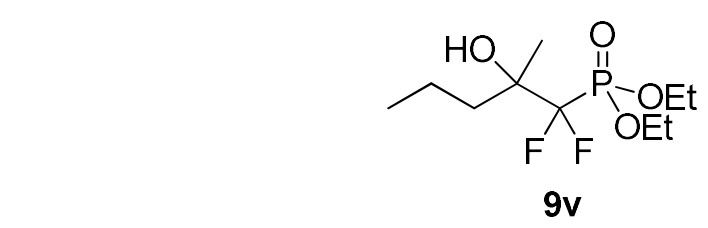

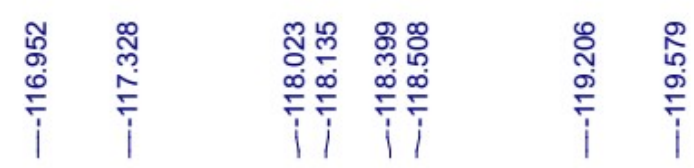
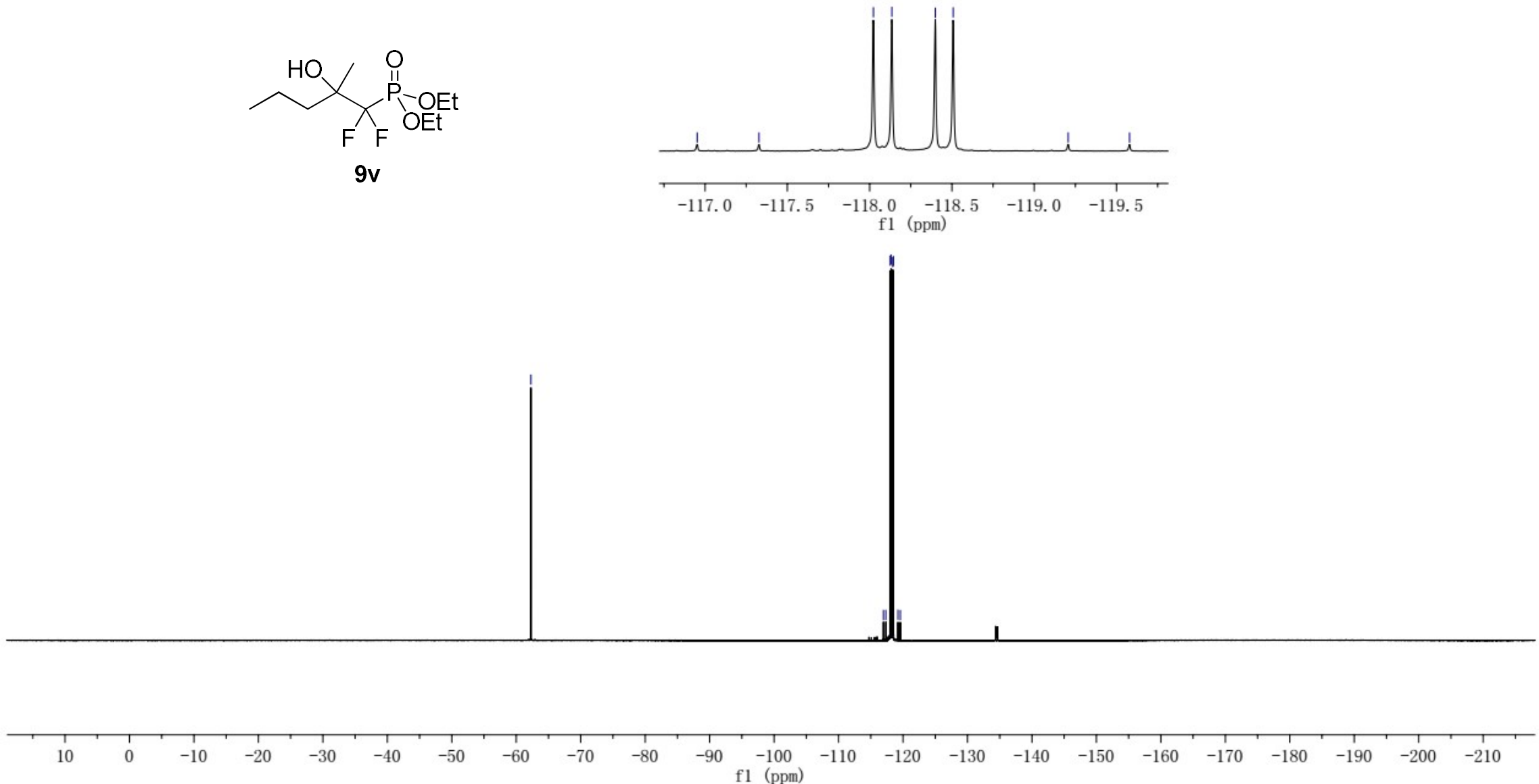


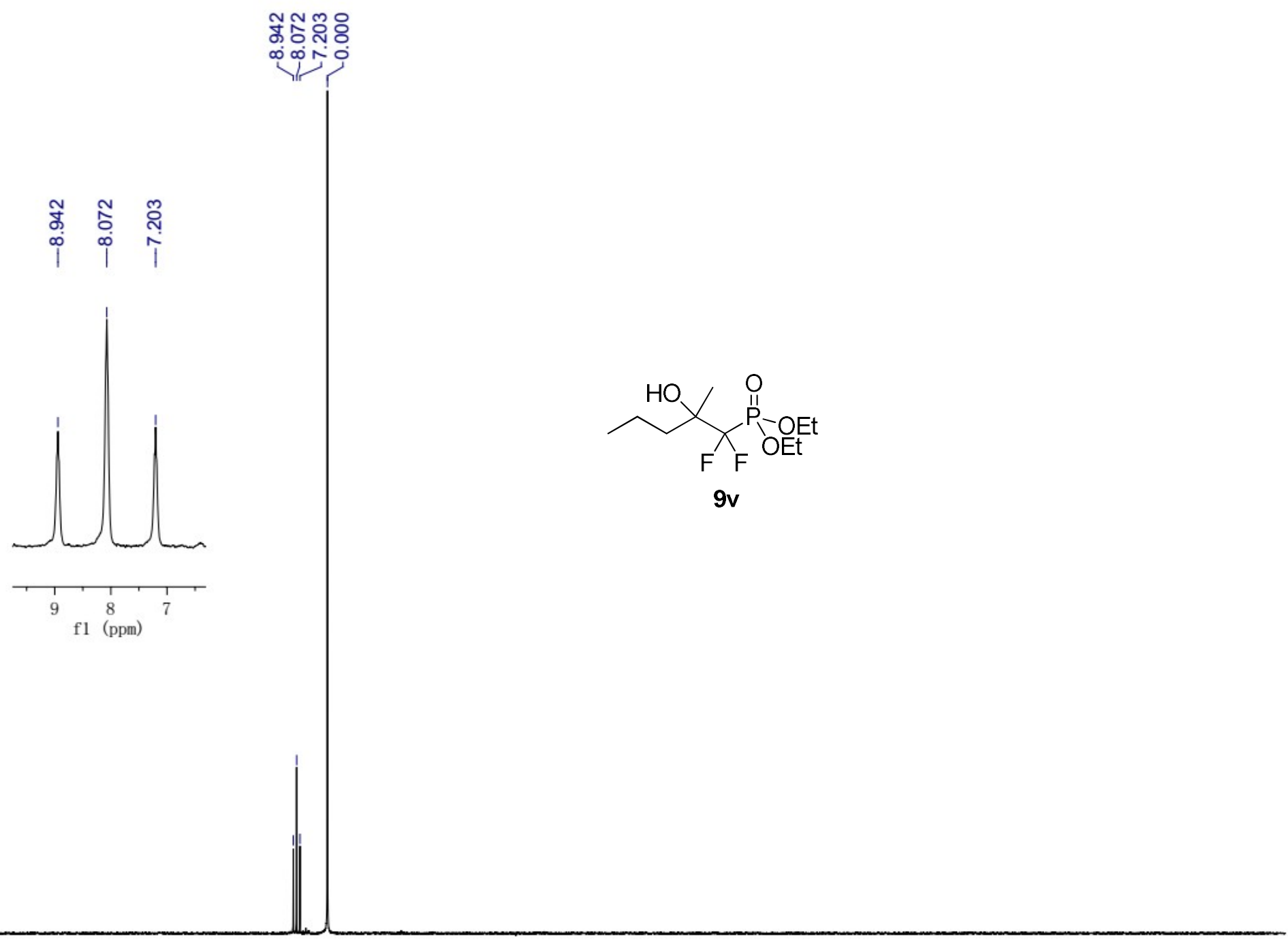




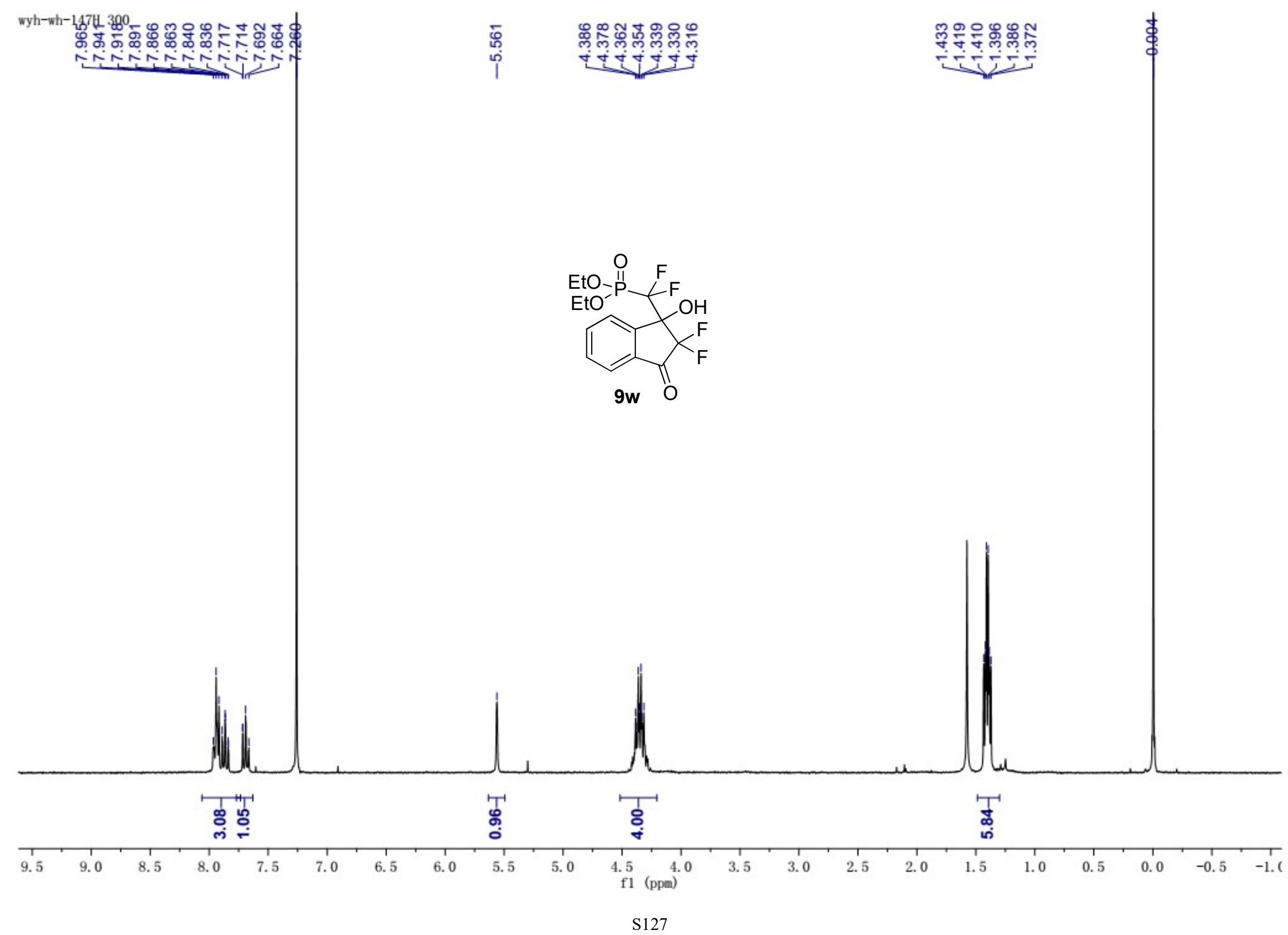




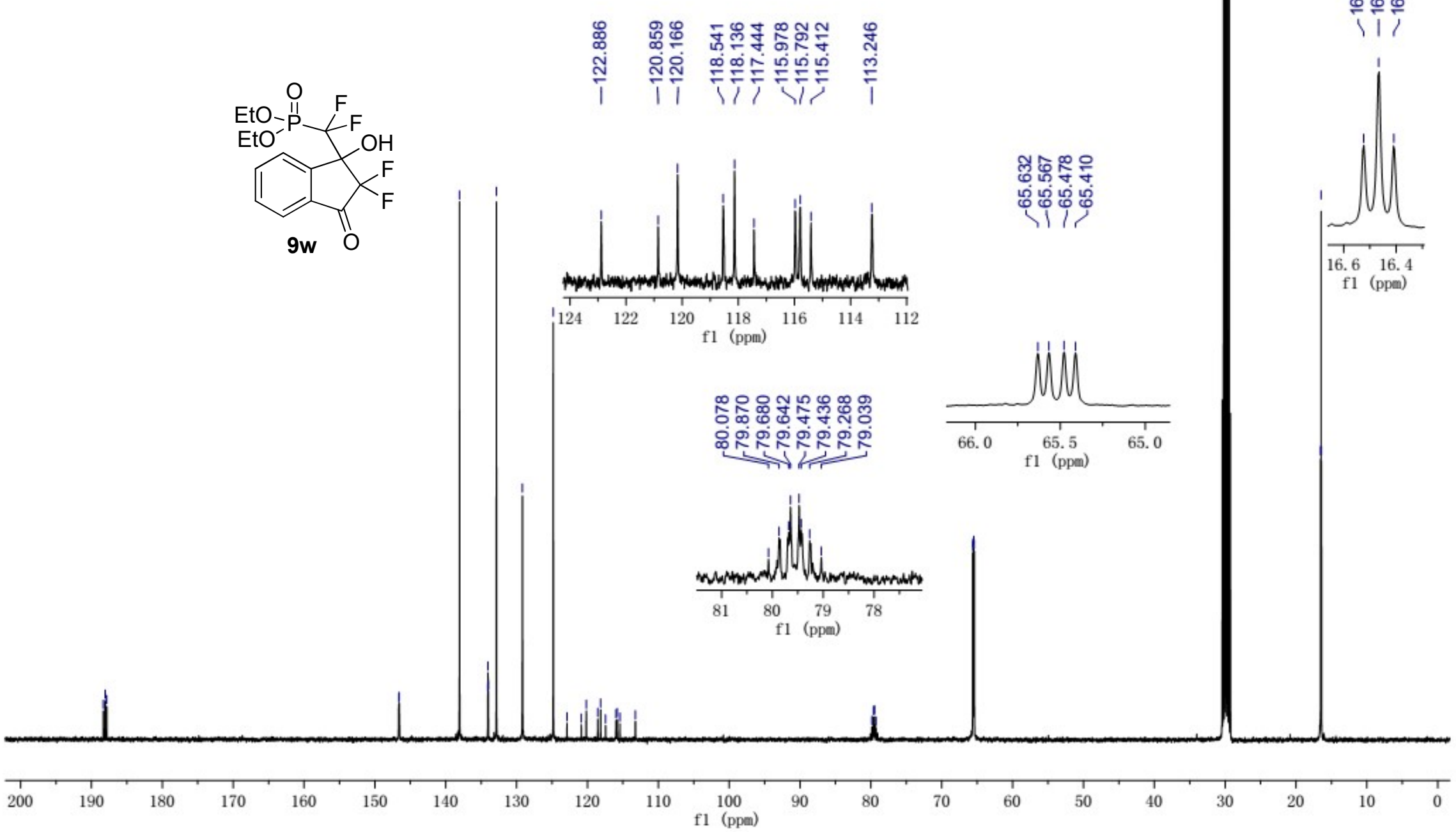




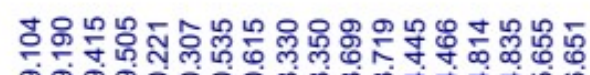

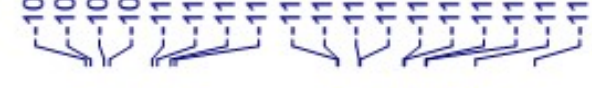
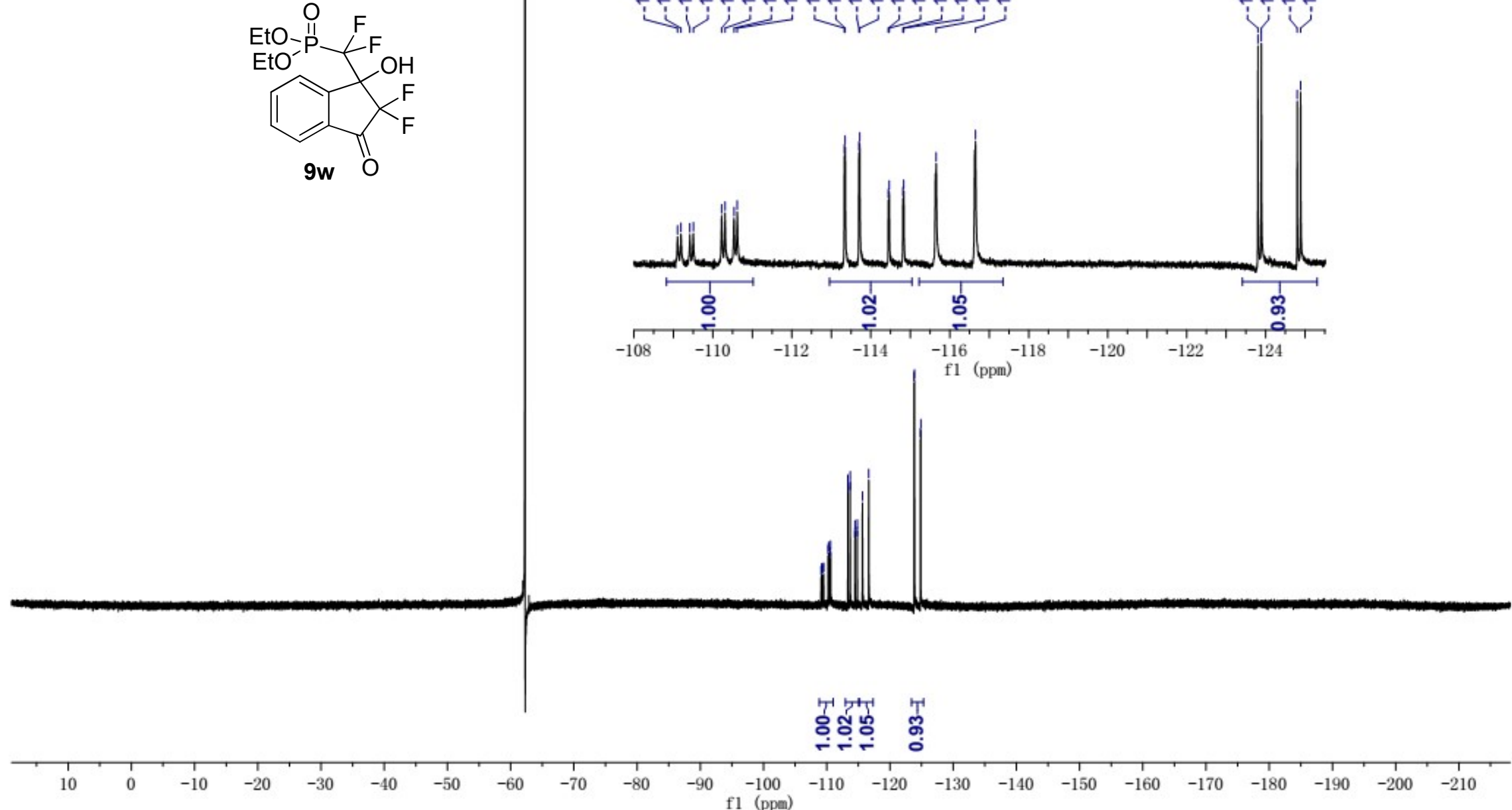

f1 (ppm) 

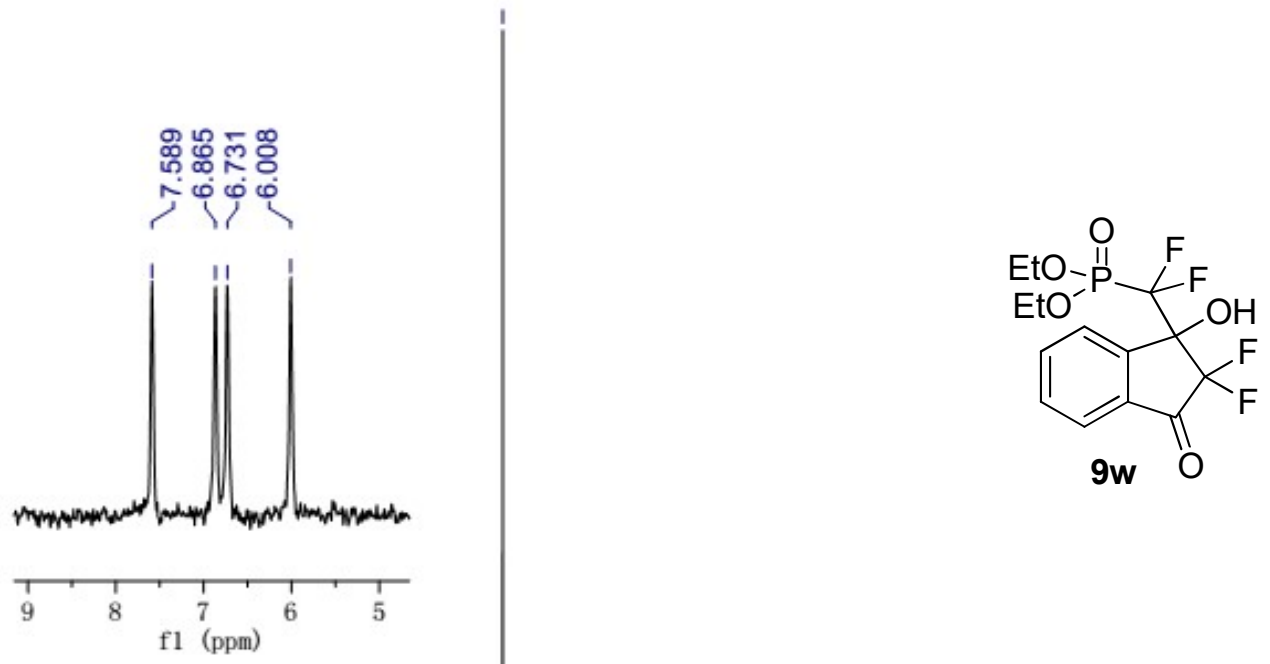


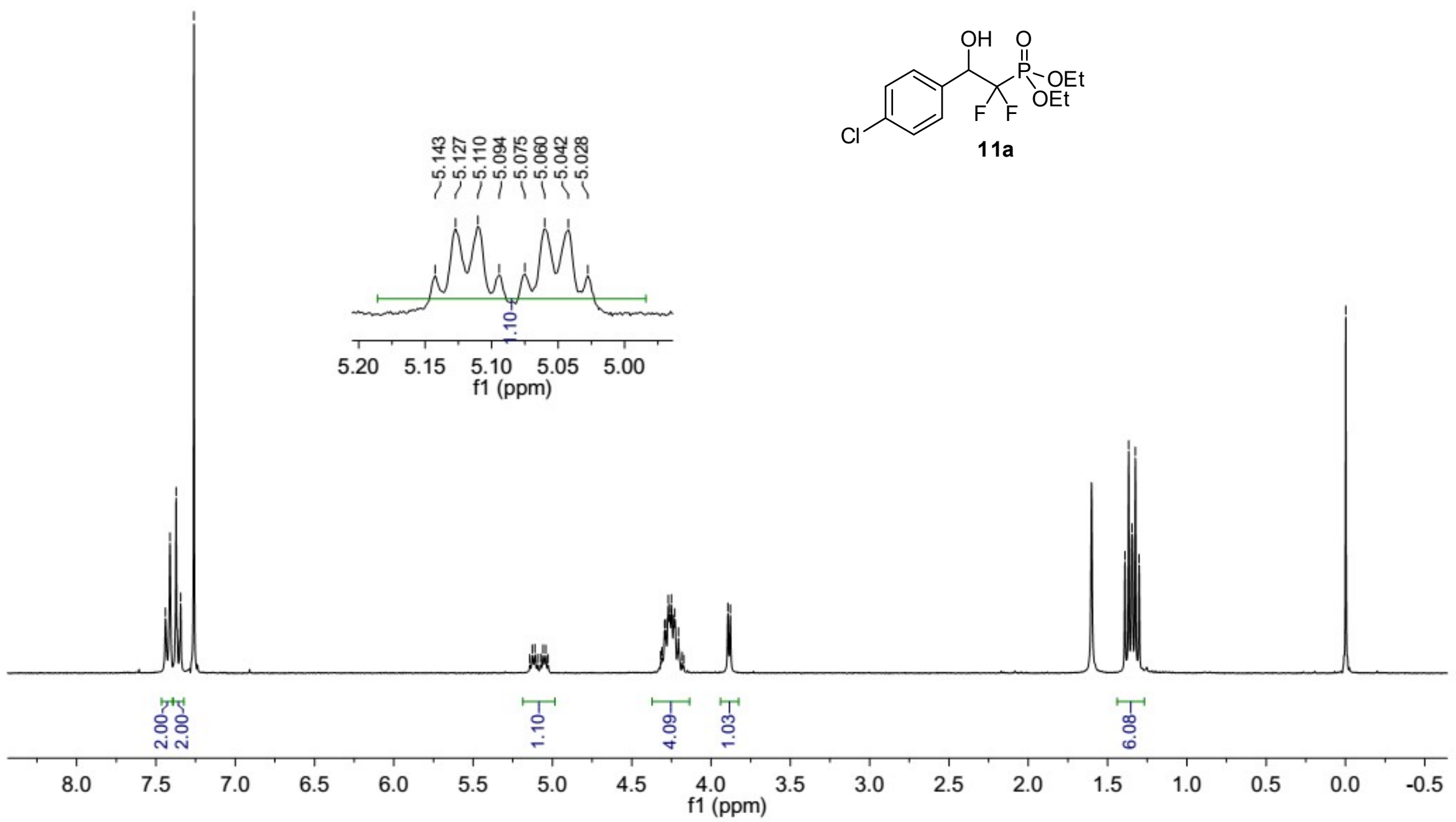




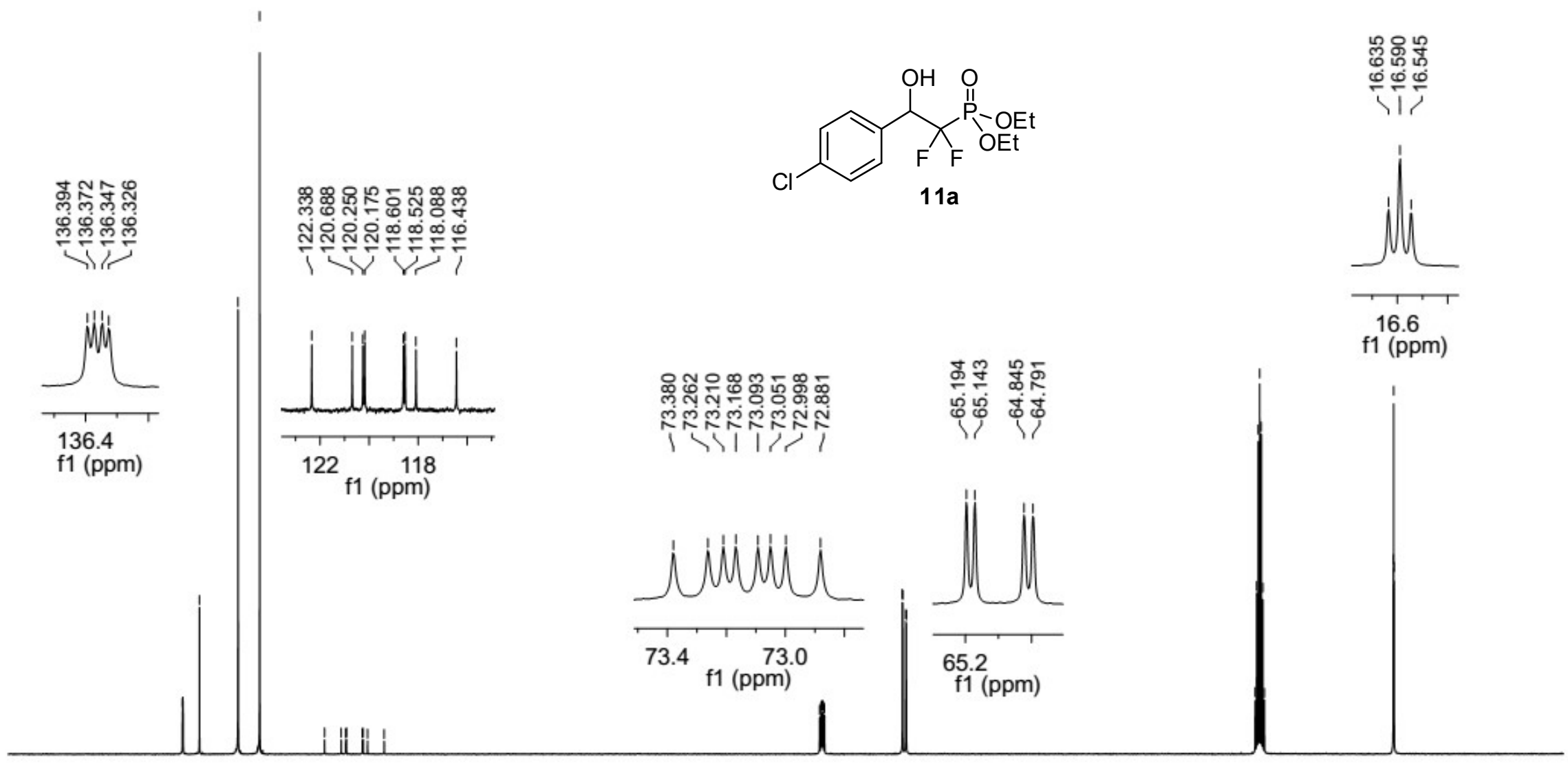

$\begin{array}{lllllllllllllllll}145 & 135 & 125 & 115 & 105 & 95 & 85 & 75 & 65 & 55 & 45 & 35 & 25 & 15 & 5 & \mathrm{C}\end{array}$



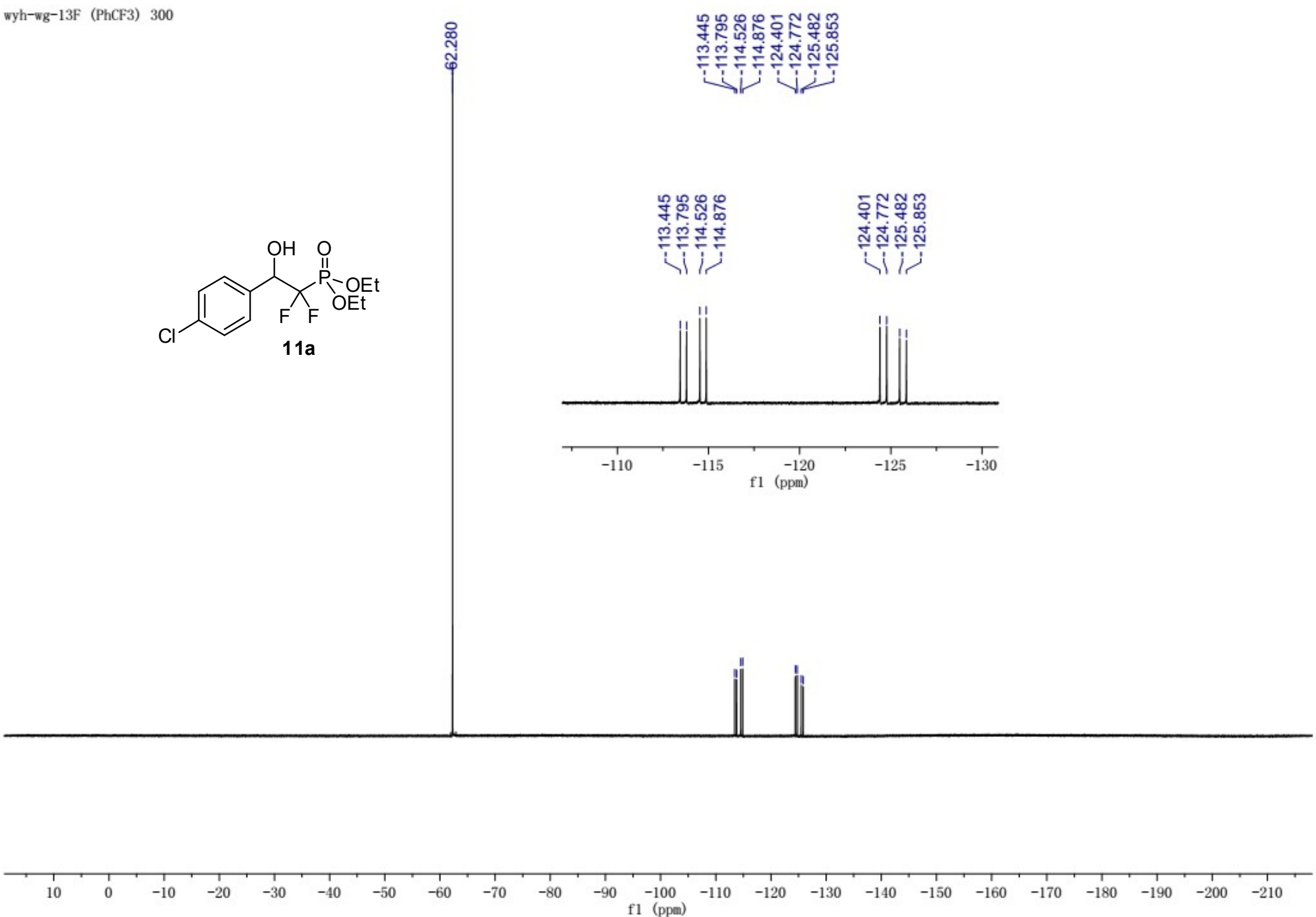

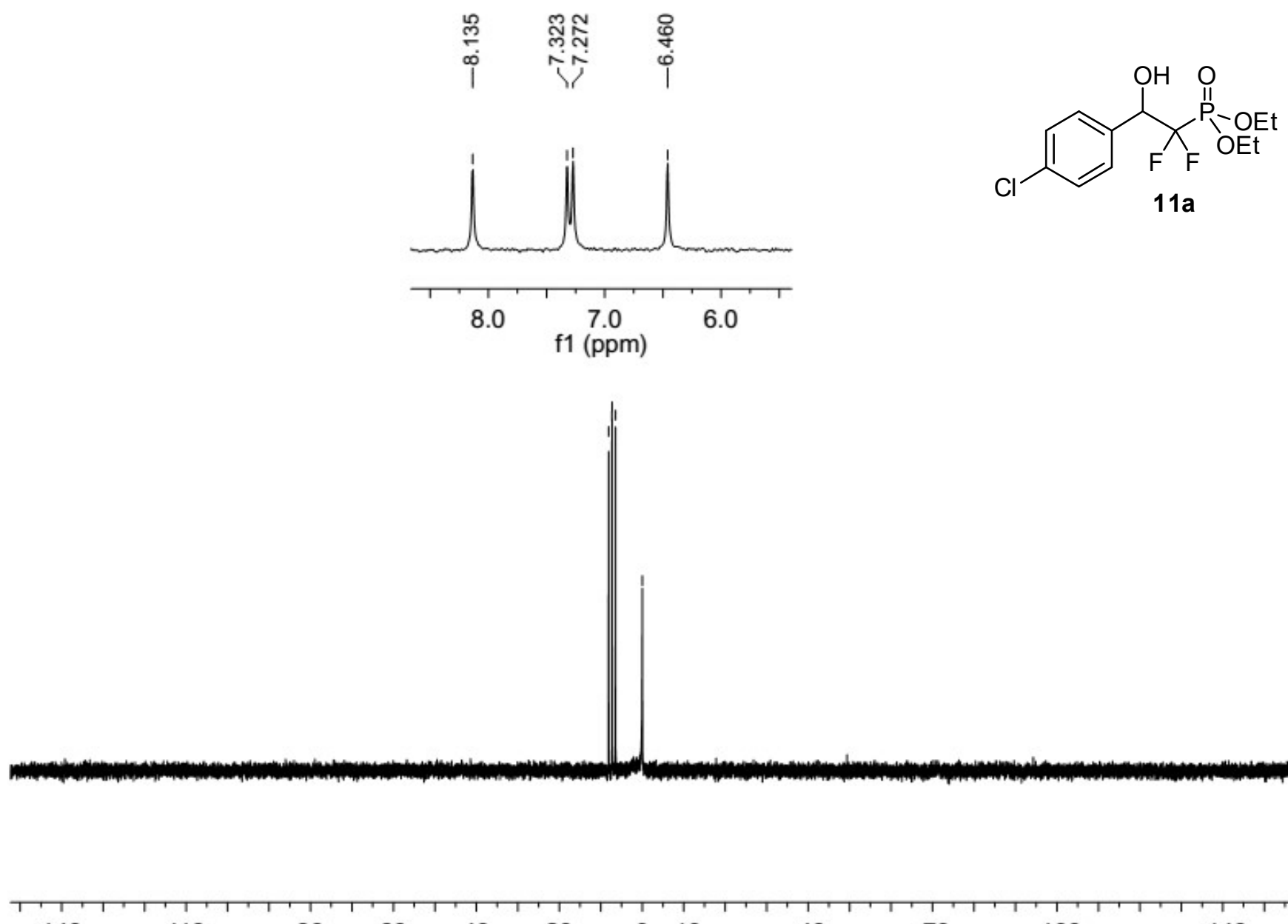


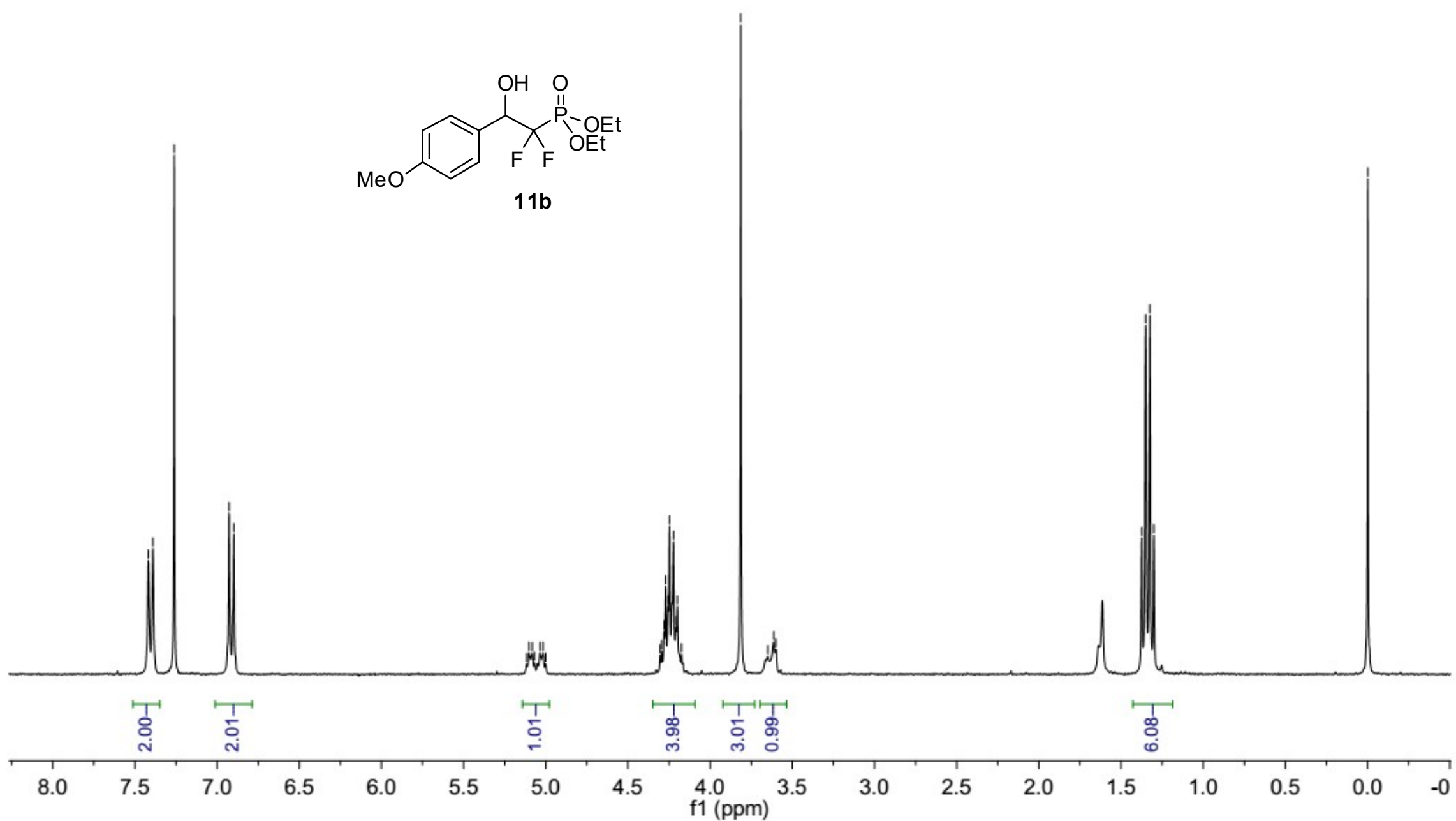




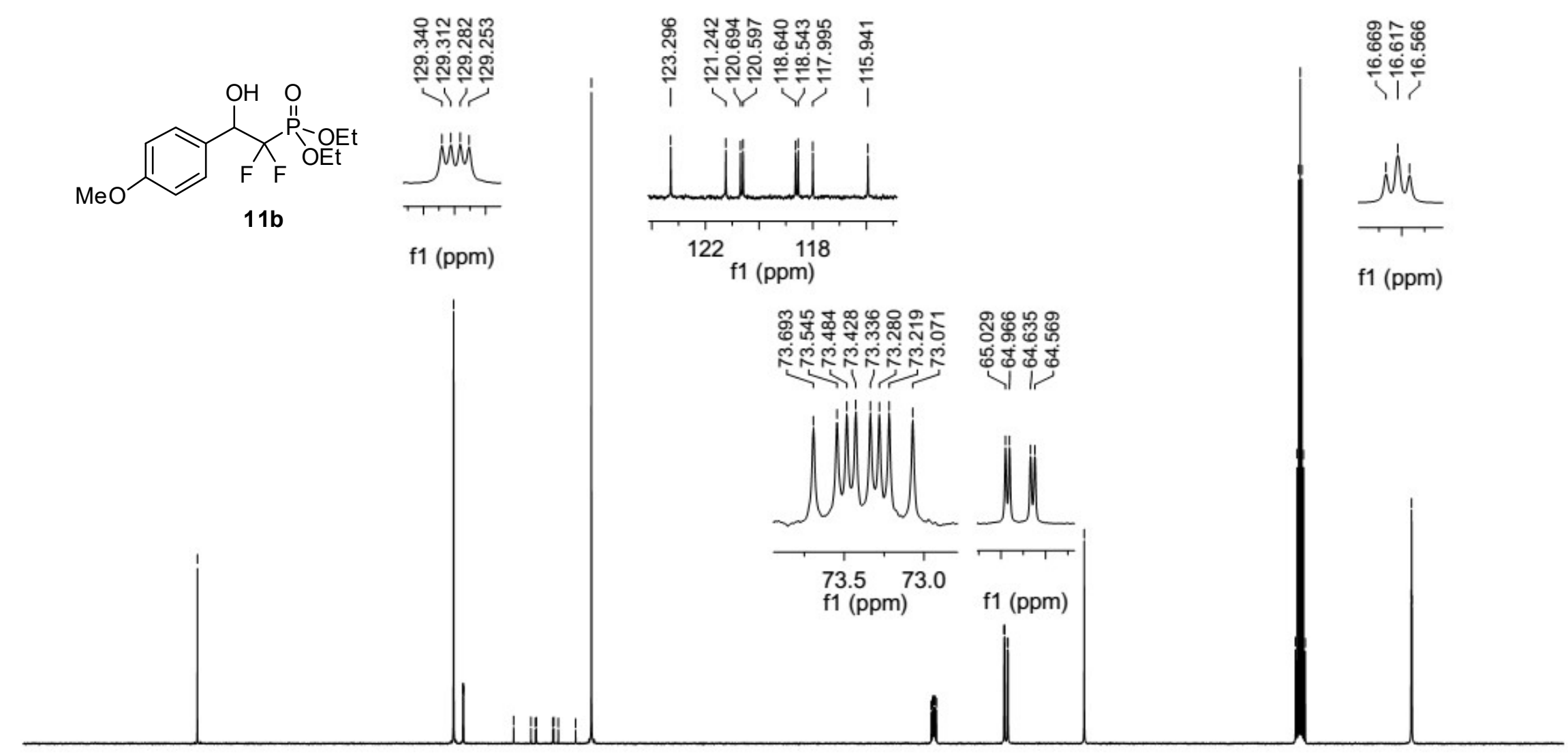

$180 \quad 170 \quad 160$ 

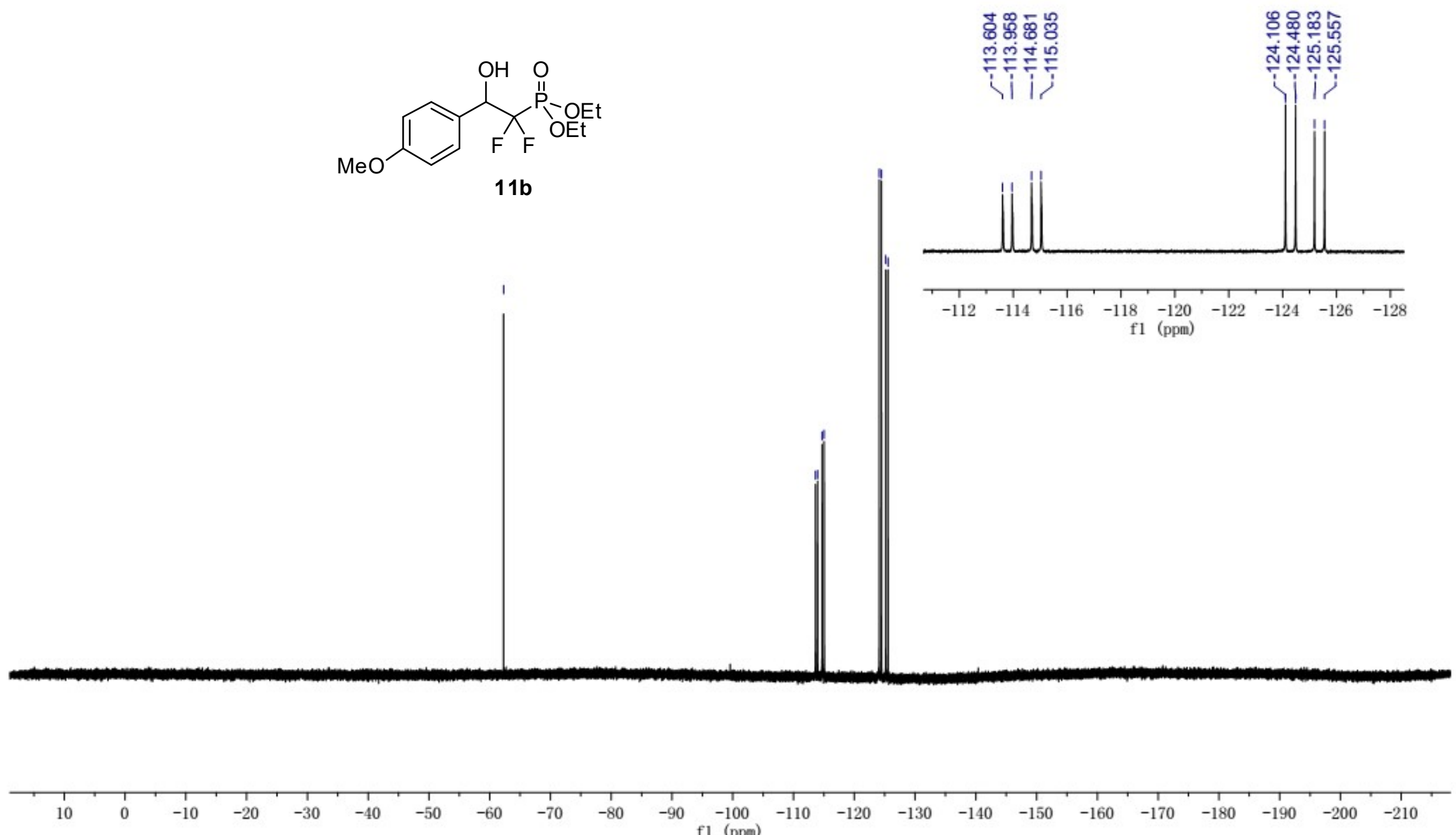
望

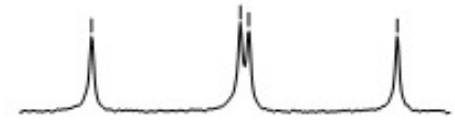

$11 \mathrm{~b}$

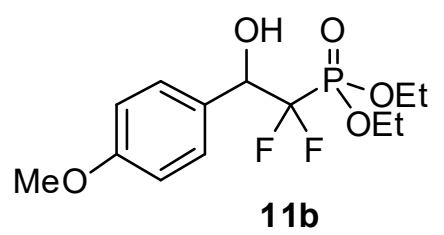

$\begin{array}{llll}8.5 & 8.0 & 7.5 & 7.0\end{array}$

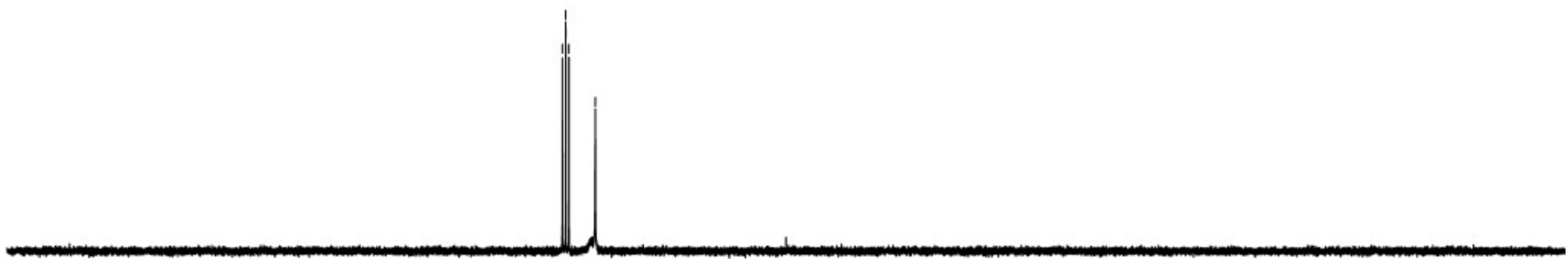




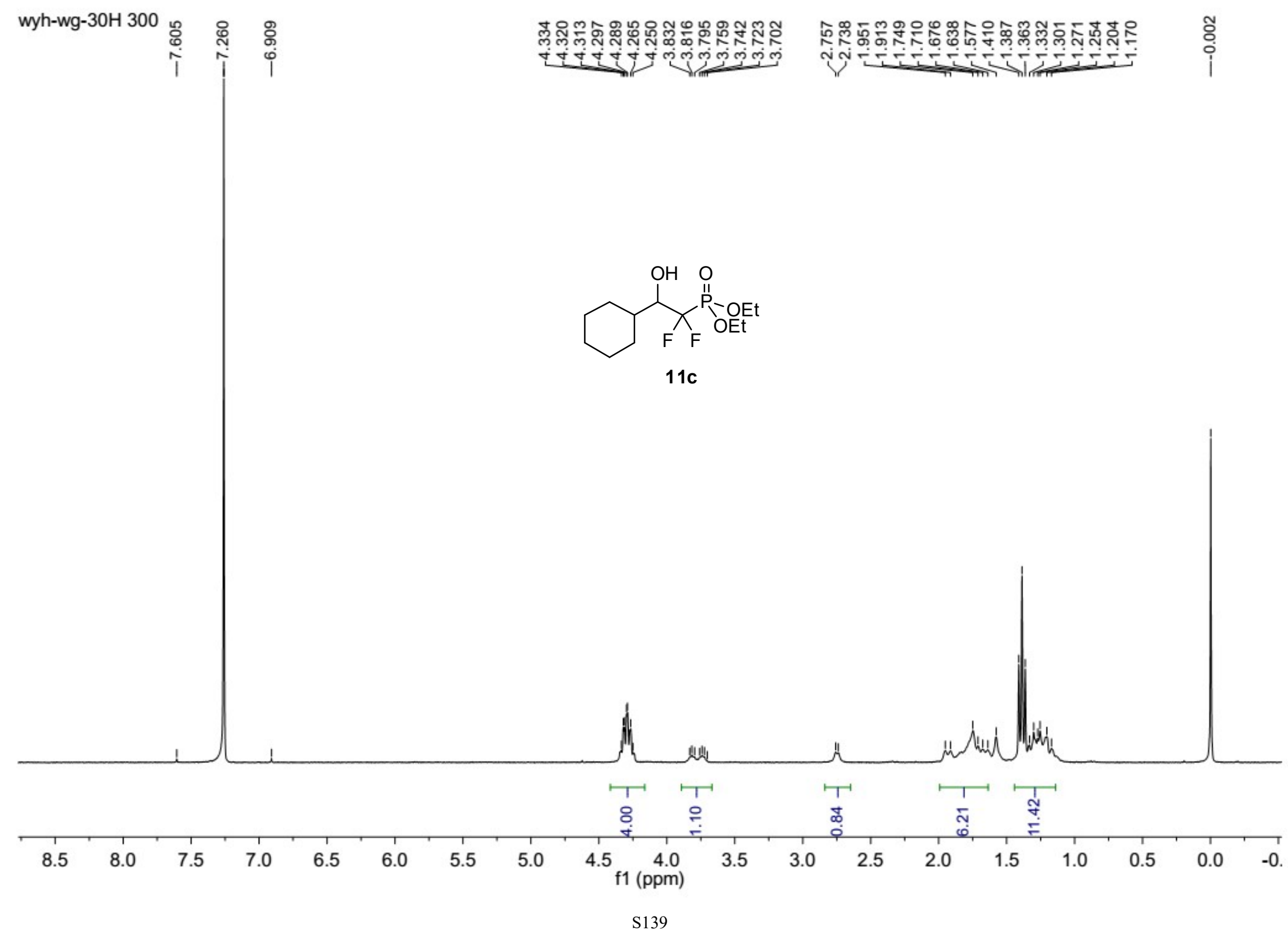




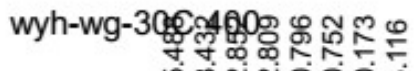

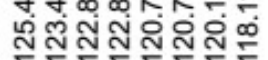

年-

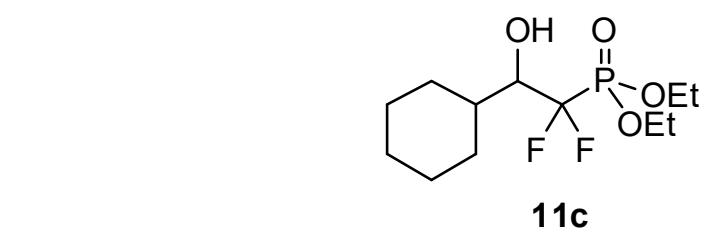

11c
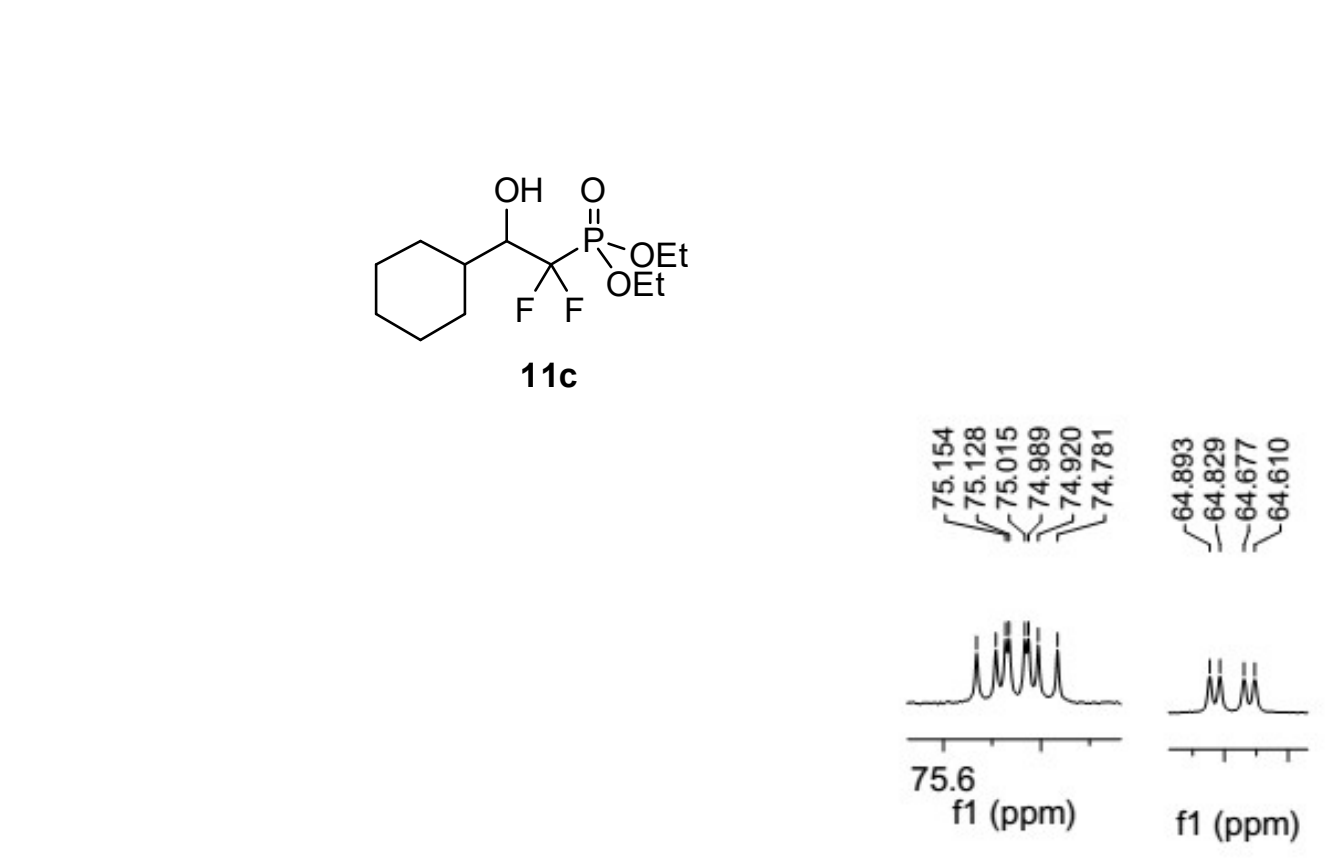

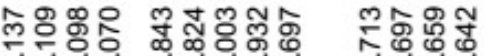

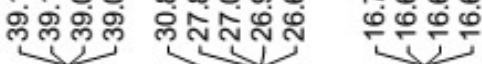
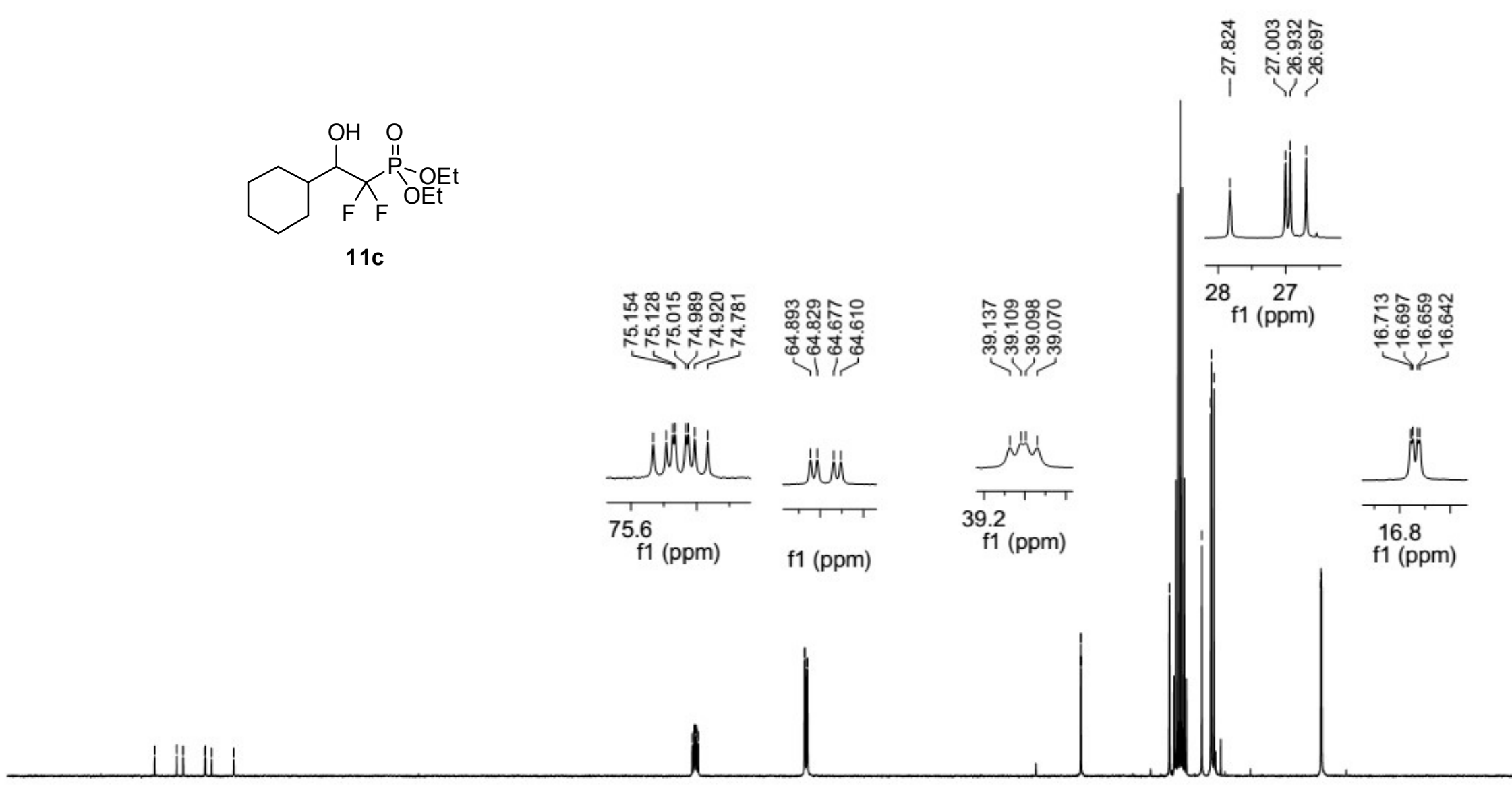
每
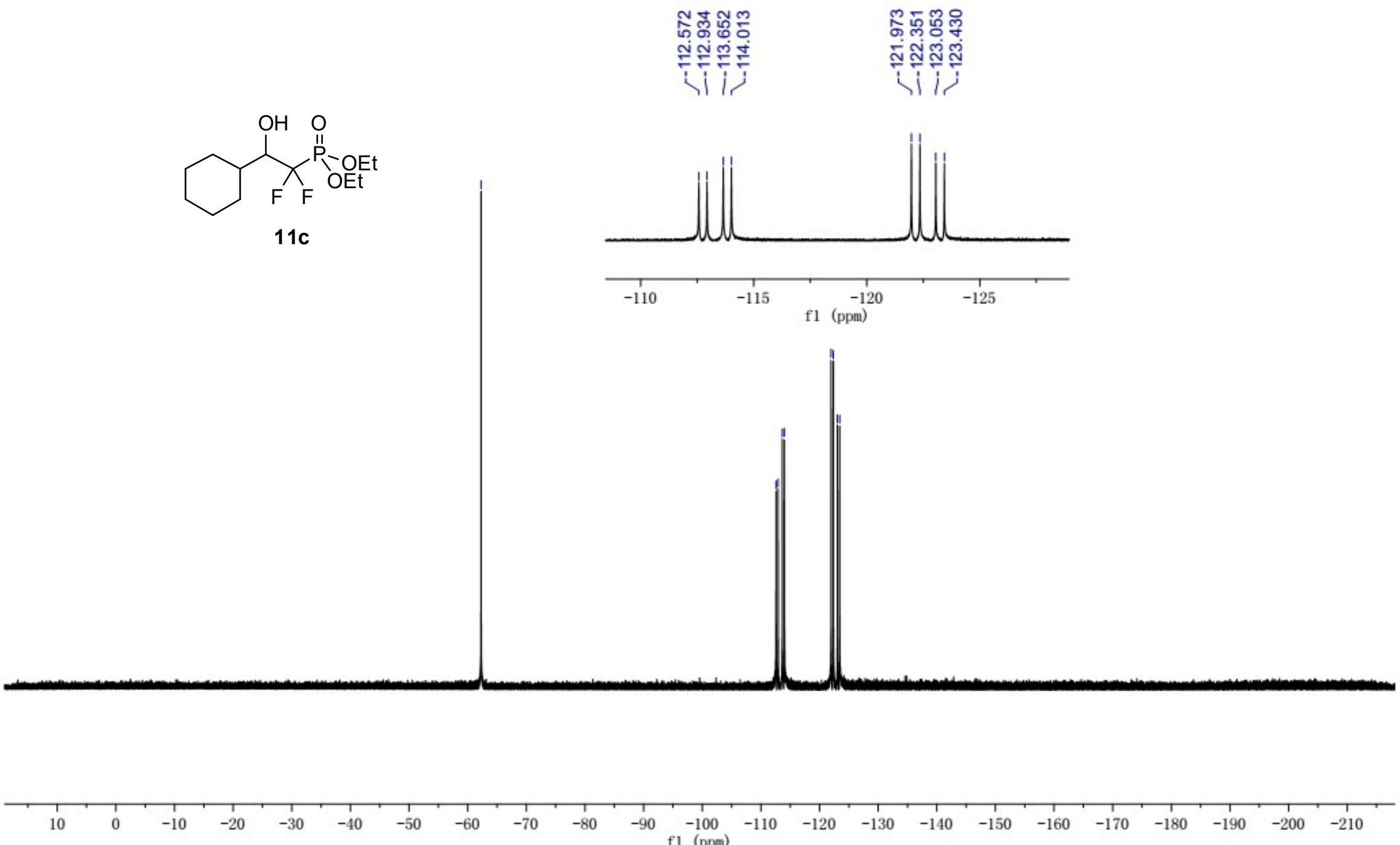
wyh-wg-30P(H3PO4) 300

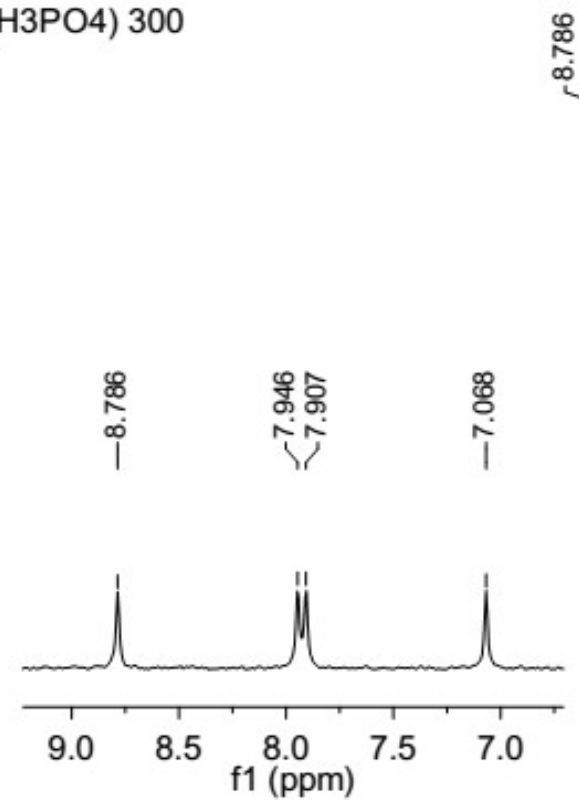

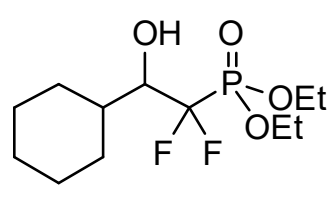

11c

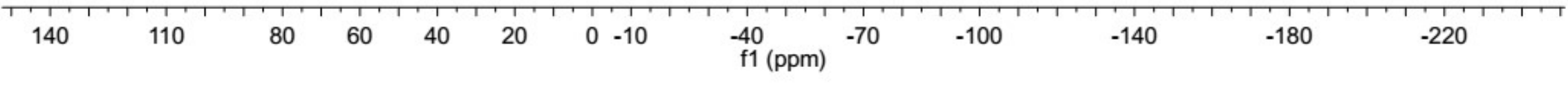




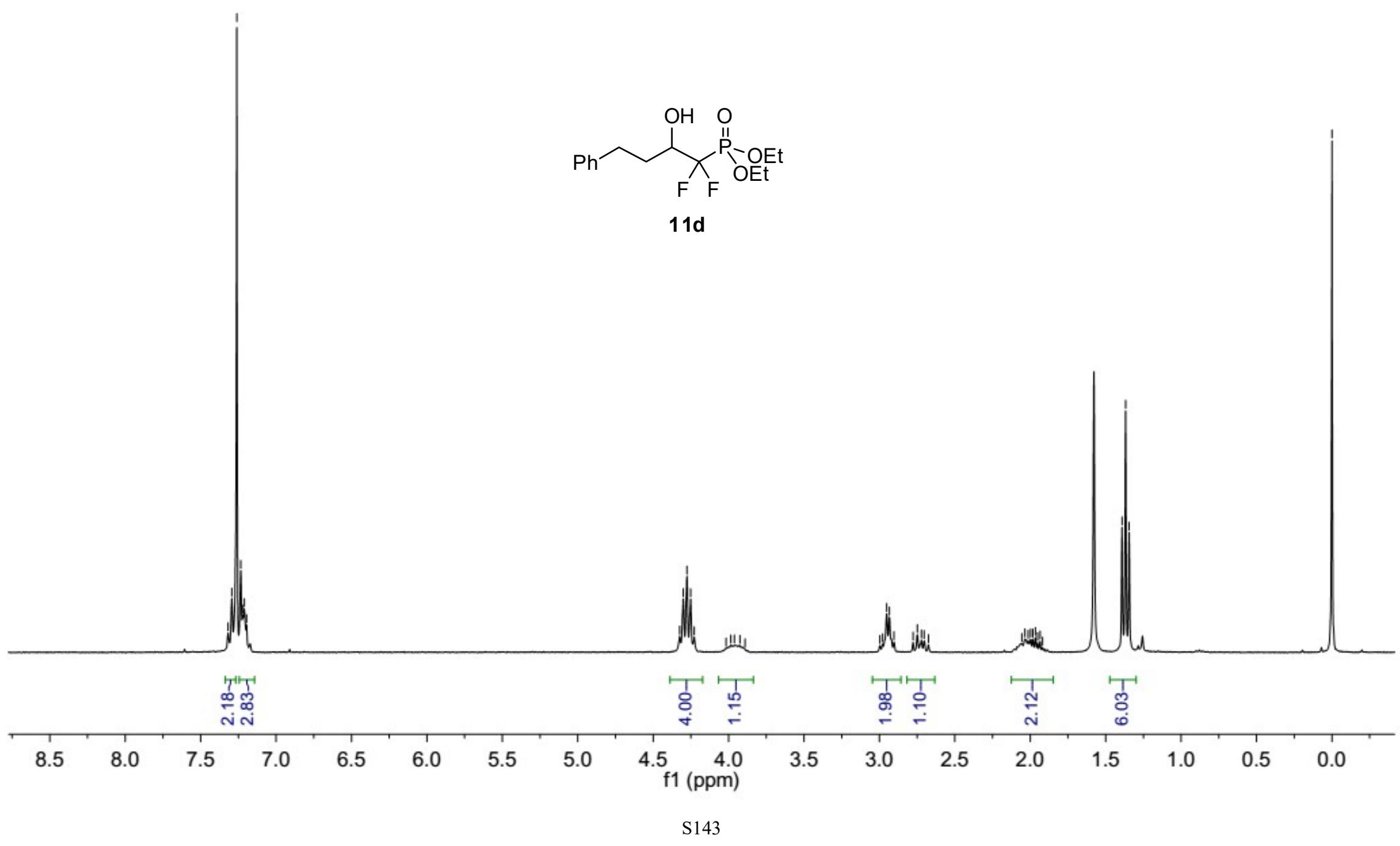



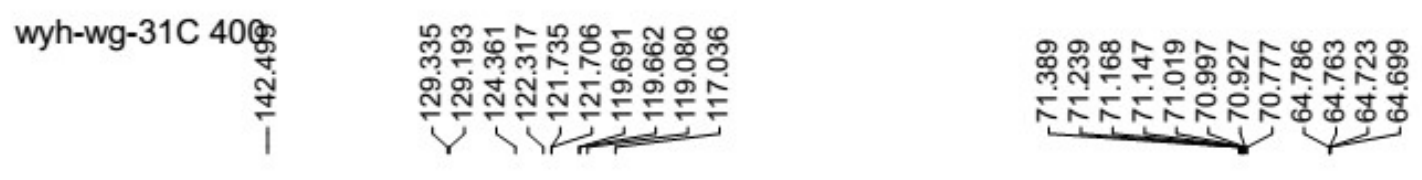

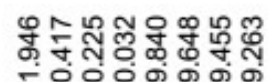

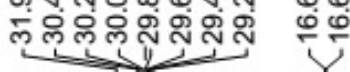
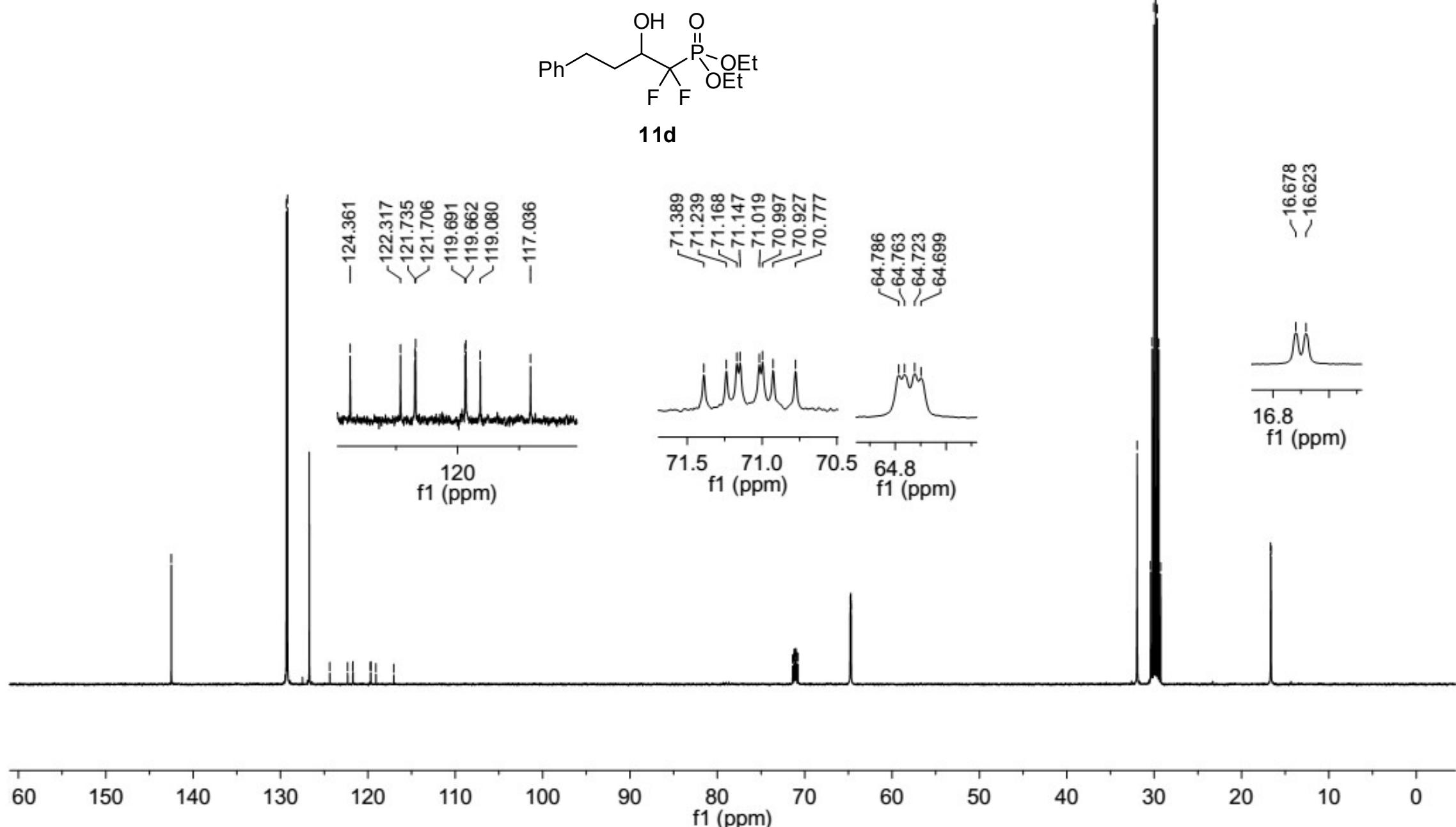

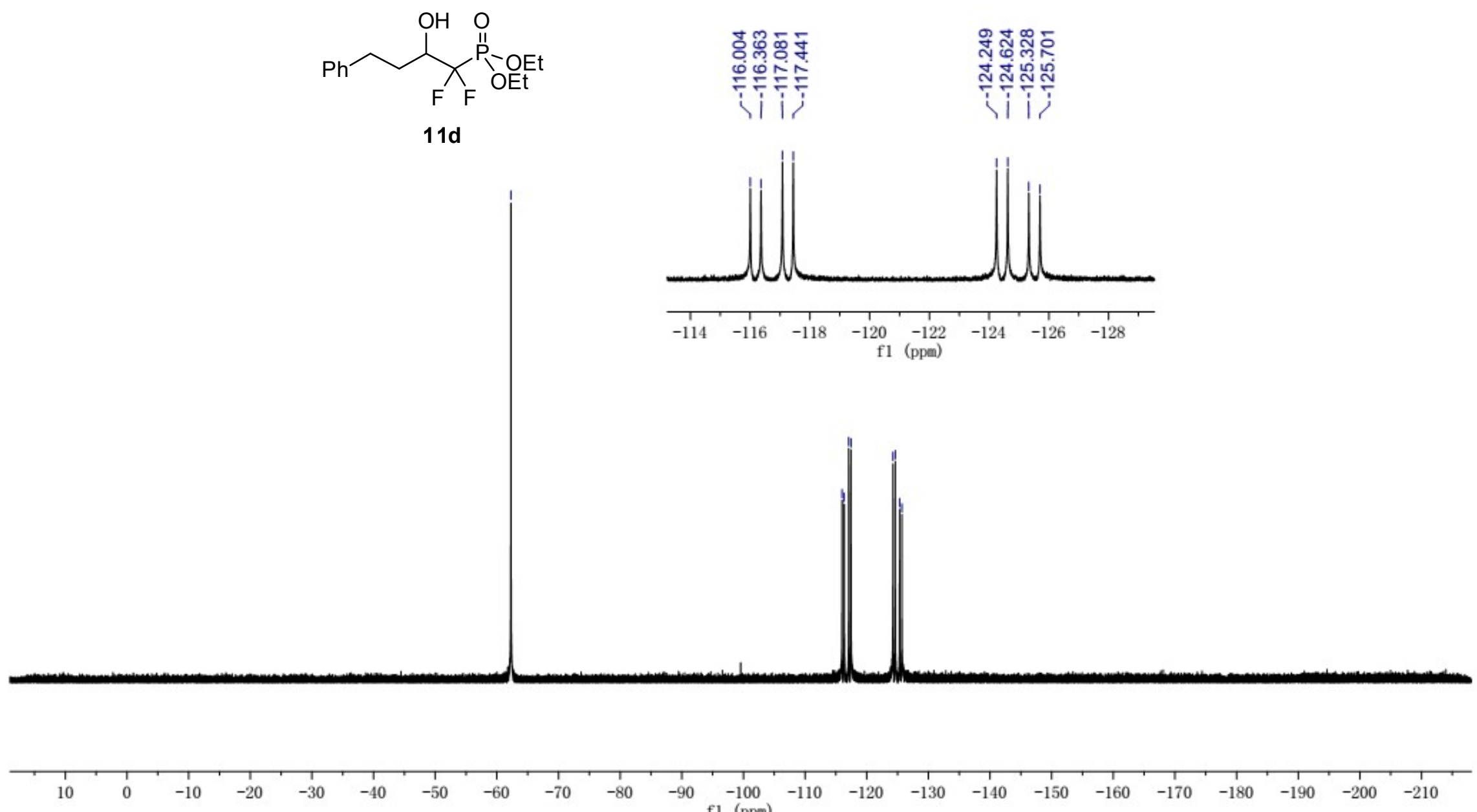

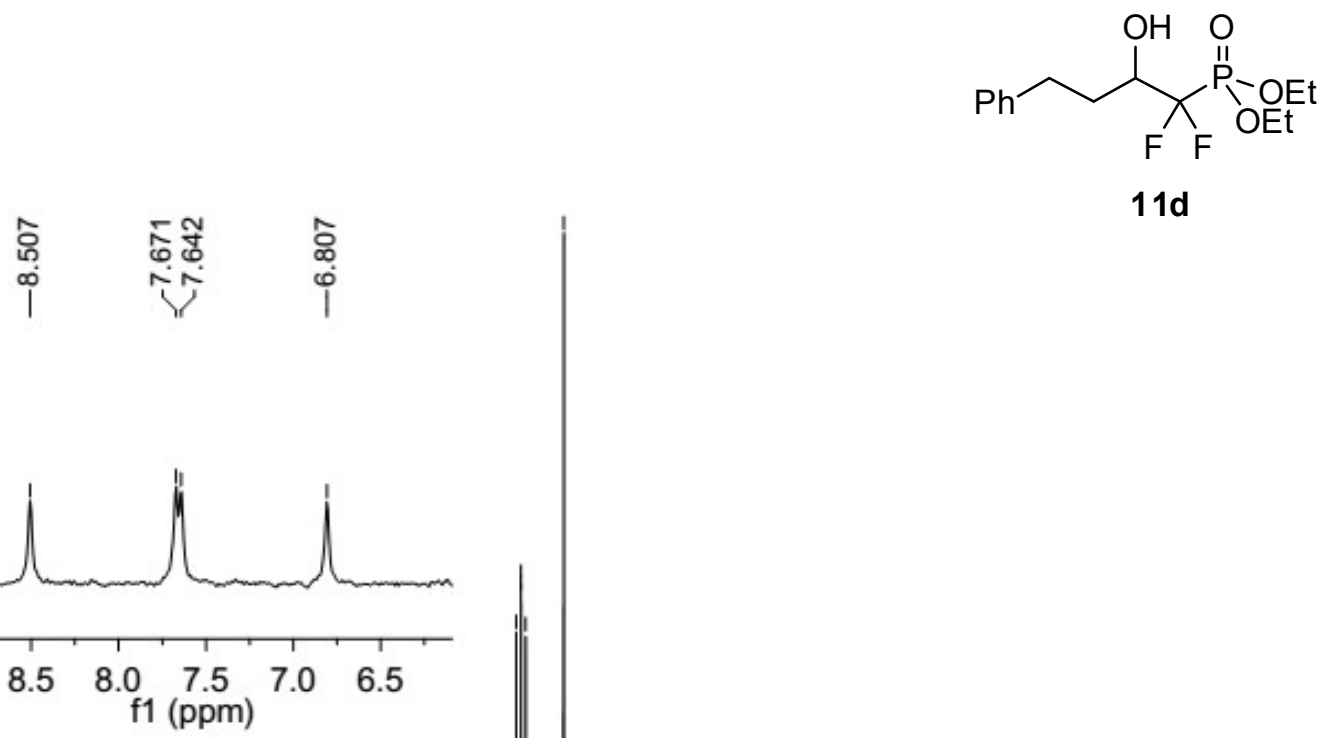

11d

\begin{tabular}{|c|c|c|c|c|c|c|c|c|c|c|c|c|}
\hline 140 & 110 & 80 & 60 & 40 & 20 & $0-10$ & $\begin{array}{l}-40 \\
\mathrm{f} 1(\mathrm{ppm})\end{array}$ & -70 & -100 & -140 & -180 & -220 \\
\hline
\end{tabular}




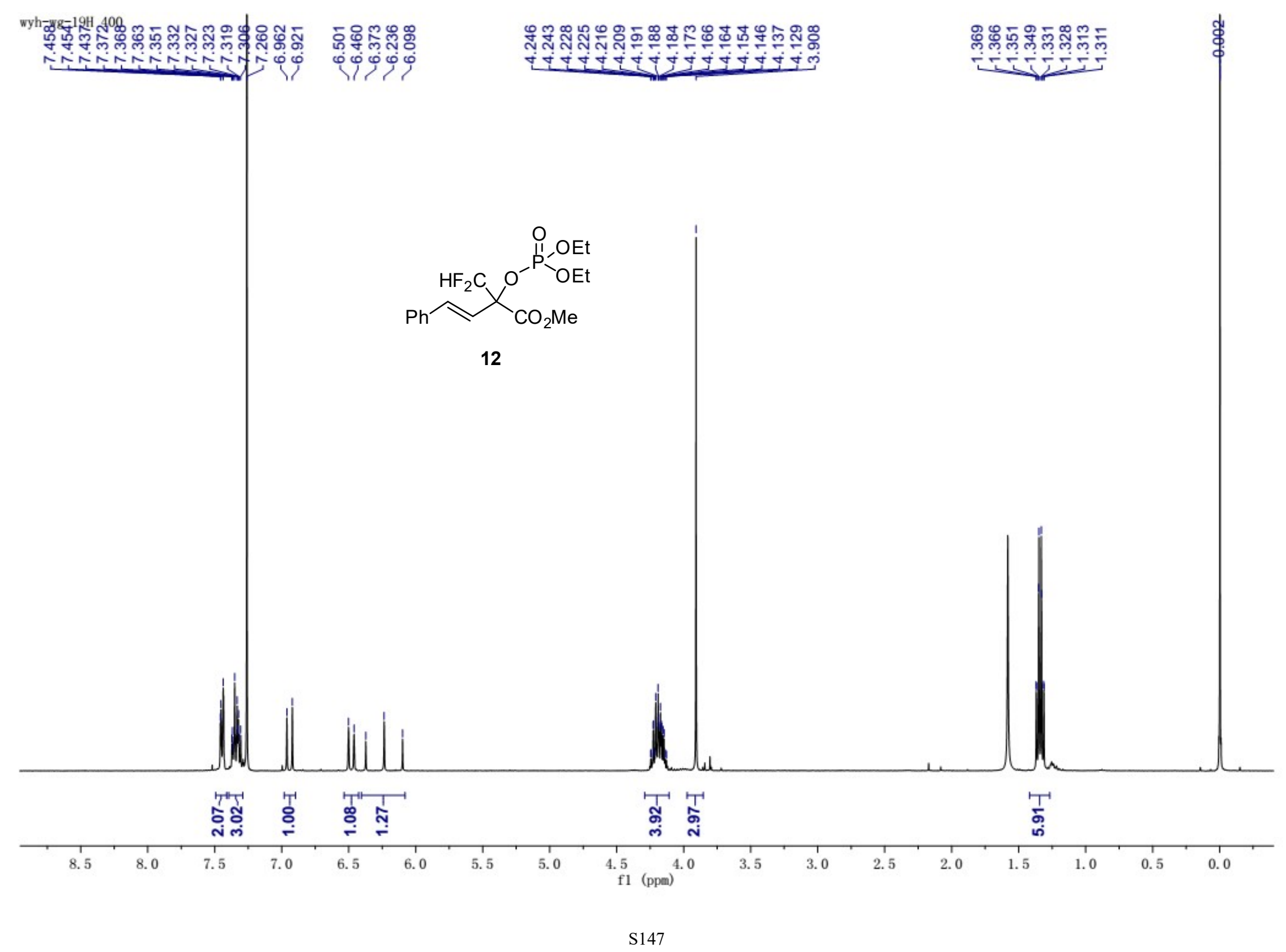



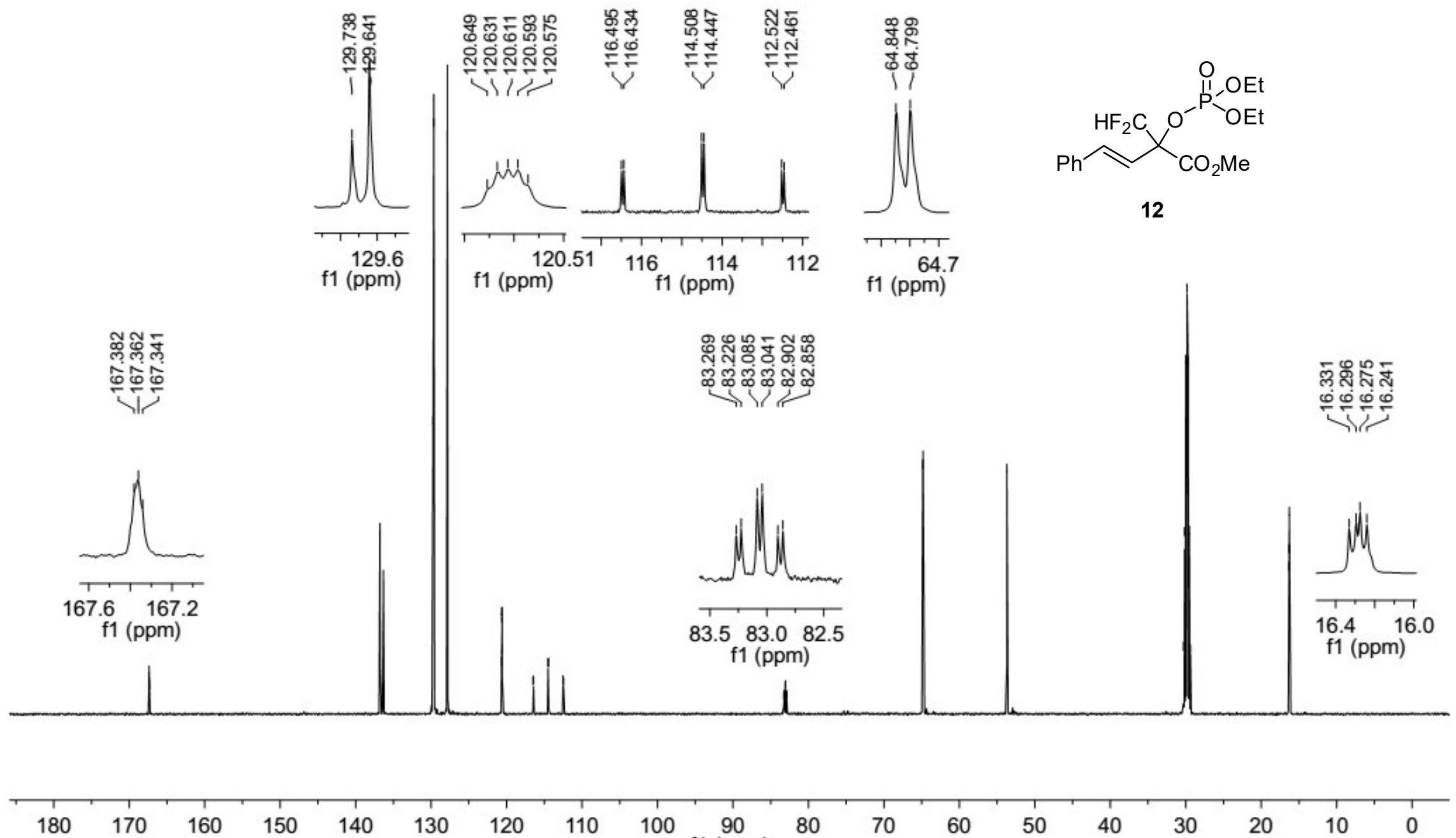
wyh-wg-19F (PhCF3) 300

$$
\overbrace{12}^{\mathrm{PF}_{2} \mathrm{C}} \overbrace{\mathrm{CO}_{2} \mathrm{Me}}^{\substack{\mathrm{O}, \mathrm{OEt} \\ \mathrm{P}-\mathrm{OEEt}}}
$$

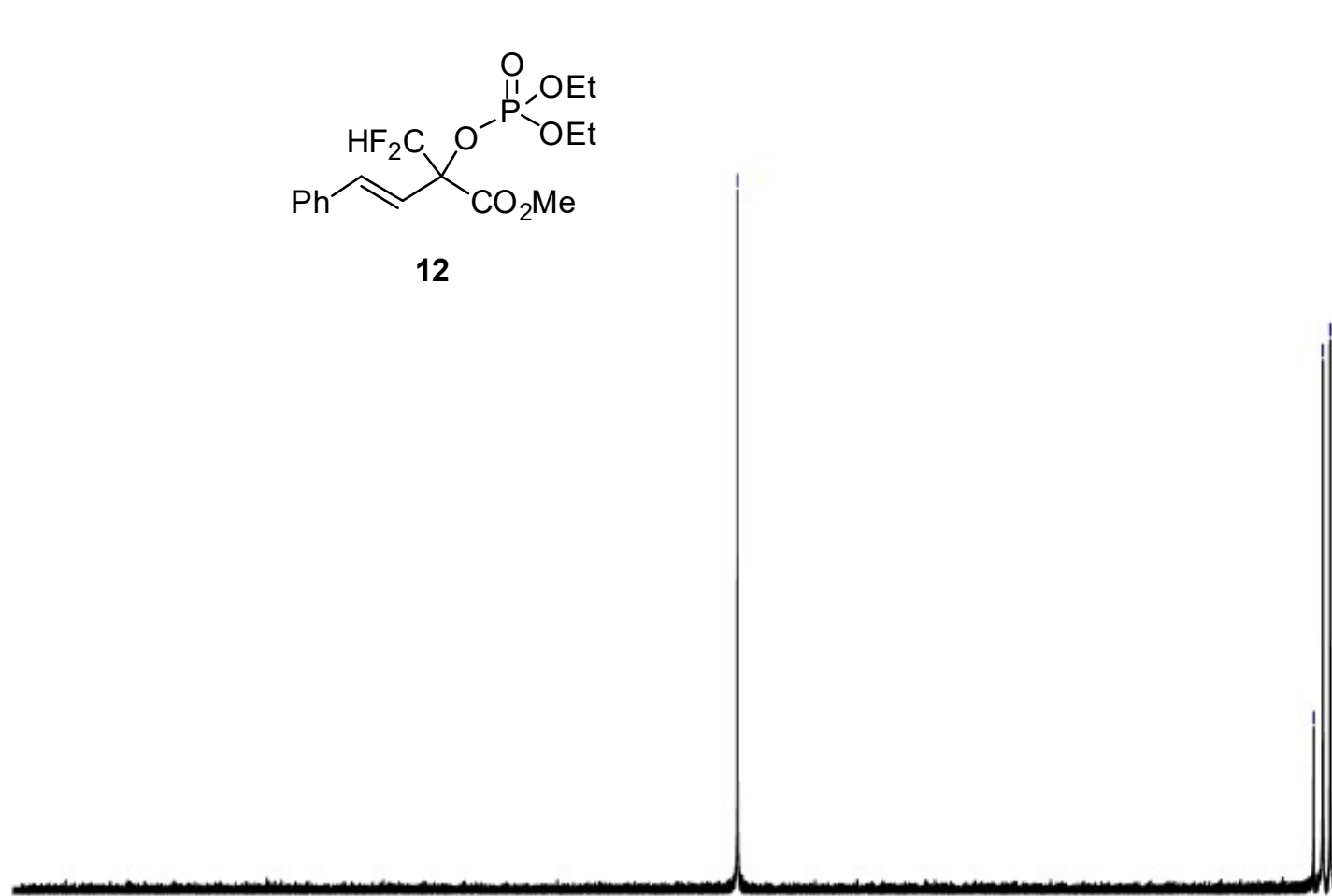

\section{뭉윰음}

ะิํํำ

证

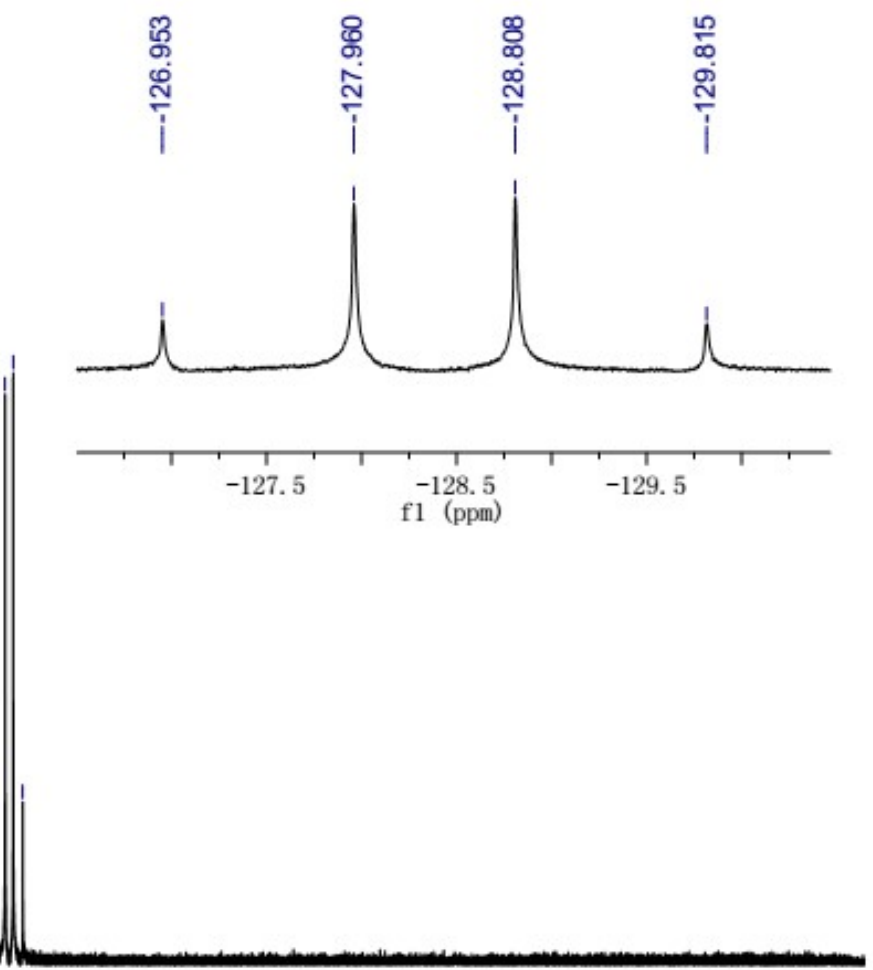

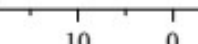
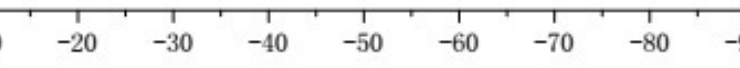

$\begin{array}{cc}1 & 1 \\ -90 & -100\end{array}$ 


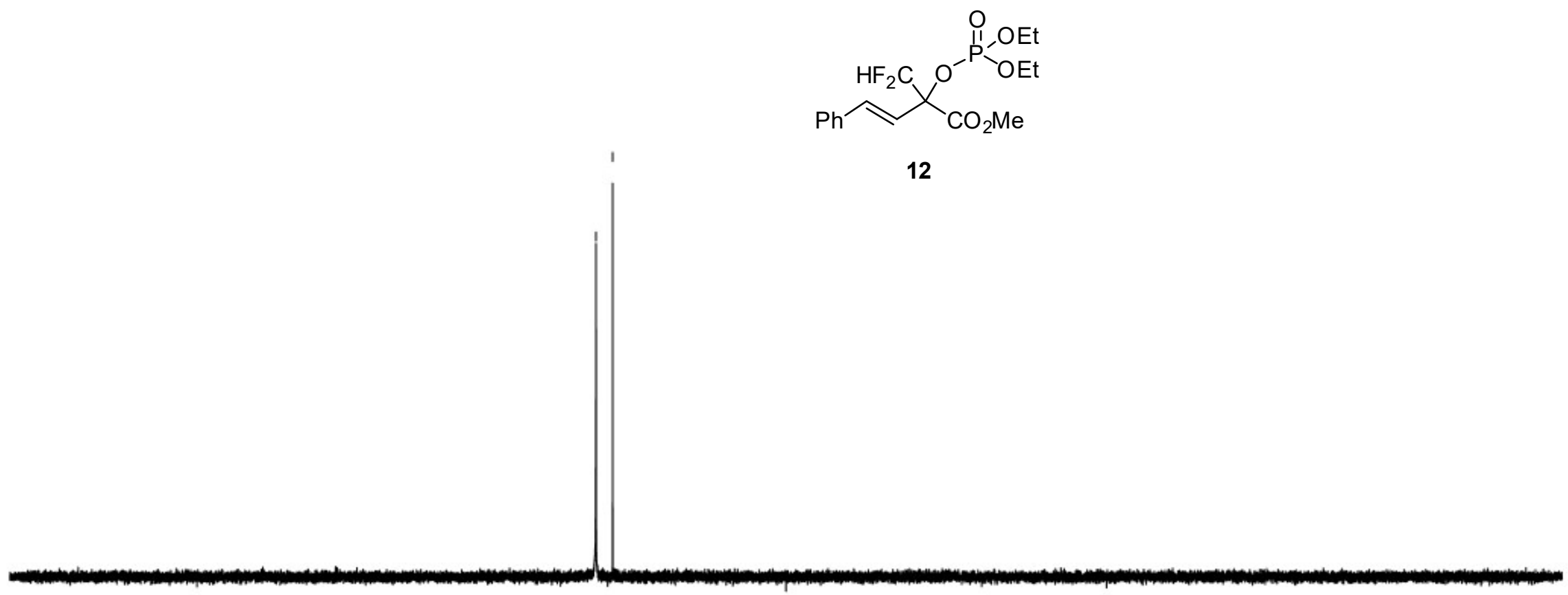

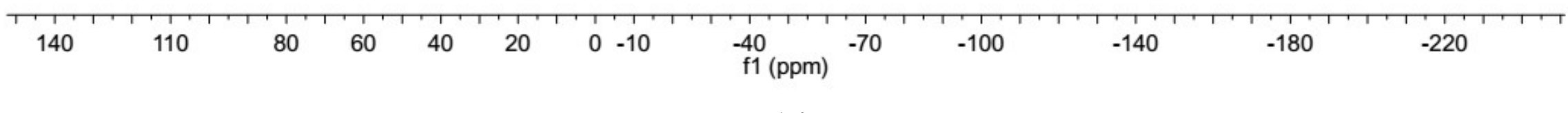




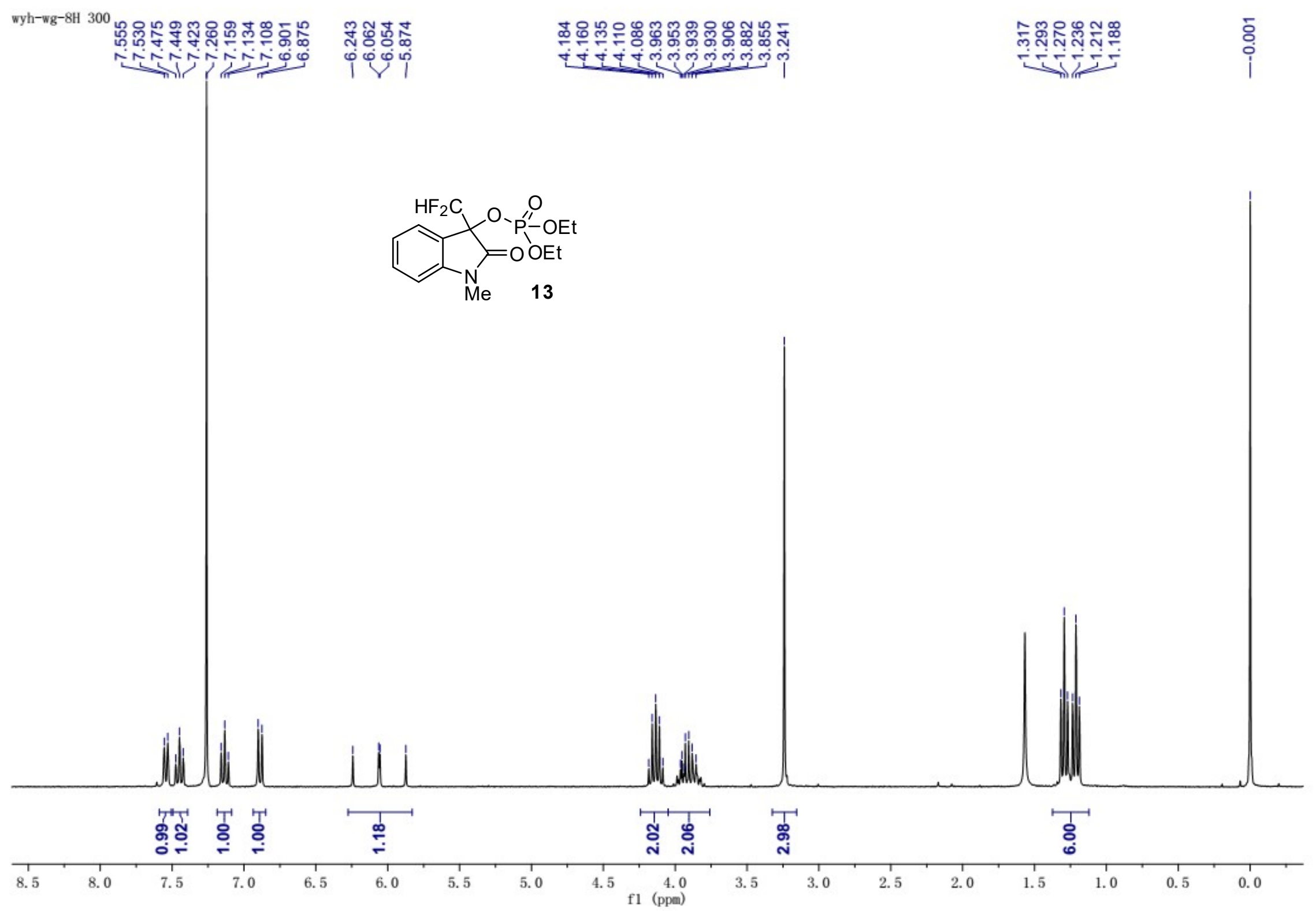




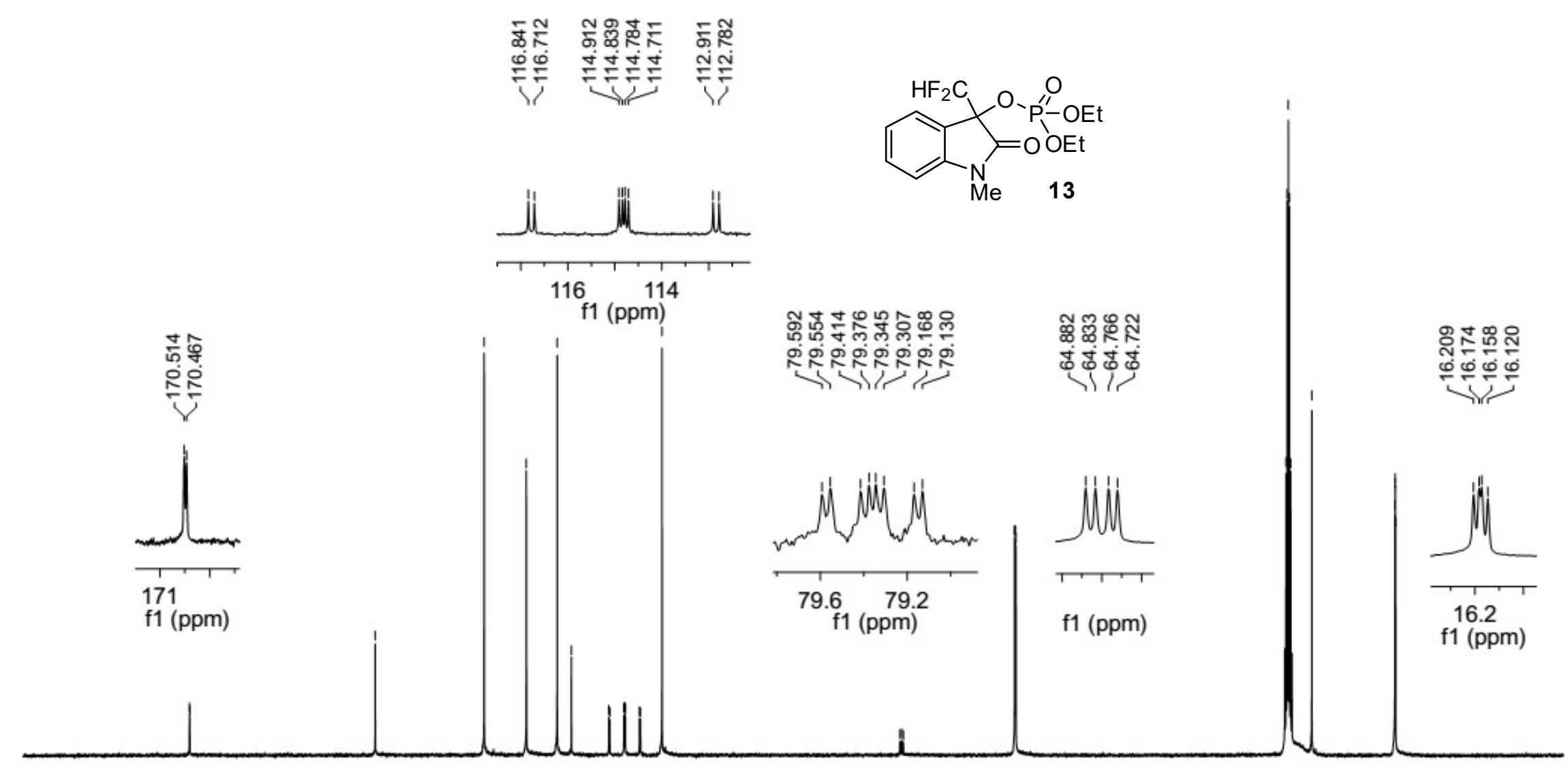

$190 \quad 180 \quad 170$ 

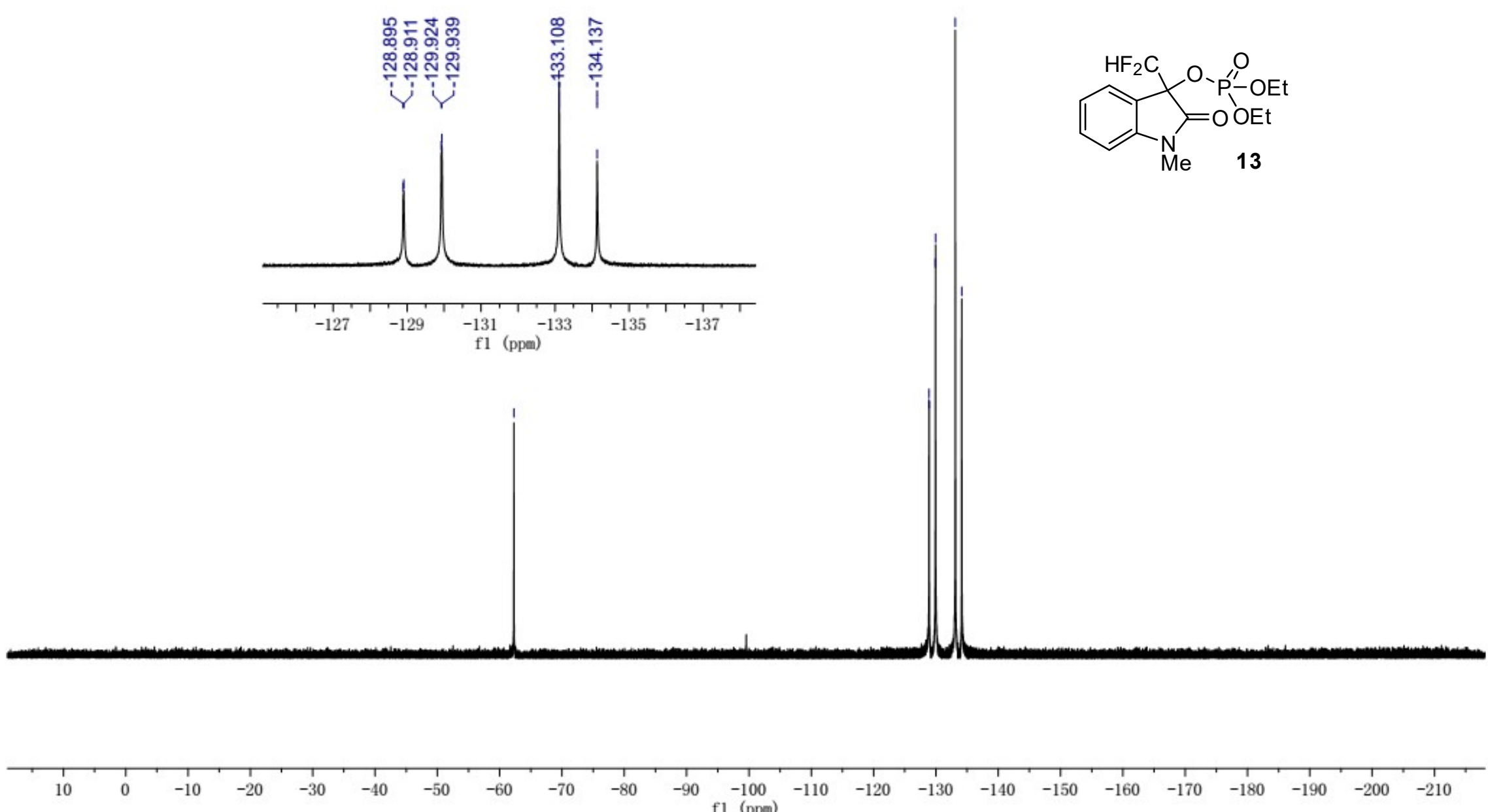

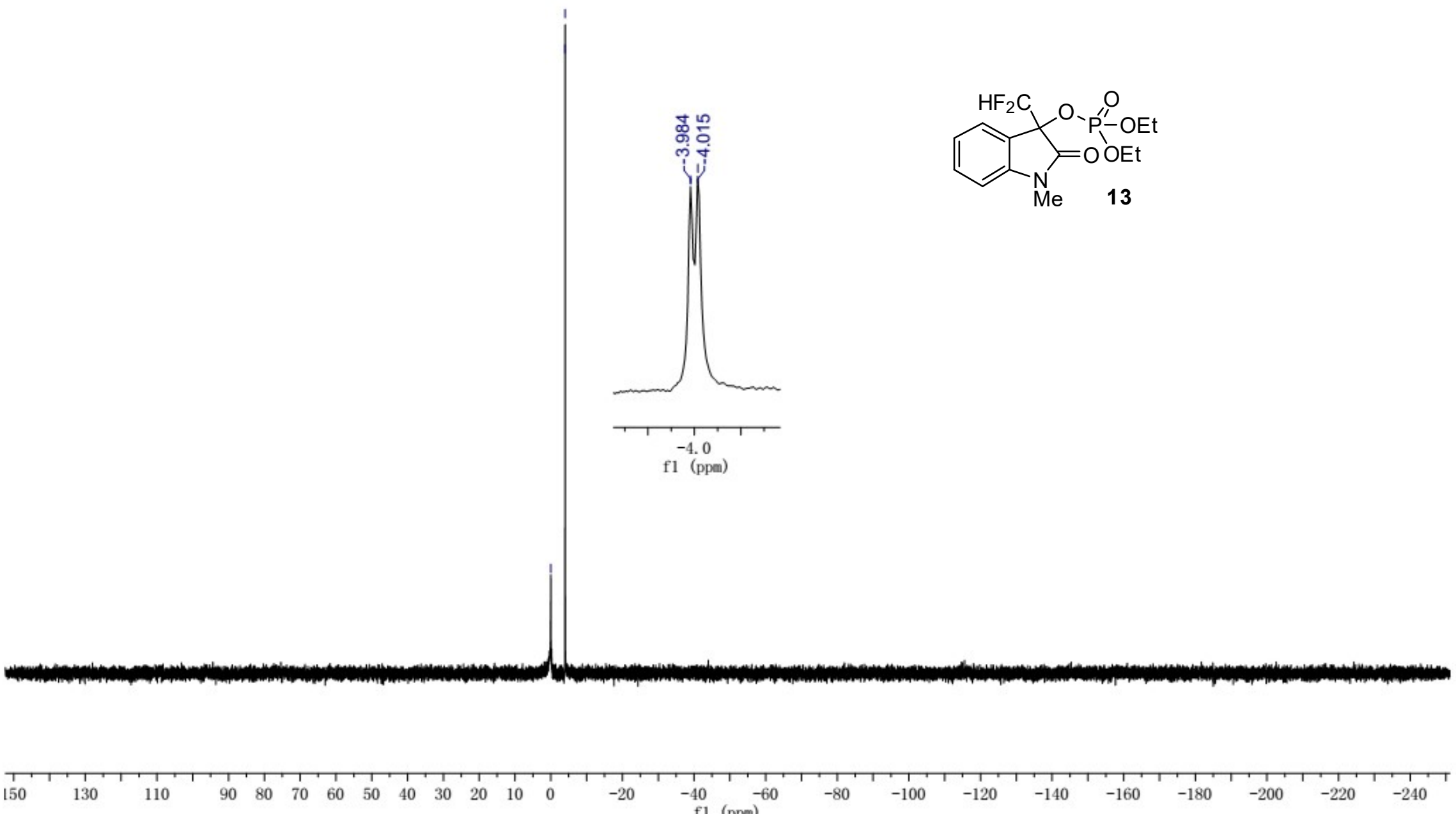